\title{
The Effect of Compost Amendment on Ammonia-Oxidizing Microbial Community Structure in an Agricultural Soil
}

Gregory S. Klinger

West Virginia University

Follow this and additional works at: https://researchrepository.wvu.edu/etd

\section{Recommended Citation}

Klinger, Gregory S., "The Effect of Compost Amendment on Ammonia-Oxidizing Microbial Community Structure in an Agricultural Soil" (2012). Graduate Theses, Dissertations, and Problem Reports. 4878. https://researchrepository.wvu.edu/etd/4878

This Thesis is protected by copyright and/or related rights. It has been brought to you by the The Research Repository @ WVU with permission from the rights-holder(s). You are free to use this Thesis in any way that is permitted by the copyright and related rights legislation that applies to your use. For other uses you must obtain permission from the rights-holder(s) directly, unless additional rights are indicated by a Creative Commons license in the record and/ or on the work itself. This Thesis has been accepted for inclusion in WVU Graduate Theses, Dissertations, and Problem Reports collection by an authorized administrator of The Research Repository @ WVU. For more information, please contact researchrepository@mail.wvu.edu. 


\title{
The Effect of Compost Amendment on Ammonia-Oxidizing Microbial Community Structure in an Agricultural Soil
}

by

\author{
Gregory S. Klinger
}

\author{
Thesis submitted to the \\ Davis College of Agriculture, Natural Resources, and Design \\ at West Virginia University \\ in partial fulfillment of the requirements \\ for the degree of \\ Master of Science \\ in \\ Agronomy \\ Alan Sexstone, Ph.D., Committee Chairperson \\ Louis McDonald, Ph.D. \\ Daniel Panaccione, Ph.D. \\ Division of Plant and Soil Sciences \\ Morgantown, West Virginia
}

2012

Keywords: nitrification, ammonia oxidation, T-RFLP, amoA, potential ammonia oxidation, potentially mineralizable nitrogen, microbial biomass carbon, compost, partially composted dairy manure. 


\title{
ABSTRACT \\ The Effect of Compost Amendment on Ammonia-Oxidizing Microbial Community Structure in an Agricultural Soil
}

\author{
by Gregory S. Klinger
}

The effect of compost amendment on nitrification rates and ammonia-oxidizing microorganisms in an agricultural soil was examined. Four different rates from 11.2 to $89.6 \mathrm{Mg}$ compost ha $^{-1}$ of partially composted dairy manure was applied annually from 2000 to 2003 and again in 2005 to 32 plots on a Dormont silt loam that was shifted from long term pasture to crop cultivation. An additional 8 plots were not amended with compost and served as negative controls. Except for lime in the initial year of the experiment, no other fertilizer was used on these plots. Soil physical, chemical, and biochemical measurements were taken from 4 randomly chosen replicate plots of each treatment. Additionally, TRFLP was used to fingerprint the community of bacteria and archaea responsible for the process of ammonia oxidation using the $a m o A$ gene. Extracted DNA concentration and potentially mineralizable nitrogen both significantly increased with increasing rates of compost amendment. There were significant positive correlations between potential ammonia oxidation and potentially mineralizable nitrogen, extracted DNA concentration and potentially mineralizable nitrogen, and extracted DNA and microbial biomass carbon in these plots. Many relationships were stronger when only the three lowest treatments were analyzed. Diversity measures generally did not show strong relationships with compost amendment rates, but there were significant correlations with biochemical variables. Ammonia-oxidizing archaeal (AOA) Shannon diversity and richness negatively correlated with the microbial biomass carbon pool size. Ammonia-oxidizing bacterial (AOB) Shannon evenness and Smith and Wilson evenness negatively correlated with potentially mineralizable nitrogen rate. Analysis of similarity showed that AOB communities with similar rates of nitrogen mineralization were more similar in community composition than would be predicted by chance alone. Nonmetric multidimensional scaling analysis showed that both AOA and AOB communities had nonlinear differences in community similarity based on compost amendment rate. AOA community similarity had a linear relationship with microbial biomass carbon and a nonlinear relationship with potentially mineralizable nitrogen. AOB community similarity had a linear relationship with both potentially mineralizable nitrogen and potential ammonia oxidation, and a weak nonlinear relationship with microbial biomass carbon. Linearity suggests a direct relationship between the two variables, while nonlinearity suggests an indirect relationship between the two variables. This evidence suggests that there is a difference in the ecological niches of the AOA and AOB, with AOB primarily responsible for ammonia oxidation in these plots. 


\section{DEDICATION}

This thesis is dedicated to anyone who ever encouraged me to pursue my passions or to try to understand the world around me, and to my parents, who cultivated my love of the natural world. 


\section{ACKNOWLEDGEMENTS}

This thesis would not have been possible without the time, support, and advice of many people. First and foremost, I want to acknowledge my advisor, Dr. Alan Sexstone. Not only did he take a chance on a graduate student with an unusual science background, he gave me the opportunity and encouragement to pursue my very specific interests in the field of environmental microbiology.

I would also like to thank my committee members, Dr. Daniel Panaccione and Dr. Louis McDonald, for their help during my time at WVU. Dr. Panaccione provided a great deal of advice on how to get my molecular biology experiments to work, and Dr. McDonald provided advice on chemical procedures I used in this research, as well as data on the plots. I would also like to thank Dr. McDonald for setting up the compost rate trial plots, without which this research would have been impossible.

Dr. William Peterjohn provided me with the time, expertise, and equipment to analyze nitrate concentrations for several experiments, for which I am eternally grateful.

I would like to thank Dr. George Merovich, without whose class or advice I would never have been able to perform my statistical analysis. I would also like to thank John Burkhardt, whose advice on statistics helped me understand the limitations of how I could analyze and interpret my data.

Additionally, I would like to thank the following people:

Dr. Jennifer Wiedhaas, who provided me with advice and protocols on the T-RFLP process, and opened her laboratory for me to work in. Alex Harris, for doing the capillary electrophoresis of my T-RFLP samples. Joan Wright, for helping me analyze organic carbon concentrations.

Dr. Jianbo Yao, for allowing me open access to use equipment in his laboratory.

Dr. Eugenia Pena-Yewtukhiw, for providing data on the compost rate trial plots and advice on my project.

While this thesis would not be here without the support of many people, there are a few friends and coworkers I want to acknowledge by name. Calene Thomas, without whom long days in the lab would have seemed much longer. Jason Gallentine, for learning (and struggling with) how to do PCR together with me. Chris Moore, for introducing me to the great recreational activities in the Morgantown area. Without the support of my friends, family, and coworkers, I would never have finished my research or this thesis. My deepest gratitude to all of you. 


\section{TABLE OF CONTENTS}

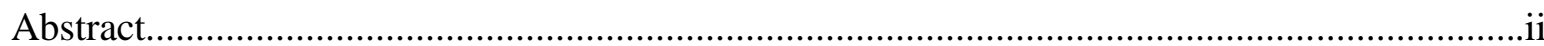

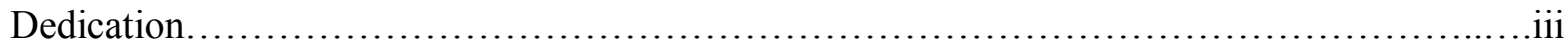

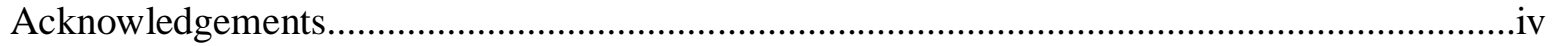

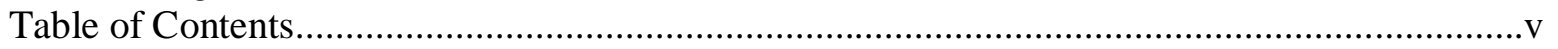

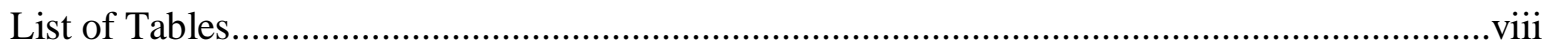

List of Figures................................................................................................................ix

Chapter I - The role of ammonia oxidizers within the nitrogen cycle: General introduction and literature review

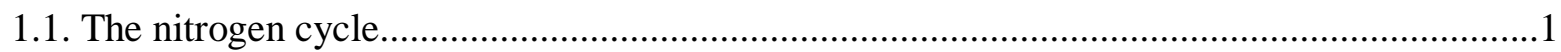

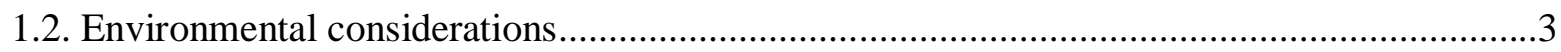

1.3. Economic considerations ......................................................

1.4. Ecology of ammonia oxidizers ..............................................

1.5. The amo gene/ammonia monooxygenase enzyme...............................6

1.6. The genomics of ammonia oxidizers......................................... 6

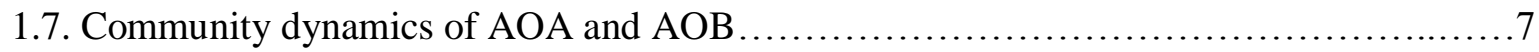

1.8. Objectives and hypotheses................................................ 12

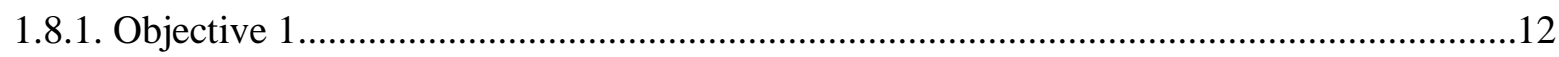

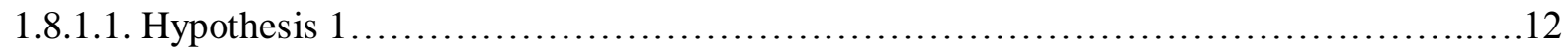

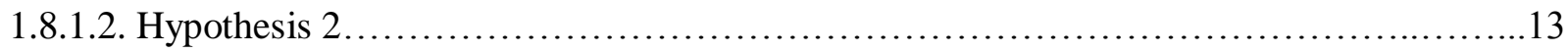

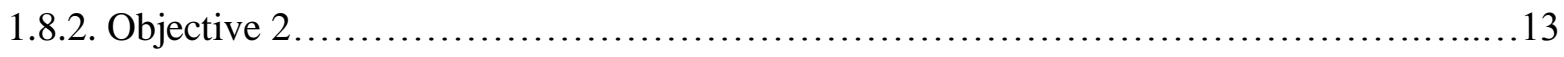

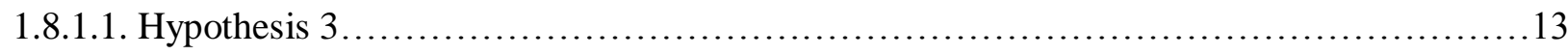

1.9. A note on ammonia/ammonium......................................... 13

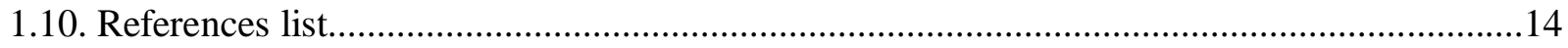

Chapter II - The effect of compost amendment on ammonia-oxidizing bacteria and archaea in a silt loam topsoil.

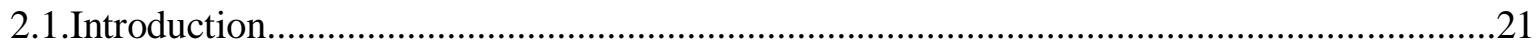

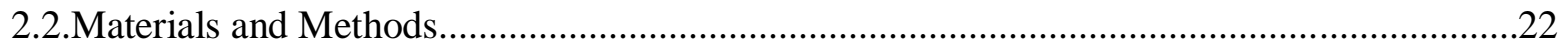

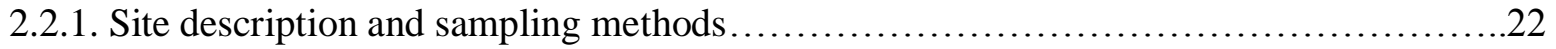




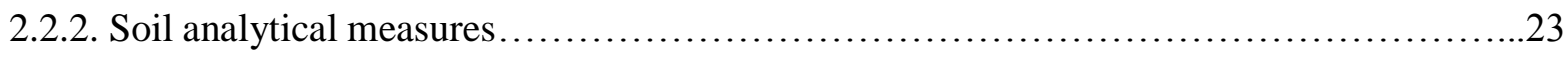

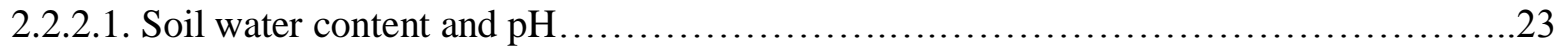

2.2.2.2. Chloroform fumigation extraction for microbial biomass carbon......................23

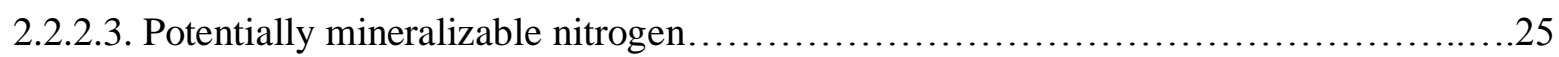

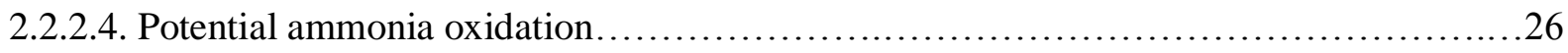

2.2.2.5. T-RFLP: DNA extraction, amplification, restriction digestion, and capillary

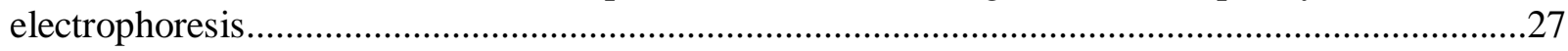

2.2.2.6. Aligning and editing electropherograms ...............................................

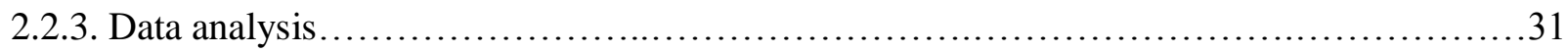

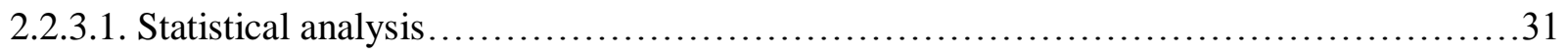

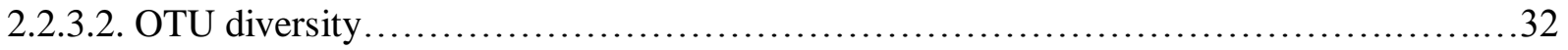

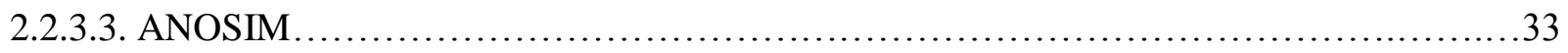

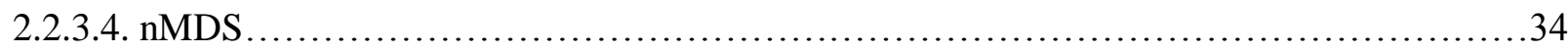

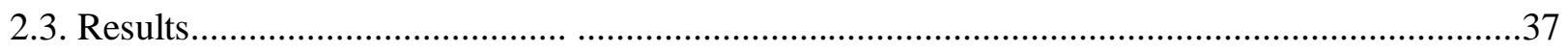

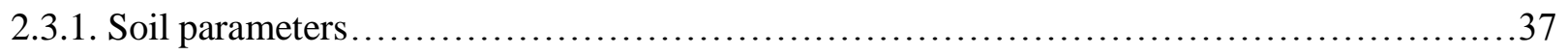

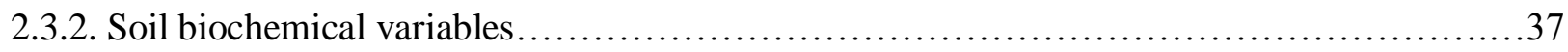

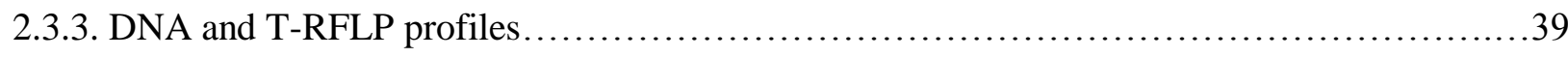

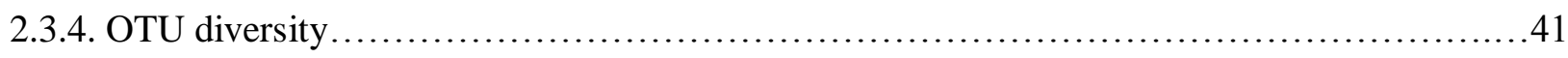

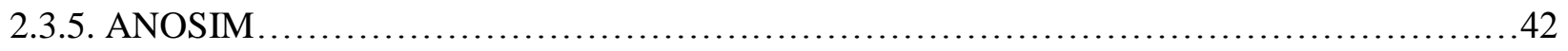

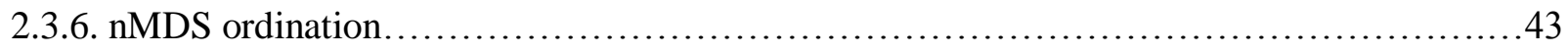

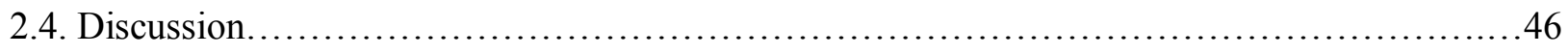

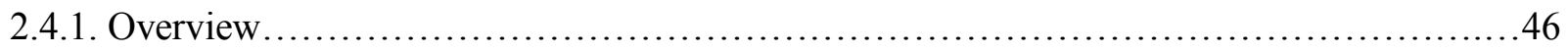

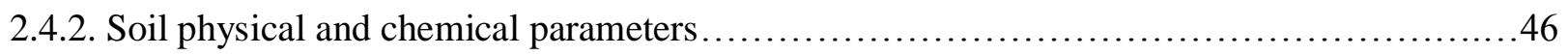

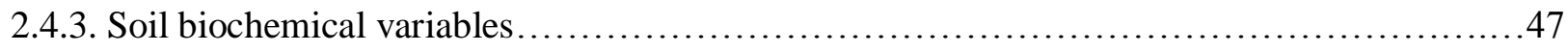

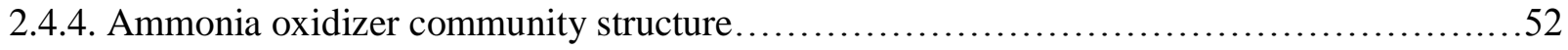




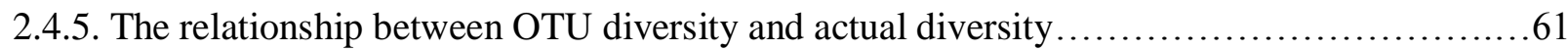

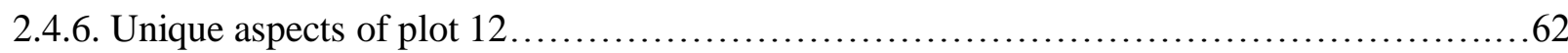

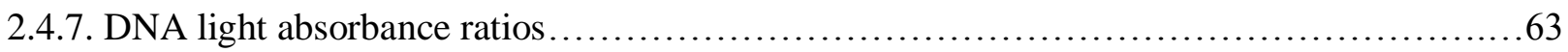

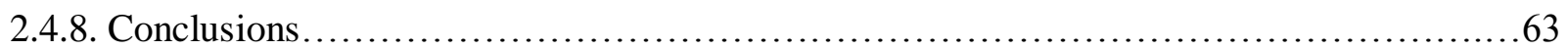

2.5.References list.............................................................. 66

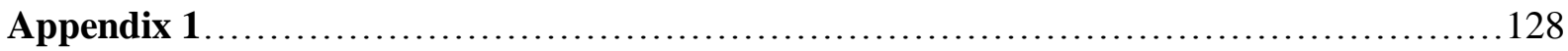




\section{List of Tables}

\section{Chapter 2}

1. Planting history for the 40 compost rate trial plots.................................... 73

2. Elemental composition of compost and straw mulch applied to the compost rate trial

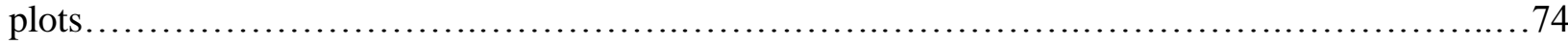

3. Extracted DNA concentrations and relevant light absorbance ratios..........................75

4. Primer names and sequences..................................................... 76

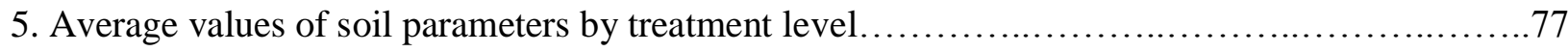

6. Average values of biochemical assays by treatment level ................................ 78

7. Relative abundance of archaeal OTUs in the different plots ..................................79

8. Average relative abundance of each archaeal OTU for each treatment level....................80

9. Relative abundance of bacterial OTUs using restriction enzymes AciI and HaeIII .............81

10. Relative abundance of bacterial OTUs using restriction enzyme RsaI ....................82

11. Average relative abundance of each bacterial OTU for each treatment level .................83

12. Average diversity metric values by treatment level for the AOA.........................................8

13. Average diversity metric values by treatment level for the AOB $\ldots \ldots \ldots \ldots \ldots \ldots \ldots \ldots \ldots \ldots$

14. The influence of environmental variables on AOA community structure using different

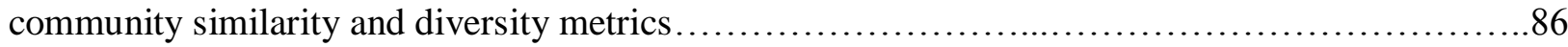

15. The influence of environmental variables on AOB community structure using different community similarity and diversity metrics............................................... 8 


\section{List of Figures}

\section{Chapter 1}

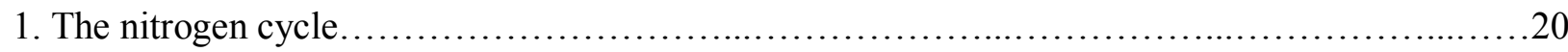

\section{Chapter 2}

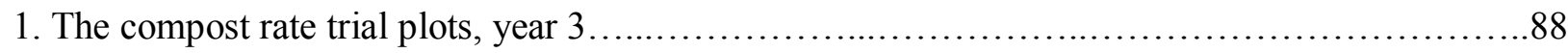

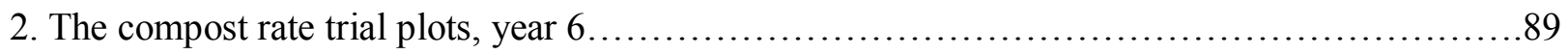

3. Diagram of the compost rate trial plot layout....................................... 90

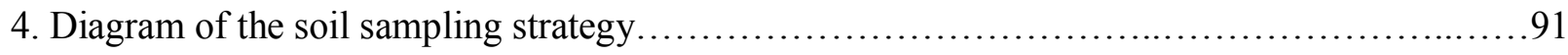

5. Flowchart of the procedures used to amplify bacterial and archaeal $a m o A$ genes..............92

6. Procedure by which raw electropherogram data was aligned and normalized.................93

7. Linear regressions between compost amendment rate and biochemical

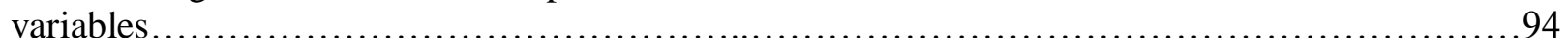

8. Linear regression of the MBC:PMN ratio as a function of compost amendment rate...........95

9. Significant and near-significant interactions between PMN, MBC, PAO, and DNA

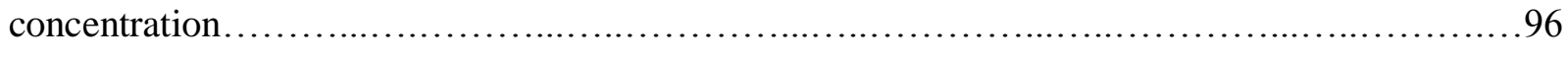

10. Correlations between soluble organic carbon concentration and nitrogen cycling rates....

11. Select relationships between compost amendment rate, PAO, PMN, and MBC when only the

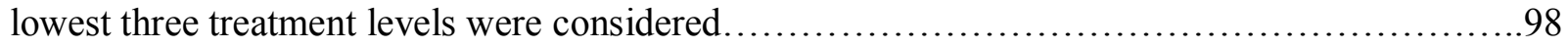

12. Short wavelength light absorbance ratios of extracted DNA as a function of compost amendment rate. .99

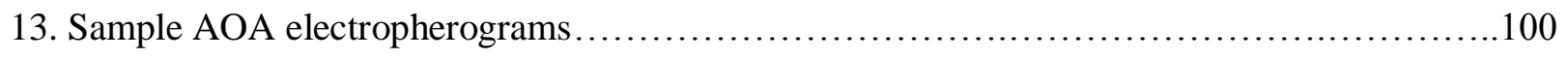

14. nMDS ordination of bacterial OTUs labeled by PCR reaction stringency $\ldots \ldots \ldots \ldots \ldots \ldots \ldots 101$

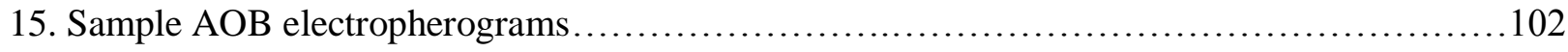

16. Significant relationships between archaeal Shannon diversity metrics, compost amendment, and biochemical variables .103

17. Correlations between archaeal Shannon and Smith and Wilson diversity values.... .104 
18. The relationship between archaeal and bacterial Shannon diversity values for the plots.......

19. Significant relationships between bacterial Shannon diversity metrics and environmental variables

20. The relationship between bacterial Smith and Wilson evenness and bacterial Shannon evenness

21. Significant relationships between bacterial Smith and Wilson evenness and environmental variables

22. nMDS ordination of bacterial community similarity with plots labeled by a posteriori PMN categories....

23. The process by which optimum ANOSIM values for the AOA were obtained

24. The process by which optimum ANOSIM values for the AOB were obtained

25. nMDS ordination of AOA community similarity with plots labeled by compost amendment rate

26. Surface fitting of archaeal Shannon diversity on a nMDS ordination of community similarity

27. Relative abundance of select archaeal OTUs as a function of archaeal Shannon diversity ......114

28. Surface fitting of MBC values on a nMDS ordination of AOA community similarity. 115

29. Surface fitting of PMN values on a nMDS ordination of AOA community similarity

30. Surface fitting of extracted DNA values on a nMDS ordination of AOA community similarity

31. Environmental fitting of important variables over a nMDS ordination of archaeal community similarity....

32. nMDS ordination of AOB community similarity with plots labeled by compost amendment rate

33. Surface fitting of bacterial Shannon diversity on a nMDS ordination of community similarity.

34. Surface fitting of MBC on a nMDS ordination of AOB community similarity

35. Surface fitting of PAO on a nMDS ordination of AOB community similarity 122

36. Surface fitting of PMN on a nMDS ordination of AOB community similarity .123 
37. Surface fitting of extracted DNA concentration on a nMDS ordination of AOB community similarity.....

38. Environmental fitting of important variables over a nMDS ordination of bacterial community similarity....

39. Average percent change in biochemical variables for compost-amended plots relative to

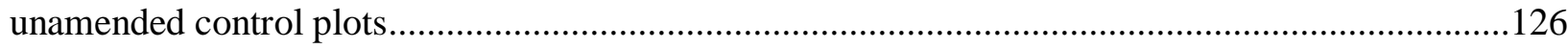

40. Comparison of nMDS ordinations for the AOA and AOB. 


\section{CHAPTER 1}

\section{The role of ammonia oxidizers within the nitrogen cycle: General introduction and literature review}

\subsection{The nitrogen cycle}

The element nitrogen is fundamental to life on earth. It is characterized by a complex set of transformations in the biosphere, most importantly between biologically active forms and inert dinitrogen gas. Historically, the changes between reactive and nonreactive species in the environment have roughly balanced each other. However, since the advent of modern agriculture, the dynamics of the global nitrogen cycle have changed drastically. The rate of creation of biologically reactive nitrogen from unreactive dinitrogen gas has increased, in large part due to production of nitrogen fertilizers using the Haber-Bosch process. From 1860 to 2000, the anthropogenic rate of reactive nitrogen species creation increased from $15 \mathrm{Tg} /$ year to $165 \mathrm{Tg} /$ year (Galloway et al., 2003). Over half of all reactive nitrogen creation every year now comes from anthropogenic sources (Galloway and Cowling, 2002). This manmade generation has had major consequences on the global nitrogen cycle, with unbalanced input and export of nitrogen occurring in many places worldwide. Excess nitrogen input has led to eutrophication of surface waters, damaged forests, and human health problems; insufficient nitrogen input relative to removal as well as nitrogen-poor diets have led to decreased ecosystem productivity and human malnutrition, respectively. The increase in reactive nitrogen is closely tied to increasing human populations: it is estimated that at least 2 billion people would not be alive today if it were not for synthetic nitrogen fertilizers (Smil, 2001). Thus, the main goal in nitrogen management today is maximizing the benefits of increased nitrogen input while minimizing its detrimental effects (Galloway et al., 2008). 
Nitrogen transformations primarily occur through redox reactions and changes in physical state. Reactive nitrogen is created predominantly in fully reduced form and undergoes various oxidations and reductions until it is once again inert dinitrogen gas (Figure 1). Because of its complex redox cycle, nitrogen can have a cascading effect, as described by Galloway and colleagues (2003), wherein a single atom of nitrogen can have multiple impacts in different environments as it cycles back to its unreactive state. Bacteria and other microorganisms mediate most of the redox transformations of nitrogen in the environment.

Nitrification, the oxidation of ammonia- $\mathrm{N}$ to nitrate- $\mathrm{N}$ via hydroxylamine and nitrite, is a key process in the nitrogen cycle. Two ecologically distinct groups of organisms take part in this process, the ammonia oxidizers and the nitrite oxidizers. The ammonia oxidizers oxidize ammonia to hydroxylamine with the membrane-bound enzyme ammonia monooxygenase (AMO), and then transform hydroxylamine to nitrite with the enzyme hydroxylamine oxidoreductase (HAO). Nitrite oxidizers transform this nitrite to nitrate with the membrane-bound enzyme nitrite oxidoreductase (NXR). Both groups of organisms conserve useable energy through this process: this amounts to approximately $275 \mathrm{~kJ} / \mathrm{mol}$ for ammonia oxidizers and $74 \mathrm{~kJ} / \mathrm{mol}$ for nitrite oxidizers. Ammonia-oxidizing microorganisms are the most studied because ammonia oxidation is the rate-limiting step in nitrification. Nitrite oxidation proceeds much more quickly. Most nitrifiers are chemolithotrophs; however, some bacteria and fungi have been shown to be capable of oxidizing ammonia without conserving energy from the process. These heterotrophic nitrifiers contribute insignificantly to the process of nitrification (Robertson and Groffman, 2007), except perhaps under highly acidic conditions.

Chemolithotrophic microorganisms responsible for ammonia oxidation include both bacteria and archaea (referred to as $\mathrm{AOB}$ and $\mathrm{AOA}$, respectively). While the vast majority of nitrogen in most soils is found in organic forms, most organic nitrogen cannot be directly taken up by organisms, instead having to first be converted to inorganic (ammonia/ammonium or nitrate) forms. Nitrification is crucial to agriculture because of the high mobility of nitrate in soils, and because of the preference of some plants or 
microorganisms for nitrogen in either ammonium or nitrate forms. Nitrification can greatly affect nitrogen retention or loss in systems. The high volatility of ammonia under hot, alkaline conditions can lead to gaseous losses; nitrification can minimize these losses by transforming the ammonia to nitrate, which largely remains in dissolved ionic form. However, nitrification can also lead to large nitrogen losses through denitrification (reduction) of its products, nitrite and nitrate, to nitrogen gases. Leaching losses of nitrate, which is poorly adsorbed to soil particles relative to ammonium, the cationic form of ammonia, also leads to nitrogen losses from systems (Kowalchuk and Stephen, 2001).

\subsection{Environmental considerations}

Denitrification is a major source of nitrogen gases responsible for depleting stratospheric ozone and acting as greenhouse gases in the troposphere. According to the Intergovernmental Panel on Climate Change, nitrous oxide has a global warming potential 310 times higher than carbon dioxide (Pachauri and Reisinger 2007). Nitrification contributes to the formation of nitrogen gases by increasing the pool of nitrate as well as by creating them during the nitrification process. Nitrogen oxides can be produced and escape the soil environment during the oxidation of hydroxylamine to nitrite. During this process, some of the intermediate $\mathrm{HNO}$ spontaneously transforms to $\mathrm{N}_{2} \mathrm{O}$ (Hooper and Terry, 1979). Nitrogen oxides can also be created by ammonia oxidizers when oxygen is limited and nitrite is utilized as a terminal electron acceptor in the oxidation of ammonia. The regulation of this process, termed nitrifier denitrification, is very poorly understood (Klotz and Stein, 2007). The production of $\mathrm{N}_{2} \mathrm{O}$ from denitrification versus nitrifier denitrification is hard to differentiate (Hayatsu et al., 2008) and represents an area where further research is needed.

One of the most prominent problems associated with nitrification is nitrate leaching. Leached nitrate can contaminate groundwater and surface water resources, leading to health risks in humans and eutrophication in aquatic systems. Nitrogen can be the limiting nutrient in surface waters, and large 
inputs of nitrate can lead to increased growth of specific groups of phototrophic and heterotrophic organisms, depleting oxygen in the water and reducing biodiversity (Kowalchuk and Stephen, 2001).

Management of nitrogen in wastewater treatment systems is extremely important in preventing the eutrophication of bodies of water into which treated sewage is discharged. Most inorganic nitrogen in raw sewage is in the form of ammonia (Kowalchuk and Stephen, 2001) and so the first step of nitrogen removal involves nitrification, followed by denitrification. Understanding the kinetics and ecology of ammonia-oxidizers is thus very important for efficient and speedy removal of nitrogen from sewage.

Nitrification and methane flux are closely connected. Ammonia-oxidizing organisms and methanotrophs (methane oxidizers) both utilize monooxygenases with broad substrate specificity. The particulate methane monooxygenase (pMMO) is capable of oxidizing ammonia, and bacterial ammonia monooxygenases are known to oxidize methane and other organic compounds. In laboratory studies, however, cultured AOB were unable to grow using methane as an energy source (Prosser and Nicol, 2008). The fact that these organisms might be capable of oxidizing each other's energy sources without concomitant energy gain for themselves has implications on our understanding of ecosystem function. Many studies have shown alterations in methane consumption in systems where ammonium concentrations were altered. Steudler et al. (1989) found that the application of ammonium nitrate fertilizer to acidic upland forest soils reduced methane uptake by up to 33\%. The conclusions of other studies since then have shown the effects of ammonium and nitrifiers on methane consumption to be varied; nevertheless, it can be seen that the nitrification process and nitrifiers have the potential to regulate methane flux. The effect of methanotrophs on nitrifiers and ammonia oxidation is less studied but potentially large in some systems.

\subsection{Economic considerations}

Major nitrogen inputs to agricultural systems are chemical fertilizers and recycled organic materials. The production of ammonia-based fertilizers from atmospheric nitrogen gas is responsible for 
a large amount of the fossil fuel inputs in agriculture. As such, it also represents a large cost, and one very susceptible to variations in energy prices, for agricultural producers. Nitrification can create nitrogen losses in agroecosystems by increasing nitrate availability for leaching and denitrification processes (Kowalchuk and Stephen, 2001). It has been estimated that only $4 \mathrm{Tg}$ of the $170 \mathrm{Tg}$ of nitrogen introduced to cropping systems annually accumulates in the soil (Smil, 1999). The rest is lost through crop harvest, erosion, leaching, and denitrification (Robertson and Groffman, 2007). It is important to note that nitrifiers appear to be poor competitors for ammonia unless availability exceeds the nitrogen demands of photo- and heterotrophic organisms (Robertson and Groffman, 2007). Therefore, management of nitrification becomes most important in high-throughput systems such as agroecosystems, where nitrogen and carbon inputs are typically unbalanced, changing the dynamics between plants, soil heterotrophs, and nitrifiers. Many natural and synthetic chemicals have been found to inhibit nitrification, and are occasionally applied to farm fields to help prevent nitrate leaching. These inhibitors are often prohibitively expensive, making other approaches to maximizing plant utilization of nitrogen and minimizing nitrate leaching necessary. In recent years, this has begun to include researching the genetic mechanisms governing plant nitrogen uptake in order to develop breeds that exhibit higher fertilizer nitrogen use efficiency (NUE) (see Good et al., 2004; Lea and Azevedo 2006). Less attention has been paid to soil management practices that can affect NUE. In particular, very little attention has gone into understanding how the dynamics of soil as a living, breathing entity can affect nitrogen retention and availability to plants. In this regard, a thorough understanding of nitrifier ecology and physiology may benefit farmers.

\subsection{Ecology of ammonia oxidizers}

The organisms responsible for nitrification include autotrophic bacteria and archaea, as well as heterotrophic bacteria and fungi. In most soils, nitrification is dominated by autotrophic organisms (Robertson and Groffman, 2007). In most cases, these autotrophs require oxygen as an electron acceptor and carbon dioxide or carbonates as a carbon source. The autotrophic ammonia oxidizers (AOA and 
$\mathrm{AOB})$ tend to be found in relatively low numbers due to the energetic inefficiency of lithoautotrophy; however, their need to oxidize a large quantity of substrate for growth and concomitant physiological adaptations allows them a disproportionately large effect on their environment (Ward and O'Mullan, 2005) and explains why ammonium-based fertilizers applied to fields are so rapidly nitrified (Khalil et al. 2004), particularly at higher temperatures. It has been proposed that many ammonia oxidizers have unique physiological traits, such as low maintenance energy demand and decay rates, to deal with periods of low substrate availability (Geets et al., 2006).

\subsection{The amo gene/ammonia monooxygenase enzyme}

Most studies using molecular biology techniques to examine ammonia-oxidizing organisms have used 16S rRNA or functional genes for primer design. In studies using functional genes, AOA and AOB communities are typically tracked or identified using the amoA gene, responsible for constructing a subunit of the ammonia monooxygenase enzyme system that performs the initial energy-conserving oxidation step in the nitrification process. All ammonia oxidizers are presumed to have this gene in some form. Comparisons between bacterial and archaeal amoA gene sequences have found little phylogenetic similarity (Treusch et al., 2005). Indeed, bacterial amo genes are generally more similar to bacterial methane monooxygenase ( $\mathrm{mmo}$ ) genes than archaeal amo genes (Klotz and Stein, 2007). Gene arrangement of the amo operon appears to differ between AOB and AOA, with highly conserved arrangements of the A, B, and C amo subunits in bacteria and larger variation within archaeal gene arrangements. Archaeal sequences have also been seen to encode an unknown protein between the amoA and $a m o B$ genes (Hayatsu et al. 2008). Although many bacterial and archaeal amo genes have now been sequenced, ammonia monooxygenase enzymes have never been fully purified (Ward and O'Mullan, 2005). They are believed to contain copper and/or iron cofactors (Ward and O’Mullan, 2005).

\subsection{The genomics of ammonia oxidizers}


All but one described strain of AOB, including all isolated terrestrial AOB, are within the subphylum Betaproteobacteria. Knowledge of AOB genomics is poorly understood, with most information based on the DNA sequencing of Nitrosomonas europaea, published in 2003 (Arp and Bottomley, 2006). This organism has a small genome of $2.8 \mathrm{MB}$. It contains many genes responsible for synthesizing cellular structures such as lipids, sugars, and amino acids, but very few responsible for degrading these substrates (Arp and Bottomley, 2006). Interestingly, it also contains 40 genes encoding different types of siderophore receptors and transporters, but does not appear to have any genes responsible for making siderophores (Arp and Bottomley, 2006). The AOA, which are a recent discovery, were initially classified as Crenarchaeota, although further genomic analysis has led the proposal of a new phylum, the Thaumarchaeota, which would contain all cultured AOA (BrochierArmanet et al. 2008). Analysis of AOA sequences obtained via metagenomics has thus far been less revealing. A fosmid clone of a archaeon discovered sequences similar to those encoding the bacterial $a m o A$ and $a m o B$ subunits, as well as sequences similar to the nitrite reductase gene family (Treusch et al. 2005). A sequenced scaffold of an archaeal ammonia oxidizer contained genes for carbon dioxide fixation and the TCA cycle (Venter et al. 2004). Further genomic research may provide further evidence on whether AOA possess the capabilities for lithotrophic, heterotrophic, or mixotrophic growth.

\subsection{Community dynamics of $\mathrm{AOA}$ and $\mathrm{AOB}$}

The existence of AOB has been known since 1889, when the Russian microbiologist Sergei Winogradsky isolated the microorganism Nitrosomonas europaea from the environment using an ammonium chloride-based medium. The discovery of the AOA has only been possible due to the intense recent interest in metagenomic studies. A 2004 metagenomic sequencing project in the Sargasso Sea obtained an amo gene that was associated with an archaeal rather than bacterial scaffold (Venter et al. 2004). With the isolation of Nitrosopumilus maritimus from marine samples, it was discovered that some mesophilic archaea were also capable of ammonia oxidation (Könneke et al., 2005). More recent genomic studies have shown that archaeal nitrifiers exist in almost every environment on earth, in many 
cases in greater abundance than bacterial nitrifiers (Prosser and Nicol, 2008). There are still far fewer cultured archaeal ammonia oxidizers than there are bacterial ammonia oxidizers, but the list is growing rapidly.

The AOB were considered to be predominantly responsible for ammonia oxidation until the recent identification of AOA. Now, the relative contribution to ammonia oxidation from AOA and AOB is largely unknown and poses a distinct challenge for microbiologists. This challenge is being addressed by physiological and genetic experiments with pure cultures, as well as community-level environmental studies. While qPCR-based amoA gene enumerations have generally shown AOA to be in greater abundances than AOB in terrestrial environments, the differences in cell structure and size between bacterial and archaeal ammonia oxidizers could lead to very different levels of ammonia oxidation per cell (Prosser and Nicol, 2008). Additionally, amoA gene copy number can vary between the two. The nature of the environment appears to play a large role in determining the relative abundances and activities of $\mathrm{AOA}$ and $\mathrm{AOB}$.

The body of literature on the relative contribution to terrestrial nitrification of the $\mathrm{AOA}$ and $\mathrm{AOB}$ is growing but still inconclusive. Recent evidence suggests that AOA are found in greater abundance than $\mathrm{AOB}$ in marine environments, and show a stronger correlation with nitrification rates than AOB (Wuchter et al., 2006). However, in nutrient-rich environments such as wastewater treatment plants, AOB appear to be more dominant than AOA (Jin et al., 2010). In most studies of ammonia oxidizers in soil, AOA appear to be more abundant than AOB. A study by Leininger et al. (2006) of 12 agricultural and grassland soils found crenarchaeal-associated amoA genes in greater abundance than bacterial amoA genes at all sites. AOA amoA copy numbers ranged from $7 \times 10^{6}$ to $1 \times 10^{8}$ /gram dry soil. The AOA:AOB amoA gene copy ratios varied from 1.5 to 232 in topsoils. In one grassland soil, the AOA:AOB ratio increased with depth, with a maximal value of 3,000 at 30-40 cm. In contrast, Shen et al. (2011) found higher AOB amoA gene copy numbers in the highest urea fertilizer amendment levels in a semiarid grassland. Andert et al. (2011) also found greater abundance of AOB in a drained forest peat 
soil, and Zeglin et al. (2011) found that AOB were more abundant than AOA in cultivated farm fields but not fallowed fields, forests, or pastures. Stopnišek et al. (2010) were unable to obtain AOB amoA amplicons from an organic peat soil. Shen et al. (2008) found that AOB numbers in an alkaline sandy loam soil receiving no fertilizer, manure, or inorganic fertilizers were significantly different between plots receiving inorganic fertilizer and those that did not. Studies of cultured AOA and AOB indicate a niche separation of the two, with AOB strains tolerant of higher concentrations of ammonia (21.4 mM to 1000 $\mathrm{mM}$ ) than AOA (2 to $50 \mathrm{mM}$ ) (Tourna et al., 2011; Lehtovirta-Morley et al., 2011). Studies on $N$. maritimus have shown that its ammonia monooxygenase has a much lower half-saturation constant than cultured AOB (Gubry-Rangin et al., 2010), leading to the idea that AOA may be adapted to lower substrate concentrations. This is reflected in correlations between AOA/AOB numbers and ammonia oxidation rates. It is suggested that AOA are largely responsible for nitrification in the open ocean (Martens-Habbena et al., 2009; Prosser and Nicol, 2008), which has low ammonia concentrations, while AOB may be mostly responsible for nitrification in high-ammonia environments such as sewage treatment plants (Jin et al., 2010). The picture in soils is less clear, as nitrogen and carbon dynamics are less uniform in the soil environment than in aquatic systems. One study found that AOA appeared to prefer low-ammonia plots and AOB preferred high-ammonia plots in a grassland ecosystem (Di et al. 2010). Culture-based studies have demonstrated that the two currently available soil AOA both fix atmospheric $\mathrm{CO}_{2}$, but one of them, Nitrososphaera viennensis, has been shown to also incorporate pyruvate as a heterotrophic carbon source leading to a higher growth rate (Tourna et al. 2011; LehtovirtaMorley et al. 2011). One strain of the AOB, Nitrosomonas europaea, has been shown to be capable of growing using fructose as a carbon source. This only occurred, however, at slower growth rates and only when there was no $\mathrm{CO}_{2}$ present (Arp et al. 2007). Some other strains of AOB are capable of growing as heterotrophs, oxidizing pyruvate and using nitrite as a terminal electron acceptor, but only under anaerobic conditions (Arp et al. 2007). 
It appears that AOA are more prevalent than AOB in acidic soils (Yao et al. 2011; Nicol et al. 2008). Nicol et al. found that archaeal amoA gene and transcript copies decreased with increasing pH while bacterial amoA gene and transcript numbers generally increased up to $\mathrm{pH}$ 6.9. Yao et al. (2011) found that in acidic tea soils, there was an exponential increase in the ratio of $\mathrm{AOB}$ amoA gene copy number to AOA amoA gene copy number $\left(\mathrm{r}^{2}=0.54\right)$ as $\mathrm{pH}$ increased, with AOA amoA genes dominating in soils of $\mathrm{pH} 4$ and lower. Many studies have found that there are significant shifts in community composition of both AOA and AOB across pH gradients (Andert et al. 2011; Nicol et al. 2008; Yao et al. 2011). Urea hydrolysis may be an important adaptation to acid soils, as AOB from soils have been seen to have the capacity to catabolize urea, while those in other environments have not (Arp et al., 2007).

In general, more studies have shown changes in AOB amoA gene copy number or community composition with measured nitrification rates or nitrogen amendment rates. However, this is not the case for all systems. Kelly et al. (2011) found that AOA amoA gene copy number had a much stronger correlation with potential nitrification rates than $\mathrm{AOB}$ amoA gene copy number in agricultural fields amended with either inorganic nitrogen fertilizer or biosolids. This was also the case in tea soils amended with urea (Yao et al. 2011) and a long-term agricultural site receiving different types of organic matter amendment or inorganic fertilizer (Wessén et al. 2010). The latter study found that AOA numbers were positively correlated to labile carbon addition rates. Gubry-Rangin et al. (2010) found the abundance of AOA but not AOB was correlated to nitrate production rates in two acid (pH 4.5 and 6) agricultural soils. They speculated that this may have been due to low ammonia availability at these pHs. Ammonia oxidation increased upon addition of inorganic nitrogen fertilizer to an agricultural soil, with a concurrent increase in ammonia-oxidizing bacteria, however, ammonia-oxidizing archaeal numbers did not increase (Jia and Conrad, 2009). In a study looking at the effect of urine amendment on AOB and AOA populations, Di et al. (2010) found a weak correlation between nitrate concentration over time and AOB amoA gene copy numbers, but no correlation between nitrate concentration and AOA amoA gene copy numbers. Additionally, they found that AOB amoA RNA transcripts increased with urine amendments, 
while AOA amoA RNA transcripts decreased with urine amendment. The authors attributed this to an adaptation of AOA to lower-fertility sites. When AOB were inhibited by the antibiotic sulfadiazine, AOA appeared to take over the nitrification process (Schauss et al., 2009). Tourna et al. (2008) demonstrated that growth of active AOA was inhibited by small amounts of acetylene, which prevents the functioning of the amo gene, suggesting chemolithotrophic metabolism in these particular archaea. Di et al. (2009) found that AOB but not AOA gene copy number correlated with nitrification potential; similar results were seen in a number other studies (Jia and Conrad 2009; Di et al. 2010; Ying et al. 2010).

Studies have also have found AOB numbers or community structure, which can be considered as the degree of order or randomness found in the presence and abundance of organisms within the community, responding to the application of ammonia or other reduced nitrogen compounds (Shen et al. 2011; Leininger et al. 2006; Hynes and Germida 2012; Shen et al. 2008). Zeglin et al. (2011) as well as Fan et al. (2010) found a correlation between AOB community similarity and nitrification potential, but they did find that it affected AOB community structure. Shen et al. (2008) found that different fertilizer regimes affected $\mathrm{AOB}$ but not $\mathrm{AOA}$ community structure, with the highest $\mathrm{AOB}$ diversity occurring in soils amended with nitrogen-potassium, nitrogen-phosphorus, or nitrogen-phosphorus-potassium fertilizers. The lowest diversity occurred in sites receiving phosphorus-potassium fertilizer, manure, or no fertilizer amendment. Gene copy numbers of AOA and AOB did not significantly differ between treatments. In contrast to the results of Shen et al. (2008), Yao et al. (2011) found that different levels of urea-based nitrogen fertilizer did not result in obvious changes in AOA and AOB community structure. Stopnišek and colleagues (2010) also found no change in AOA community structure in a peat soil due to rates of ammonium fertilizer amendment. This study found that ammonium fertilization did not increase nitrification rates, supporting the hypothesis that organic nitrogen mineralization was driving nitrification. Wessén et al. (2010) found differences in AOA/AOB community similarity and abundance due to longterm amendments of different types of organic matter or inorganic fertilizer. For this study, peat amendment greatly changed community structure. 
In summary, previous studies suggest that $\mathrm{AOA}$ and $\mathrm{AOB}$ occupy different niches. AOA appear to be dominant in both numbers and control over ammonia oxidation in the low-ammonia environment of the open ocean, while AOB exhibit control over ammonia oxidation in high-ammonia environments such as wastewater treatment plants. Soil ecosystems exhibit a much wider range of conditions, but there still appear to be some trends. AOA are generally numerically dominant. In agroecosystems, changes in AOB numbers or community composition are more often associated with nitrification rates than changes in AOA. This is particularly the case in systems receiving high rates of inorganic fertilizers, where carbon and nitrogen inputs are unbalanced. AOA become more important in highly acidic or alkaline agricultural soils, and in agricultural soils receiving organic nitrogen fertiizers. Less studied are natural terrestrial ecosystems (forests and grasslands), although they appear to follow the same trends as other soils- AOA are numerically dominant, but AOB may be more correlated to nitrification rates in higher fertility sites. Overall, the AOA appear to be found in more varied environments than AOB and adapted to a wider range of growth conditions (Schleper, 2010). The purpose of the present study was to contribute to the body of literature that is seeking to understand ammonia oxidizer dynamics in different environments and resolve the ecological roles of the AOA and AOB. Our study addressed the community structure of AOA and AOB in an agroecosystem that received compost amendment as a sole source of fertilizer input.

\subsection{Objectives and hypotheses}

\subsubsection{Objective 1}

Determine what environmental factors correlate with changes in community similarity and diversity of $\mathrm{AOA}$ and $\mathrm{AOB}$ and whether either the $\mathrm{AOA}$ or $\mathrm{AOB}$ are responsible for nitrification in these plots.

\subsubsection{Hypothesis 1}


Archaeal diversity will decline as compost amendment increases, while bacterial diversity will increase as compost amendment increases.

\subsubsection{Hypothesis 2}

Nitrification rates will affect $\mathrm{AOB}$ community similarity and diversity but not AOA community similarity or diversity.

\subsubsection{Objective 2}

Determine how compost amendment affects the overall microbial community and nitrogen cycling in these plots.

\subsubsection{Hypothesis 3}

Microbial biomass carbon, potentially mineralizable nitrogen, and potential ammonia oxidation will all significantly increase with increasing compost amendment.

\subsection{A note on ammonia/ammonium}

Ammonia and ammonium are closely related chemically, being the conjugate base and acid, respectively, of the other. Ammonia has a high pKa (9.23), so under most soil conditions ammonium is present in higher concentrations than ammonia. This relationship between ammonia is of great practical importance. It is believed than $\mathrm{AOB}$ and $\mathrm{AOA}$ utilize ammonia, not ammonium, as their substrate, the reason most often given for the low rates of ammonia oxidation seen at low $\mathrm{pHs}$. 


\subsection{REFERENCES}

Andert, J., E. Wessén, G. Börjesson, and S. Hallin. 2011. Temporal changes in abundance and composition of ammonia-oxidizing bacterial and archaeal communities in a drained peat soil in relation to $\mathrm{N}_{2} \mathrm{O}$ emissions. Journal of Soils \& Sediments 11: 1399-1407.

Arp, D.J., and P.J. Bottomley. 2006. Nitrifiers: more than 100 years from isolation to genome sequences. Microbe 1: 229-234.

Arp, D.J., P.S.G. Chain, and M.G. Klotz. 2007. The impact of genome analyses on our understanding of ammonia-oxidizing bacteria. Annual Review of Microbiology 61: 503-528.

Brochier-Armanet, C., B. Boussau, S. Gribaldo, and P. Forterre. 2008. Mesophilic crenarchaeota: proposal for a third archaeal phylum, the Thaumarchaeota. Nature Reviews Microbiology 6: 245-252.

Di, H.J., K.C. Cameron, J.P. Shen, C.S. Winefield, M. O'Callaghan, S. Bowatte, and J. He. 2009. Nitrification driven by bacteria and not archaea in nitrogen-rich grassland soils. Nature Geoscience 2: 621-624.

Di, H.J., K.C. Cameron, J. Shen, C.S. Winefield, M. O'Callaghan, S. Bowatte, and J. He. 2010. Ammonia-oxidizing bacteria and archaea grow under contrasting soil nitrogen conditions. FEMS Microbiology and Ecology 72: 386-394.

Fan, F., F. Zhang, and Y. Lu. 2010. Linking plant identity and interspecific competition to soil nitrogen cycling through ammonia oxidizer communities. Soil Biology \& Biochemistry 43: 46-54.

Galloway, J.N., J.D. Aber, J.W. Erisman, S.P. Seitzinger, R.W. Howarth, E.B. Cowling, and B.J. Cosby. 2003. The nitrogen cascade. Bioscience 53: 341-356. 
Galloway, J.N., and E.B. Cowling. 2002. Reactive nitrogen and the world: two hundred years of change. Ambio 31: 64-71.

Galloway, J.N., A.R. Townsend, J.W. Erisman, M. Bekunda, Z. Cai, J.R. Freney, L.A. Martinelli, S.P. Seitzinger, and M.A. Sutton. 2008. Transformation of the nitrogen cycle: recent trends, questions, and potential solutions. Science 320: 889-892.

Geets, J., N. Boon, and W. Verstraete. 2006. Strategies of aerobic ammonia-oxidizing bacteria for coping with nutrient and oxygen fluctuations. FEMS Microbiology and Ecology 58: 1-13.

Good, A.G., A.K. Shrawat, and D. G. Muench. 2004. Can less yield more? Is reducing nutrient input into the environment compatible with maintaining crop production? Trends in Plant Science 9: 597-605.

Gubry-Rangin, C., G.W. Nicol, and J.I. Prosser. 2010. Archaea rather than bacteria control nitrification in two agricultural acidic soils. FEMS Microbiology and Ecology 74: 566-574.

Hayatsu, M., K. Tago, and M. Saito. 2008. Various players in the nitrogen cycle: diversity and functions of the microorganisms involved in nitrification and denitrification. Soil Science and Plant Nutrition 54: 33-45.

Hooper, A.B., and K.R. Terry. 1979. Hydroxylamine reductase of Nitrosomonas production of nitric oxide from hydroxylamine. Biochimica et Biophysica Acta 571: 12-20.

Hynes, H.M., and J.J. Germida. 2012. Relationship between ammonia oxidizing bacteria and bioavailable nitrogen in harvested forest soils of central Alberta. Soil Biology \& Biochemistry 46: 18-25.

Jia, Z., and R. Conrad. 2009. Bacteria rather than archaea dominate microbial ammonia oxidation in an agricultural soil. Environmental Microbiology 11: 1658-1671. 
Jin, T., T. Zhang, and Q. Yan. 2010. Characterization and quantification of ammonia-oxidizing archaea (AOA) and bacteria $(\mathrm{AOB})$ in a nitrogen-removing reactor using T-RFLP and qPCR. Applied Microbiology and Biotechnology 87: 1167-1176.

Kelly, J.J., K. Policht, T. Grancharova, and L.S. Hundal. 2011. Distinct responses in ammoniaoxidizing archaea and bacteria after addition of biosolids to an agricultural soil. Applied and Environmental Microbiology 77: 6551-6558.

Khalil, K., B. Mary, and P. Renault. 2004. Nitrous oxide production by nitrification and denitrification in soil aggregates as affected by $\mathrm{O}_{2}$ concentration. Soil Biology \& Biochemistry 36: 687-699.

Klotz, M.G., and L.Y. Stein. 2007. Nitrifier genomics and evolution of the nitrogen cycle. FEMS Microbiology Letters 278: 146-156.

Könneke, M., A.E. Bernhard, J.R. de la Torre, C.B. Walker, J.B. Waterbury, and D.A. Stahl. 2005. Isolation of an autotrophic ammonia-oxidizing marine archaeon. Nature 437: 543-546.

Kowalchuk, G.A., and J.R. Stephen. 2001. Ammonia-oxidizing bacteria: a model for molecular microbial ecology. Annual Review of Microbiology 55: 485-529.

Lea, P.J., and R.A. Azevedo. 2006. Nitrogen use efficiency. 1. Uptake of nitrogen from the soil. Annals of Applied Biology 149: 243-247.

Lehtovirta-Morley, L.E., K. Stoecker, A. Vilcinskas, J.I. Prosser, and G.W. Nicol. 2011. Cultivation of an obligate acidophilic ammonia oxidizer from a nitrifying acid soil. PNAS 108: 15,892-15,897.

Leininger, S., T. Urich, M. Schloter, L. Schwark, J. Qi, G.W. Nicol, J.I. Prosser, S.C. Shuster, and C. Schleper. 2006. Archaea predominate among ammonia-oxidizing prokaryotes in soils. Nature $\mathbf{4 4 2}$ : 806-809. 
Martens-Habbena, W., P.M. Berube, H. Urakawa, J.R. de la Torre, and D.A. Stahl. 2009. Ammonia oxidation kinetics determine niche separation of nitrifying archaea and bacteria. Nature 461: 976-981.

Nicol, G.W., S. Leininger, C. Schleper, and J.I. Prosser. 2008. The influence of soil pH on the diversity, abundance and transcriptional activity of ammonia oxidizing archaea and bacteria. Environmental Microbiology 10: 2966-2978.

Pachauri, R.K., and A. Reisinger. 2007. Climate change 2007: Synthesis report. Intergovernmental Panel on Climate Change, Geneva, Switzerland.

Prosser, J.I., and G.W. Nicol. 2008. Relative contributions of archaea and bacteria to aerobic ammonia oxidation in the environment. Environmental Microbiology 10: 2931-2941.

Robertson, G.P., and P.M. Groffman. 2007. Nitrogen transformations. In Paul, E.A. (ed.) Soil microbiology, ecology, and biochemistry. Academic Press, Burlington, MA.

Schauss, K., A. Focks, S. Leininger, A. Kotzerke, H. Heuer, S. Thiele-Bruhn, S. Sharma, B. Wilke, M. Mathies, K. Smalla, J.C. Munch, W. Amelung, M. Kaupenjohann, M. Schloter, and C. Schleper. 2009. Dynamics and functional relevance of ammonia-oxidizing archaea in two agricultural soils. Environmental Microbiology 11: 446-456.

Schleper, C. 2010. Ammonia oxidation: different niches for bacteria and archaea? ISME Journal 4: 10921094.

Shen, J., L. Zhang, Y. Zhu, J. Zhang, and J. He. 2008. Abundance and composition of ammoniaoxidizing bacteria and ammonia-oxidizing archaea communities of an alkaline sandy loam. Environmental Microbiology 10: 1601-1611. 
Shen, X., L. Zhang, J. Shen, L. Li, C. Yuan, and J. He. 2011. Nitrogen loading levels affect abundance and composition of soil ammonia oxidizing prokaryotes in semiarid temperate grassland. Journal of Soils and Sediments 11: 1243-1252.

Smil, V. 1999. Nitrogen in crop production: an account of global flows. Global Biogeochemical Cycles 13: $647-662$.

Smil, V. 2001. Enriching the earth: Fritz Haber, Carl Bosch and the transformation of world food production. MIT Press, Cambridge, MA.

Steudler, P.A., R.D. Bowden, J.M. Melillo, and J.D. Aber. 1989. Influence of nitrogen fertilisation on methane uptake in forest soils. Nature 341: 314-316.

Stopnišek, N., C. Gubry-Rangin, S. Höfferle, G.W. Nicol, I. Mandič-Mulec, and J.I. Prosser. 2010. Thaumarchaeal ammonia oxidation in an acidic forest peat soil is not influenced by ammonium amendment. Applied and Environmental Microbiology 76: 7626-7634.

Tourna, M., T.E. Freitag, G.W. Nicol, and J.I. Prosser. 2008. Growth, activity and temperature responses of ammonia-oxidizing archaea and bacteria in soil microcosms. Environmental Microbiology 10: $1357-1364$.

Tourna, M., M. Stieglmeier, A. Spang, M. Könneke, A. Schintlmeister, T. Urich, M. Engel, M. Schloter, M. Wagner, A. Richter, and C. Schleper. 2011. Nitrososphaera viennensis, an ammonia oxidizing archaeon from soil. PNAS 108: 8420-8425.

Treusch, A.H., S. Leininger, A. Kietzin, S.C. Schuster, H.P. Klenk, and C. Schleper. 2005. Novel genes for nitrite reductase and amo-related proteins indicate a role of uncultivated mesophilic crenarchaeota in nitrogen cycling. Environmental Microbiology 7: 1985-1995. 
Venter, J.C., K. Remington, J.F. Heidelberg, A.L. Halpern, D. Rusch, J.A. Eisen, D. Wu, I. Paulsen, K.E. Nelson, W. Nelson, D.E. Fouts, S. Levy, A.H. Knap, M.W. Lomas, K. Nealson, O. White, J. Peterson, J. Hoffman, R. Parsons, H. Baden-Tillson, C. Pfannkoch, Y. Rogers, and H.O. Smith. 2004. Environmental genome shotgun sequencing of the Sargasso Sea. Science 304: 66-74.

Ward, B.B., and G.D. O’Mullan. 2005. Community level analysis: genetic and biogeochemical approaches to investigate community composition and function in aerobic ammonia oxidation. Methods in Enzymology 397: 395-413.

Wessén, E., K. Nyberg, J.K. Jansson, and S. Hallin. 2010. Responses of bacterial and archaeal ammonia oxidizers to soil organic and fertilizer amendments under long-term management. Applied Soil Ecology 45: 193-200.

Wuchter, C., B. Abbas, M.J.L. Coolen, L. Herfort, J. van Bleijswijk, P. Timmers, M. Strous, E. Teira, G.J. Herndl, J.J. Middelburg, S. Schouten, and J.S. Sinninghe Damsté. 2006. Archaeal nitrification in the ocean. Proceedings of the National Academy of Sciences 103: 12317-12322.

Yao, H., Y. Gao, G.W. Nicol, C.D. Campbell, J.I. Prosser, L. Zhang, W. Han, and B.K. Singh. 2011. Links between ammonia oxidizer community structure, abundance, and nitrification potential in acidic soils. Applied and Environmental Microbiology 77: 4618-4625.

Ying, J., L. Zhang, and J. He. 2010. Putative ammonia-oxidizing bacteria and archaea in an acidic red soil with different land utilization patterns. Environmental Microbiology Reports 2: 304-312.

Zeglin, L.H., A.E. Taylor, D.D. Myrold, and P.J. Bottomley. 2011. Bacterial and archaeal amoA gene distribution covaries with soil nitrification properties across a range of land uses. Environmental Microbiology Reports 3: 717-726. 


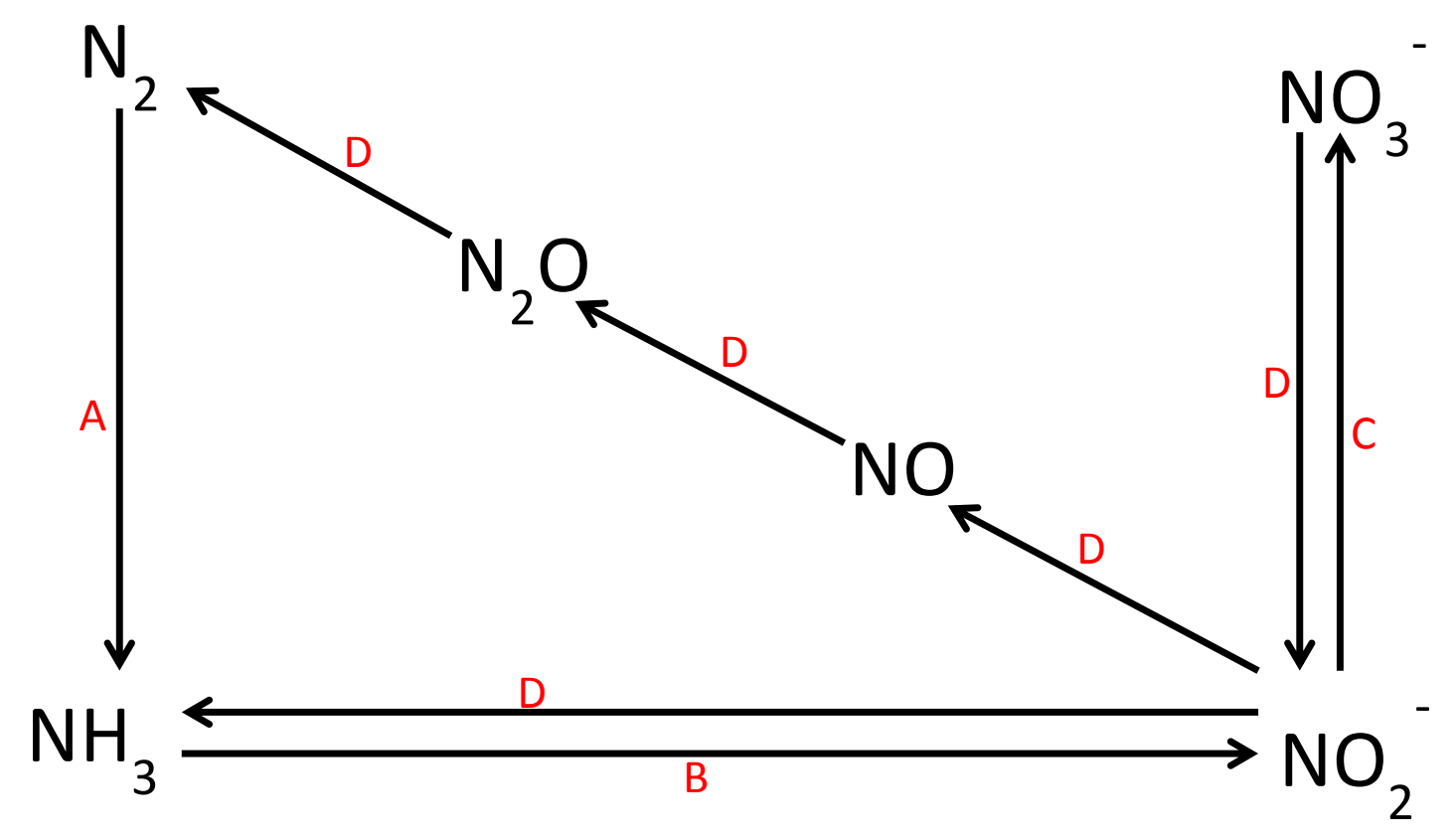

Figure 1. The nitrogen cycle.

A. The reduction of dinitrogen $\left(\mathrm{N}_{2}\right)$ gas to organic nitrogen compounds and ammonia $\left(\mathrm{NH}_{3}\right)$. The energy required to synthesize ammonia stoichiometrically from its constituents $\left(\mathrm{N}_{2}\right.$ and $\left.\mathrm{H}_{2}\right)$ is substantial $\left(392.4 \mathrm{~kJ} / \mathrm{mol} \mathrm{NH}_{3}\right)$. Traditionally, this process was performed by nitrogen-fixing microorganisms found in the soil and plant roots; in agroecosystems, biological nitrogen fixation has been either increased from historical levels by increased planting of legumes or supplanted by fossil-fuel produced ammonia using the Haber-Bosch process (which requires, on average, 798.0 $\mathrm{kJ} / \mathrm{mol} \mathrm{NH}_{3}$ ).

B. The oxidation of ammonia to nitrite. Typically, this oxidation is tied to the reduction of molecular oxygen; however, in some instances it can be tied to the reduction of nitrite to dinitrogen gas- this is termed nitrifier denitrification.

C. The oxidation of nitrite to nitrate. This reaction is also typically aerobic.

D. Denitrification. Nitrate gets sequentially reduced to nitrite, nitric oxide, nitrous oxide, and dinitrogen gas. Alternatively, nitrite can be reduced to ammonia in a process termed dissimilatory nitrate reduction to ammonia (DNRA). Denitrification is a process largely performed by heterotrophic microorganisms in the absence of oxygen. 


\section{CHAPTER 2}

\section{The effect of compost amendment on ammonia-oxidizing bacteria and archaea in a silt loam topsoil}

\subsection{INTRODUCTION}

Nitrification, the transformation of ammonia to nitrate, is the key oxidative process in the nitrogen cycle. The microorganisms responsible for oxidizing ammonia to nitrite, the first step of nitrification, include both bacteria and archaea (AOB and AOA, respectively). Traditionally, AOB were thought to be solely responsible for soil nitrification but recent studies have demonstrated high numbers of archaeal amoA genes in worldwide soils (Leininger et al. 2006). These new studies have employed molecular techniques such as terminal-restriction fragment length polymorphism (T-RFLP), quantitative PCR (qPCR), high-throughput sequencing (Xia et al. 2011; Gubry-Rangin et al. 2011), stable-isotope probing (Jia and Conrad 2009), and gene cloning to address the challenges of tying microbial ecology to a specific process. Additionally, some researchers have studied the physiology of cultured strains of AOA and AOB (Lehtovirta-Morley et al. 2011; Tourna et al. 2011; Chain et al. 2003) or focused on rates of gross and net nitrification to understand this process (Booth et al. 2005).

This study represents an attempt to elucidate changes in AOA and AOB community structure along a fine-scale gradient of soil fertility in sites where the only fertilizer input was varying levels of compost. The central technique in this work, terminal-restriction fragment length polymorphism (TRFLP), was used to fingerprint specific microbial communities in soils. T-RFLP often uses bacterial or archaeal 16S rRNA genes (Thies 2007), however, in this study the amoA gene was utilized instead (Ward and O'Mullan 2005). I used a community level approach, tracking population differences using T-RFLP and several measures of nitrogen flow rates and soil biomass pool size (potentially mineralizable nitrogen, potential ammonia oxidation, and microbial biomass carbon) to understand changes in $\mathrm{AOA} / \mathrm{AOB}$ 
community structure as affected by different fertility management regimes. The primary objective was to determine what factors influenced community structure of AOA and $\mathrm{AOB}$ and who was responsible for nitrification in these soils. A secondary objective was to see how compost amendment affected the overall microbial community and nitrogen cycling in the system. My primary hypothesis was that archaeal diversity would decline as compost amendment increased, while bacterial diversity would increase as compost amendment increased. I further hypothesized that only AOB would correlate to nitrification in these sites. My secondary hypothesis was that microbial biomass carbon, potentially mineralizable nitrogen, and potential ammonia oxidation would all significantly increase with increasing compost amendment.

\subsection{MATERIALS AND METHODS}

\subsubsection{Site description and sampling methods}

Soil samples were collected in May 2011 from compost rate plots (Figures 1 and 2) at the West Virginia University (WVU) Organic Research Farm in Morgantown, WV (Lat. 39³8’ 43” N, Long. 79 56 ' 15" W). The compost rate trial at WVU was initiated in 2000 when 40 plots of $2.44 \mathrm{~m}$ by $3.96 \mathrm{~m}$, with $0.61 \mathrm{~m}$ alleys in between, were laid out on a Dormont silt loam (fine-loamy, mixed, superactive, mesic Oxyaquic Hapludalfs) previously in pasture. Sod from each plot was removed to a depth of $5 \mathrm{~cm}$, plots were limed to approximately $\mathrm{pH} 6.2$, and partially composted dairy manure (mixed with grass clippings, leaves, and woodchips) applied at 5 different rates $(0,11.2,22.4,44.8$, and $89.6 \mathrm{Mg}$ compost ha $^{-1}$, or 0 to 40 tons/acre), with 8 randomly determined replicates of each treatment (Figure 3 ). This compost was added in late spring or early summer and tilled into the soil to a depth of approximately 10 $\mathrm{cm}$. In this first year, 4 randomly selected plots of each treatment were planted with buckwheat, and the other 4 plots of each treatment were planted with millet. In each year thereafter, all the plots originally planted with buckwheat were planted with the same crop, and all the plots originally planted with millet 
were planted with the same crop (Table 1). Compost (Table 2) application was repeated at the same rates in 2001, 2002, 2003, and 2005. The plots were left fallow in 2004 and 2006-2009. In 2010, all plots were planted with Miscanthus sinensis, and either straw or hay mulches were placed on the soil surface according to a randomized plot design (Figure 3). All plots that received straw mulch (applied at a rate of 5.5 Mg straw ha ${ }^{-1}$ ) were sampled for this project. The elemental composition of the straw mulch is reported in Table 2. Plots were sampled in order from least to greatest amounts of compost amendment, and all tools were rinsed with deionized water and sterilized with $70 \%$ ethanol between plots. Gloves were changed between each plot. Seven cores were taken to a depth of $15 \mathrm{~cm}$ from each plot, as diagrammed in Figure 4. The cores from each individual plot were placed into a sterile jar and stored on ice for the duration of the field sampling. Samples were sieved $(2 \mathrm{~mm})$ and composited. The sieve was washed in deionized water, sterilized with ethanol, and dried between each sample, and gloves were changed between each sample. Composite samples were placed in sterile Whirlpak bags and stored at $20^{\circ} \mathrm{C}$.

\subsubsection{Soil analytical measures}

\subsubsection{Soil water content and $\mathrm{pH}$}

Soil moisture and $\mathrm{pH}$ were measured directly after sieving and compositing of samples using standard procedures (Klute 1986; Sparks 1986). Soil moisture was obtained by taking 5.0 grams of soil from each composited sample and baking it in an oven at $105^{\circ} \mathrm{C}$ for 24 hours. Moisture was measured in triplicate.

One gram of soil was combined with $2.5 \mathrm{ml}$ deionized water to obtain soil $\mathrm{pH}$ for each sample. Soil $\mathrm{pH}$ was determined in triplicate, and a 3-point calibration was performed with the electrode.

\subsubsection{Chloroform fumigation extraction for microbial biomass carbon}


Microbial biomass carbon (MBC) is a procedure that measures the size of the overall microbial biomass in soils, assuming soils have been sieved to remove plant roots and larger fauna. It operates on the principle that chloroform will lyse microbial cells, and the organic carbon released can then be extracted to give a measure of the microbial biomass size. In order to do this, soil samples are incubated in bottles with chloroform and the bottles are vacuum-sealed to volatilize the chloroform. After a suitable incubation time, the samples are then extracted with a salt solution. The equation used to calculate biomass carbon is

$$
\text { Biomass } \mathrm{C}\left(\mathrm{B}_{\mathrm{C}}\right)=\mathrm{E}_{\mathrm{C}} / \mathrm{k}_{\mathrm{EC}}
$$

where $E_{C}$ is the carbon extracted from fumigated soils minus carbon extracted from unfumigated soils and $\mathrm{k}_{\mathrm{EC}}$ is a constant, 0.45 , reflecting the efficiency of lysis and extraction of organic carbon from microbes in agricultural soils (Brookes and Joergensen, 2006).

Soil samples had been frozen but had been thawed and equilibrated at $4{ }^{\circ} \mathrm{C}$ for 4 months prior to performing this assay. Samples were allowed to sit in the dark at room temperature for 24 hours before being incubated or extracted (negative controls), respectively. Ten grams of soil from each plot, adjusted for moisture content, were placed into $160 \mathrm{ml}$ serum bottles along with test tubes containing $2 \mathrm{ml}$ of amylene-stabilized chloroform. The bottles were sealed with rubber stoppers and the chloroform was volatilized by creating a vacuum pressure of $720 \mathrm{~mm} \mathrm{Hg}$ for 30 seconds on each bottle. The bottles were placed in the dark and allowed to incubate for 24 hours at $25^{\circ} \mathrm{C}$. After this time, the test tubes were removed and the samples were extracted with $50 \mathrm{ml}$ of $0.5 \mathrm{M} \mathrm{K}_{2} \mathrm{SO}_{4}$. The bottles were shaken at $200 \mathrm{rpm}$ for one hour and the supernatant was vacuum filtered through $0.22 \mu \mathrm{m}$ filter paper. Unincubated controls were also placed in serum bottles and immediately extracted with $50 \mathrm{ml}$ of $0.5 \mathrm{M} \mathrm{K}_{2} \mathrm{SO}_{4}$, thereafter following the same procedure as the incubated samples. Dissolved organic carbon concentrations were determined in quadruplicate using a Sievers 5310C Laboratory TOC Analyzer (General Electric, Trevose, PA). 


\subsubsection{Potentially mineralizable nitrogen}

Potentially mineralizable nitrogen $(\mathrm{PMN})$ is a procedure that measures the rate at which organic nitrogen gets hydrolyzed to ammonia. It is a potential assay measured under optimum temperature for nitrogen mineralization $\left(40^{\circ} \mathrm{C}\right)$ and waterlogged conditions. The anaerobic conditions do not appreciably affect relative nitrogen mineralization rates (Waring and Bremner 1964), but do prevent ammonia from being oxidized to nitrate by the aerobic ammonia oxidizers. Additionally, the net nitrogen mineralization rate correlates well with gross mineralization rates obtained by $\mathrm{N}^{15}$ studies (Booth et al. 2005) if incubation times are short.

Soil samples had been frozen but were allowed to thaw and equilibrate at $4^{\circ} \mathrm{C}$ for two weeks prior to performing this assay. Samples were allowed to sit in the dark at room temperature for 24 hours before being incubated or extracted, as the negative controls were. The procedure used was as follows: 4.8 grams of soil (oven dry weight) from each plot were combined with $12 \mathrm{ml}$ of distilled water and anaerobically incubated in the dark for 7 days at $40^{\circ} \mathrm{C}$. Samples were manually shaken to suspend the soil before incubation and every day during the incubation. After incubating, samples were combined with 12 $\mathrm{ml}$ of $2 \mathrm{M} \mathrm{KCl}$ and shaken for one hour at $200 \mathrm{rpm}$. The supernatant was vacuum-filtered through 0.22 $\mu \mathrm{m}$ filters and stored at $-20^{\circ} \mathrm{C}$ prior to analysis. Unincubated controls were combined with $12 \mathrm{ml}$ of distilled water and $12 \mathrm{ml} 2 \mathrm{M} \mathrm{KCl}$. They were shaken, filtered, and stored as per the incubated samples until analysis. Unincubated controls were also used to establish soil $\mathrm{NH}_{4}{ }^{+}$concentrations.

Ammonium was determined colorimetrically following a modification of the protocol of Mulvaney (1996). Three reagents were prepared. The first reagent was produced by creating a solution comprised of $7.81 \%(\mathrm{wt} / \mathrm{vol})$ sodium salicylate and $0.125 \%$ sodium nitroprusside in deionized water. The second solution contained $2.96 \%$ (wt/vol) $\mathrm{NaOH}, 9.96 \% \mathrm{Na}_{2} \mathrm{HPO}_{4} * 7 \mathrm{H}_{2} 0$, and $0.6 \% \mathrm{NaOCl}$ in deionized water. This solution was titrated to $\mathrm{pH} 13$ with $0.1 \mathrm{M} \mathrm{NaOH}$. The third reagent contained $6 \%$ (wt/vol) NaEDTA and $0.5 \% \mathrm{NaOH}$ in deionized water. Three $\mathrm{ml}$ aliquots of soil filtrates were combined with one 
$\mathrm{ml}$ of the EDTA reagent, $4 \mathrm{ml}$ of the sodium salicylate reagent, and $2 \mathrm{ml}$ of the hypochlorite buffer, and brought to a total volume of $28 \mathrm{ml}$ with deionized water. The samples were allowed to sit at room temperature for 2 hours in order to develop color. At this time absorbance at $667 \mathrm{~nm}$ was measured using a Cary 50 Probe UV-Visible spectrophotometer (Varian, Santa Clara, CA). Standards were prepared by combining $1 \mathrm{M} \mathrm{KCl}$ solution containing $0.1,0.2,0.3,0.5,1,2,3,5$, and $10 \mathrm{mg} / \mathrm{L} \mathrm{NH}_{4}{ }^{+}$with the same amounts of EDTA, salicylate, and hypochlorite solutions as above.

\subsubsection{Potential ammonia oxidation}

Potential ammonia oxidation (PAO) is a measure of the rate of nitrification that can occur under optimum substrate concentrations and aeration in a given soil. Acetylene is added to soil samples to create negative controls because it irreversibly inhibits both bacterial and archaeal ammonia monoxygenase enzymes (Offre et al. 2009). As the only ammonia oxidation occurring under these conditions would be due to heterotrophic nitrifiers, the difference between nitrate/nitrite accumulation in the samples without acetylene and those with acetylene is considered to be the rate of autotrophic nitrification. Samples are shaken to maintain oxic conditions in order to prevent denitrification from occurring. Being a measure of the activity of the nitrifying community, potential ammonia oxidation can also be seen as a proxy for the functional size of the community.

Soil samples had been frozen but had been thawed and equilibrated at $4^{\circ} \mathrm{C}$ for 6 months prior to performing this assay. Samples were allowed to sit in the dark at room temperature for 24 hours before being either incubated or extracted to establish initial $\mathrm{NO}_{3}{ }^{-} / \mathrm{NO}_{2}{ }^{-}$concentrations, respectively. Potential ammonia oxidation was measured for each plot using the protocol of Boyle-Yarwood et al. (2008), a modification of the procedure advocated by Hart et al. (1994). Fifteen grams of soil from each plot were placed in $250 \mathrm{ml}$ plastic centrifuge bottles and washed with $135 \mathrm{ml}$ of a $\mathrm{pH} 7.2$ phosphate buffer. They were centrifuged for 10 minutes at $6000 \mathrm{x}$ g and decanted. The soil pellet was then resuspended in 135 $\mathrm{ml}$ of a $\mathrm{pH} 7.2$ phosphate buffer containing $1.5 \mathrm{mM}$ ammonium in the form of ammonium sulfate. 
Twenty milliliters of suspended sediment from each sample was added to one of six $160 \mathrm{ml}$ serum vials and sealed with rubber stoppers; the remaining sediment from each plot was filtered through $0.22 \mu \mathrm{m}$ filters and used to establish initial $\mathrm{NO}_{3}{ }^{-}+\mathrm{NO}_{2}{ }^{-}$concentrations. Three of the 6 serum bottle aliquots from each plot were injected with acetylene gas to obtain a final partial pressure of $10 \mathrm{kPa}$, and all aliquots were incubated in the dark for 30 hours while being shaken at $200 \mathrm{rpm}$. After this time, aliquots were filtered and stored at $-20^{\circ} \mathrm{C}$ until colorimetric analysis of combined $\mathrm{NO}_{3}{ }^{-} / \mathrm{NO}_{2}{ }^{-}$. After trial samples were analyzed to determine relative concentrations of $\mathrm{NO}_{3}{ }^{-} / \mathrm{NO}_{2}{ }^{-}$, the QuikChem Method 10-107-04-1-C was used to measure potential ammonia oxidation rates by determining the difference in $\mathrm{NO}_{3}{ }^{-} / \mathrm{NO}_{2}{ }^{-}$production between samples incubated with acetylene and those not incubated with acetylene. This was done with flow injection by injecting samples into a carrier comprised of an ammonium chloride buffer ( $\mathrm{pH}$ 8.5). The samples were then passed through a cadmium column to reduce all the $\mathrm{NO}_{3}{ }^{-}$to $\mathrm{NO}_{2}{ }^{-}$. $\mathrm{This}_{2} \mathrm{NO}_{2}^{-}$was then mixed with an excess sulfanilamide/ N-(1-napthyl)ethylenediamine solution, with which it formed a red dye. The concentration of this red dye, reflective of the combined $\mathrm{NO}_{3}{ }^{-} / \mathrm{NO}_{2}{ }^{-}$concentration in the samples, was measured by light absorbance at $520 \mathrm{~nm}$. This colorimetric analysis was performed using a Lachat QuikChem flow injection analyzer (Hach Company, Loveland, CO).

\subsubsection{T-RFLP: DNA extraction, amplification, restriction digestion, and capillary electrophoresis}

Terminal restriction fragment length polymorphism (T-RFLP) is a polymerase chain reaction (PCR) -based technique used to track microbial populations that operates on the principle that different strains or species of bacteria or archaea with a given gene will often have slightly different gene sequences. Genes are amplified by PCR using fluorescent tags on the 5' end of the forward primer and then cut with restriction enzymes that only attach and cut at specific restriction sites (for example, the restriction enzyme AciI only recognizes the sites 5'-CCGC-3' or 5'-GCGG-3' and cuts after the first base of either sequence). Variation within gene sequences between strains will result in cuts in different locations by a specific restriction enzyme, generating gene fragments of different lengths. The fragments are then separated by size using capillary electrophoresis. The machine detector can only visualize the 
gene fragment that contains the fluorescently labeled forward primer. This means that each gene copy, no matter how many fragments it has been cut into, will only show up once. The detector visualizes the fluorescently-labeled fragments as peaks on an electropherogram, with fragment lengths increasing from left to right along the $\mathrm{x}$ axis. Fragment lengths can be determined by adding fluorescently labeled size standards. Relative peak height or area of each visualized fragment, or operational taxonomic unit (OTU), shows the relative abundance of that OTU. Because strains with different gene sequences can appear to be the same on an electropherogram if sequence differences only occur after the restriction enzyme cut closest to the forward primer, multiple restriction enzymes are used to give a better sense of diversity. In this study, bacterial and archaeal amoA genes were separately amplified from each plot for the purposes of fingerprinting their populations with T-RFLP using the restriction enzymes AluI, MboI, and AciI for the archaea, and AciI, RsaI, and HaeIII for the bacteria.

\section{Soil DNA was extracted using a MoBio Powersoil kit (MoBio, Carlsbad, CA). DNA was} extracted in quadruplicate and pooled for each plot. DNA concentrations, absorbance curves, $\mathrm{A}_{260: 280}$, and $\mathrm{A}_{260: 230}$ were determined with a NanoDrop 1000 spectrometer (Thermo Scientific, Wilmington, DE)

(Table 3). $A_{260: 230}$ measures the ratio of light absorbed at $260 \mathrm{~nm}$ wavelength relative to that absorbed at $230 \mathrm{~nm}$, and low values $(<1.5)$ indicate contamination with humic acids that can interfere with PCR amplification. $A_{260: 280}$ measures the ratio of light absorbed at $260 \mathrm{~nm}$ wavelength relative to that absorbed at $280 \mathrm{~nm}$. Low values $(<1.8)$ for A260:280 are indicative of protein contamination, while higher values $(>2)$ can indicate coextraction of RNA.

Archaeal amoA genes were amplified using a protocol modified from Wessen et al. (2010). The protocol utilized primers crenamoA23f and crenamoA616r, which are specific to archaeal amoA genes. The PCR reaction mixture was made up of $400 \mathrm{nM}$ FAM-labeled forward primer, $400 \mathrm{nM}$ reverse primer (Table 4), $1 \mathrm{X}$ buffer (New England Biolabs, Ipswich, MA), $3.7 \mathrm{mM} \mathrm{MgCl} 2,100$ ng BSA, $1.25 \mathrm{U}$ Taq, $200 \mu \mathrm{M}$ each dNTP, and approximately $150 \mathrm{ng}$ DNA template in a $25 \mu 1$ reaction. The thermocycling protocol consisted of an initial denaturation at $94^{\circ} \mathrm{C}$ for 3 minutes, 40 cycles of $94^{\circ} \mathrm{C}$ for 1 minute, $56^{\circ} \mathrm{C}$ 
for 1 minute, and $72^{\circ} \mathrm{C}$ for 3 minutes, and a final extension at $72^{\circ} \mathrm{C}$ for 10 minutes. Some plots $(10,12$, 19) failed to amplify with this protocol. When the number of cycles was increased to 45, plots 10 and 19 both amplified. Finally, plot 12 was tested with a strong positive (plot 2) under the following conditions: 50 cycles at $46^{\circ} \mathrm{C}$ annealing, with $5 \mathrm{U}$ instead of $1.25 \mathrm{U}$ Taq polymerase. Under these conditions, archaeal amoA genes were amplified in plot 12, but to a much lesser extent than in plot 2. Due to the fact that bacterial amoA genes did not amplify in plot 12 and the large differences in reaction conditions needed to amplify archaeal $a m o A$ genes in plot 12 as compared to all other plots, amplified DNA from plot 12 was not used for T-RFLP. This left only 3 of the unamended plots for AOA and AOB community analysis. Other archaeal primer sets (amo111F/amo643R from Boyle-Yarwood 2008, archamoAF/archamoAR from O'Callaghan et al. 2010) were tested but did not produce bands or resulted in nonspecific binding.

Bacterial amoA genes were amplified using a modified version of the protocol of Mintie et al. (2003). The primers used, amoA-1F and amoA-2R, were used because of their specificity in amplifying bacterial amoA genes but not the closely related $m m o A$ (methane monooxygenase) gene. The PCR reaction mixture was made up of $400 \mathrm{nM}$ FAM-labeled forward primer, $400 \mathrm{nM}$ reverse primer (Table 4), $1 \mathrm{X}$ buffer, $3 \mathrm{mM} \mathrm{MgCl} 2,100 \mathrm{ng} \mathrm{BSA}, 1.25 \mathrm{U}$ Taq, $200 \mu \mathrm{M}$ each dNTP, and approximately $150 \mathrm{ng}$ DNA template in a $25 \mu 1$ reaction. The initial denaturation was performed at $94^{\circ} \mathrm{C}$ for 5 minutes, followed by 40 cycles of $94^{\circ} \mathrm{C}$ for 1 minute, $55^{\circ} \mathrm{C}$ for 1 minute, and $72^{\circ} \mathrm{C}$ for 90 seconds, with a final extension at $72^{\circ} \mathrm{C}$ for 7 minutes. Some samples did not amplify at this annealing temperature (plots $3,5,12,19,37$ ). Plots 3 and 5 were amplified by the same protocol, modified with a $45^{\circ} \mathrm{C}$ annealing temperature. The remaining plots were tested alongside strong positive controls (plots 6 and 9, which always amplified in previous experiments) changing the following conditions from before: 45 cycles at $41^{\circ} \mathrm{C}$ annealing and 5 U Taq polymerase instead of $1.25 \mathrm{U}$. Under these conditions, plots 19 and 37 had amplification. Bacterial amoA genes could not be amplified in plot 12 under any conditions. Analysis discussed in the results section titled "DNA and T-RFLP Profiles" was used to exclude the 4 samples (plots 3, 5, 19, and 
37) that required less stringent conditions for amplification from subsequent analyses of AOB community dynamics. A flowchart of the procedures used to generate archaeal and bacterial amoA amplicons can be seen in Figure 5.

Triplicate PCR products from each plot were pooled and purified using a MoBio Ultraclean PCR Clean-up (MoBio, Carlsbad, CA). DNA concentrations were checked using a NanoDrop 1000 spectrometer (Thermo Scientific, Wilmington, DE). One hundred fifty nanograms of archaeal DNA was incubated separately with AluI, MboI, and AciI restriction enzymes following reaction conditions specified by the manufacturer (Invitrogen for AluI and MboI or New England Biolabs for AciI). One hundred nanograms of bacterial DNA was incubated separately with AciI, RsaI, and HaeIII restriction enzymes following reaction conditions specified by the manufacturer (Invitrogen for RsaI and HaeIII or New England Biolabs for AciI). Samples were desalted and purified using spin filters and an ethanol solution. Triplicates of each sample $(2 \mu \mathrm{l})$ from each restriction digestion were loaded onto 96 well plates, along with $7.5 \mu \mathrm{l}$ of Hi-Dye (Applied Biosystems, Warrington, UK) and $0.5 \mu 1$ of GeneScan LIZ500 internal ladder (Applied Biosystems, Warrington, UK). Multiple negative controls were loaded onto each plate. Capillary electrophoresis was performed on an ABI 3130XL Genetic Analyzer (Applied Biosystems, Warrington, UK).

\subsubsection{Aligning and editing electropherograms}

Alignment and editing of T-RFLP profiles was performed using Genemapper (Applied Biosystems, Warrington, UK). Given the few number of peaks generated (from 5 to 19 per restriction enzyme), a \pm 0.5 base pair bin was sufficient to align most peaks between samples. Remaining mismatches were aligned manually after profiles were examined and edited. Areas called as peaks that were considered to be a residue of other peaks were deleted. Each profile was examined to determine a noise threshold, which was set as low as possible in order that no potential peaks were lost. This resulted in noise thresholds ranging from 10 fluorescence units (FU) to $30 \mathrm{FU}$, and anything above these 
thresholds was initially considered a peak. Under these thresholds, negative controls exhibited no peaks. After a baseline threshold had been set, profiles were normalized using the method of Dunbar et al. (2001). Total peak height was calculated for each well in order to determine which well had the smallest overall peak height. This height was then divided by the height obtained for each other well to create a correction factor for each well. The height of each individual peak was multiplied by this correction factor; peaks with adjusted peak heights below the threshold were discarded from further analysis. Peak heights were averaged and relative abundance (percentage) data was generated for each peak by dividing the peak height by the total (corrected) peak height obtained previously. A data set was generated from this information in which all peaks representing less than $5 \%$ of the total peak height were not used in further analysis. At this point, all plots for each restriction enzyme were examined to see if any OTUs were within 2 base pairs of each other. Where this occurred, peaks were examined to make sure they were actual peaks and that binning was accurate; if binning was inaccurate, peaks were manually aligned. In some cases, peaks had not been called and were manually added. Results from triplicates of each plot/restriction enzyme combination were pooled and peaks that were not present in all replicates were discarded. Community data was then analyzed based on both presence/absence and relative abundance matrices of the three different restriction enzymes for bacteria and archaea. A flowchart of this approach to normalizing and aligning electropherograms can be seen in Figure 6.

\subsubsection{Data analysis}

\subsubsection{Statistical analysis}

Data analysis was performed using Microsoft Excel and the freeware statistical program R. No data was transformed, as transformations did not improve relationships between variables. Pairwise comparisons for ANOVA were performed using JMP (SAS Analytics, Cary, NC). Appendix 1 contains the $\mathrm{R}$ code and approach used for this study. Correlation and linear regression were employed to examine the relationships between different environmental variables. Because treatment rates were not truly 
continuous, representing discrete points along a continuum of compost amendment rates, both linear regression and ANOVA were utilized to examine relationships between environmental variables and treatment. Tukey's HSD was used in conjunction with ANOVA to investigate which treatment level means were significantly different. Where used, standard error was calculated by taking the standard deviation around a given treatment mean and dividing it by the square root of the number or replicate plots in that treatment level.

\subsubsection{OTU diversity}

OTU diversity was calculated for each plot using the Shannon diversity index and Smith and Wilson evenness measures. Linear correlation was used to see if there were any statistically significant relationships between archaeal or bacterial diversity, richness, or evenness and soil biochemical variables or treatment.

Smith and Wilson evenness (Smith and Wilson 1996) is calculated with the following formula:

$$
E_{\mathrm{var}}=1-\frac{2}{\pi} \arctan \left[\frac{\sum_{S=1}^{S}\left(\ln \left(x_{s}\right)-\sum_{t=1}^{S} \ln \left(x_{t}\right) / S\right)^{2}}{S}\right]
$$

where $S$ is the number of OTUs found in a given site, $x_{s}$ is the relative abundance of a given OTU found in that site, and $x_{t}$ is the relative abundance of any other OTU found in that site.

Shannon diversity (Shannon 1948) is calculated as follows:

$$
H=-\sum_{S=1}^{S} p_{i} \ln p_{i}
$$

where $p_{i}$ is the relative abundance of a particular OTU found in a given site and $\mathrm{S}$ is the total number of OTUs found in that site.

Shannon evenness (also called Pielou evenness) is calculated from the Shannon diversity value and OTU richness as follows: 


$$
E_{H}=H / H \max =H / \ln S
$$

Smith and Wilson evenness and Shannon evenness differ in how they respond to changes in OTU richness and abundance. Smith and Wilson evenness values changes in abundance and richness of rare and common OTUs equally, while Shannon evenness is less sensitive to changes in richness and abundance for rare OTUs than for common ones (Beisel et al. 2003).

\subsubsection{ANOSIM}

Analysis of similarity (ANOSIM) was performed using the Bray-Curtis dissimilarity method. Bray-Curtis measures the dissimilarity in community composition between two sites, with a value of 0 indicating that two sites being compared have the exact same abundance of the exact same OTUs, and a value of 1 indicating the two sites have completely different communities (no shared OTUs). The formula used to calculate this value for any two given sites is:

$$
B C_{i j}=D_{i j} /\left(S_{i}+S_{j}\right)
$$

where $B C_{i j}$ is the Bray-Curtis dissimilarity value for the two sites, $D_{i j}$ is the sum of the absolute value of the difference in abundance between sites for every OTU found in either site, $S_{i}$ is the total abundance of OTUs found in one site, and $S_{j}$ is the total abundance of the OTUs found in the other site. This method was utilized because it does not consider shared absence of a peak between samples a similarity and both presence/absence and abundance data can be used, making it very useful for T-RFLP (Rees et al., 2004). Bray-Curtis generates a matrix of dissimilarity values for every binary combination of sites. ANOSIM then takes this matrix and ranks the values, with the smallest number in the matrix receiving a rank dissimilarity value of 1 , and the largest number in the matrix receiving a rank dissimilarity value equal to the number of values in the Bray-Curtis matrix. These rank dissimilarity values are then sorted based on whether they are comparisons between two sites within the same group (in this case, treatment level) or between two different groups. An $\mathrm{R}$ value, which indicates how much more strongly similar rank 
dissimilarity values are within groups as compared to between groups, is obtained using the following formula:

$$
\mathrm{R}=r_{b}-r_{w} /(1 / 4[n(n-1)])
$$

where $r_{b}$ is the average rank dissimilarity between groups, $r_{w}$ is the average rank dissimilarity within groups, and $n$ is the number of sites being compared. A p value is then obtained by permuting the rank dissimilarities. That is, all the Bray-Curtis dissimilarity values are randomly assigned to be either between groups or within group comparisons, and the $\mathrm{R}$ statistic is obtained. This is done a specified number of times, and the $\mathrm{p}$ value is equal to the proportion of $\mathrm{R}$ values that are greater or equal to the original calculated $\mathrm{R}$ value.

In this study, ANOSIM was used primarily to examine whether treatment had a significant effect on community similarity in bacterial and archaeal communities. Bray-Curtis dissimilarity matrices were created separately for archaeal and bacterial communities using relative abundance data, and dissimilarities between sites were ranked. ANOSIM was run using 999 permutations and average rank dissimilarity between treatments and within individual treatments was compared. Additionally, ANOSIM was used to examine whether AOA and $\mathrm{AOB}$ communities within a posteriori-assigned groups based on relative rates (low, medium, or high) of $\mathrm{PMN}, \mathrm{PAO}$, or $\mathrm{MBC}$, respectively, were more similar than communities between the groups.

\subsubsection{4. nMDS}

Nonmetric multidimensional scaling analysis (nMDS) is a data ordination technique designed to visually orient sites, with farther distances between any two sites corresponding to higher dissimilarities in given examined variables, typically species community datasets. The technique takes a Bray-Curtis dissimilarity matrix and plots sites on a two-or-more dimensional graph using dissimilarity values. The distance between two sites on the graph corresponds roughly to the dissimilarity between the two; since sites are being added one at a time it is impossible for the distances between all the sites on the graph to 
accurately represent the dissimilarities between them. The difference between the distance on the ordination and the dissimilarity for two sites is referred to as the stress, which provides a measure of how accurately the visual ordination reflects community dissimilarity of the sites. Average stress values above 0.2 are generally considered to make the visual ordination unreliable while values below 0.2 are considered to accurately represent the dissimilarity between sites. nMDS can often produce stress results that are higher than optimal. This requires iterative problem solving, and so nMDS is run repeatedly until stress values converge around one point. Ordinations are initially run in 2 dimensions so distances can be seen visually. However, stress can be reduced by adding additional dimensions to the ordination, so 2dimensional ordinations with stress values above 0.2 are often run again in 3 or more dimensions. In the case of this study, community similarity of the AOA could be effectively ordinated in 2 dimensions while AOB required 3 dimensions. There are several techniques used to visually relate dissimilarity ordinations to gradients in the values of environmental variables. One of them is environmental fitting, which fits a vector whose direction points in the direction on the ordination that the given environmental variables increase, and whose magnitude reflects the strength of the gradient. The values of that environmental variable for the sites on the ordination can be permuted, as with ANOSIM, to give $\mathrm{p}$ values, and $\mathrm{r}^{2}$ values can be calculated based on how linearly the gradient occurs along both axes. Environmental fitting assumes a linear relationship between the examined environmental variable and the community similarity ordination. In contrast to environmental fitting, the ordisurf surface fitting program in $\mathrm{R}$ is based on a general additive model that does not assume a linear relationship between environmental variables and the community similarity ordination. Instead, it generates a smoothed curve to fit the data. $\mathrm{r}^{2}$ values are calculated based on the unexplained variation between the curved fit and the data points, and $p$ values are obtained through random permutation. Ordisurf expands on environmental fitting by modeling a 2dimensional overlay of the environmental gradient onto the ordination. Deviance explained values generated with a model can be used to compare different variables modeled over the ordination. 
Nonmetric multidimensional scaling analysis (nMDS) was used to visually ordinate community data in 2-dimensional space. Archaeal community data was examined in 2 dimensions with a final stress value converging at 0.09091793 . Bacterial community data was resolved in a 3-dimensional ordination with a final stress value of 0.09734344. Environmental fitting of continuous data for sites (i.e. MBC, PMN, PAO, pH) was run using 999 permutations and vectors were created on the ordinations. Ordisurf models were built and overlain on ordinations to examine community response to environmental gradients and other continuous variables; these models were compared to environmental fitting to determine how linearly communities responded to environmental variables. 


\subsection{RESULTS}

\subsubsection{Soil parameters}

Soil moisture content showed little variation between plots (Table 5), with no significant relationship to compost amendment level seen using either linear regression or ANOVA. Soil pH varied significantly between treatment levels. Soil inorganic nitrogen in the form of $\mathrm{NH}_{4}{ }^{+}$showed a great deal of variation between plots, but there was no significant variation between treatment levels. The detection limit using this method was approximately $3.6 \mathrm{mg} \mathrm{N} \mathrm{kg} \mathrm{soil}^{-1}$, and values seen in the plots ranged from 3.6 to $51.9 \mathrm{mg} \mathrm{N} \mathrm{kg} \mathrm{soil}{ }^{-1}$, with 4 sites having $\mathrm{NH}_{4}{ }^{+}$concentrations below the detection limit (plots 2, 23, 24, 26). The average soil ammonium concentration was $17.3 \mathrm{mg} \mathrm{N} \mathrm{kg} \mathrm{soil}{ }^{-1}$, while the median ammonium concentration was $10.6 \mathrm{mg} \mathrm{N} \mathrm{kg} \mathrm{soil}^{-1}$. There was no significant effect of compost amendment on soluble carbon concentrations, which ranged from $45.7 \mathrm{mg} \mathrm{C} \mathrm{kg} \mathrm{soil}^{-1}$ to $92.1 \mathrm{mg} \mathrm{C} \mathrm{kg}$ soil $^{-1}$. The planting histories (i.e. those sites planted with millet in the first year versus those planted with buckwheat) had no effect on any other variables or AOA/AOB communities and OTUs. This also was to be expected, as there had been no differences in planting or management between them since 2005 .

\subsubsection{Soil biochemical variables}

Both PMN $\left(\mathrm{r}^{2}=0.40, \mathrm{p}=0.018\right)$ and $\mathrm{MBC}\left(\mathrm{r}^{2}=0.24, \mathrm{p}=0.033\right)$ increased with increasing compost amendment (Figure 7). PMN was initially fitted as an exponential response to compost amendment level, but was best fitted as a linear response to compost amendment rate for only 0 to $22.4 \mathrm{Mg}$ compost ha ${ }^{-1}$ $\left(\mathrm{r}^{2}=0.66, \mathrm{p}=0.0024\right)$, with no linear relationship occurring from 22.4 to $89.6 \mathrm{Mg}$ compost $\mathrm{ha}^{-1}\left(\mathrm{r}^{2}=0.00044\right.$, $\mathrm{p}=0.95$ ). Both fits indicated a leveling off of PMN rate at high compost amendment rates. PAO was not significantly related to compost amendment rate $\left(\mathrm{r}^{2}=0.098, \mathrm{p}=0.18\right)$ using linear regression (Figure 7). Extracted DNA concentration, another soil pool related to the microbial biomass, significantly increased with increasing compost amendment level $\left(\mathrm{r}^{2}=0.69, \mathrm{p}=0.00055\right)$ (Figure 7). The observed relationships were generally weak. However, compost had not been applied to the plots since 2005, so time may have 
moderated the differences between treatments. When the ratio of biomass pool size to organic nitrogen mineralization rate (MBC:PMN) was examined as a function of compost amendment rate, it was seen that there was a significant decline as compost input increased $\left(r^{2}=0.49, p=0.023\right)$, but only for the lower treatments (0 to $22.4 \mathrm{Mg}$ compost ha $\left.{ }^{-1}\right)$ (Figure 8$)$. There was no relationship for the higher treatments. Extracted DNA concentration significantly correlated with MBC (Figure 9A; $r=0.59, p=0.0073$ ). There was no statistically significant correlation between $\mathrm{PMN}$ and $\mathrm{MBC}$ at an alpha value of $0.05(\mathrm{r}=0.40$, $\mathrm{p}=0.093$ ), but visual examination of the data suggested they were related (Figure 9B), as is generally seen in other studies (Booth et al. 2005). However, when PMN was compared to extracted DNA concentration, a strong positive correlation was seen $(r=0.74, p=0.00018$; Figure $9 \mathrm{C})$. PAO appeared to be dependent on PMN rates, as the two showed a strong positive correlation ( $r=0.66, p=0.0016)$ (Figure 9D). There was no relationship between PAO and $\mathrm{MBC}(\mathrm{r}=0.13, \mathrm{p}=0.59)$. Interestingly, there were strong correlations between soluble organic carbon concentration and PMN ( $r=0.53, p=0.015$; Figure $10 \mathrm{~A})$ as well as soluble organic carbon and PAO ( $r=0.70, p=0.00062$; Figure 10B).

Some variables seemed to be best related when only the 3 lowest treatments $(0$ to $22.4 \mathrm{Mg}$ compost ha ${ }^{-1}$ ) were examined. PAO appeared to have been more strongly dependent on compost amendment rate for these levels (Figure 11A; $\mathrm{r}^{2}=0.28, \mathrm{p}=0.091$ ) than for all levels $\left(\mathrm{r}^{2}=0.098, \mathrm{p}=0.27\right.$ ). This was true for PMN and compost rate, as mentioned before (Figure $11 \mathrm{~B} ; \mathrm{r}^{2}=0.66, \mathrm{p}=0.0024$ as compared to $\mathrm{r}^{2}=0.40, \mathrm{p}=0.018$ ). PMN and PAO correlated more strongly as well (Figure $11 \mathrm{C} ; \mathrm{r}=0.79$, $\mathrm{p}=0.0037$, as opposed to $\mathrm{r}=0.66, \mathrm{p}=0.0016$ ). As previously discussed, the ratio of MBC:PMN declined significantly only for these treatments (Figure $11 \mathrm{D} ; \mathrm{r}^{2}=0.49, \mathrm{p}=0.024$ ).

ANOVA and Tukey's HSD multiple comparison test were also used to examine the relationship between biochemical variables and treatment. A summary of the means of a given treatment level for MBC, PMN, PAO, and extracted DNA concentration is reported in Table 6. Using this approach, only $\operatorname{PMN}\left(\mathrm{F}_{(4,15)}=6.16, \mathrm{p}=0.004\right)$ and DNA concentration $\left(\mathrm{F}_{(4,15)}=8.90, \mathrm{p}=0.0007\right)$ had statistically significant differences among treatments. 


\subsubsection{DNA and T-RFLP profiles}

DNA concentration significantly increased as compost amendment rate increased $\left(r^{2}=0.69\right.$, $\mathrm{p}<0.0001$ ). Likewise, $\mathrm{A}_{260: 230}$ (as explained in the methods) increased with increasing compost amendment rate $\left(\mathrm{r}^{2}=0.36, \mathrm{p}=0.0055\right)$, while $\mathrm{A}_{260: 280}$ decreased with increasing compost amendment rate $\left(\mathrm{r}^{2}=0.21, \mathrm{p}=0.040\right)$ (Figure 12). While ANOVA demonstrated differences among treatments for extracted DNA concentrations, no differences were found for either $A_{260: 280}\left(F_{(4,15)}=2.88, p=0.059\right)$ or $A_{260: 230}$ $\left(\mathrm{F}_{(4,15)}=2.10, \mathrm{p}=0.13\right)$.

A representative AOA electropherogram can be seen in Figure 13. AOA OTU fingerprints showed a simple community dominated by a few common OTUs. There were 22 OTUs visualized using AluI, MboI, and AciI restriction enzymes (Table 7). Only 4 of these were unique to individual plots. Three more were found in 2 or 3 plots; two were found in every plot; three were found in 13 or more plots (66\% of the plots or more). Two OTUs were found in all plots. The 5 common OTUs represented a $76.74 \%$ average relative abundance for the sites, while the 7 rare OTUs represented an average $1.81 \%$ relative abundance. Three OTUs (AciI 168, AluI 285, and MboI 441) were found in all of the $11.2 \mathrm{Mg}$ compost ha ${ }^{-1}$ plots and only sporadically in plots of other treatments. One OTU (AluI 284(2)) was found in all of the unamended plots but only sporadically in other treatments. Average relative abundance of OTUs by treatment can be seen in Table 8 . Treatment level generally did not affect the presence and relative abundance of OTUs. ANOVA was used to examine if there were significant differences among relative abundance of OTUs by treatment level for the most commonly seen OTUs. There were no significant differences between treatments for any of these OTUs. Observation of the relative abundance of OTUs and ANOSIM (as explained in the methods) did not show evidence of any significant bias of the 5 extra cycles used to amplify AOA amoA genes in plots 10 and 19.

ANOSIM was also used to determine whether different DNA amplification conditions for bacteria may have affected the community data that was recovered. ANOSIM demonstrated a significant 
effect of amplification conditions on community structure $(\mathrm{R}=0.94, \mathrm{p}=0.001)$ and nonmetric multidimensional scaling (nMDS) visually supported this assessment (Figure 14). As a result, the four plots that required less rigorous amplification conditions (plots 3, 5, 19, and 37) were deemed incomparable to the other plots and removed from further bacterial community analysis. This removal

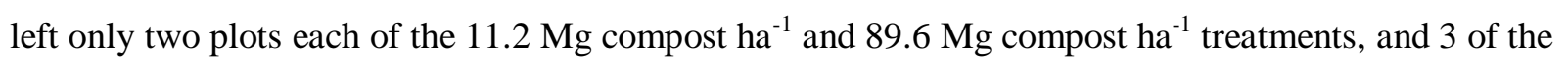
unamended plots for bacterial community analysis. Before the T-RFLP profiles from these four plots were removed, there were 54 total bacterial OTUs present in the sites. These four sites had very different fingerprints than the other plots. Plot 3 had 8 total OTUs obtained with restriction enzymes AciI, RsaI, and HaeIII. Of these, 4 were unique to this site. Of the 6 OTUs common to $66 \%$ of the sites, Plot 3 only had one. Plot 5 had 10 OTUs, 5 of which were unique, and only had 3 of the 6 common OTUs. Plot 19 had 6 OTUs. None of these were unique, and 3 were commonly seen OTUs. Plot 37 had 5 unique OTUs out of a total of 11, and also had 3 of the 6 most commonly seen OTUs.

Fingerprints obtained from the 15 remaining electropherograms of the AOB (Figure 15) showed highly divergent OTUs between the different plots. Of the 36 different OTUs obtained from AciI, RsaI, and HaeIII restriction enzymes (Tables 9 and 10), 17 were found in only one plot. Six more were found in 3 or fewer plots. Only 2 OTUs were found in every site, and 6 others were found in at least $66 \%$ of the plots (10 plots or more). Nevertheless, these 8 most commonly found OTUs represented an average relative abundance of $75.79 \%$ for the plots, while the 23 rare OTUs represented a mere $11.10 \%$ relative abundance for the plots. This meant that an individual common OTU represented approximately 20 times the abundance of an individual rare OTU in these sites. Average relative abundance of bacterial OTUs by treatment level can be seen in Table 11. Variability in the presence and relative abundance of OTUs was generally very high for the AOB. Treatment level had little influence on the trends in relative abundance of specific OTUs. ANOVA was used to examine if there were significant differences among relative abundance of OTUs by treatment level for the most commonly seen OTUs. The only OTU that was seen 
to have significant differences between treatment levels was AciI $96\left(F_{(4,10)}=8.26, p=0.0033\right)$, which was significantly higher in the highest two treatment levels than the rest.

\subsubsection{OTU diversity}

Diversity metrics (Shannon, diversity, Shannon evenness, OTU richness, and Smith and Wilson evenness) were calculated from T-RFLP datasets. For those metrics that utilized relative abundance data, results from all 3 restriction enzymes used were combined. Since total relative abundance for each restriction enzyme already added up to one, all values were divided by three in order that the total abundance used for diversity metrics would still only add up to one. Shannon and Smith and Wilson metrics, which are weighted more towards changes in common or rare OTUs, respectively, were compared.

Archaeal Shannon OTU diversity declined as compost amendment increased (Figure 16A; $\mathrm{r}^{2}=0.30, \mathrm{p}=0.016$ ) and as MBC increased (Figure 16B; $\left.\mathrm{r}=-0.48, \mathrm{p}=0.044\right)$. Archaea OTU richness had similarly declined with increasing treatment level (Figure $16 \mathrm{C} ; \mathrm{r}^{2}=0.34, \mathrm{p}=0.0087$ ) and increasing $\mathrm{MBC}$ (Figure 16D; $r=-0.47, p=0.047)$. Another diversity metric used, Smith and Wilson evenness, was found to correlate well with Shannon values for the archaea. It had a positive relationship with Shannon evenness (Figure 17A; r=0.87, p<0.0001), although strength of linear associations declined with Shannon diversity (Figure 17B; r=0.81, p<0.0001) and OTU richness (Figure 17C; $r=0.66, p=0.002$ ). Archaeal Smith and Wilson evenness did not have statistically significant relationships with compost amendment rate, MBC, or PMN. This was also seen with archaeal Shannon evenness. A summary of these values arranged by treatment is tabulated in Table 12. Using ANOVA, the only diversity metric for AOA that had significant differences among treatment levels was AOA OTU richness $\left(\mathrm{F}_{(4,14)}=3.46, \mathrm{p}=0.036\right)$, and when Tukey's HSD was used for multiple comparisons, there were no significant differences among treatments. 
There was a strong positive correlation between AOA and AOB diversity (Figure 18; r=0.72, $\mathrm{p}=0.0027$ ), despite different relationships to environmental variables. Bacterial Shannon evenness significantly declined with increasing compost amendment rate (Figure $19 \mathrm{~A} ; \mathrm{r}^{2}=0.35, \mathrm{p}=0.020$ ) and negatively correlated with PMN (Figure 19B; $r=-0.53, p=0.044$ ), while bacterial OTU richness negatively correlated with MBC (Figure 19C; $r=-0.54, p=0.047$ ). In the case of AOB, Smith and Wilson evenness correlated well with Shannon evenness (Figure 20; $r=0.91, \mathrm{p}<0.0001$ ) but had no significant relationship with either Shannon diversity $(\mathrm{r}=0.22, \mathrm{p}=0.42)$ or OTU richness $(\mathrm{r}=0.073, \mathrm{p}=0.80)$. Bacterial Smith and Wilson evenness significantly declined with increasing treatment levels (Figure 21A; $\mathrm{r}^{2}=0.30, \mathrm{p}=0.033$ ) and negatively correlated with PMN (Figure 21B; $r=-0.57, \mathrm{p}=0.026$ ), which were quite similar to results obtained for Shannon evenness. No diversity metrics for either AOA or AOB had significant relationships with PAO at an alpha= 0.05 level. Using ANOVA, no diversity metric for AOA or AOB had significant differences among treatment levels. A summary of average diversity values by treatment can be seen in Table 13.

\subsubsection{ANOSIM}

Analysis of similarity (ANOSIM) failed to find any strongly significant effect of treatment on community similarity in either archaeal $(\mathrm{R}=0.15, \mathrm{p}=0.092)$ or bacterial $(\mathrm{R}=0.24, \mathrm{p}=0.052)$ communities at an alpha $=0.05$ level, although visual inspection suggested a relationship, as seen in Section 2.3.6. A posteriori categories of MBC, PMN and PAO rates (low, medium, or high) were applied to samples and ANOSIM was run based on these categories. Bacteria appeared to have significant community differences based on PMN category $(\mathrm{R}=0.29, \mathrm{p}=0.016)$, while archaea did not $(\mathrm{R}=0.091, \mathrm{p}=0.21)$. These differences could be easily visualized using nMDS (Figure 22). Neither archaea $(\mathrm{R}=0.099, \mathrm{p}=0.17)$ nor bacteria $(\mathrm{R}=0.057, \mathrm{p}=0.32)$ had significant community differences based on MBC. ANOSIM also failed to find any significant differences based on PAO rates for either bacteria $(\mathrm{R}=0.031, \mathrm{p}=0.39)$ or archaea $(\mathrm{R}=0.041, \mathrm{p}=0.32)$. 
Dendrograms (using Bray-Curtis dissimilarity and average linkage) were constructed for both archaeal and bacterial OTUs. After the dendrogram was created, the plots were split into different groupings based on how they clustered together. This was done to artificially group the sites with the most similar community structure into the same category, in order to determine the highest $\mathrm{R}$ value ANOSIM could obtain from 3 or 4 different categories. These groupings were then analyzed using ANOSIM. For archaea, the highest value attained with 3 groupings was an $\mathrm{R}$ value of $0.73(\mathrm{p}=0.001)$ (Figure 23). For bacteria, the $\mathrm{R}$ value (using 4 groupings) was 0.66 ( $\mathrm{p}=0.001$ ) (Figure 24). The results obtained using ANOSIM for the effects of treatment on AOA and AOB, as well as PMN on AOB, were compared to the optimum ANOSIM results based on 3 or 4 groupings. These values were $\mathrm{R}=0.15$, $\mathrm{p}=0.092, \mathrm{R}=0.24, \mathrm{p}=0.052$, and $\mathrm{R}=0.29, \mathrm{p}=0.016$, respectively. Given that the optimum grouping of $\mathrm{AOA}$ and $\mathrm{AOB}$ resulted in $\mathrm{R}$ values of 0.73 and 0.66 , respectively, it does appear qualitatively that compost amendment rate has some influence on AOA and AOB structure while PMN has substantial influence on $\mathrm{AOB}$ structure.

\subsection{6. nMDS ordination}

Data ordination of AOA community similarity using nonmetric multidimensional scaling (nMDS) revealed that community similarity did change as a result of compost amendment rate (stress $=0.091$; dimensions=2), although not in a linear manner (Figure 25). Higher treatments (22.4 to $89.6 \mathrm{Mg}$ compost $\mathrm{ha}^{-1}$ ) tended to cluster together while lower treatments ( 0 to $22.4 \mathrm{Mg}$ compost ha $^{-1}$ ) tended to be more spread out, although some clustering of lower treatments did occur. Ordisurf surface fitting (discussed in the methods) of Shannon diversity on the AOA ordination showed a near-linear relationship between community similarity and community diversity (Figure 26), with the model explaining $92.7 \%$ of the deviance seen $\left(\mathrm{r}^{2}=0.93, \mathrm{p}<0.0001\right)$. This is a strong indication that differences in diversity between sites were mainly reflective of community similarity, with the presence or absence of specific OTUs largely being responsible for the observed diversity differences. When specific OTUs were plotted against AOA Shannon diversity, some (Aci 168, Alu 285, and Mbo 441) were seen to only be found in high diversity 
sites (Figure 27). These 3 OTUs generally appeared in the same sites, including all of the $11.2 \mathrm{Mg}$ compost ha ${ }^{-1}$ sites, and in similar relative abundances, indicating the possibility that they corresponded to the same archaeal strain. In general, higher diversity corresponded to the lower treatment sites. Surface fitting showed significant gradients with MBC (Figure 28; $\mathrm{r}^{2}=0.59, \mathrm{p}=0.0045$ ) and PMN (Figure 29; $\left.\mathrm{r}^{2}=0.52, \mathrm{p}=0.03\right)$. The smoothed fit applied to PAO was not statistically significant $\left(\mathrm{r}^{2}=0.30, \mathrm{p}=0.25\right)$. Deviance explained was highest for MBC (67\%), followed by PMN (64.7\%). PAO had an explained deviance of $46.5 \%$. Extracted DNA concentration was also surface fitted over the AOA ordination (Figure 30) and produced a highly significant result $\left(\mathrm{r}^{2}=0.68, \mathrm{p}=0.0074\right.$, deviance explained $\left.=80 \%\right)$, while a surface fit of soluble carbon concentration produced a statistically insignificant result $\left(r^{2}=0.099, p=0.48\right)$. Environmental fitting (explained in the methods) of variables against the AOA community similarity ordination (Figure 31) indicated that MBC was the most important of the 3 primary biochemical variables (PMN, MBC, PAO) in explaining community similarity. While environmental fitting of PMN also produced significant results, no significant relationship between AOA community similarity and PAO could be found. Coefficients of determination and $\mathrm{p}$ values obtained through environmental fitting were very similar to those seen with surface fitting for MBC. This implied AOA community similarity responded linearly to MBC. Surface fitting coefficients of determination were substantially larger than for environmental fitting for PMN and extracted DNA concentration, indicating a nonlinear gradient in community similarity based on these variables.

AOB community similarity was also ordinated using nMDS (stress=0.097; dimensions=3). Community similarity changed as a result of compost amendment in a similar manner to the AOA (Figure

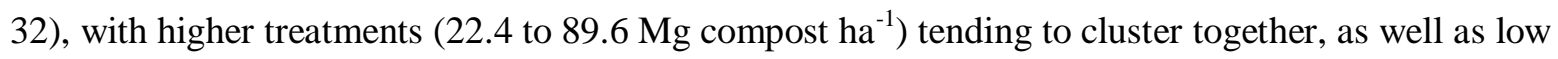
treatments (11.2 to 22.4 Mg compost $\mathrm{ha}^{-1}$ ). Unamended soils did not appear to be very similar in structure. Overall, similarity in AOB structure by treatment was lower than for AOA. Surface fitting of bacterial Shannon diversity on the AOB ordination (Figure 33) explained 99.2\% of the deviance seen $\left(r^{2}=0.979, p<0.0001\right)$, although in a nonlinear manner. This indicates that the changes seen in community 
similarity were largely driven by changes in the richness and abundance of OTUs, although not to the extent seen with AOA. This was largely because there were many more rare OTUs for the AOB than the AOA, weakening the linearity of the relationship between diversity and community similarity. Higher diversity generally corresponded to the lower treatment sites for the AOB. Surface fitting of MBC (Figure 34; $\mathrm{r}^{2}=0.20, \mathrm{p}=0.11$ ), PAO (Figure 34; $\mathrm{r}^{2}=0.42, \mathrm{p}=0.026$ ), and PMN (Figure 36; $\mathrm{r}^{2}=0.46$, $\mathrm{p}=0.0093$ ) showed that PMN was the most important variable in relating to community similarity, with an explained deviance of 54.1\%. Explained deviances for MBC and PAO were 30.6\% and 51.7\%, respectively. $\mathrm{MBC}$ did not appear to be significantly correlated with AOB community similarity. By comparison, extracted DNA concentration had a highly nonlinear but significant fit $\left(r^{2}=0.69, p=0.022\right.$, deviance explained=82.2\%) over AOB community similarity (Figure 37), while soluble carbon had an insignificant fit over AOB community similarity $\left(\mathrm{r}^{2}=0.25, \mathrm{p}=0.070\right.$, deviance explained $\left.=35.8 \%\right)$. Environmental fitting of the major variables (PMN, MBC, and PAO) against the AOB community similarity ordination (Figure 38) indicated that PMN was the most important variable in explaining community similarity, although PAO was almost as important. For PMN and PAO, coefficients of determination and $\mathrm{p}$ values were very similar between environmental fitting and surface fitting. This was not the case for MBC. 


\subsection{DISCUSSION}

\subsubsection{Overview}

The purpose of this study was to examine the effects of compost on the overall microbial biomass, nitrogen cycling rates, and ammonia oxidizer community structure. Three hypotheses were proposed. One hypothesis was that microbial biomass carbon (MBC), potentially mineralizable nitrogen (PMN), and potential ammonia oxidation (PAO), would all significantly increase with increasing compost amendment. Addressing the effects of compost amendment on ammonia oxidizers, it was expected that archaeal diversity would decline as compost amendment increased, while bacterial diversity would increase as compost amendment increased. It was further hypothesized that changes in observed nitrification rates would correlate with changes in the community composition of the AOB but not the AOA, implying that the AOB were primarily responsible for nitrification at the study site. Other soil physical and chemical variables were measured and analyzed to understand their effects on the previously mentioned biochemical variables, as well as AOA and AOB community structure.

\subsubsection{Soil physical and chemical parameters}

Significant differences between treatments were seen in soil $\mathrm{pH}$ values, which ranged from 5.74 to 7.18 in the plots. While plots had been limed to the same $\mathrm{pH}$, it was expected that the buffering capacity of the compost, which had an average $\mathrm{pH}$ of 8.1, would prevent acidification of the high compost plots over time.

Management history and soil genetic factors (slope, aspect, age, parent material) were largely constant across the area containing all the plots, so it was expected that some factors governing soil water retention would be largely constant as well. Some factors governing soil water retention may have been affected by compost amendment, and so it was somewhat surprising that different input rates of organic matter from compost did not affect soil moisture percentage. Since compost amendment ceased in 2005, differences in the active pool size of organic matter, largely responsible for maintaining the structural 
stability of the soil that promotes water infiltration, may have been erased. Indeed, soluble organic carbon concentrations were not observed to differ significantly between treatment levels. However, this result may have been due to flushes of soluble carbon released from cell lysis during freezing and thawing of samples.

A meta-analysis of nitrogen cycling papers showed that nitrogen mineralization $\left(r^{2}=0.40\right.$, $\mathrm{p}<0.0001)$, along with soil carbon $\left(\mathrm{r}^{2}=0.45, \mathrm{p}<0.0001\right)$ and soil nitrogen $\left(\mathrm{r}^{2}=0.40, \mathrm{p}<0.0001\right)$, strongly influenced soil $\mathrm{NH}_{4}{ }^{+}$concentration (Booth et al. 2005). Thus, it was surprising that there were no correlations between extracted $\mathrm{NH}_{4}{ }^{+}$and either PMN or PAO. However, the study performed by Booth et al. was based on gross rather than net mineralization rates, in contrast to the present study. While 7 day net nitrogen mineralization assays typically correlate highly with gross mineralization rates, this is not always the case (Booth et al. 2005). $\mathrm{NH}_{4}{ }^{+}$concentrations were also often at or below the detection limit of the method used to colorimetrically measure $\mathrm{NH}_{4}{ }^{+}$, so these values may not have been particularly accurate.

\subsubsection{Soil biochemical variables}

PAO rates seen in the plots were low but comparable to rates seen in other studies. Potential ammonia oxidation rates varied from 0.40 to $4.64 \mathrm{mg} \mathrm{N} \mathrm{kg} \mathrm{soil}^{-1} \mathrm{day}^{-1}$. Boyle-Yarwood et al. (2008) found similar results using the same procedure in Douglas fir and red alder soils of the Pacific Northwest, where PAO ranged from $0.1 \mathrm{mg} \mathrm{N} \mathrm{kg} \mathrm{soil}{ }^{-1}$ day $^{-1}$ to $3.23 \mathrm{mg} \mathrm{N} \mathrm{kg} \mathrm{soil}^{-1}$ day $^{-1}$. Using a similar procedure with longer incubation times, Jia and Conrad (2009) found PAO rates of approximately $17 \mathrm{mg} \mathrm{N} \mathrm{kg} \mathrm{soil}{ }^{-1}$ day $^{-1}$. Their site, however, was a corn field fertilized with inorganic nitrogen. Wessén et al. (2010) used a chlorate inhibition technique to determine PAO in agricultural plots with long term differences in fertilizer and organic matter amendments, and found that rates varied from $1.58 \mathrm{mg} \mathrm{N} \mathrm{kg} \mathrm{soil}{ }^{-1} \mathrm{day}^{-1}$ in plots receiving peat as an amendment to $15.26 \mathrm{mg} \mathrm{N} \mathrm{kg} \mathrm{soil}^{-1}$ day $^{-1}$ in plots receiving inorganic nitrogen fertilizer and straw mulch as amendments. 
PMN values found in this study were higher than those typically found in other publications. Values ranged from 16.8 to $45.1 \mathrm{mg} \mathrm{N} \mathrm{kg} \mathrm{soil}{ }^{-1}$ day $^{-1}$. In African lowland rice soils, values ranged from 1.5 to $11.8 \mathrm{mg} \mathrm{N} \mathrm{kg} \mathrm{soil}^{-1}$ day $^{-1}$ (Narteh and Sahrawat 1996). Using aerobic rather than anaerobic incubations, values observed were from 0.2 to $3.1 \mathrm{mg} \mathrm{N} \mathrm{kg} \mathrm{soil}^{-1}$ day $^{-1}$ (Friedel and Gabel 2001, Sharifi et al. 2007, Liu et al. 2011). It is interesting that in my study PMN values were high while PAO rates were low to moderate. This may have been due to suppression of nitrification by soil microorganisms or plant communities (Subbarao and Ito 2006). Alternately, this may have been an artifact of cold storage. Soil samples had been both frozen and stored at $4^{\circ} \mathrm{C}$ for extended periods of time before these assays were performed, although they had been kept at room temperature for 24 hours before the start of incubations or extractions. The procedure for PAO was a short term incubation (30 hours) while the procedure for PMN was longer (7 days), so it is feasible that the microbial community may have rebounded from the effects of cold storage for PMN but not for PAO. Additionally, nitrifiers are known to be slow-growing (Helder and de Vries 1983) and nitrification has been shown to be inhibited at low temperatures (Addiscott 1983; Stark 1996). The broad community responsible for mineralizing organic nitrogen is not subject to these limitations. PAO could also have been low due to nitrate assimilation by heterotrophic microorganisms. The PAO procedure used excess $(1.5 \mathrm{mM})$ ammonium to prevent competition with heterotrophs and shaking to maintain oxic conditions in the slurry. With a flush of dissolved organic carbon from cell lysis due to freezing and thawing, it is possible that the heterotrophic community was still competitive with the ammonia oxidizers for this otherwise excess ammonium.

$\mathrm{MBC}$ values were on the lower end of values seen in literature using the chloroform fumigation extraction method. Values in this study ranged from 146 to $287 \mathrm{mg} \mathrm{C} \mathrm{kg} \mathrm{soil}^{-1}$. Grisi et al. (1998) obtained values of 161 to $599 \mathrm{mg} \mathrm{C} / \mathrm{kg}$ soil in tropical agricultural soils and 177 to $1285 \mathrm{mg} \mathrm{C} \mathrm{kg} \mathrm{soil}^{-1}$ in temperate agricultural soils. In loamy sand soils that were either grassland, arable cropland, or fallowed for 60 years, values were from 74 to $947 \mathrm{mg} \mathrm{C} \mathrm{kg} \mathrm{soil}^{-1}$ (Wu et al. 2011). Sharifi et al. (2007) found lower values that ranged from 25 to $861 \mathrm{mg} \mathrm{C} \mathrm{kg} \mathrm{soil}^{-1}$. Values ranging from approximately 1500 to 3500 
mg C kg soil ${ }^{-1}$ were found in the litter layer and upper A horizon of a temperate hardwood forest (Li et al. 2002). In the present study, freezing and thawing during storage likely lysed some cells. This in turn could have artificially increased organic carbon concentrations in the filtrate from negative controls, decreasing the values seen for microbial biomass size.

ANOVA produced more conservative results than linear regression when significant differences in biochemical variables between treatment levels were tested. Less significant $\mathrm{p}$ values with ANOVA were due to different assumptions and a different number of degrees of freedom compared with regression analysis. It should also be noted that Tukey's HSD is one of the most conservative multiple comparison procedures. Since the treatment levels were different rates and there were strong visual indications that there were linear relationships between compost amendment level and biochemical variables, regression was still a useful analytical tool. Nevertheless, while linear regression showed a significant relationship between compost amendment rate and MBC, ANOVA did not.

One hypothesis was that PMN, PAO, and MBC would all significantly increase with increasing compost amendment. This did occur for PMN and possibly MBC but not PAO. It also occurred for extracted DNA concentrations. Some regressions and correlations were stronger for only the 0 to 22.4 Mg compost ha ${ }^{-1}$ treatments compared with the full 0 to $89.6 \mathrm{Mg}$ compost ha $^{-1}$ range. This trend was most apparent with PAO and PMN when compared with treatment level and each other. The trend could again be seen in the decline of the MBC:PMN ratio for these treatment levels, although the effects on carbon pools was less obvious. Overall, biochemical measurements and treatment levels were most tightly coupled at these lowest treatment rates. Average DNA concentration and MBC continued to increase in all treatment levels, although it appeared that the rate of increase declined above $22.4 \mathrm{Mg}$ compost ha ${ }^{-1}$. PMN was best modeled with a strong linear relationship from 0 to $22.4 \mathrm{Mg}$ compost ha $^{-1}$, and no relationship from 22.4 to $89.6 \mathrm{Mg}$ compost ha $^{-1}$, indicating these higher treatment levels had become saturated with organic nitrogen. This may have been due to nitrogen in the plots of the highest two treatment levels exceeding the assimilatory capacity of the soil biota and organic matter, and simply 
leaching away after nitrification. As a result, organic nitrogen concentrations and nitrogen mineralization rates reached a steady state at $22.4 \mathrm{Mg}$ compost $\mathrm{ha}^{-1}$ and above. PAO responded very similarly to PMN. This correlation, combined with the general lack of correlation between biomass size and nitrogen cycling rates, indicates a fundamental decoupling of nitrogen cycling and microbiological community size at these high treatment rates, with nitrogen exceeding soil storage but carbon still limiting biological pool size. Given that the average C:N ratio of the compost was quite high (38:1), this is surprising. However, the dairy manure had not been consistently turned during production and only briefly composted with grass clippings and leaves before application, so perhaps it still contained a great deal of labile carbon. Elements and biochemicals subject to rapid translocation may have been removed from the compost during this composting period. Ammonia in the compost could have rapidly volatilized, and nitrates in the compost may have rapidly leached, reducing the nitrogen content. In contrast, large pockets of mostly undigested organic materials in the compost may have still been present when applied to the plots due to the incomplete turning. It may have not been until after application to the plots that labile carbon was oxidized on a large scale, reducing the $\mathrm{C}: \mathrm{N}$ ratio.

Decoupling of microbiological community size and nitrogen cycling may have been related to different responses over time rather than relative proportions of carbon and nitrogen found in the compost inputs. Compost was only applied to the plots in the time period of 2000 to 2005 . As a result, all carbon inputs for the past 6 years have come from primary production rather than compost. It is possible that this may have erased differences between treatments in these intervening years. This was seen in the lack of significant differences among treatment levels in soluble carbon concentrations. Indeed, it has been repeatedly shown that $\mathrm{MBC}$ responds rapidly to changes in carbon inputs or soil management (Kaschuk et al. 2010). Having rapidly metabolized the readily oxidizable carbon found in the compost, the microbial biomass may have declined in size in the years since the last compost amendment. Alternately, the composting process itself may have removed most labile carbon. In this case, the amendment would 
mainly provide a reservoir for other nutrients and structural benefits, and the heterotrophic biomass would not necessarily show a large increase.

It is unclear why the correlation between MBC and PMN was not stronger, as studies have generally shown a significant relationship between MBC and nitrogen mineralization rate (Booth et al. 2005). In addition to the previous discussion on decoupling of carbon-nitrogen dynamics, it should be noted that $\mathrm{MBC}$ measures the total biomass rather than the active biomass, while PMN is an activity assay. Because of this, MBC could include carbon from dead or dormant cells that would not contribute to PMN and obscure the relationship between microbial biomass and mineralizable nitrogen.

Interestingly, there was a significant correlation between PMN and extracted DNA concentration. Several studies have shown soil DNA concentration to be related to microbial biomass size, organic carbon and nitrogen concentrations in soil (Hofman and Dušek 2003; Dequiedt et al. 2011). While it may correlate with these other variables, it is not considered an effective proxy for any of them.

PAO was strongly correlated to PMN but did not have a significant relationship with compost amendment rate, indicating that PAO was dependent not on treatment but on PMN rate specifically. This fits with the general understanding of controls on nitrification- a synthesis study showed that nitrogen mineralization rate had a substantially stronger positive relationship with nitrification $\left(\mathrm{r}^{2}=0.32, \mathrm{p}<0.0001\right)$ than any other tested variables, including soil carbon $\left(r^{2}=0.21, p<0.0001\right)$ and soil nitrogen $\left(r^{2}=0.24\right.$, $\mathrm{p}<0.0001$ ), using the results from 167 different studies (Booth et al. 2005). Different thresholds and rates of response over time are likely responsible for some of the differences seen in different biochemical assays.

Soil biochemical parameters showed smaller differences in values than did many other studies. MBC had a 2-fold increase from smallest to largest value, and PMN had a 2.7-fold increase from lowest to highest. Extracted DNA concentration had a 2.5-fold increase, while soluble organic carbon concentration had a 2-fold increase. In contrast to this, PAO showed an approximately 11-fold increase 
between plots. Other studies also had large ranges of values for PAO (Boyle-Yarwood et al. 2008; Wessén et al. 2010). The largest average percentage increases over rates at the 0 treatment level were found with PAO rather than PMN or MBC (Figure 39). PAO changed similarly to PMN. However, it had much greater and more erratic changes. Both had their highest average rates in the $22.4 \mathrm{Mg}$ compost $\mathrm{ha}^{-1}$ treatment. In both cases, the average rate declined from 22.4 to $44.8 \mathrm{Mg}$ compost $\mathrm{ha}^{-1}$. There were large standard errors relative to average values for PAO and MBC. This large variability may have obscured real trends in the data. Of 7 chemical and biochemical variables measured (MBC, PMN, PAO, extracted DNA, soluble organic carbon, $\mathrm{NH}_{4}{ }^{+}$, and $\mathrm{NO}_{3}{ }^{-}$), 5 had their highest standard errors in the 22.4 $\mathrm{Mg}$ compost ha ${ }^{-1}$ plots (PMN, PAO, soluble organic carbon, $\mathrm{NH}_{4}{ }^{+}$, and $\mathrm{NO}_{3}{ }^{-}$), and 3 had their lowest standard errors in the $44.8 \mathrm{Mg}$ compost ha ${ }^{-1}$ plots (PMN, PAO, and soluble organic carbon). The spatial proximity of the $44.8 \mathrm{Mg}$ compost $\mathrm{ha}^{-1}$ to one another may have been responsible for this result. However, the $44.8 \mathrm{Mg}$ compost ha ${ }^{-1}$ plots were problematic, as they showed declines in average $\mathrm{NH}_{4}{ }^{+}$, $\mathrm{NO}_{3}{ }^{-}$, soluble organic carbon, $\mathrm{PAO}$, and PMN values from the $22.4 \mathrm{Mg}$ compost ha ${ }^{-1}$ plots. The reason for this phenomenon is unknown.

\subsubsection{Ammonia oxidizer community structure}

I anticipated that archaeal diversity would decline with increasing compost amendment rate while bacterial diversity would increase. This was due to the observed trend of AOB being found in greater abundance in high fertility sites, while AOA are typically more predominant in lower fertility sites. AOB cultures have been seen to have higher ammonia concentration tolerances than AOA cultures (Tourna et al. 2011), so in higher nitrogen fertility locations there may be fewer AOA strains able to thrive with the high ammonia concentrations. Linear regression showed significant decreases in AOA Shannon diversity and AOA OTU richness with increasing rates of compost amendment. ANOVA was much more conservative than linear regression, demonstrating that no AOA diversity measure had a significant relationship with compost amendment rate using Tukey's HSD. Unlike with biochemical variables, there was no reason to expect linear relationships between diversity values and compost amendment rate. 
Therefore, I conclude that there was no strong effect of compost amendment rate on AOA diversity. This does not mean that there was no relationship between AOA community structure and compost amendment rate. While examination of specific archaeal OTUs revealed that none had a strong relationship with treatment level, ANOSIM found evidence of a possible relationship between compost amendment rate and AOA community similarity. The data reduction technique of nMDS was able to more effectively see community relationships between plots than examination of individual OTUs, and revealed that compost level had some effect on community structure of AOA. The effects seen with nMDS were nonlinear. This implies there might be an indirect influence of treatment on AOA community structure.

In contrast to the AOA, only evenness values negatively related to compost amendment rate for the AOB. Using ANOVA, there were no significant relationships. It appeared that there was no strong influence of compost amendment on AOB diversity. One of the bacterial OTUs (AciI 96) was seen to significantly differ with different treatment levels. As with the AOA, there was evidence of a possibly significant relationship between AOB community similarity and treatment. nMDS provided corroborating evidence of a substantial but nonlinear relationship between AOB community similarity and treatment.

I hypothesized that PAO would correlate with AOB community structure and diversity, due to a number of studies where AOB community similarity but not AOA community similarity correlated with nitrification rate (Zeglin et al. 2011; Fan et al. 2010). This supposition appeared to be largely accurate. Using ANOSIM, no significant similarity was found in community structure between sites with similar PAO rates. However, surface fitting and environmental fitting found a strong linear relationship between AOB community similarity and PAO rate. Diversity metrics found no significant relationships at an alpha $=0.05$ level. It is possible that there was a weak negative relationship between AOB OTU evenness (using the Shannon method) and PAO rate $(\mathrm{r}=-0.44, \mathrm{p}=0.098)$. When the relationship between OTU relative abundance and PAO was examined, no individual OTU correlated with PAO rate. 
AOA showed different results to AOB when compared with PAO. There was no discernable pattern between AOA community similarity and PAO rate using either ANOSIM or nMDS. PAO rate may have had negative correlations with Shannon AOA diversity $(r=-0.40, p=0.086)$ and OTU richness $(r=-0.40, p=0.092)$, respectively. Data observation revealed that in no case did the relative abundance of specific archaeal OTUs show a strong relationship with PAO rate. Correlations between community similarity or diversity and PAO could have been weakened by suppression of nitrification rates due to long term cold storage.

MBC negatively correlated with AOA Shannon diversity, AOA OTU richness, and AOB OTU richness but no other measures of diversity. There was no significant effect of MBC on AOA or AOB community similarity seen with ANOSIM. Surface and environmental fitting on nMDS ordinations found that MBC had the strongest relationship of any of the main biochemical variables with AOA, but the weakest with the AOB. This indicated that MBC had an overall weak influence on ammonia oxidizing bacteria. It would be interesting to re-examine the relationship between $\mathrm{AOA}, \mathrm{AOB}$, and the heterotrophic soil community by utilizing other indicators such as respiration, metabolic quotients, and qPCR of AOA and AOB amoA genes.

PMN had no discernable effect on AOA diversity, but did negatively correlate with AOB evenness (both Shannon and Smith and Wilson). PMN influenced community similarity of the bacteria, with ANOSIM indicating much greater similarity between sites with similar nitrogen mineralization rates than would be predicted by chance alone. This was particularly apparent when compared to the reasonably attainable maximum $\mathrm{R}$ value for the $\mathrm{AOB}(0.66$, compared to $\mathrm{R}=0.31$ for $\mathrm{PMN})$. nMDS ordinations showed strong correlations of PMN with both AOA and AOB community similarity using surface and environmental fitting. For the AOA, this relationship was nonlinear which suggests indirect influence of PMN on AOA community structure. There could have been several reasons why PMN had less effect on AOA community structure than on AOB. There has been much speculation that AOA could exhibit mixotrophic or heterotrophic growth (Prosser and Nicol, 2008) and thus be less dependent on 
ammonia availability, particularly when coupled with a lower cellular maintenance energy requirement than other microorganisms (Valentine 2007). It is also possible that many archaeal ammonia oxidizers could utilize urea as a substrate for ammonia oxidation rather than ammonia itself, decoupling the process from the rate of nitrogen mineralization. However, organic nitrogen pool size and nitrogen mineralization rates are often tightly coupled (Booth et al. 2005), which argues against this possibility.

While some biochemical measurements had stronger trends when examining just the 3 lowest (022.4 $\mathrm{Mg} \mathrm{ha}^{-1}$ ) treatment levels, this did not translate into stronger trends involving microbial community structure in just the low treatments. AOA almost invariably had weaker coefficients of determination and $\mathrm{p}$ values when examining just these treatments than it did for all the treatments when diversity measures were compared to compost amendment rate or biochemical variables. nMDS visualizations and ANOSIM similarly did not improve. For the AOB, there was an indication that the strength of some relationships may have increased when only examining the 0 to $22.4 \mathrm{Mg}$ compost $\mathrm{ha}^{-1}$ treatments. Diversity generally had much weaker $\mathrm{p}$ values and projected linear relationships with compost amendment rate and MBC. The same was the case when correlated with PMN and PAO, with the exception of Shannon evenness values. In these cases, $\mathrm{p}$ values declined due to fewer data points but projected linear relationships evidenced by correlation coefficients increased (from $r=-0.44, p=0.098$ to $\mathrm{r}=-0.49, \mathrm{p}=0.15$ for the correlation to $\mathrm{PAO}$, and from $\mathrm{r}=-0.53, \mathrm{p}=0.044$ to $\mathrm{r}=-0.58, \mathrm{p}=0.076$ for the $\mathrm{PMN}$ regression). ANOSIM values for MBC and PAO improved although they were still insignificant (from $\mathrm{R}=0.057, \mathrm{p}=0.32$ to $\mathrm{R}=0.29, \mathrm{p}=0.16$ for $\mathrm{MBC}$; from $\mathrm{R}=0.031, \mathrm{p}=0.39$ to $\mathrm{R}=0.21, \mathrm{p}=0.19$ for $\mathrm{PAO}$ ). The ANOSIM R value obtained from a posteriori PMN groupings did not change when examining only the low treatments $(\mathrm{R}=0.29, \mathrm{p}=0.016$ for all treatment levels to $\mathrm{R}=0.31, \mathrm{p}=0.059$ for just the low treatments).

To the extent that environmental variables (PMN, PAO, and MBC) had significant correlations with diversity, all these correlations were negative. The higher the nitrogen cycling rate or total biomass size, the lower the diversity of AOA and AOB obtained in the plots. These nutrient-rich conditions may have favored copiotrophs in the soil environment (Fierer et al. 2007). For PMN, which significantly 
correlated with bacterial evenness, this may simply have meant that more copiotrophic members of the AOB community were more prevalent, not that AOB diversity truly declined. Recent literature on AOB ecology support this interpretation (Shen et al. 2011; Leininger et al. 2006; Hynes and Germida 2012; Shen et al. 2008). This interpretation of diversity and evenness is due to the fact that relative rather than absolute abundance is the basis of OTU diversity. Diversity metrics are based on both evenness and richness, and the meaning of OTU richness differs from the species richness used in many studies of macrobiota ecology because absence of an OTU does not mean that OTU was not present in the site. Richness could be a reflection of either an actual loss of diversity due to the elimination of specific OTUs or a decline in relative abundance so that a given OTU fell below the relative abundance threshold of $5 \%$. There is a stronger indication that increasing MBC truly led to a suppression of ammonia oxidizer diversity, as there were negative correlations between $\mathrm{MBC}$ and $\mathrm{AOA} / \mathrm{AOB}$ richness but not evenness. In this instance, a larger biomass may have had an inhibitory effect on ammonia oxidizers. This did not translate into an inhibitory effect on ammonia oxidation, however, as there was no strong relationship between MBC and PAO. The negative effects of increased nitrogen cycling rates on ammonia oxidizer diversity are corroborated by one study in the literature that calculated Shannon diversity indices. Shen $e t$ al. (2011) found that AOB Shannon diversity and evenness decreased with increasing nitrogen deposition rates, but that there was no effect on AOA.

AOA and AOB Shannon diversity values were highly correlated, providing an indication that the two populations were being structured by similar factors. Figure 40 shows evidence that this is not entirely the case. Ordinations of community similarity were structured differently in AOB compared to AOA. A small cluster of sites (plots 1, 23, 24, 29, and 30) showed similarity in both AOA and AOB ordinations. These sites all had higher levels of compost amendment (22.4 to $89.6 \mathrm{Mg}$ compost ha $^{-1}$ ), similar PMN rates, and 4 of the 5 were spatially very close to each other. Additionally, the measured variables AOA and AOB related to differed, both for community similarity metrics and diversity metrics. Tables 14 and 15 present this information. In these tables, different categories should be given different 
weights in understanding the influences on ammonia oxidizer community structure. Community similarity was a more valuable approach for understanding community dynamics than diversity metrics, as it took into much greater account the role of specific OTUs rather than just numbers and proportions of OTUs. Additionally, I felt that nMDS combined with environmental or surface fitting was the most useful way to interpret community similarity data in this study. ANOSIM was also useful in interpreting the relationship between community similarity and compost rate, but much less useful with comparisons between community similarity and continuous variables such as PMN, MBC, and PAO.

Many researchers have posited the idea that AOA and AOB inhabit different ecological niches (Di et al. 2010; Schleper 2010). The present study provides support for this hypothesis. While overall diversity of AOA and $\mathrm{AOB}$ showed similar responses to each other, there were differences seen in the variables AOA and $\mathrm{AOB}$ had relationships with using different data analysis approaches. The strongest relationships with AOA community structure were compost amendment rate and MBC. It appears that the greatest influence on AOA community structure were effects of compost not specific to PMN or PAO, even though PMN increased with increasing compost amendment. When relationships between treatment, environmental variables, and diversity metrics were examined, the strongest were between diversity metrics and MBC. Linear regression gave equally strong coefficients of determination and significance values to relationships between compost rate and diversity, but because compost rate was not a truly continuous variable it could not be adequately judged whether regression analysis was appropriate. There were no relationships between OTU diversity metrics and PMN, and only possibly significant relationships between diversity and PAO. There was little indication from diversity changes that the AOA were dependent on ammonia, and almost nothing connected them to the potential rates of ammonia oxidation possible in these sites.

When a community similarity rather than diversity approach was used, similar results were obtained. This was to be expected, as surface fitting of Shannon diversity on community similarity showed the two were very closely related. nMDS ordination visually showed separation based on 
treatment, although it was not a purely linear response and so may have been an indirect connection. Increasing treatment levels did not move across the ordination in an orderly fashion, but there was a definite tendency for higher and lower treatment level sites, respectively, to cluster together.

Environmental fitting and surface fitting of continuous variables (PMN, PAO, MBC) showed MBC to be the most important correlation to community similarity, although PMN was important as well. Surface fitting of PMN over an AOA ordination showed a nonlinear relationship, and the coefficient of determination declined substantially when a linear rather than general additive model was used, as in environmental fitting. This raises the possibility that another variable that covaries with PMN rather than PMN itself may have influenced AOA community structure. No significant correlation could be found between community similarity and PAO, which is corroborated by a number of other studies (Fan et al. 2010; Shen et al. 2008; Zeglin et al. 2011). Interestingly, extracted DNA concentration had a very strong nonlinear relationship with AOA community similarity. It is unclear why this connection was so strong. ANOSIM, which is only robust for compost amendment rate since it is both a categorical and continuous variable, showed a possible relationship between compost amendment rate and community similarity. ANOSIM showed no correlations for community similarity as compared to MBC, PAO, or PMN, although the inherent problems with adapting continuous variables (PMN, PAO, MBC) to a categorical analysis means these ANOSIM results must be interpreted with great reservations.

The story for the AOB was more complicated. All examined variables (treatment, MBC, PMN, and PAO) showed some relationship to $\mathrm{AOB}$, depending on the approach used. When diversity metrics were compared to environmental variables and treatment, the strongest relationship was between Shannon evenness and compost rate, followed by (in order): Smith and Wilson evenness and PMN, Smith and Wilson evenness and compost rate, OTU richness and MBC, Shannon evenness and PMN, and, possibly, a relationship between Shannon evenness and PAO. The weaknesses of using regression analysis for comparisons to compost rate have already been discussed. The lack of significant relationships between PAO and diversity metrics was surprising given its strong correlation to PMN, its strong correlation to 
community similarity using environmental fitting, and PMN's correlations with AOB evenness. It may have been that AOB evenness correlated with PMN because different AOB were adapted to different substrate concentrations, but that all $\mathrm{AOB}$ were actively involved in ammonia oxidation. Diversity has already been shown to be of limited use in interpretation. AOB evenness changes as a reflection of adaptation to different substrate concentrations may imply a greater niche diversity for the AOB than the $\mathrm{AOA}$, at least in regards to ammonia oxidation, as correlations for AOA largely involved changes in overall diversity or richness rather than evenness.

Using a community similarity approach showed less similar results to the diversity approach for AOB than it did for AOA. A weaker relationship (compared to AOA) between diversity and community similarity had been visualized using surface fitting, so this was not entirely unexpected. Using a data ordination approach based on nMDS, it could be seen visually that compost amendment rate was affecting community similarity. As with the AOA, this effect was nonlinear but appeared less distinct than for the AOA. Environmental fitting and surface fitting of PMN and PAO showed that both could be significantly correlated with community similarity, as is commonly seen in the literature (Zeglin et al. 2011; Shen et al. 2008; Fan et al. 2010). PMN was the stronger correlation, followed closely by PAO. Surface fitting showed that both of these variables had highly linear correlations with AOB community similarity. MBC had a substantially weaker, nonlinear relationship to community similarity using environmental fitting. Soluble carbon concentration appeared to relate to AOB similarity more than MBC. As with the AOA, extracted DNA concentration strongly related to AOB community similarity in a nonlinear fashion. ANOSIM showed significant effects of PMN on ranked community similarity between sites, and a possible effect of treatment on community similarity. It showed no relationship between PAO or MBC and community similarity.

While the evidence implies that AOA community structure may have been most related to effects of compost amendment that did not include PMN or PAO, the AOB appeared to be more related to effects specific to PMN and PAO. This could be seen by the strongly linear environmental fitting for PMN and 
PAO, as well as the weaker trends between compost amendment rate and community similarity seen for the AOB compared to the AOA. ANOSIM results showing significant effects of PMN on community similarity further suggest this interpretation. MBC did appear to weakly influence AOB community structure, but not as much as either PAO or PMN. This was surprising- it had been surmised that a higher microbial biomass would suppress nitrifiers due to competition for ammonia. However, MBC only varied 2-fold in the plots, which may not have been enough to capture a weak but real relationship. The reasons why diversity did not show many strong relationships with any environmental variables is not completely known. However, the fact that community evenness was the primary diversity metric that changed significantly indicates that only part of the AOB community might be ammonia dependent and tied to ammonia oxidation. If this is to be believed, it might further explain why some community similarity comparisons with PAO and PMN were not stronger. Additionally, diversity did not relate to community similarity as well for the AOB as it had for the AOA.

It appears that $\mathrm{AOB}$ are more strongly associated with a chemolithotrophic ammonia oxidation process found in environments where ammonia availability outpaces carbon availability or plant utilization potential, limiting the ability of the heterotrophic biomass to utilize the ammonia (Cavagnaro et al. 2008). AOA, in contrast, seem to be associated with a wider range of conditions- lower $\mathrm{pH}$ soils (Yao et al. 2011), soils with more competition for resources from heterotrophs (Stopnišek et al. 2010), and lower nitrogen fertility soils (Shen et al. 2011). They often respond less to fertilizer and other changes in nitrogen economies than the AOB (Shen et al. 2008). Some AOA may be mixotrophs or heterotrophs (Prosser and Nicol 2008), however, evidence shows many are likely true chemolithotrophic ammonia oxidizers- it has been hypothesized that the archaea as a domain are physiologically designed for low cellular maintenance costs and thus adapted to energy-stressed environments (Valentine 2007). If this is true, it might explain why AOA respond less to management changes- they may simply be able to withstand or even thrive under unfavorable and fluctuating conditions.

\subsubsection{The relationship between OTU diversity and actual diversity}


While I concluded in the previous section that compost amendment rate did not strongly affect ammonia oxidizer diversity, the degree to which OTU diversity is actually representative of true microbial diversity is still not well established. Blackwood et al. (2007) performed in silico simulations of bacterial communities to compare how well diversity indices generated from T-RF profiles would correlate to the actual diversity of the community structure using $16 \mathrm{~S}$ rRNA genes. They found that for communities composed of 1200 or fewer species, there were good linear relationships between several different diversity measures calculated from T-RFLP profiles and actual species diversity, richness, and evenness. In particular, they found good correlations between species diversity and both the Shannon diversity index and Smith and Wilson evenness. In their study, calculated Shannon diversity had strong linear correlations with true diversity $(r=0.71)$ and true species evenness $(r=0.67)$. Calculated Shannon evenness correlated well with true diversity $(r=0.72)$ and true species evenness $(r=0.70)$. Smith and Wilson evenness was the most robust measure of diversity, correlating well with true diversity $(\mathrm{r}=0.81)$ and true species evenness $(\mathrm{r}=0.71)$. This was determined using a $1 \%$ threshold. When a higher threshold (4\%) was used, only Smith and Wilson evenness correlated well with true community diversity (r=0.66). A 5\% threshold was considered necessary for the present study, as less abundant peaks may have reflected PCR artifacts (von Wintzingerode et al., 1997; Egert \& Friedrich 2003) rather than actual OTUs. Additionally, the perceived small community size of AOA/AOB as seen in T-RFLP (for example, see Wessén et al. 2010) indicated that a 5\% threshold would likely capture most true OTUs in the community. Our data did show that the most robust technique, Smith and Wilson evenness, was highly correlated with and obtained similar results to Shannon evenness. There was no indication that one metric was more effective than the other in this study. Indeed, since Smith and Wilson evenness values changes in abundance and richness of rare and common OTUs equally, while Shannon evenness is less sensitive to changes in richness and abundance for rare OTUs than for common ones, the two approaches were complementary. 
Additionally, the previously mentioned results of Blackwood et al. (2007) indicate that diversity values generated from T-RFLP profiles were not necessarily strongly related to actual diversity. This is partially due to the possibility of multiple species appearing as the same peak with a given restriction enzyme, and partially due to rarer members of the community falling below threshold levels. However, their study was performed to address overall bacterial community diversity using 16S $r R N A$ genes, while the current study addressed ammonia-oxidizer diversity using the functional amoA gene. This is a substantially smaller community, and so may respond differently than their results indicated. Their results did indicate that diversity indices in smaller communities were more reflective of true diversity. To help address the issue of species richness being obscured by multiple species showing up as the same peak, the data from 3 different restriction enzymes was combined to determine diversity.

\subsubsection{Unique aspects of plot 12}

Due to the inability to amplify bacterial $a m o A$ genes and the difficulty in amplifying archaeal $a m o A$ genes, it appears that ammonia oxidizers exist in very low abundance in plot 12 . Technical issues interfering with PCR amplification from this site did not appear to be the culprit. Absorbance ratios for 260:280 nm and 260:230 nm, used to determine contaminants that could potentially interfere with PCR reactions, ranged from 1.61 to 2.38 for $260: 280$ and 1.125 to 2.61 for $260: 230$. Plot 12 had values of 1.89 and 1.72 , respectively, for these ratios. In both cases, these ratios fell within the ideal range that indicated little coextraction of RNA and no contamination with humic acids or proteins. This plot was one of the soils that received no fertilizer amendment. It had the lowest PAO rate of any plot. Aside from that, however, none of the physical, chemical or biochemical soil variables for this site give any strong indication as to why ammonia oxidizers seemed to be present in such low numbers. It had one of the lowest PMN rates, as well as a relatively small microbial biomass pool size. The ratio of microbial biomass pool size to soil organic nitrogen mineralization rate for this site was among the highest. Soil moisture and $\mathrm{pH}$ in this site were fairly average. Since PMN seems to exert strong control over PAO rates at these sites, it is interesting that other low PMN sites easily produced $\mathrm{AOB}$ amplicons while plot 
12 did not. The lack of AOB gene product coupled with the extremely low PAO rate provides some indication that AOB may be more important in ammonia oxidation at these sites; however, it should be noted that the other plots that required less stringent reaction conditions to amplify bacterial amoA genes (plots 3, 5, 19, and 37) did not show any strong tendencies towards low PAO rates.

\subsubsection{DNA light absorbance ratios}

In general, the absorbance ratios measured in extracted DNA samples fell within a desirable range of values. The values for $\mathrm{A}_{260: 280}$ ranged from 1.61 to 2.38; the range for $\mathrm{A}_{260: 230}$ was from 1.125 to 2.61. The ideal range for $\mathrm{A}_{260: 280}$ is 1.8 and above and the ideal range for $\mathrm{A}_{260: 230}$ is 1.5 and above. Four of the 20 plots fell below the ideal 260:280 nm range, while 4 other plots (there was no overlap between the two) fell below the ideal 260:230 nm range. In neither case did this appear to interfere with DNA amplification: none of these 8 plots were the ones that required less stringent conditions to amplify bacterial amoA genes. Plot 10, with a low 260:230 ratio (1.28), did require an extra 5 cycles to amplify archaeal amoA genes. Both $\mathrm{A}_{260: 280}$ and $\mathrm{A}_{260: 230}$ correlated with compost amendment rate using regression analysis. The positive correlation between $\mathrm{A}_{260: 230}$ and compost amendment rate implied that the proportion of DNA to humic acids increased with increasing compost amendment. The significant negative correlation between compost amendment rate and 260:280 $\mathrm{nm}$ absorbance ratio was difficult to interpret, as the presence of RNA would raise the ratio and the presence of proteins would lower it. Without quantifying either of those types of biochemicals in the DNA extracts, it would be impossible to determine the meaning of the correlation. Regardless, ANOVA found no significant differences between treatments for either $A_{260: 280}$ or $A_{260: 230}$. As with the biochemical variables, high within treatment level variability may have obscured real trends.

\subsubsection{Conclusions}

The present study provided evidence that, in the top $15 \mathrm{~cm}$ of these experimental plots, shifts could be seen in both $\mathrm{AOA}$ and $\mathrm{AOB}$ communities. In this study, no measured factor varied by more than 
3-fold between the plots except PAO. Yet, despite the narrow range of differences in soil fertility among the plots, large differences could be seen in the AOA and AOB community fingerprints and nitrification rate. $\mathrm{AOB}$ but not $\mathrm{AOA}$ community structure appeared to be linked to nitrification rate. AOB community structure changed linearly with changes in nitrogen mineralization rate and nitrification rate. In contrast, the AOA community exhibited a change in structure and a decline in diversity with small changes in the size of the overall microbial biomass, but was not strongly affected by changes in nitrogen mineralization rates. AOA community structure did not appear to change at all with changes in nitrification rates. AOA evenness did not significantly change with changes in treatment or specific biochemical variables, which implies that members of the AOA community respond uniformly to changes in different variables. The different factors AOA and AOB community structure responded to indicate a separate niche for the two groups, as has been posited before (Prosser and Nicol 2008). My data fits within a broad trend that indicates that $\mathrm{AOB}$ are the dominant microorganisms actively oxidizing ammonia in higher nitrogen fertility sites, including the present study site, which appeared to be rich in organic nitrogen. While AOA may be present in high numbers in high fertility sites, they rarely appear to be controlling ammonia oxidation rates; dominance of the ammonia oxidation process by the AOA is more often seen in low fertility sites or other inhospitable locales. This study and others have shown that many carbon and nitrogen biochemical pools and flow rates affect ammonia oxidizers. It is very clear that carbon-nitrogen dynamics are important in structuring ammonia-oxidizing communities, and that these interactions will have profound impacts on the future climate and life as we know it (Mulvaney et al. 2009; Erisman et al. 2011; Kulmala and Petäjä 2011; Bodelier 2011; Zaele and Dalmonech 2011; MacDonald et al. 2011). Future studies on AOA and AOB ecology should incorporate many measures of different carbon and nitrogen pools and flow rates into their design as these factors are likely to elucidate controlling factors on ammonia oxidizers. Combining biochemical measurements such as heterotrophic respiration, potential nitrification assays that can distinguish between bacterial and archaeal nitrification (see Zeglin et al. 2011) and potential nitrogen mineralization with gene copy number, gene cloning, and community profiles of AOA and AOB may yield some interesting trends about the ecology of ammonia 
oxidizers. Likewise, examining these trends over time could yield fruitful information on the development of soils on a human timescale and as affected by fertility inputs. 


\subsection{REFERENCES}

Addiscott, T.M. 1983. Kinetics and temperature relationships of mineralization and nitrification in Rothamsted soils with differing histories. Journal of Soil Science 34: 343-353.

Beisel, J., P. Usseglio-Polatera, V. Bachmann, and J. Moreteau. 2003. A comparative analysis of evenness index sensitivity. International Review of Hydrobiology 88: 3-15.

Blackwood, C.B., D. Hudleston, D.R. Zak, and J.S. Buyer. 2007. Interpreting ecological diversity indices applied to terminal restriction fragment length polymorphism data: insights from simulated microbial communities. Applied and Environmental Microbiology 73: 5276-5283.

Bodelier, P.L.E. 2011. Interactions between nitrogenous fertilizers and methane cycling in wetland and upland soils. Current Opinion in Environmental Sustainability 3: 379-388.

Booth, M.S., J.S. Stark, and E. Rastetter. 2005. Controls on nitrogen cycling in terrestrial ecosystems: a synthetic analysis of literature data. Ecological Monographs 75: 139-157.

Boyle-Yarwood, S.A., P.J. Bottomley, and D.D. Myrold. 2008. Community composition of ammoniaoxidizing bacteria and archaea in soils under stands of red alder and Douglas fir in Oregon. Environmental Microbiology 10: 2956-2965.

Brookes, P.C., and R.G. Joergensen. 2006. Microbial biomass measurements by fumigation-extraction. In Bloem, J., D.W. Hopkins, and A. Benedetti (eds.) Microbiological methods for assessing soil quality. CAB International, Wallingford, UK.

Cavagnaro, T.R., L.E. Jackson, K. Hristova, and K.M. Scow. 2008. Short-term population dynamics of ammonia oxidizing bacteria in an agricultural soil. Applied Soil Ecology 40: 13-18.

Chain, P., J. Lamerdin, F. Larimer, W. Regala, V. Lao, M. Land, L. Hauser, A. Hooper, M. Klotz, J. Norton, L. Sayavedra-Soto, D. Arciero, N. Hommes, M. Whitaker, and D. Arp. 2003. Complete 
genome sequence of the ammonia-oxidizing bacterium and obligate chemolithotroph Nitrosomonas europaea. Journal of Bacteriology 185: 2759-2773.

Dequiedt, S., N.P.A. Saby, M. Lelievre, C. Jolivet, J. Thioulouse, B. Toutain, D. Arrouays, A. Bispo, P. Lemanceau, and L. Ranjard. 2011. Biogeographical patterns of soil molecular microbial biomass as influenced by soil characteristics and management. Global Ecology and Biogeography 20: 641-652.

Di, H.J., K.C. Cameron, J.P. Shen, C.S. Winefield, M. O'Callaghan, S. Bowatte, and J. He. 2010. Ammonia-oxidizing bacteria and archaea grow under contrasting soil nitrogen conditions. FEMS Microbiology Ecology 72: 386-394.

Dunbar, J., L.O. Ticknor, and C.R. Kuske. 2001. Phylogenetic specificity and reproducibility and new method for analysis of terminal restriction fragment profiles of 16S rRNA genes from bacterial communities. Applied \& Environmental Microbiology 67: 190-197.

Egert, M., and M.W. Friedrich. 2003. Formation of pseudo-terminal restriction fragments, a PCRrelated bias affecting terminal restriction fragment length polymorphism analysis of microbial community structure. Applied and Environmental Microbiology 69: 2555-2562.

Erisman, J.W., J. Galloway, S. Seitzinger, A. Bleeker, and K. Butterbach-Bahl. 2011. Reactive nitrogen in the environment and its effect on climate change. Current Opinion in Environmental Sustainability 3: 281-290.

Fierer, N., M.A. Bradford, and R.B. Jackson. 2007. Towards an ecological classification of soil bacteria. Ecology 88: 1354-1364.

Gubry-Rangin, C., B. Hai, C. Quince, M. Engel, B.C. Thomson, P. James, M. Schloter, R.I.

Griffiths, J. I. Prosser, and G.W. Nicol. 2011. Niche specialization of terrestrial archaeal ammonia oxidizers. PNAS 108: 21,206-211. 
Gupta, W.S.R., M.M. Roper, J.A. Kirkegaard, and J.F. Angus. 1994. Changes in microbial biomass and soil organic-matter levels during the $1^{\text {st }}$ year of modified tillage and stubble-management-practices on a red earth. Australian Journal of Soil Research 32: 1339-1354.

Grisi, B., C. Grace, P.C. Brookes, A. Benedetti, and M.T. Dell'Abate. 1998. Temperature effects on organic matter and microbial biomass dynamics in temperate and tropical soils. Soil Biology and Biochemistry 30: 1309-1315.

Hart, S.C. 1994. Nitrogen Mineralization, Immobilization, and Nitrification. In Methods of Soil Analysis. Part 2. Microbiological and Biochemical Properties. (ed. R.W. Weaver). American Society of Agronomy-Soil Science Society of America, Inc., Madison, Wisconsin, 1011-1015.

Helder, W., and R.T.P. de Vries. 1983. Estuarine nitrite maxima and nitrifying bacteria (EMS-Dollard estuary). Netherlands Journal of Sea Research 17: 1-18.

Hofman, J., and L. Dušek. 2003. Biochemical analysis of soil organic matter and microbial biomass composition- a pilot study. European Journal of Soil Biology 39: 217-224.

Hynes, H.M., and J.J. Germida. 2012. Relationship between ammonia oxidizing bacteria and bioavailable nitrogen in harvested forest soils of central Alberta. Soil Biology \& Biochemistry 46: 18-25.

Jia, Z., and R. Conrad. 2009. Bacteria rather than archaea dominate microbial ammonia oxidation in an agricultural soil. Environmental Microbiology 11: 1658-1671.

Kaschuk, G., O. Alberton, and M. Hungria. 2010. Three decades of soil microbial biomass studies in Brazilian ecosystems: lessons learned about soil quality and indications for improving sustainability. Soil Biology \& Biochemistry 42: 1-13. 
Klute, E.A. (ed). 1986. Methods of Soil Analysis. Part 1. Physical and Mineralogical Methods. American Society of Agronomy-Soil Science Society of America, Madison, Wisconsin. ISBN 0891188118.

Kulmala, M., and T. Petäjä. 2011. Soil nitrites influence atmospheric chemistry. Science 333: 15861587.

Lehtovirta-Morley, L.E., K. Stoecker, A. Vilcinskas, J.I. Prosser, and G.W. Nicol. 2011. Cultivation of an obligate acidophilic ammonia oxidizer from a nitrifying acid soil. PNAS 108: 15,892-15,897.

Leininger, S., T. Urich, M. Schloter, L. Schwark, J. Qi, G. W. Nicol, J. I. Prosser, S. C. Schuster and C. Schleper. 2006. Archaea predominate among ammonia-oxidizing prokaryotes in soils. Nature 442: 806-809.

Li, X., M.C. Fisk, T.J. Fahey, and P.J. Bohlen. 2002. Influence of earthworm invasion on soil microbial biomass and activity in a northern hardwood forest. Soil Biology and Biochemistry 34: 1929-1937.

MacDonald, C.A., I.C. Anderson, R.D. Bardgett, and B.K. Singh. 2011. Role of nitrogen in carbon mitigation in forest ecosystems. Current Opinion in Environmental Sustainability 3: 303-310.

Mulvaney, R.L.1996. Nitrogen-inorganic forms. In Methods of Soil Analysis. Part 3. Chemical Methods (ed. Donald Sparks). American Society of Agronomy-Soil Science Society of America, Inc., Madison Wisconsin.

Mulvaney, R.L., S.A. Khan, and T.R. Ellsworth. 2009. Synthetic nitrogen fertilizers deplete soil nitrogen: a global dilemma for sustainable cereal production. Journal of Environmental Quality 38: 22952314. 
O'Callaghan, M., E.M. Gerard, P.E. Carter, R. Lardner, U. Sarathchandra, G. Burch, A. Ghani, and N. Bell. 2010. Effect of the nitrification inhibitor dicyandiamide (DCD) on microbial communities in a pasture soil amended with bovine urine. Soil Biology \& Biochemistry 42: 1425-1436.

Offre, P., J.I. Prosser, and G.W. Nicol. 2009. Growth of ammonia-oxidizing archaea in soil microcosms isinhibited by acetylene. FEMS Microbiology Ecology 70: 99-108.

Prosser, J.I. and G.W. Nicol. 2008. Relative contributions of archaea and bacteria to aerobic ammonia oxidation in the environment. Environmental Microbiology 10: 2931-2941.

Rees, G.N., D.S. Baldwin, G.O. Watson, S. Perryman, and D.L. Nielsen. 2004. Ordination and significance testing of microbial community composition derived from terminal restriction fragment length polymorphisms: application of multivariate statistics. Antonie van Leeuwenhoek 86: 339-347.

Schleper, C. 2010. Ammonia oxidation: different niches for bacteria and archaea? ISME Journal 4: 10921094.

Shannon, C.E. 1948. A mathematical theory of communication. The Bell System Technical Journal 27: $379-423$.

Shen, J., L. Zhang, Y. Zhu, J. Zhang, and J. He. 2008. Abundance and composition of ammoniaoxidizing bacteria and ammonia-oxidizing archaea communities of an alkaline sandy loam. Environmental Microbiology 10: 1601-1611.

Shen, X., L. Zhang, J. Shen, L. Li, C. Yuan, J. He. 2011. Nitrogen loading levels affect abundance and composition of soil ammonia oxidizing prokaryotes in semiarid temperate grassland. Journal of Soils and Sediments 11: 1243-1252.

Smith, B., and J.B. Wilson. 1996. A consumer's guide to evenness indices. Oikos 76: 70-82. 
Sparks, D.L. (ed). 1996. Methods of Soil Analysis. Part 3. Chemical Methods. American Society of Agronomy-Soil Science Society of America, Madison, WI. ISBN 0891188258.

Stark, J.M. 1996. Modeling the temperature response of nitrification. Biogeochemistry 35: 433-445.

Subbarao, G.V., and O. Ito. 2006. Scope and strategies for regulation of nitrification in agricultural systems- challenges and opportunities. Critical Reviews in Plant Science 25:303-335.

Thies, J.E. 2007. Soil microbial community analysis using terminal restriction fragment length polymorphisms. Soil Science Society of America Journal 71: 579-591.

Tourna, M., M. Stieglmeier, A. Spang, M. Könneke, A. Schintlmeister, T. Urich, M. Engel, M. Schloter, M. Wagner, A. Richter, and C. Schleper. 2011. Nitrososphaera viennensis, an ammonia oxidizing archaeon from soil. PNAS 108: 8420-8425.

Valentine, D.L. 2007. Adaptations to energy stress dictate the ecology and evolution of the Archaea. Nature Reviews Microbiology 5: 316-323.

Von Wintzingerode, Friedrich, U.B. Gobel, and E. Stackebrandt. 1997. Determination of microbial diversity in environmental samples: pitfalls of PCR-based rRNA analysis. FEMS Microbiology Reviews 21: 213-229.

Ward, B.B., and G.D. O’Mullan. 2005. Community level analysis: genetic and biogeochemical approaches to investigate community composition and function in aerobic ammonia oxidation. Methods in Enzymology 397: 395-413.

Waring, S.A., and J.M. Bremner. 1964. Ammonium production in soil under waterlogged conditions as index of nitrogen availability. Nature 201: 951-952. 
Wessén, E., K. Nyberg, J.K. Jansson, and S. Hallin. 2010. Responses of bacterial and archaeal ammonia oxidizers to soil organic and fertilizer amendments under long-term management. Applied Soil Ecology 45: 193-200.

Wu, Y., S. Kemmitt, R.P. White, J. Xu, and P.C. Brookes. 2011. Carbon dynamics in a 60 year fallowed loamy-sand soil compared to that in a 60 year permanent arable or permanent grassland UK soil. Plant and Soil 352: 51-63.

Xia, W., C. Zhang, X. Zeng, Y. Feng, J. Weng, X. Lin, J. Zhu, Z. Xiong, J. Xu, Z. Cai and Z. Jia. 2011. Autotrophic growth of nitrifying community in an agricultural soil. ISME Journal 5: 1226-1236.

Zaele, S., and D. Dalmonech. 2011. Carbon-nitrogen interactions on land at global scales: current understanding in modelling climate biosphere feedbacks. Current Opinion in Environmental Sustainability 3: 311-320.

Zeglin, L.H., A.E. Taylor, D.D. Myrold, and P.J. Bottomley. 2011. Bacterial and archaeal amoA gene distribution covaries with soil nitrification properties across a range of land uses. Environmental Microbiology Reports 3: 717-726. 


\section{Tables}

Table 1. Planting history for the 40 compost rate trial plots. Four plots of each treatment level were randomly assigned to one of two groups and planted with either buckwheat or millet in 2000. The two groups continued to be planted with different crops until 2006.

\begin{tabular}{ccc}
\hline Year & Group 1 & Group 2 \\
\hline 2000 & Buckwheat & Millet \\
2001 & Buckwheat & Millet \\
2002 & Bush snap beans & Buckwheat \\
2003 & Buckwheat & Bush snap beans \\
2004 & - -fallow-- & --fallow-- \\
2005 & Pumpkin & Sunflowers \\
2006 & -- fallow-- & --fallow-- \\
2007 & -- fallow-- & --fallow-- \\
2008 & -- fallow-- & - -fallow-- \\
2009 & -- covered with ground cloth-- & -- covered with ground cloth-- \\
2010 & Miscanthus & Miscanthus \\
2011 & Miscanthus & Miscanthus \\
\hline
\end{tabular}


Table 2. The elemental composition of partially composted dairy manure and straw mulch applied to the compost rate trial plots. Variable rates of compost were applied to the top $10 \mathrm{~cm}$ of soil in 2000,2001, 2002, 2003, and 2005. Straw mulch was used to cover the soil surface in 2010.

\begin{tabular}{cccccccccccc}
\hline Material & $\mathbf{p H}$ & $\boldsymbol{\%} \mathbf{C}$ & $\boldsymbol{\%} \mathbf{N}$ & $\begin{array}{c}\mathbf{C : N} \\
\text { ratio }\end{array}$ & $\boldsymbol{\%} \mathbf{P}$ & $\boldsymbol{\%} \mathbf{K}$ & $\boldsymbol{\%} \mathbf{C a}$ & $\boldsymbol{\%} \mathbf{M g}$ & $\mathbf{p p m} \mathbf{C u}$ & $\mathbf{p p m} \mathbf{Z n}$ & $\mathbf{p p m} \mathbf{M n}$ \\
\hline Compost & 8.1 & 18.24 & 0.48 & $38: 1$ & 0.45 & 0.63 & 0.71 & 0.2 & - & - & - \\
Straw & & - & 0.647 & - & 0.118 & 1.429 & 0.225 & 0.079 & 6.21 & 8.86 & 23.49 \\
\hline
\end{tabular}


Table 3. Extracted DNA concentrations and relevant light absorbance ratios used to determine contamination of extracted DNA with proteins $(260: 280 \mathrm{~nm})$ and humic acids $(260: 230 \mathrm{~nm})$. Plots are organized by treatment level.

\begin{tabular}{|c|c|c|c|c|}
\hline $\begin{array}{c}\text { Compost amendment } \\
\text { rate }\left(\mathrm{Mg} \mathrm{ha}^{-1}\right)\end{array}$ & Plot & $\begin{array}{c}\text { DNA (mg DNA } \\
\left.\text { kg soil }^{-1}\right)\end{array}$ & $260: 280 \mathrm{~nm}$ ratio & 260:230 nm ratio \\
\hline 0 & 9 & 4.08 & 1.78 & 1.71 \\
\hline 0 & 12 & 3.88 & 1.88 & 1.72 \\
\hline 0 & 25 & 2.42 & 2.35 & 1.33 \\
\hline 0 & 26 & 3.08 & 1.88 & 1.86 \\
\hline 11.2 & 2 & 4.24 & 2.01 & 1.36 \\
\hline 11.2 & 5 & 4.44 & 2.19 & 1.94 \\
\hline 11.2 & 6 & 3.62 & 2.37 & 1.12 \\
\hline 11.2 & 19 & 4.26 & 2.29 & 2.28 \\
\hline 22.4 & 4 & 4.82 & 1.83 & 1.66 \\
\hline 22.4 & 10 & 4.12 & 1.92 & 1.28 \\
\hline 22.4 & 24 & 5.8 & 2.02 & 2.05 \\
\hline 22.4 & 20 & 4.66 & 2.03 & 2.04 \\
\hline 44.8 & 28 & 5.46 & 1.60 & 1.82 \\
\hline 44.8 & 29 & 6 & 1.68 & 1.93 \\
\hline 44.8 & 30 & 4.96 & 2.09 & 1.88 \\
\hline 44.8 & 33 & 4.88 & 2.04 & 2.07 \\
\hline 89.6 & 1 & 5 & 1.94 & 2.61 \\
\hline 89.6 & 3 & 6.08 & 1.88 & 2.31 \\
\hline 89.6 & 23 & 6.02 & 1.73 & 2.15 \\
\hline 89.6 & 37 & 5.1 & 1.69 & 1.91 \\
\hline
\end{tabular}


Table 4. Primer names and sequences used in this study.

\begin{tabular}{cc}
\hline Primers Used & Sequence \\
\hline Bacteria & \\
& amoA-1F \\
amoA-2R & 5'-GGGGTTTCTACTGGTGGT-3' \\
\hline Archaea & 5 '-CCCCTCKGSAAAGCCTTCTTC-3, \\
crenamoA23f & \\
crenamoA616r & 5'-ATGGTCTGGCTWAGACG-3' \\
\hline
\end{tabular}


Table 5. Average values of soil parameters by treatment level. Standard errors are in parentheses. Values in a column not connected by the same letter are significantly different using Tukey's HSD.

\begin{tabular}{|c|c|c|c|c|}
\hline $\begin{array}{c}\text { Compost } \\
\text { amendment rate } \\
\left(\mathrm{Mg} \mathrm{ha}^{-1}\right)\end{array}$ & $\%$ moisture & pH & {$\left[\mathrm{NH}_{4}{ }^{+}\right]\left(\mathrm{mg} \mathrm{N} \mathrm{kg} \mathrm{soil}{ }^{-1}\right)$} & $\begin{array}{l}\text { Soluble carbon (mg C kg } \\
\left.\text { soil }^{-1}\right)\end{array}$ \\
\hline 0 & $15.05(0.32)^{\mathrm{a}}$ & $5.91(0.06)^{\mathrm{a}}$ & $22.29(11.19)^{\mathrm{a}}$ & $54.35(2.57)^{\mathrm{a}}$ \\
\hline 11.2 & $15.45(0.39)^{\mathrm{a}}$ & $6.14(0.08)^{b}$ & $11.47(4.17)^{\mathrm{a}}$ & $58.92(4.49)^{\mathrm{a}}$ \\
\hline 22.4 & $15.83(0.07)^{\mathrm{a}}$ & $6.44(0.16)^{b c}$ & $20.06(12.21)^{\mathrm{a}}$ & $67.12(8.78)^{\mathrm{a}}$ \\
\hline 44.8 & $15.60(0.24)^{\mathrm{a}}$ & $6.77(0.05)^{\mathrm{cd}}$ & $19.54(11.11)^{\mathrm{a}}$ & $53.97(1.95)^{\mathrm{a}}$ \\
\hline 89.6 & $15.40(0.33)^{\mathrm{a}}$ & $6.92(0.09)^{\mathrm{d}}$ & $12.60(4.32)^{\mathrm{a}}$ & $70.81(2.53)^{\mathrm{a}}$ \\
\hline
\end{tabular}


Table 6. Average values by treatment level for biochemical assays. Standard errors are in parentheses. Values in a column not connected by the same letter are significantly different using Tukey's HSD.

\begin{tabular}{|c|c|c|c|c|}
\hline $\begin{array}{c}\text { Compost } \\
\text { amendment } \\
\text { rate }\left(\mathrm{Mg} \mathrm{ha}^{-1}\right)\end{array}$ & $\underset{\left.\operatorname{kg~soil}^{-1}\right)}{\operatorname{MBC}\left(\mathrm{mg} \mathrm{C}^{-}\right.}$ & $\begin{array}{l}\text { DNA (mg DNA } \\
\left.\quad \operatorname{kg~soil~}^{-1}\right)\end{array}$ & 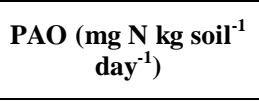 & $\underset{\left.\text { day }^{-1}\right)}{\text { PMN }}$ \\
\hline 0 & $164.7(13.3)^{\mathrm{a}}$ & $3.36(0.38)^{\mathrm{a}}$ & $1.1(0.37)^{\mathrm{a}}$ & $19.3(1.00)^{\mathrm{a}}$ \\
\hline 11.2 & $170.5(6.80)^{\mathrm{a}}$ & $4.14(0.18)^{\mathrm{ab}}$ & $1.5(0.41)^{\mathrm{a}}$ & $23.9(2.14)^{\mathrm{a}}$ \\
\hline 22.4 & $177.8(23.8)^{\mathrm{a}}$ & $4.85(0.35)^{b c}$ & $3.19(1.01)^{\mathrm{a}}$ & $32.7(3.00)^{\mathrm{b}}$ \\
\hline 44.8 & $220.8(24.5)^{\mathrm{a}}$ & $5.32(0.26)^{b c}$ & $1.8(0.25)^{\mathrm{a}}$ & $28.8(0.47)^{\mathrm{ab}}$ \\
\hline 89.6 & $212.1(16.5)^{\mathrm{a}}$ & $5.55(0.29)^{\mathrm{c}}$ & $2.73(0.79)^{\mathrm{a}}$ & $32.4(3.5)^{b}$ \\
\hline
\end{tabular}


Table 7. Relative abundance (expressed as a percentage of the total abundance) of archaeal OTUs obtained using T-RFLP from the different plots. Plots are organized by treatment level.

\begin{tabular}{|c|c|c|c|c|c|c|c|c|c|c|c|c|c|c|c|c|c|c|c|c|c|c|c|}
\hline $\begin{array}{c}\text { Compost } \\
\text { amendment } \\
\text { rate }(\mathrm{Mg} \\
\left.\mathrm{ha}^{-1}\right) \\
\end{array}$ & Plot & $\begin{array}{r}\text { AluI } \\
205 \\
\end{array}$ & $\begin{array}{c}\text { AluI } \\
207 \\
\end{array}$ & $\begin{array}{c}\text { AluI } \\
258 \\
\end{array}$ & $\begin{array}{r}\text { AluI } \\
284 \\
\end{array}$ & $\begin{array}{c}\text { AluI } \\
284(2)\end{array}$ & $\begin{array}{r}\text { AluI } \\
285 \\
\end{array}$ & $\begin{array}{c}\text { AluI } \\
327 \\
\end{array}$ & $\begin{array}{r}\text { AluI } \\
562 \\
\end{array}$ & $\begin{array}{c}\text { AluI } \\
609 \\
\end{array}$ & $\begin{array}{c}\text { AciI } \\
168 \\
\end{array}$ & $\begin{array}{c}\text { AciI } \\
203 \\
\end{array}$ & $\begin{array}{l}\text { AciI } \\
204 \\
\end{array}$ & $\begin{array}{c}\text { AciI } \\
\mathbf{3 7 8} \\
\end{array}$ & $\begin{array}{c}\text { AciI } \\
403 \\
\end{array}$ & $\begin{array}{c}\text { MboI } \\
326 \\
\end{array}$ & $\begin{array}{c}\text { MboI } \\
327\end{array}$ & $\begin{array}{c}\text { MboI } \\
\mathbf{3 2 8} \\
\end{array}$ & $\begin{array}{c}\text { MboI } \\
366 \\
\end{array}$ & $\begin{array}{c}\text { MboI } \\
\mathbf{3 6 7} \\
\end{array}$ & $\begin{array}{c}\text { MboI } \\
417 \\
\end{array}$ & $\begin{array}{c}\text { MboI } \\
441 \\
\end{array}$ & $\begin{array}{c}\text { MboI } \\
442 \\
\end{array}$ \\
\hline 0 & 9 & 7.9 & 0.0 & 27.7 & 0.0 & 29.9 & 24.0 & 0.0 & 0.0 & 10.6 & 25.3 & 0.0 & 0.0 & 56.9 & 17.8 & 0.0 & 18.0 & 26.7 & 0.0 & 7.8 & 27.2 & 20.3 & 0.0 \\
\hline 0 & 25 & 18.3 & 0.0 & 53.7 & 0.0 & 28.0 & 0.0 & 0.0 & 0.0 & 0.0 & 0.0 & 18.4 & 8.0 & 73.6 & 0.0 & 0.0 & 0.0 & 29.2 & 0.0 & 29.4 & 41.4 & 0.0 & 0.0 \\
\hline 0 & 26 & 16.2 & 0.0 & 77.3 & 0.0 & 6.5 & 0.0 & 0.0 & 0.0 & 0.0 & 0.0 & 8.4 & 0.0 & 91.6 & 0.0 & 0.0 & 0.0 & 22.0 & 0.0 & 0.0 & 78.0 & 0.0 & 0.0 \\
\hline 11.2 & 2 & 10.4 & 0.0 & 55.9 & 0.0 & 0.0 & 33.7 & 0.0 & 0.0 & 0.0 & 31.3 & 10.4 & 0.0 & 58.3 & 0.0 & 0.0 & 0.0 & 19.3 & 0.0 & 8.6 & 42.2 & 30.0 & 0.0 \\
\hline 11.2 & 5 & 7.9 & 0.0 & 64.4 & 0.0 & 0.0 & 15.3 & 0.0 & 0.0 & 12.5 & 12.7 & 0.0 & 0.0 & 65.3 & 22.0 & 0.0 & 21.6 & 11.8 & 0.0 & 0.0 & 52.8 & 13.8 & 0.0 \\
\hline 11.2 & 6 & 12.1 & 0.0 & 54.2 & 0.0 & 0.0 & 26.2 & 0.0 & 0.0 & 7.5 & 17.9 & 0.0 & 0.0 & 68.0 & 14.1 & 0.0 & 14.2 & 16.9 & 0.0 & 6.2 & 41.0 & 21.7 & 0.0 \\
\hline 11.2 & 19 & 8.8 & 0.0 & 60.1 & 5.7 & 12.3 & 13.1 & 0.0 & 0.0 & 0.0 & 17.5 & 0.0 & 0.0 & 82.5 & 0.0 & 0.0 & 0.0 & 13.3 & 6.9 & 12.9 & 48.8 & 18.1 & 0.0 \\
\hline 22.4 & 4 & 13.5 & 0.0 & 61.0 & 0.0 & 0.0 & 0.0 & 0.0 & 15.8 & 9.8 & 0.0 & 0.0 & 0.0 & 83.8 & 16.2 & 0.0 & 21.4 & 17.6 & 0.0 & 0.0 & 61.0 & 0.0 & 0.0 \\
\hline 22.4 & 10 & 0.0 & 0.0 & 44.6 & 0.0 & 17.8 & 22.2 & 0.0 & 0.0 & 15.4 & 22.7 & 0.0 & 0.0 & 54.5 & 22.8 & 0.0 & 30.6 & 0.0 & 0.0 & 9.9 & 35.9 & 23.5 & 0.0 \\
\hline 22.4 & 20 & 12.2 & 0.0 & 41.2 & 8.2 & 17.3 & 21.1 & 0.0 & 0.0 & 0.0 & 19.9 & 9.2 & 0.0 & 70.9 & 0.0 & 0.0 & 0.0 & 21.0 & 9.2 & 17.7 & 30.0 & 22.1 & 0.0 \\
\hline 22.4 & 24 & 18.7 & 8.6 & 63.5 & 0.0 & 0.0 & 0.0 & 0.0 & 9.3 & 0.0 & 0.0 & 0.0 & 0.0 & 100.0 & 0.0 & 0.0 & 0.0 & 25.1 & 0.0 & 0.0 & 74.9 & 0.0 & 0.0 \\
\hline 44.8 & 28 & 21.0 & 0.0 & 69.6 & 0.0 & 0.0 & 0.0 & 0.0 & 9.4 & 0.0 & 0.0 & 0.0 & 0.0 & 100.0 & 0.0 & 0.0 & 0.0 & 31.9 & 0.0 & 0.0 & 59.3 & 8.8 & 0.0 \\
\hline 44.8 & 29 & 23.1 & 0.0 & 76.9 & 0.0 & 0.0 & 0.0 & 0.0 & 0.0 & 0.0 & 0.0 & 0.0 & 0.0 & 89.5 & 10.5 & 0.0 & 13.6 & 28.1 & 0.0 & 0.0 & 58.3 & 0.0 & 0.0 \\
\hline 44.8 & 30 & 20.4 & 0.0 & 66.5 & 0.0 & 0.0 & 0.0 & 0.0 & 13.0 & 0.0 & 0.0 & 0.0 & 0.0 & 100.0 & 0.0 & 0.0 & 11.5 & 27.8 & 0.0 & 0.0 & 60.7 & 0.0 & 0.0 \\
\hline 44.8 & 33 & 18.1 & 0.0 & 67.9 & 0.0 & 0.0 & 0.0 & 14.0 & 0.0 & 0.0 & 0.0 & 0.0 & 0.0 & 79.4 & 20.6 & 0.0 & 24.7 & 18.2 & 0.0 & 0.0 & 47.7 & 0.0 & 9.4 \\
\hline 89.6 & 1 & 18.3 & 0.0 & 67.8 & 0.0 & 0.0 & 0.0 & 0.0 & 13.8 & 0.0 & 0.0 & 0.0 & 0.0 & 86.6 & 13.4 & 0.0 & 18.2 & 20.7 & 0.0 & 0.0 & 61.2 & 0.0 & 0.0 \\
\hline 89.6 & 3 & 23.4 & 0.0 & 76.6 & 0.0 & 0.0 & 0.0 & 0.0 & 0.0 & 0.0 & 0.0 & 0.0 & 0.0 & 87.6 & 12.4 & 0.0 & 17.2 & 27.9 & 0.0 & 0.0 & 54.9 & 0.0 & 0.0 \\
\hline 89.6 & 23 & 16.9 & 0.0 & 72.5 & 0.0 & 0.0 & 0.0 & 0.0 & 10.6 & 0.0 & 0.0 & 0.0 & 0.0 & 100.0 & 0.0 & 0.0 & 0.0 & 76.5 & 0.0 & 0.0 & 0.0 & 0.0 & 23.5 \\
\hline 89.6 & 37 & 14.1 & 0.0 & 65.1 & 0.0 & 0.0 & 20.8 & 0.0 & 0.0 & 0.0 & 0.0 & 0.0 & 0.0 & 100.0 & 0.0 & 9.8 & 0.0 & 22.8 & 0.0 & 0.0 & 46.2 & 21.2 & 0.0 \\
\hline
\end{tabular}


Table 8. Average relative abundance (expressed as the percentage of the total abundance) of each archaeal OTU for each treatment level. Standard errors are in parentheses.

Compost Amendment Rate (Mg ha $\left.{ }^{-1}\right)$

\begin{tabular}{|c|c|c|c|c|c|c|}
\hline $\begin{array}{c}\text { Restriction } \\
\text { Enzyme }\end{array}$ & $\begin{array}{c}\text { Length (base } \\
\text { pairs) }\end{array}$ & $\mathbf{0}$ & 11.2 & 22.4 & 44.8 & 89.6 \\
\hline AluI & 205 & $14.1(3.2)$ & $9.8(0.9)$ & $11.1(4.0)$ & $20.7(1.0)$ & $18.2(2.0)$ \\
\hline AluI & 207 & 0.0 & 0.0 & $2.1(2.1)$ & 0.0 & 0.0 \\
\hline AluI & 258 & $52.9(14.3)$ & $58.7(2.3)$ & $52.6(5.6)$ & $70.2(2.3)$ & $70.5(2.5)$ \\
\hline AluI & 284 & 0.0 & $1.4(1.4)$ & $2.0(2.0)$ & 0.0 & 0.0 \\
\hline AluI & $284(2)$ & $21.5(7.5)$ & $3.1(3.1)$ & $8.8(5.1)$ & 0.0 & 0.0 \\
\hline AluI & 285 & $8.0(8.0)$ & $22.1(4.8)$ & $10.8(6.2)$ & 0.0 & $5.2(5.2)$ \\
\hline AluI & 327 & 0.0 & 0.0 & 0.0 & $3.5(3.5)$ & 0.0 \\
\hline AluI & 562 & 0.0 & 0.0 & $6.3(3.8)$ & $5.6(3.3)$ & $6.1(3.6)$ \\
\hline AluI & 609 & $3.5(3.5)$ & $5.0(3.1)$ & $6.3(3.8)$ & 0.0 & 0.0 \\
\hline AciI & 168 & $8.4(8.4)$ & $19.9(4.0)$ & $10.6(6.2)$ & 0.0 & 0.0 \\
\hline AciI & 203 & $8.9(5.3)$ & $2.6(2.6)$ & $2.3(2.3)$ & 0.0 & 0.0 \\
\hline AciI & 204 & $2.7(2.7)$ & 0.0 & 0.0 & 0.0 & 0.0 \\
\hline AciI & 378 & $74.1(10.0)$ & $68.5(5.1)$ & $77.3(9.7)$ & $92.2(4.9)$ & $93.6(3.7)$ \\
\hline AciI & 403 & $5.9(5.9)$ & $9.0(5.5)$ & $9.7(5.8)$ & $7.8(4.9)$ & $6.4(3.7)$ \\
\hline MboI & 326 & 0.0 & 0.0 & 0.0 & 0.0 & $2.4(2.4)$ \\
\hline MboI & 327 & $6.0(6.0)$ & $8.9(5.4)$ & $13.0(7.7)$ & $12.4(5.1)$ & $8.8(5.1)$ \\
\hline MboI & 328 & $26.0(2.1)$ & $15.3(1.7)$ & $15.9(5.5)$ & $26.5(2.9)$ & $37.0(13.3)$ \\
\hline MboI & 366 & 0.0 & $1.7(1.7)$ & $2.3(2.3)$ & 0.0 & 0.0 \\
\hline MboI & 367 & $12.4(8.8)$ & $6.9(2.7)$ & $6.9(4.3)$ & 0.0 & 0.0 \\
\hline MboI & 417 & $48.9(15.1)$ & $46.2(2.8)$ & $50.5(10.6)$ & $56.5(3.0)$ & $40.6(13.9)$ \\
\hline MboI & 441 & $6.8(6.8)$ & $20.9(3.4)$ & $11.4(6.6)$ & $2.2(2.2)$ & $5.3(5.3)$ \\
\hline MboI & 442 & 0.0 & 0.0 & 0.0 & $2.4(2.4)$ & $5.9(5.9)$ \\
\hline
\end{tabular}


Table 9. Relative abundance of bacterial OTUs (expressed as a percentage of the total abundance) detected using restriction enzymes AciI and HaeIII. Plots are organized by treatment level.

\begin{tabular}{|c|c|c|c|c|c|c|c|c|c|c|c|c|c|c|c|c|c|c|}
\hline $\begin{array}{c}\text { Compost } \\
\text { amendment } \\
\text { rate }(\mathrm{Mg} \\
\left.\mathrm{ha}^{-1}\right)\end{array}$ & Plot & $\begin{array}{c}\text { AciI } \\
64\end{array}$ & $\begin{array}{c}\text { AciI } \\
90\end{array}$ & $\begin{array}{c}\text { AciI } \\
93\end{array}$ & $\begin{array}{c}\text { AciI } \\
96\end{array}$ & $\begin{array}{c}\text { AciI } \\
112\end{array}$ & $\begin{array}{c}\text { AciI } \\
120\end{array}$ & $\begin{array}{c}\text { AciI } \\
125\end{array}$ & $\begin{array}{c}\text { AciI } \\
191\end{array}$ & $\begin{array}{c}\text { AciI } \\
210\end{array}$ & $\begin{array}{c}\text { AciI } \\
234\end{array}$ & $\begin{array}{c}\text { AciI } \\
484\end{array}$ & $\begin{array}{c}\text { HaeIII } \\
140\end{array}$ & $\begin{array}{c}\text { HaeIII } \\
159\end{array}$ & $\begin{array}{c}\text { HaeIII } \\
160\end{array}$ & $\begin{array}{c}\text { HaeIII } \\
161\end{array}$ & $\begin{array}{c}\text { HaeIII } \\
167\end{array}$ & $\begin{array}{c}\text { HaeIII } \\
174\end{array}$ \\
\hline 0 & 1 & 0.0 & 0.0 & 0.0 & 38.5 & 11.9 & 0.0 & 33.1 & 16.5 & 0.0 & 0.0 & 0.0 & 11.1 & 17.6 & 13.2 & 0.0 & 43.6 & 14.5 \\
\hline 0 & 2 & 0.0 & 19.4 & 15.8 & 41.8 & 0.0 & 0.0 & 23.0 & 0.0 & 0.0 & 0.0 & 0.0 & 0.0 & 44.8 & 0.0 & 0.0 & 55.2 & 0.0 \\
\hline 0 & 4 & 0.0 & 0.0 & 0.0 & 46.7 & 0.0 & 0.0 & 26.7 & 0.0 & 0.0 & 0.0 & 0.0 & 0.0 & 70.6 & 0.0 & 0.0 & 29.4 & 0.0 \\
\hline 11.2 & 6 & 0.0 & 14.1 & 16.1 & 27.5 & 7.3 & 10.1 & 15.1 & 9.8 & 0.0 & 0.0 & 0.0 & 0.0 & 20.0 & 32.0 & 18.4 & 29.6 & 0.0 \\
\hline 11.2 & 9 & 0.0 & 0.0 & 0.0 & 55.9 & 17.8 & 0.0 & 26.2 & 0.0 & 0.0 & 0.0 & 0.0 & 0.0 & 43.5 & 23.6 & 0.0 & 33.0 & 0.0 \\
\hline 22.4 & 10 & 0.0 & 21.9 & 0.0 & 39.2 & 0.0 & 0.0 & 22.3 & 16.6 & 0.0 & 0.0 & 0.0 & 0.0 & 11.7 & 30.2 & 25.4 & 32.8 & 0.0 \\
\hline 22.4 & 20 & 0.0 & 0.0 & 0.0 & 28.1 & 10.2 & 0.0 & 13.5 & 12.7 & 0.0 & 7.3 & 11.9 & 0.0 & 0.0 & 33.5 & 22.4 & 44.1 & 0.0 \\
\hline 22.4 & 23 & 0.0 & 9.0 & 0.0 & 47.8 & 8.8 & 0.0 & 21.3 & 13.1 & 0.0 & 0.0 & 0.0 & 10.7 & 18.3 & 17.9 & 0.0 & 53.1 & 0.0 \\
\hline 22.4 & 24 & 9.4 & 0.0 & 0.0 & 46.4 & 0.0 & 0.0 & 16.5 & 18.0 & 9.7 & 0.0 & 0.0 & 0.0 & 9.3 & 0.0 & 0.0 & 90.7 & 0.0 \\
\hline 44.8 & 25 & 0.0 & 0.0 & 0.0 & 46.2 & 7.5 & 0.0 & 18.6 & 18.6 & 0.0 & 0.0 & 0.0 & 7.2 & 0.0 & 0.0 & 0.0 & 92.8 & 0.0 \\
\hline 44.8 & 26 & 0.0 & 0.0 & 0.0 & 67.1 & 0.0 & 0.0 & 32.9 & 0.0 & 0.0 & 0.0 & 0.0 & 0.0 & 22.7 & 21.4 & 13.4 & 42.4 & 0.0 \\
\hline 44.8 & 28 & 0.0 & 0.0 & 0.0 & 64.0 & 0.0 & 0.0 & 23.6 & 12.4 & 0.0 & 0.0 & 0.0 & 0.0 & 18.1 & 13.1 & 9.7 & 59.1 & 0.0 \\
\hline 44.8 & 29 & 0.0 & 0.0 & 0.0 & 61.8 & 0.0 & 0.0 & 24.7 & 13.4 & 0.0 & 0.0 & 0.0 & 0.0 & 26.6 & 0.0 & 0.0 & 73.4 & 0.0 \\
\hline 89.6 & 30 & 0.0 & 0.0 & 0.0 & 57.2 & 0.0 & 0.0 & 24.0 & 18.8 & 0.0 & 0.0 & 0.0 & 0.0 & 19.2 & 25.6 & 16.1 & 39.1 & 0.0 \\
\hline 89.6 & 33 & 0.0 & 0.0 & 0.0 & 75.1 & 0.0 & 0.0 & 0.0 & 24.9 & 0.0 & 0.0 & 0.0 & 0.0 & 27.0 & 20.2 & 19.4 & 33.4 & 0.0 \\
\hline
\end{tabular}


Table 10. Relative abundance (expressed as a percentage of the total abundance) of bacterial OTUs detected using restriction enzyme RsaI. Plots are organized by treatment level.

\begin{tabular}{|c|c|c|c|c|c|c|c|c|c|c|c|c|c|c|c|c|c|c|c|c|}
\hline $\begin{array}{c}\text { Compost } \\
\text { amendment } \\
\text { rate }(\mathrm{Mg} \\
\left.\text { ha }^{-1}\right) \\
\end{array}$ & Plot & $\begin{array}{c}\text { RsaI } \\
\mathbf{5 0} \\
\end{array}$ & $\begin{array}{c}\text { RsaI } \\
51 \\
\end{array}$ & $\begin{array}{c}\text { RsaI } \\
56 \\
\end{array}$ & $\begin{array}{c}\text { RsaI } \\
73 \\
\end{array}$ & $\begin{array}{c}\text { RsaI } \\
74 \\
\end{array}$ & $\begin{array}{c}\text { RsaI } \\
79 \\
\end{array}$ & $\begin{array}{c}\text { RsaI } \\
83 \\
\end{array}$ & $\begin{array}{c}\text { RsaI } \\
84 \\
\end{array}$ & $\begin{array}{c}\text { RsaI } \\
151 \\
\end{array}$ & $\begin{array}{c}\text { RsaI } \\
198 \\
\end{array}$ & $\begin{array}{c}\text { RsaI } \\
199 \\
\end{array}$ & $\begin{array}{c}\text { RsaI } \\
201 \\
\end{array}$ & $\begin{array}{c}\text { RsaI } \\
202 \\
\end{array}$ & $\begin{array}{c}\text { RsaI } \\
203 \\
\end{array}$ & $\begin{array}{c}\text { RsaI } \\
210 \\
\end{array}$ & $\begin{array}{c}\text { RsaI } \\
211 \\
\end{array}$ & $\begin{array}{c}\text { RsaI } \\
242 \\
\end{array}$ & $\begin{array}{c}\text { RsaI } \\
250 \\
\end{array}$ & $\begin{array}{c}\text { RsaI } \\
253 \\
\end{array}$ \\
\hline 0 & 1 & 36.6 & 0.0 & 0.0 & 14.1 & 0.0 & 0.0 & 0.0 & 0.0 & 0.0 & 0.0 & 0.0 & 0.0 & 23.1 & 0.0 & 0.0 & 0.0 & 26.2 & 0.0 & 0.0 \\
\hline 0 & 2 & 0.0 & 0.0 & 17.1 & 0.0 & 0.0 & 11.8 & 0.0 & 0.0 & 0.0 & 11.7 & 0.0 & 0.0 & 28.4 & 10.4 & 0.0 & 0.0 & 20.7 & 0.0 & 0.0 \\
\hline 0 & 4 & 0.0 & 25.4 & 0.0 & 0.0 & 0.0 & 0.0 & 0.0 & 0.0 & 34.6 & 0.0 & 0.0 & 0.0 & 0.0 & 0.0 & 0.0 & 0.0 & 40.0 & 0.0 & 0.0 \\
\hline 11.2 & 6 & 0.0 & 0.0 & 0.0 & 0.0 & 0.0 & 0.0 & 0.0 & 0.0 & 0.0 & 0.0 & 0.0 & 0.0 & 59.6 & 0.0 & 0.0 & 17.6 & 22.9 & 0.0 & 0.0 \\
\hline 11.2 & 9 & 0.0 & 0.0 & 0.0 & 0.0 & 0.0 & 0.0 & 0.0 & 0.0 & 0.0 & 0.0 & 0.0 & 0.0 & 39.7 & 0.0 & 0.0 & 0.0 & 60.3 & 0.0 & 0.0 \\
\hline 22.4 & 10 & 18.5 & 0.0 & 0.0 & 0.0 & 0.0 & 0.0 & 8.6 & 0.0 & 0.0 & 0.0 & 37.3 & 0.0 & 25.6 & 0.0 & 0.0 & 0.0 & 10.0 & 0.0 & 0.0 \\
\hline 22.4 & 20 & 23.3 & 0.0 & 0.0 & 0.0 & 0.0 & 0.0 & 0.0 & 0.0 & 0.0 & 0.0 & 0.0 & 0.0 & 30.8 & 0.0 & 10.1 & 12.9 & 22.8 & 0.0 & 0.0 \\
\hline 22.4 & 23 & 0.0 & 0.0 & 0.0 & 0.0 & 0.0 & 0.0 & 0.0 & 0.0 & 0.0 & 0.0 & 0.0 & 0.0 & 25.5 & 0.0 & 13.3 & 22.7 & 20.7 & 0.0 & 17.8 \\
\hline 22.4 & 24 & 0.0 & 0.0 & 0.0 & 0.0 & 0.0 & 0.0 & 0.0 & 17.8 & 0.0 & 0.0 & 41.9 & 0.0 & 30.2 & 0.0 & 0.0 & 10.1 & 0.0 & 0.0 & 0.0 \\
\hline 44.8 & 25 & 0.0 & 0.0 & 0.0 & 0.0 & 0.0 & 0.0 & 0.0 & 0.0 & 0.0 & 42.2 & 0.0 & 0.0 & 29.4 & 8.6 & 0.0 & 0.0 & 11.1 & 8.7 & 0.0 \\
\hline 44.8 & 26 & 0.0 & 0.0 & 0.0 & 0.0 & 0.0 & 0.0 & 0.0 & 0.0 & 0.0 & 0.0 & 0.0 & 0.0 & 77.3 & 0.0 & 0.0 & 22.7 & 0.0 & 0.0 & 0.0 \\
\hline 44.8 & 28 & 0.0 & 0.0 & 0.0 & 0.0 & 0.0 & 0.0 & 0.0 & 0.0 & 0.0 & 0.0 & 36.7 & 0.0 & 38.4 & 0.0 & 0.0 & 14.4 & 10.5 & 0.0 & 0.0 \\
\hline 44.8 & 29 & 0.0 & 0.0 & 0.0 & 0.0 & 0.0 & 0.0 & 0.0 & 0.0 & 0.0 & 0.0 & 0.0 & 22.8 & 35.6 & 15.2 & 0.0 & 14.9 & 11.5 & 0.0 & 0.0 \\
\hline 89.6 & 30 & 0.0 & 0.0 & 0.0 & 0.0 & 7.2 & 0.0 & 0.0 & 0.0 & 0.0 & 0.0 & 46.1 & 0.0 & 28.6 & 0.0 & 0.0 & 7.6 & 10.5 & 0.0 & 0.0 \\
\hline 89.6 & 33 & 0.0 & 0.0 & 0.0 & 0.0 & 0.0 & 0.0 & 0.0 & 0.0 & 0.0 & 0.0 & 0.0 & 0.0 & 100.0 & 0.0 & 0.0 & 0.0 & 0.0 & 0.0 & 0.0 \\
\hline
\end{tabular}


Table 11. Average relative abundance (expressed as a percentage of the total abundance) of each bacterial OTU for each treatment level. Standard errors are in parentheses.

Compost amendment rate $\left(\mathrm{Mg} \mathrm{ha}^{-1}\right)$

\begin{tabular}{|c|c|c|c|c|c|c|}
\hline $\begin{array}{c}\text { Restriction } \\
\text { Enzyme }\end{array}$ & $\begin{array}{c}\text { Length (base } \\
\text { pairs) }\end{array}$ & 0 & 11.2 & 22.4 & 44.8 & 89.6 \\
\hline AciI & 64 & 0.0 & 0.0 & $2.3(2.3)$ & 0.0 & 0.0 \\
\hline AciI & 90 & $6.5(6.5)$ & $7.1(7.1)$ & $7.7(5.2)$ & 0.0 & 0.0 \\
\hline AciI & 93 & $5.3(5.3)$ & $8.1(8.1)$ & 0.0 & 0.0 & 0.0 \\
\hline AciI & 96 & $42.3(2.4)$ & $41.7(14.2)$ & $40.4(4.5)$ & $59.8(4.7)$ & $66.1(8.9)$ \\
\hline AciI & 112 & $4.0(4.0)$ & $12.5(5.3)$ & $4.8(2.8)$ & $1.9(1.9)$ & 0.0 \\
\hline AciI & 120 & 0.0 & $5.0(5.0)$ & 0.0 & 0.0 & 0.0 \\
\hline AciI & 125 & $27.6(3.0)$ & $20.7(5.6)$ & $18.4(2.1)$ & $25.0(3.0)$ & $12.0(12.0)$ \\
\hline AciI & 191 & $5.5(5.5)$ & $4.9(4.9)$ & $15.1(1.3)$ & $11.1(3.9)$ & $21.9(3.1)$ \\
\hline AciI & 210 & 0.0 & 0.0 & $2.4(2.4)$ & 0.0 & 0.0 \\
\hline AciI & 234 & 0.0 & 0.0 & $1.8(1.8)$ & 0.0 & 0.0 \\
\hline AciI & 484 & 0.0 & 0.0 & $3.0(3.0)$ & 0.0 & 0.0 \\
\hline HaeIII & 140 & 3.7 (3.7) & 0.0 & $2.7(2.7)$ & $1.8(1.8)$ & 0.0 \\
\hline HaeIII & 159 & $44.3(15.3)$ & 31.7 (11.7) & $9.8(3.8)$ & $16.8(5.9)$ & $23.1(3.9)$ \\
\hline HaeIII & 160 & $4.4(4.4)$ & $27.8(4.2)$ & $20.4(7.6)$ & $8.6(5.3)$ & $22.9(2.7)$ \\
\hline HaeIII & 161 & 0.0 & $9.2(9.2)$ & $12.0(6.9)$ & $5.8(3.4)$ & $17.7(1.7)$ \\
\hline HaeIII & 167 & $42.7(7.5)$ & $31.3(1.7)$ & $55.2(12.6)$ & $66.9(10.7)$ & $36.2(2.8)$ \\
\hline HaeIII & 174 & $4.8(4.8)$ & 0.0 & 0.0 & 0.0 & 0.0 \\
\hline RsaI & 50 & $12.2(12.2)$ & 0.0 & $10.4(6.1)$ & 0.0 & 0.0 \\
\hline RsaI & 51 & $8.5(8.5)$ & 0.0 & 0.0 & 0.0 & 0.0 \\
\hline RsaI & 56 & $5.7(5.7)$ & 0.0 & 0.0 & 0.0 & 0.0 \\
\hline RsaI & 73 & $4.7(4.7)$ & 0.0 & 0.0 & 0.0 & 0.0 \\
\hline RsaI & 74 & 0.0 & 0.0 & 0.0 & 0.0 & $3.6(3.6)$ \\
\hline RsaI & 79 & 3.9 (3.9) & 0.0 & 0.0 & 0.0 & 0.0 \\
\hline RsaI & 83 & 0.0 & 0.0 & $2.1(2.1)$ & 0.0 & 0.0 \\
\hline RsaI & 84 & 0.0 & 0.0 & $4.5(4.5)$ & 0.0 & 0.0 \\
\hline RsaI & 151 & $11.5(11.5)$ & 0.0 & 0.0 & 0.0 & 0.0 \\
\hline RsaI & 198 & 3.9 (3.9) & 0.0 & 0.0 & 10.6 & 0.0 \\
\hline RsaI & 199 & 0.0 & 0.0 & $19.8(11.5)$ & $9.2(9.2)$ & $23.0(23.0)$ \\
\hline RsaI & 201 & 0.0 & 0.0 & 0.0 & $5.7(5.7)$ & 0.0 \\
\hline RsaI & 202 & $17.1(8.7)$ & $49.6(9.9)$ & $28.0(1.4)$ & $45.2(10.9)$ & $64.3(35.7)$ \\
\hline RsaI & 203 & $3.5(3.5)$ & 0.0 & 0.0 & $5.9(3.7)$ & 0.0 \\
\hline RsaI & 210 & 0.0 & 0.0 & $5.8(3.4)$ & 0.0 & 0.0 \\
\hline RsaI & 211 & 0.0 & $8.8(8.8)$ & $11.4(4.7)$ & $13.0(4.7)$ & $3.8(3.8)$ \\
\hline RsaI & 242 & $29.0(5.7)$ & $41.6(18.7)$ & $13.4(5.3)$ & $8.3(2.8)$ & $5.3(5.3)$ \\
\hline RsaI & 250 & 0.0 & 0.0 & 0.0 & $2.2(2.2)$ & 0.0 \\
\hline RsaI & 253 & 0.0 & 0.0 & $4.5(4.5)$ & 0.0 & 0.0 \\
\hline
\end{tabular}


Table 12. Average diversity metric values by treatment level for the AOA. Standard errors are in parentheses. While ANOVA found significant differences among treatment levels for archaeal OTU richness, Tukey's HSD found no differences between specific treatment levels.

\begin{tabular}{ccccc}
\hline $\begin{array}{c}\text { Compost amendment } \\
\text { rate }\left(\mathbf{M g ~ h a}^{-1}\right)\end{array}$ & Shannon Diversity & OTU Richness & Shannon Evenness & $\begin{array}{c}\text { Smith and Wilson } \\
\text { Evenness }\end{array}$ \\
\hline 0 & $2.02(0.24)$ & $9.7(1.8)$ & $0.81(0.05)$ & $0.69(0.10)$ \\
11.2 & $2.15(0.03)$ & $11.2(0.5)$ & $0.77(0.03)$ & $0.69(0.02)$ \\
22.4 & $2.05(0.17)$ & $10.0(1.3)$ & $0.80(0.04)$ & $0.72(0.07)$ \\
44.8 & $1.75(0.07)$ & $7.5(0.5)$ & $0.78(0.01)$ & $0.65(0.03)$ \\
89.6 & $1.73(0.07)$ & $7.2(0.5)$ & $0.78(0.01)$ & $0.67(0.02)$ \\
\hline
\end{tabular}


Table 13. Average diversity metric values by treatment level for the AOB. Standard errors are in parentheses. No parameters in this table were significantly different for different treatment levels using ANOVA and Tukey's HSD.

\begin{tabular}{ccccc}
\hline $\begin{array}{c}\text { Compost amendment } \\
\text { rate }\left(\mathbf{M g ~ h a}^{-1}\right)\end{array}$ & Shannon Diversity & OTU Richness & Shannon Evenness & $\begin{array}{c}\text { Smith and Wilson } \\
\text { Evenness }\end{array}$ \\
\hline 0 & $2.27(0.13)$ & $11.0(1.5)$ & $0.90(0.02)$ & $0.87(0.03)$ \\
11.2 & $2.25(0.24)$ & $11.0(3.0)$ & $0.90(0.03)$ & $0.86(0.04)$ \\
22.4 & $2.41(0.11)$ & $13.2(0.8)$ & $0.85(0.04)$ & $0.81(0.04)$ \\
44.8 & $2.08(0.06)$ & $10.2(0.8)$ & $0.79(0.04)$ & $0.74(0.04)$ \\
89.6 & $2.03(0.29)$ & $10.0(2.0)$ & $0.78(0.06)$ & $0.76(0.01)$ \\
\hline
\end{tabular}


Table 14.The influence of environmental variables on AOA community structure using different community similarity and diversity metrics. The metrics used were nMDS, including environmental and surface fitting, ANOSIM, Shannon diversity, and Smith and Wilson evenness metrics. + indicates a significant relationship between AOA community structure and the given variable, \pm indicates a possibly significant relationship (either p-values between 0.05 and 0.10 or positive results seen with linear regression but not ANOVA), - indicates no significant relationship, and NA indicates a comparison that was not applicable or could not be made. NA was applied to basic nMDS ordinations for MBC, PMN, and PAO because they were not categorical variables. NA was also applied to compost amendment rate for environmental and surface fitting because it was a categorical variable as well as a continuous variable.

\begin{tabular}{|c|c|c|c|c|c|c|c|}
\hline $\begin{array}{c}\text { Environmental } \\
\text { variable }\end{array}$ & nMDS & $\begin{array}{l}\text { Environmental/ } \\
\text { Surface fitting }\end{array}$ & ANOSIM & $\begin{array}{l}\text { Shannon } \\
\text { Diversity }\end{array}$ & $\begin{array}{l}\text { Shannon } \\
\text { evenness }\end{array}$ & OTU richness & $\begin{array}{c}\text { Smith and } \\
\text { Wilson } \\
\text { evenness }\end{array}$ \\
\hline $\mathrm{MBC}$ & NA & + & - & + & - & + & - \\
\hline PAO & NA & - & - & \pm & - & \pm & - \\
\hline PMN & NA & + & - & - & - & - & - \\
\hline Treatment & + & NA & \pm & \pm & - & \pm & - \\
\hline
\end{tabular}


Table 15. The influence of environmental variables on AOB community structure using different community similarity and diversity metrics. The metrics used were nMDS, including environmental and surface fitting, ANOSIM, Shannon diversity, and Smith and Wilson evenness metrics. + indicates a significant relationship between AOB community structure and the given variable, \pm indicates a possibly significant relationship (either p-values between 0.05 and 0.10 or positive results seen with linear regression but not ANOVA), - indicates no significant relationship, and NA indicates a comparison that was not applicable or could not be made. NA was applied to basic nMDS ordinations for MBC, PMN, and PAO because they were not categorical variables. NA was also applied to compost amendment rate for environmental fitting and surface fitting because it was a categorical variable as well as a continuous variable.

\begin{tabular}{|c|c|c|c|c|c|c|c|}
\hline $\begin{array}{c}\text { Environmental } \\
\text { variable }\end{array}$ & nMDS & $\begin{array}{l}\text { Environmental/ } \\
\text { Surface fitting }\end{array}$ & ANOSIM & $\begin{array}{l}\text { Shannon } \\
\text { Diversity }\end{array}$ & $\begin{array}{l}\text { Shannon } \\
\text { evenness }\end{array}$ & OTU richness & $\begin{array}{c}\text { Smith and } \\
\text { Wilson } \\
\text { evenness }\end{array}$ \\
\hline $\mathrm{MBC}$ & NA & \pm & - & - & - & + & - \\
\hline PAO & NA & + & - & - & \pm & - & - \\
\hline PMN & NA & + & + & - & + & - & + \\
\hline Treatment & \pm & NA & \pm & - & \pm & - & \pm \\
\hline
\end{tabular}




\section{Figures}

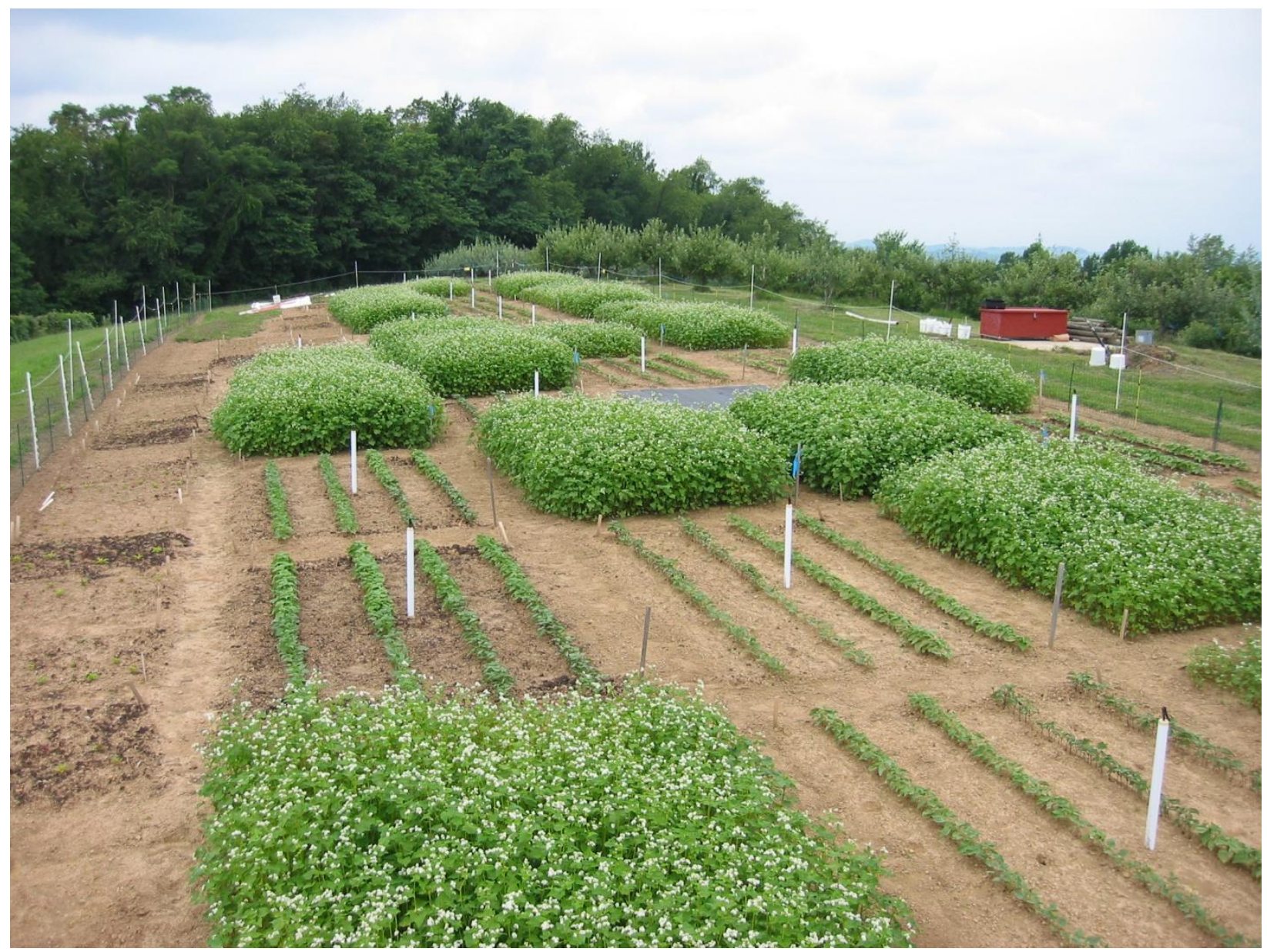

Figure 1. The 40 plots at the WVU Organic Farm compost rate trial. This photograph is from 2002, when half of the plots were planted with buckwheat and the other half planted with snap beans. Photo courtesy of Dr. Louis McDonald. 


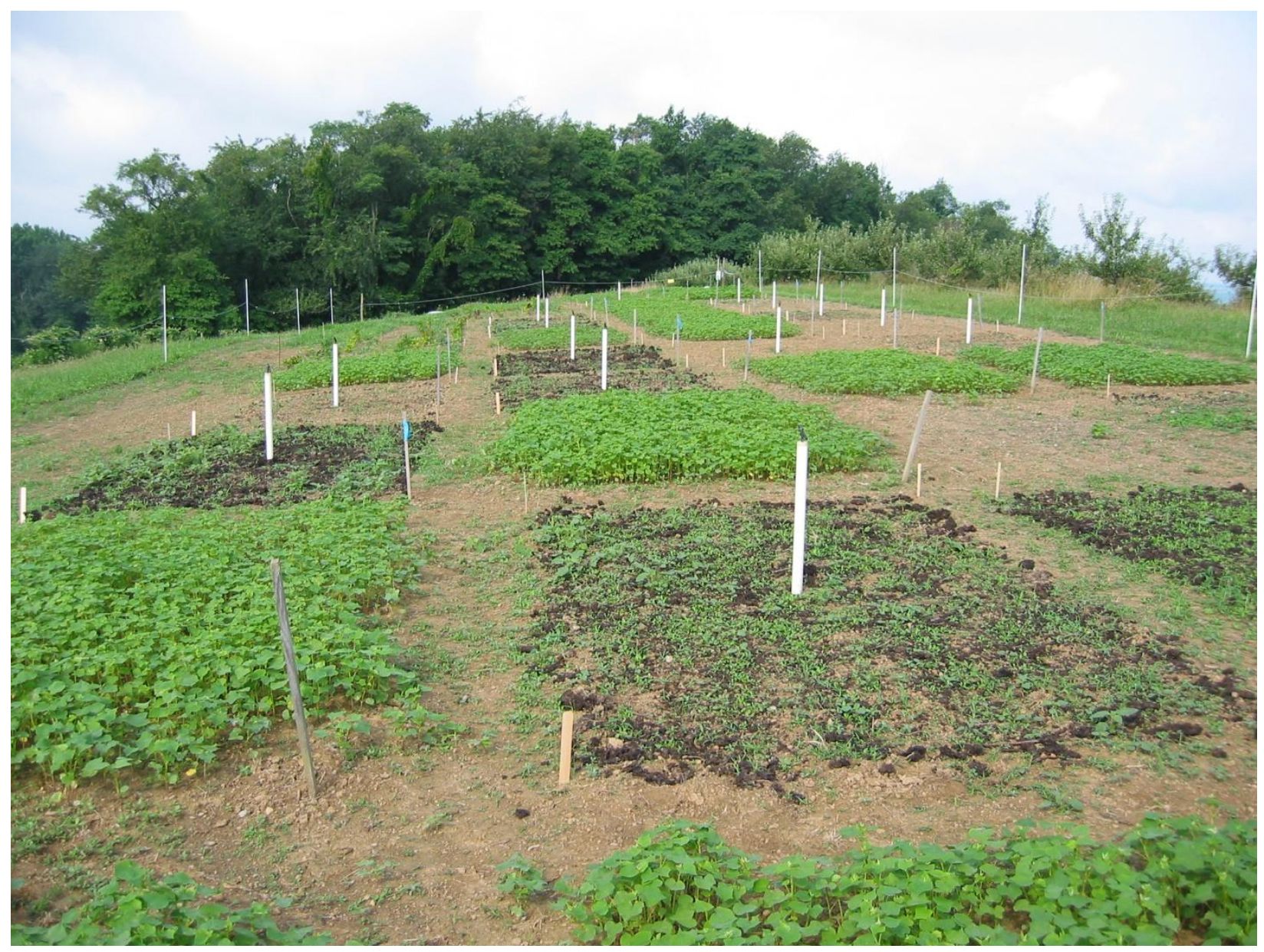

Figure 2. The different amounts of compost being added to the plots can be seen. This photograph is from 2005, when pumpkin and sunflowers were planted. Photo courtesy of Dr. Louis McDonald. 


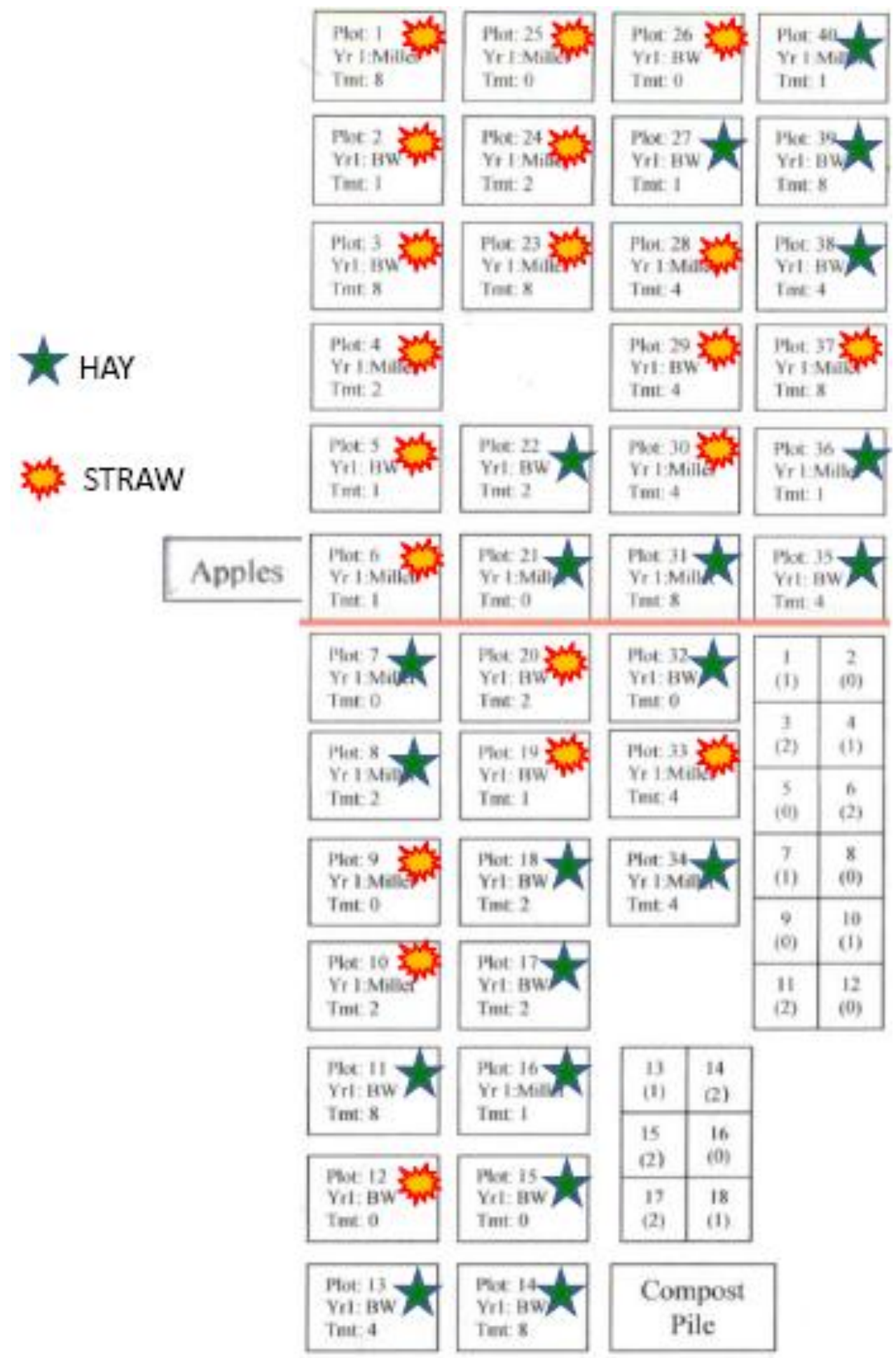

Figure 3. The layout of the compost rate trial plots. Relative to Figure 1, plots 26 and 40 are in the immediate foreground, facing in the direction of plots 13 and 14. Plots are labeled by plot number, the crop they were planted with the first year of the experiment ("BW" stands for buckwheat), and the treatment level. In this diagram, the treatments are labeled from 0 to 8 rather than 0 to 40 . These values correspond to 0 to 8 buckets of compost applied to a plot; each bucket applied is equal to $11.2 \mathrm{Mg}$ compost ha ${ }^{-1}$. Plots with stars on them had hay applied as a surface mulch in 2010; those with an orange flash had straw applied as a surface mulch in 2010. Only plots with straw mulches were sampled for this study. Figure courtesy of Dr. Eugenia Pena-Yewtukhiw. 

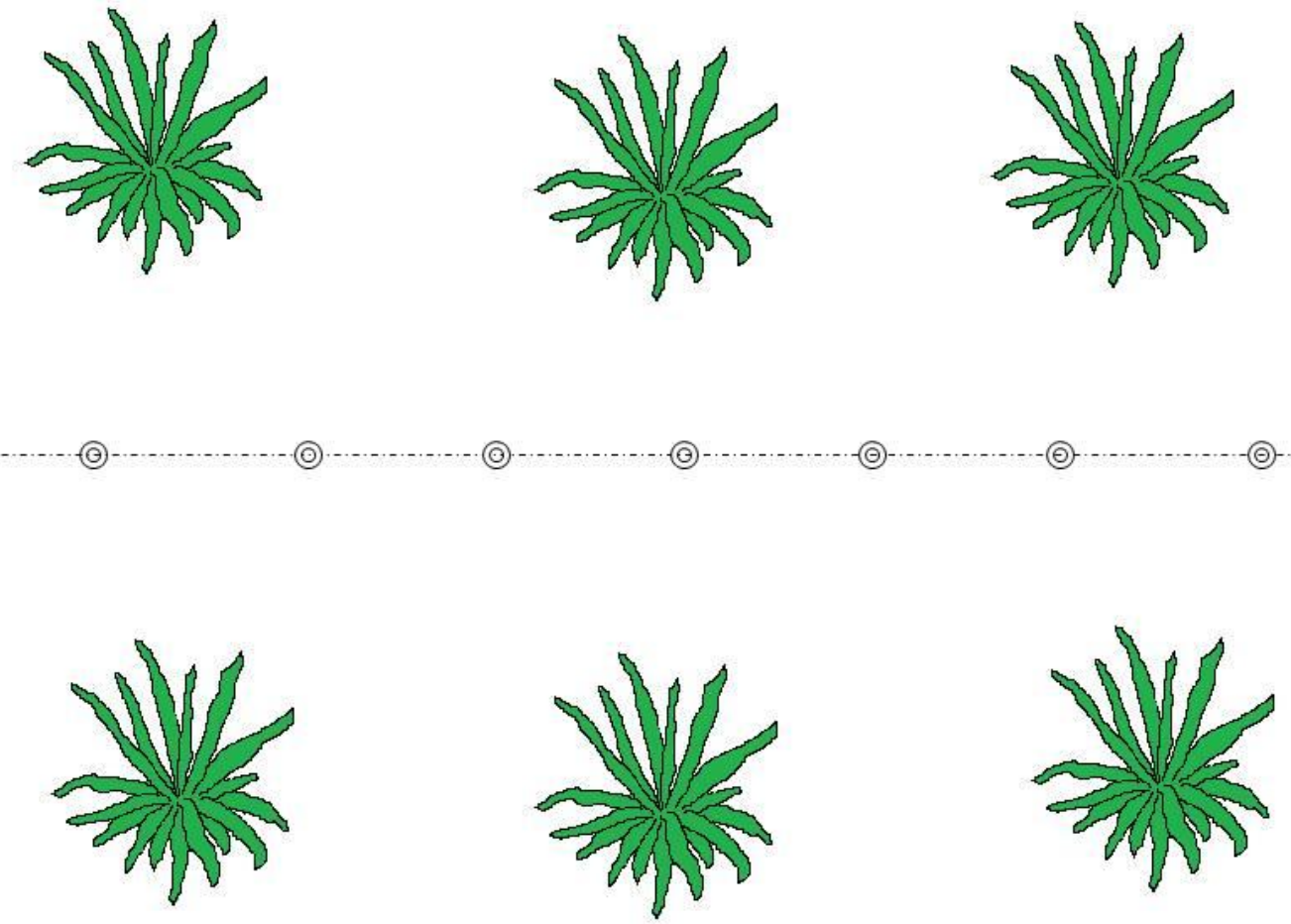

Figure 4. A diagram of the sampling strategy used for each plot. Seven cores were taken to a depth of $15 \mathrm{~cm}$ with a soil probe, starting $0.5 \mathrm{~m}$ from the end of the plot and sampling approximately every $0.5 \mathrm{~m}$. The cores were taken along a transect down the center of the plot, between the rows of Miscanthus. At the time of the sampling, the soil surface along the transect had been recently weeded and was largely bare. 
Bacteria reaction conditions:

$400 \mathrm{nM}$ each primer

$1 \mathrm{X}$ buffer

$3 \mathrm{mM} \mathrm{MgCl}_{2}$

100 ng BSA

$1.25 \cup \mathrm{Taq}$

$200 \mu \mathrm{M}$ each dNTP

150 ng DNA template

40 cycles

$55^{\circ} \mathrm{C}$ annealing

temperature

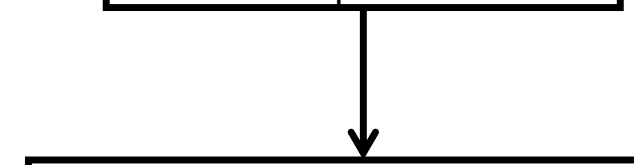

Amplified all but plots 3, 5, 12, 19, and 37

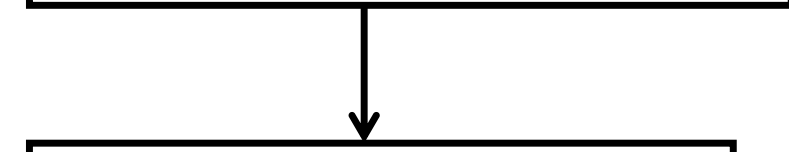

New reaction conditions:

Reduced annealing temperature to $45^{\circ} \mathrm{C}$

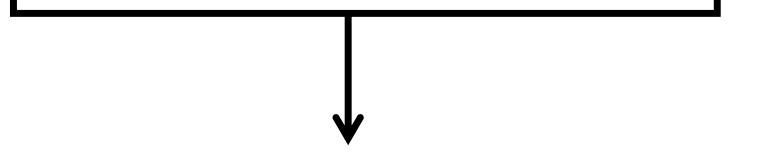

Amplified plots 3 and 5

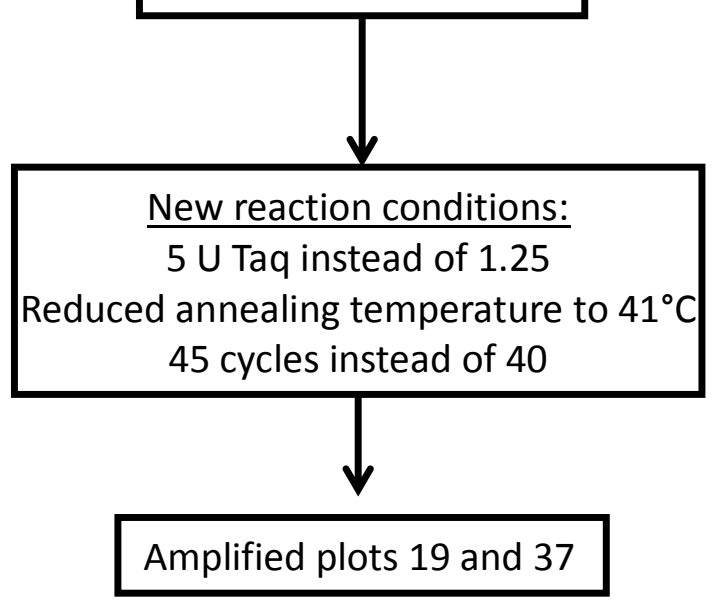

Archaea reaction conditions:

$400 \mathrm{nM}$ each primer

$1 \mathrm{X}$ buffer

$3.7 \mathrm{mM} \mathrm{MgCl}_{2}$

100 ng BSA

$1.25 \mathrm{U}$ Taq

$200 \mu \mathrm{M}$ each dNTP

150 ng DNA template

40 cycles

$55^{\circ} \mathrm{C}$ annealing

temperature

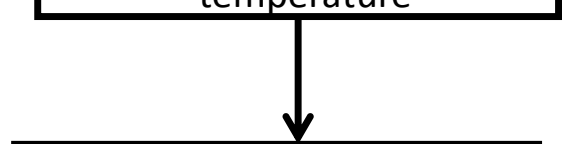

Amplified all but plots 10, 12, and 19

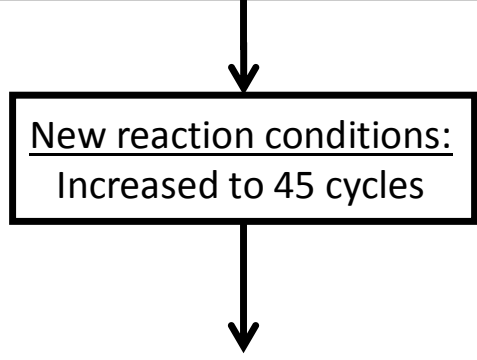

Amplified plots 10 and 19

New reaction conditions:

Increased to 50 cycles

Reduced annealing temperature

to $46^{\circ} \mathrm{C}$

$5 \mathrm{U}$ Taq instead of 1.25

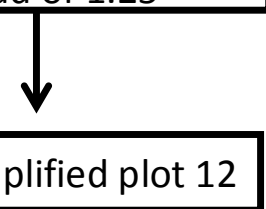

Figure 5. Flowchart of the procedures used to amplify bacterial and archaeal amoA genes. No bacterial amoA genes could be amplified in plot 12. Amplified genes from plot 12 for the archaea and plots 3, 5, 19, and 37 for the bacteria were discarded from analysis. 


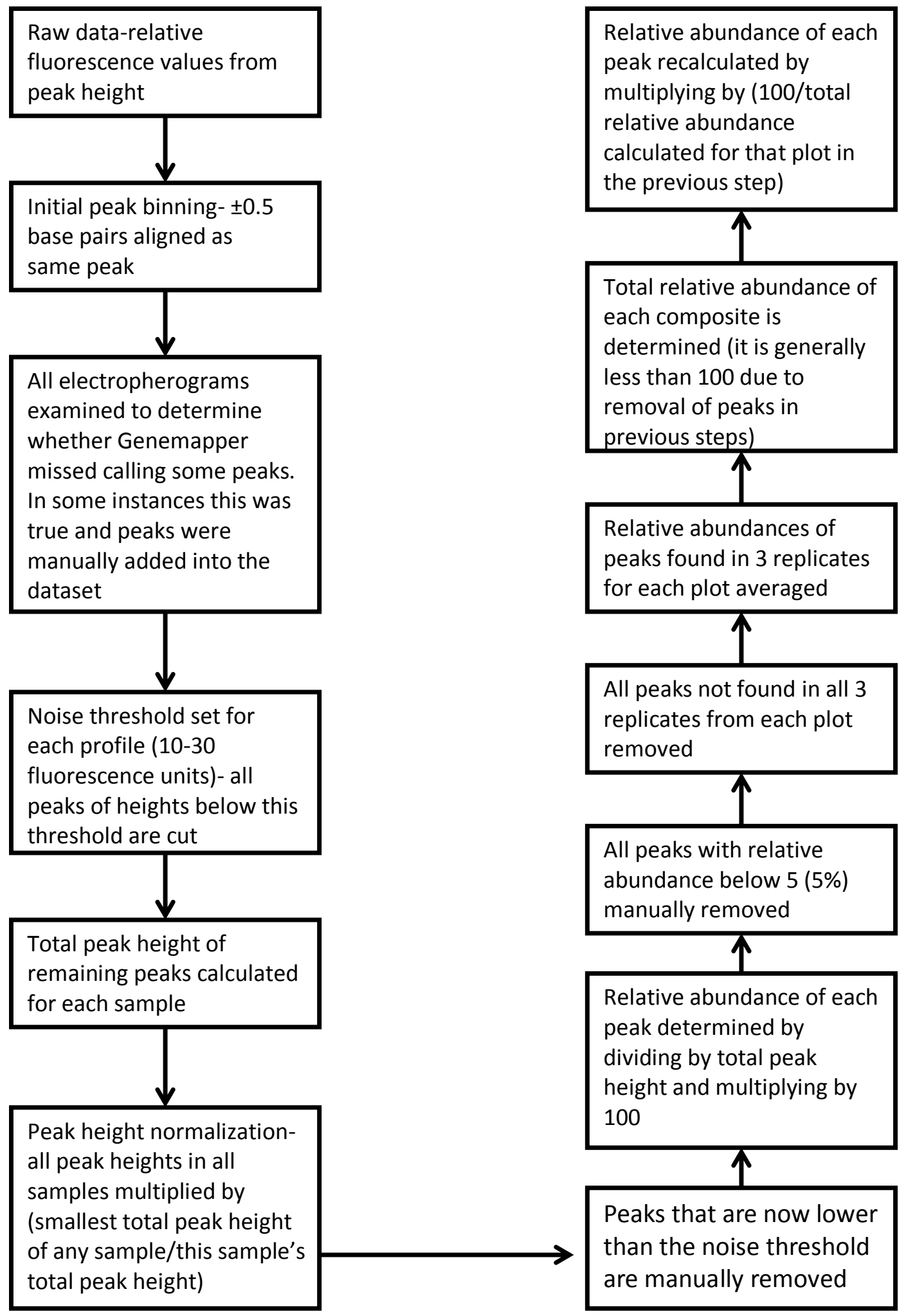

Figure 6. An outline of the procedure by which raw electropherogram data was aligned and normalized. In this figure, a sample refers to any individual electropherogram output. There were 3 replicate samples of each plot-restriction enzyme combination for the AOA and AOB. 
(A)

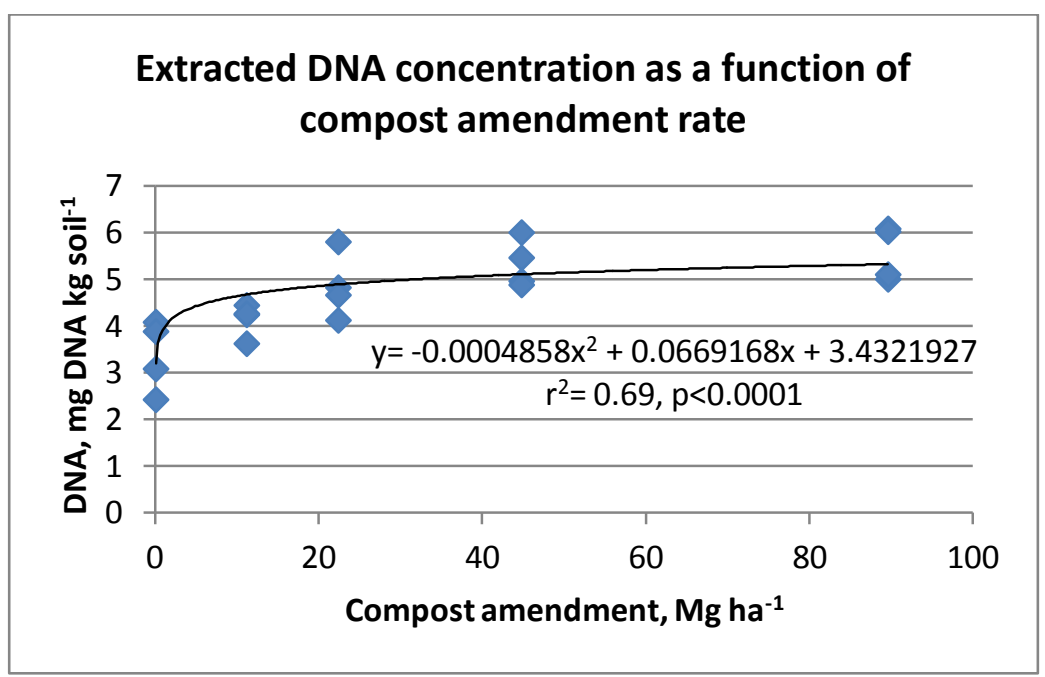

(C)

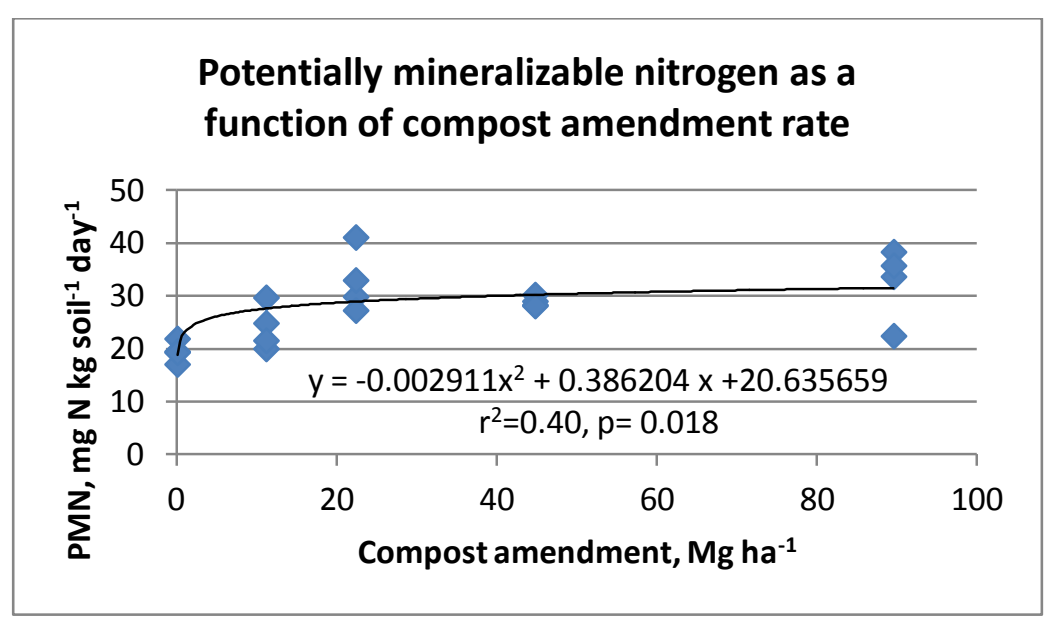

(B)

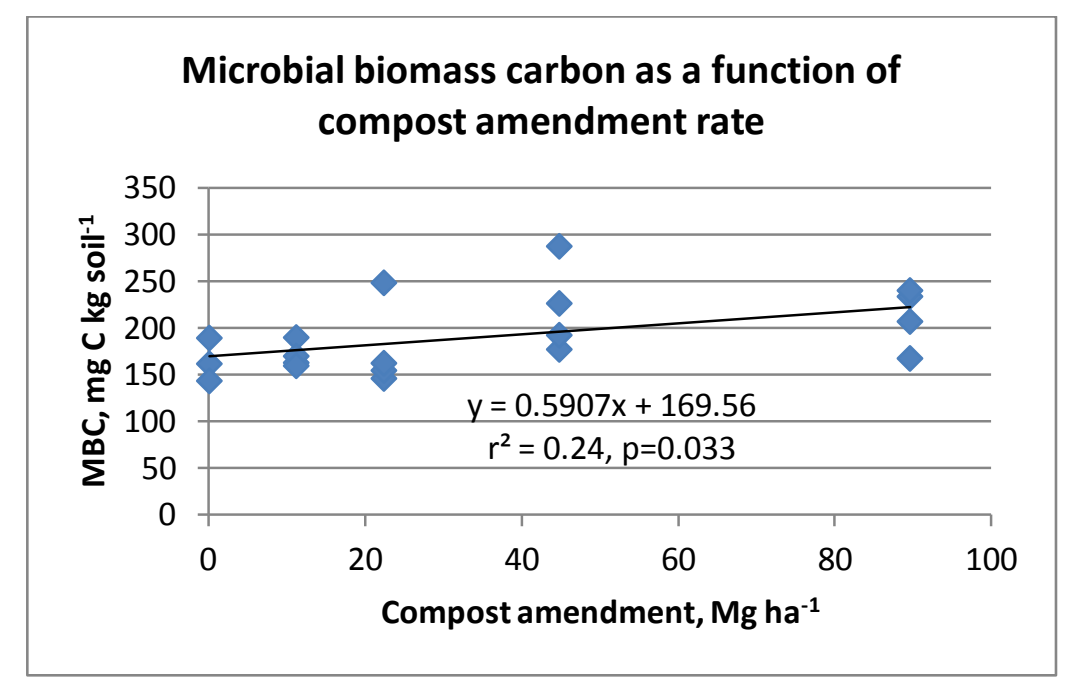

(D)

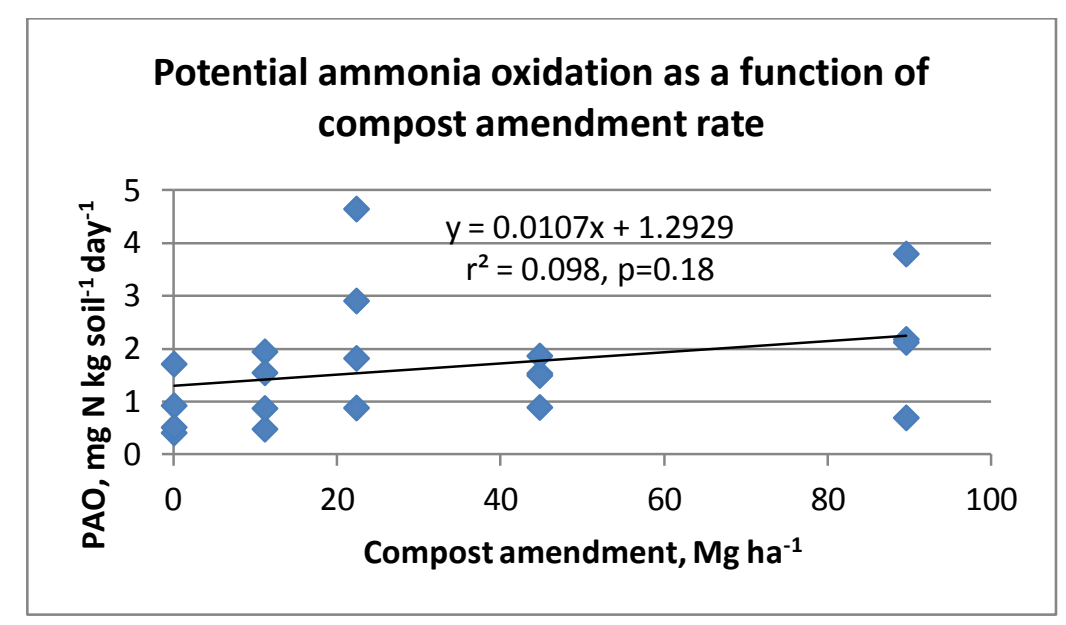

Figure 7. Linear regressions between compost amendment rate and 4 biochemical variables: (A) extracted DNA concentration, (B) microbial biomass carbon, (C) potentially mineralizable nitrogen and (D) potential ammonia oxidation. (A) and (C) were best fit with a quadratic trendline. 
(A)

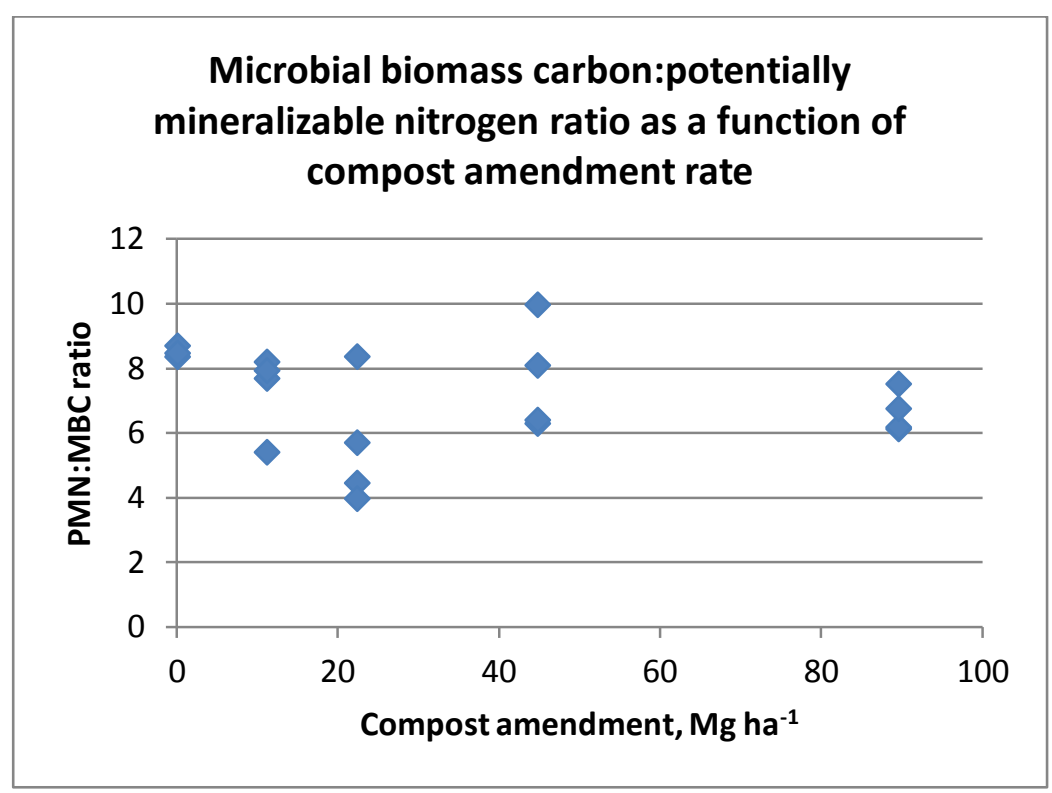

(B)

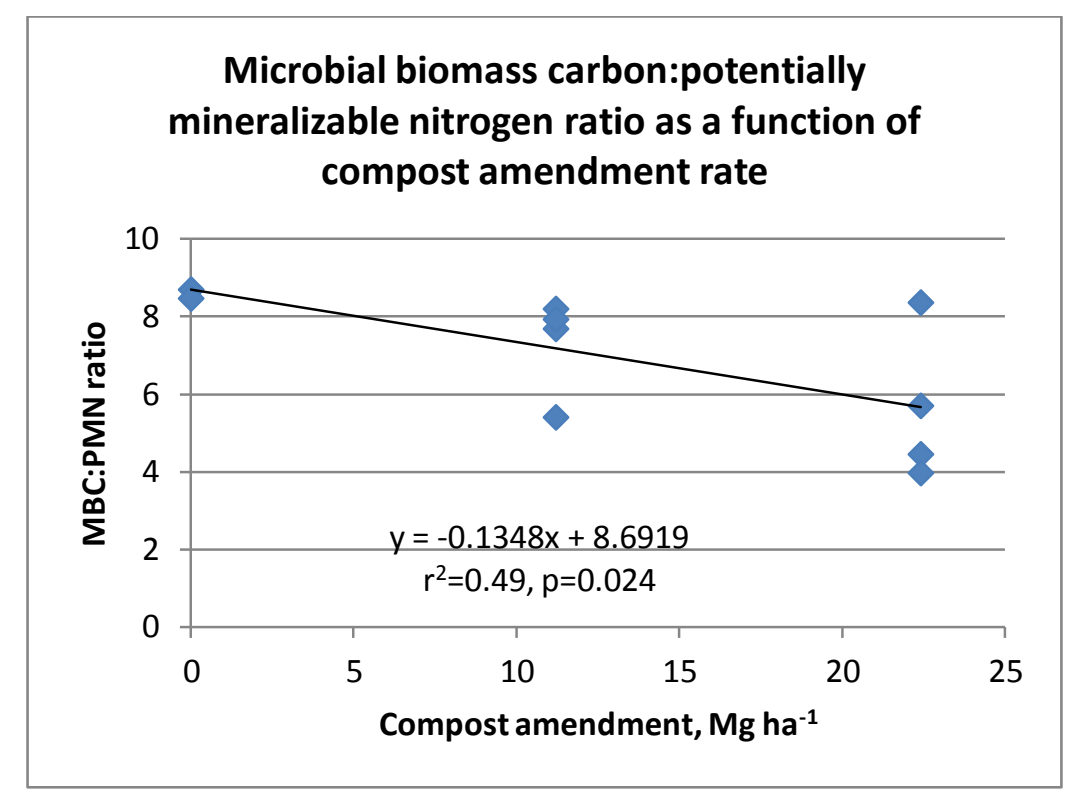

Figure 8. Linear regression of the MBC:PMN ratio as a function of compost amendment rate. (A) shows the values for the entire range of treatment levels. (B) shows the values for just the lowest three treatment levels. 
(A)

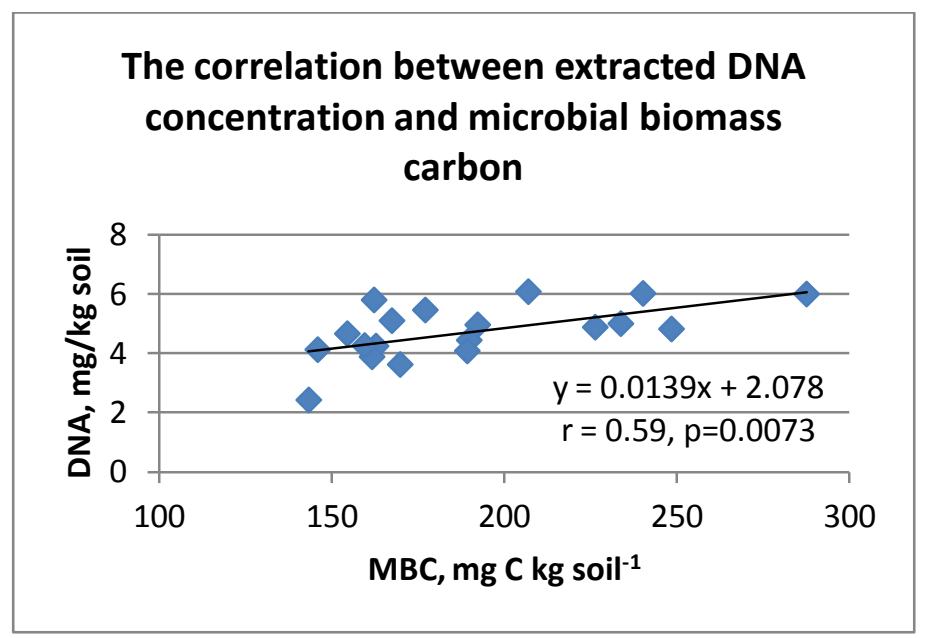

(C)

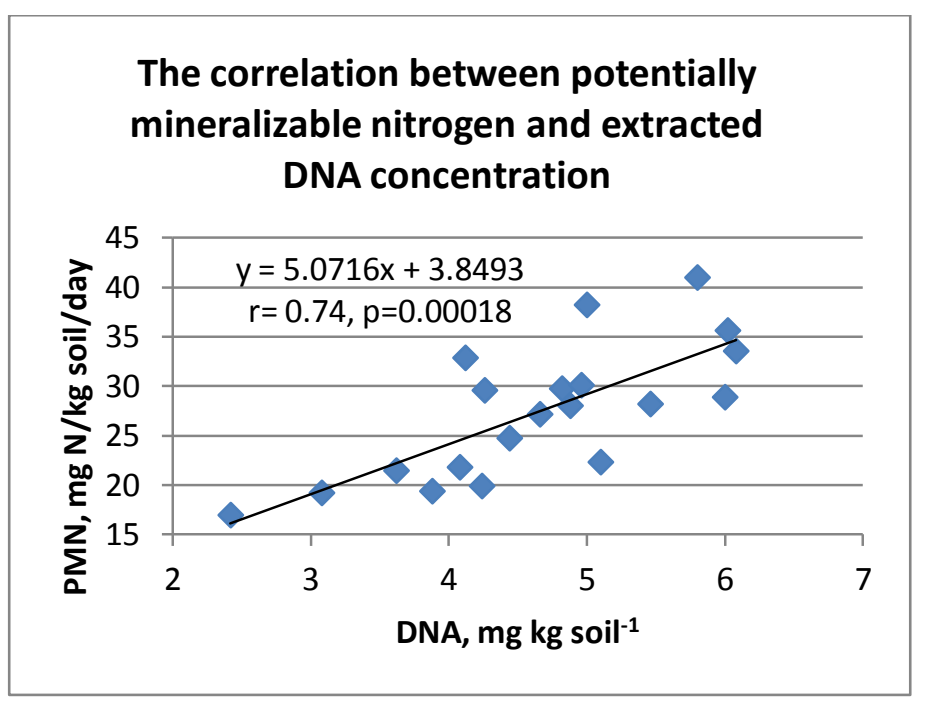

(B)

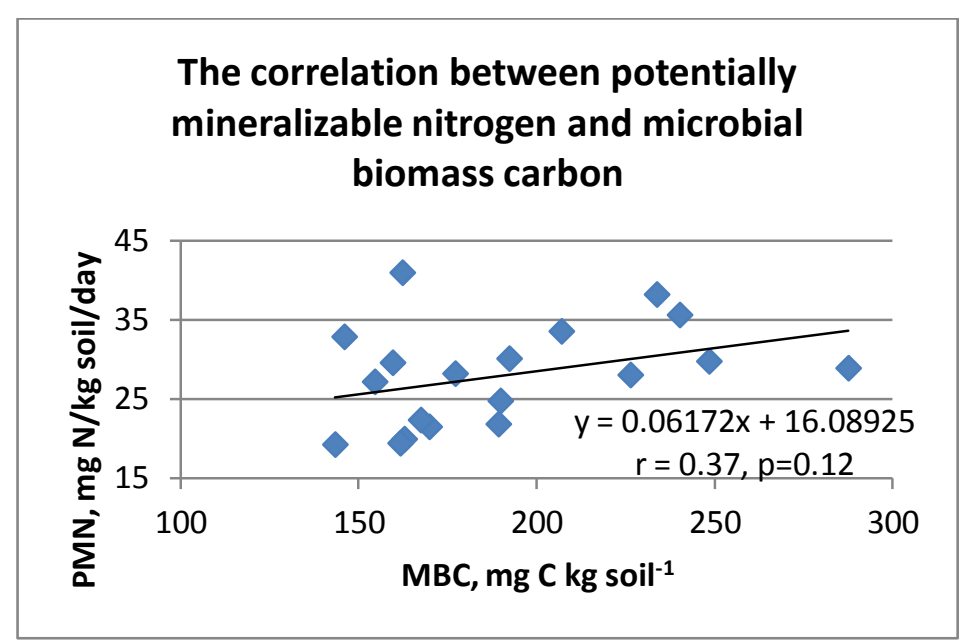

(D)

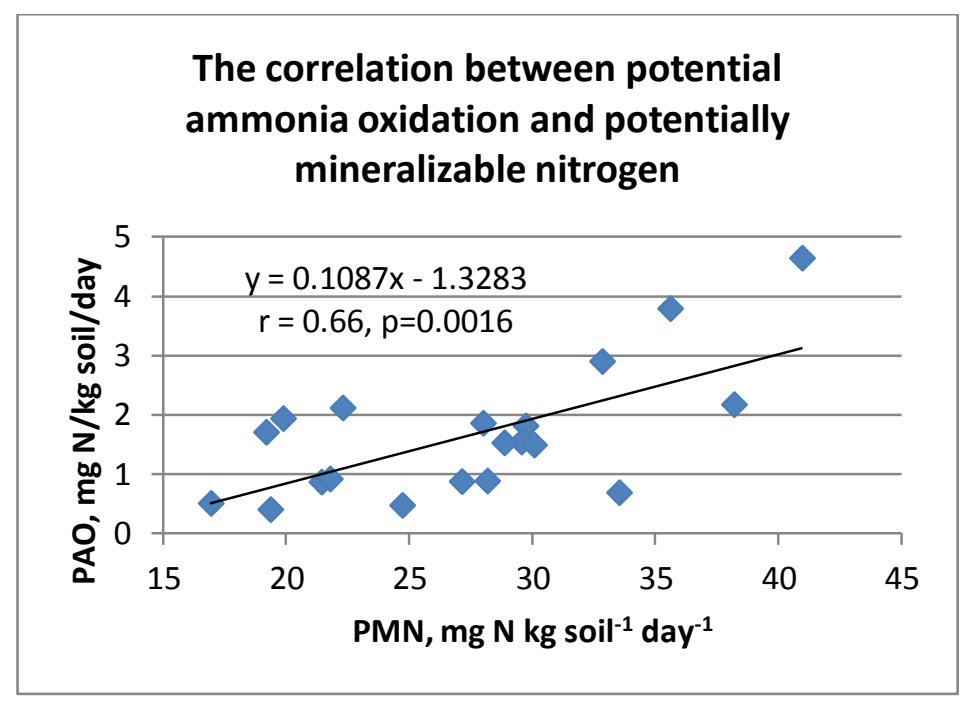

Figure 9. Significant and near-significant correlations between 4 biochemical variables: potentially mineralizable nitrogen, microbial biomass carbon, potential ammonia oxidation, and extracted DNA concentration. All trendlines were linear. 
(B)
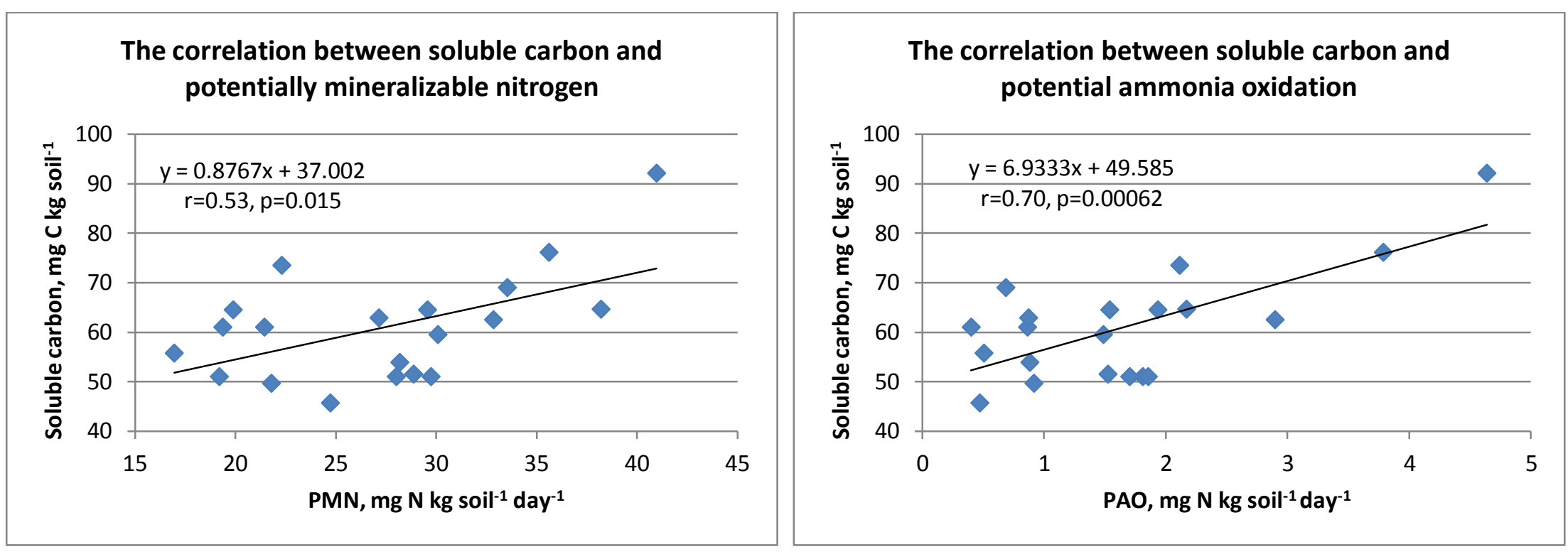

Figure 10. Correlations between soluble organic carbon concentration and nitrogen cycling rates. 

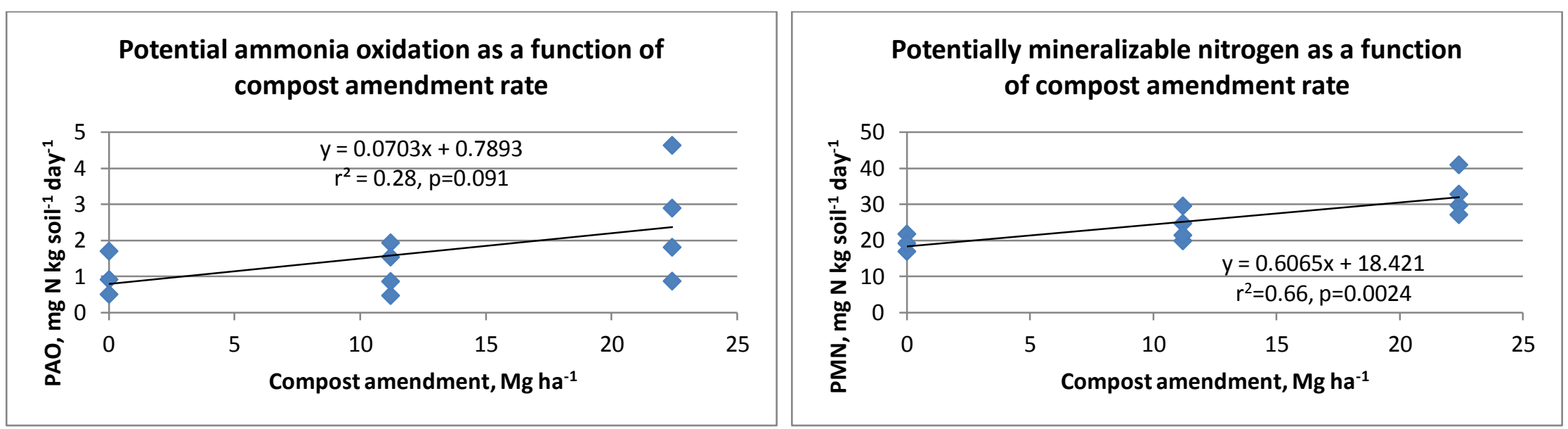

(C)

(D)
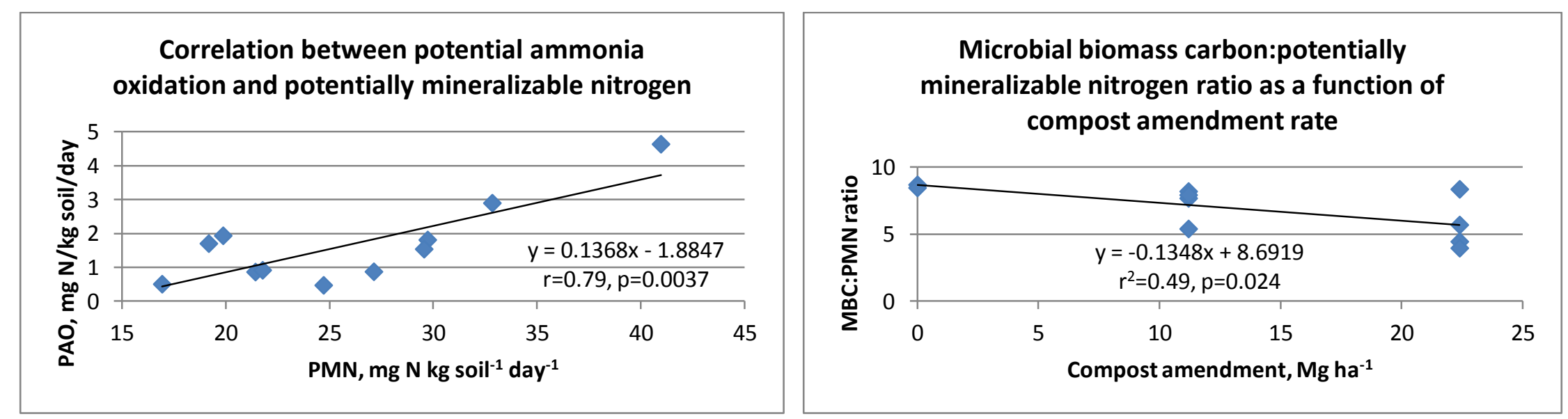

Figure 11. Select relationships between biochemical variables and compost amendment rate for the 3 lowest treatments ( 0 to $22.4 \mathrm{Mg}$ compost ha $\left.{ }^{-1}\right)$. 
(A)

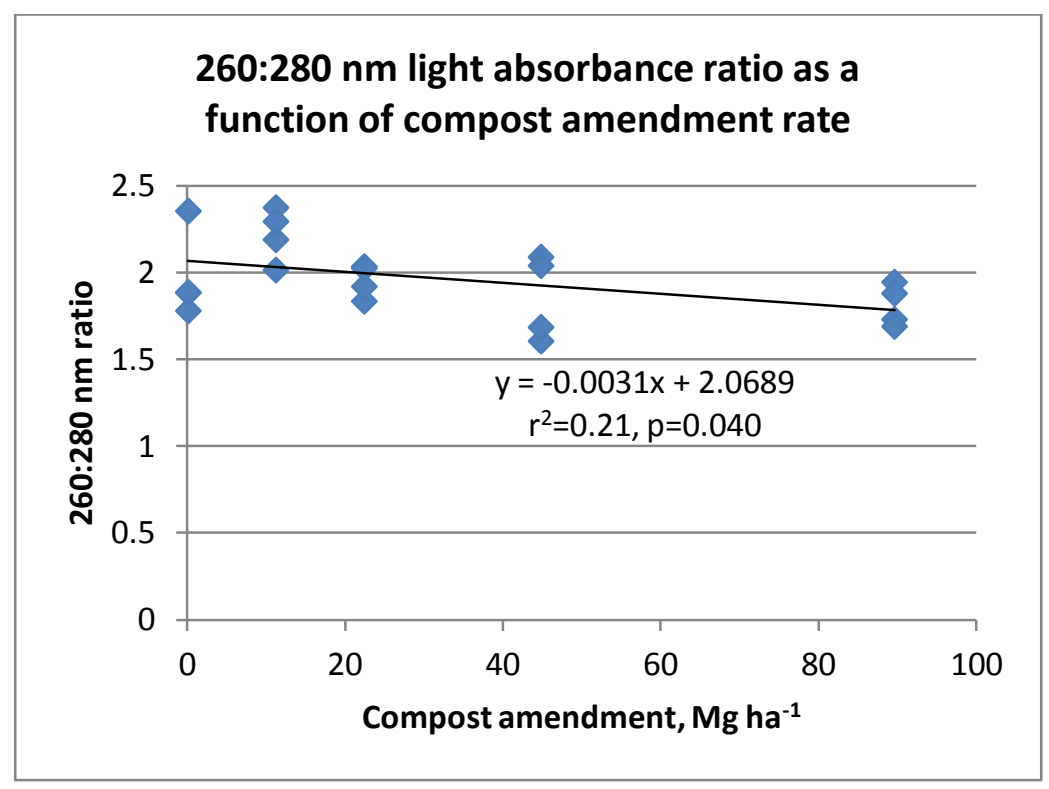

(B)

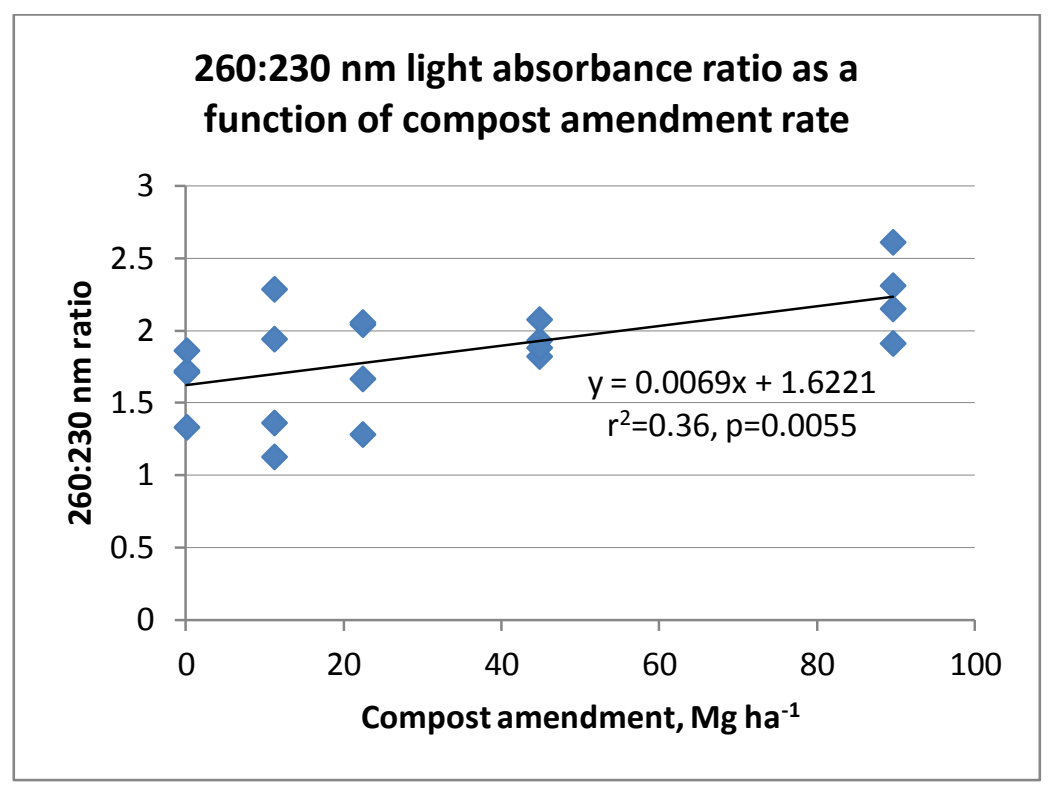

Figure 12. Light absorbance ratios of extracted DNA as a function of compost amendment rate. The 260:280 ratio is reflective of protein contamination in the DNA extracts- a value above 1.8 is ideal. The 260:230 ratio is reflective of humic acid contamination- a value above 1.5 is ideal. In neither case did values outside these ideal ranges appear to interfere with PCR. 
(A)

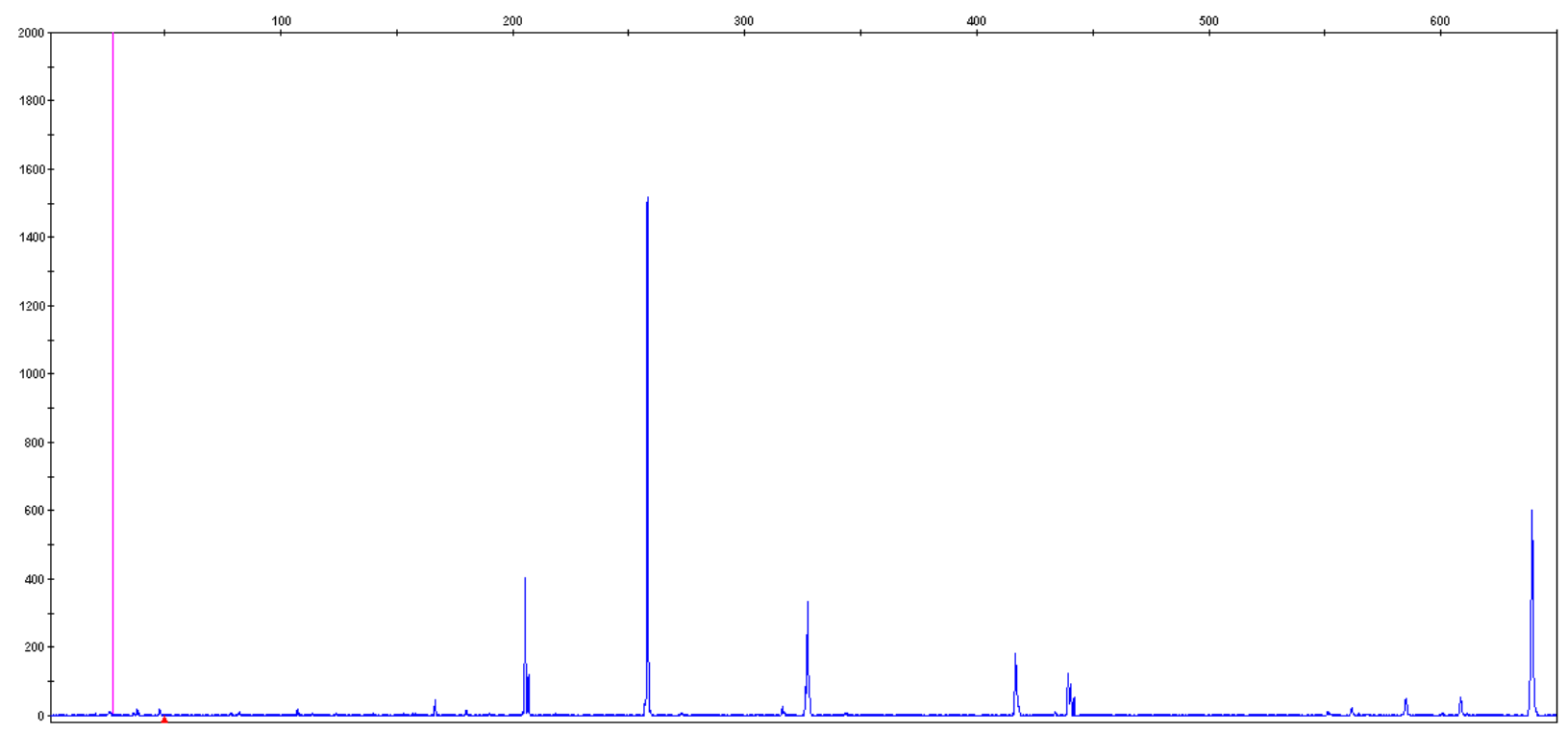

(B)

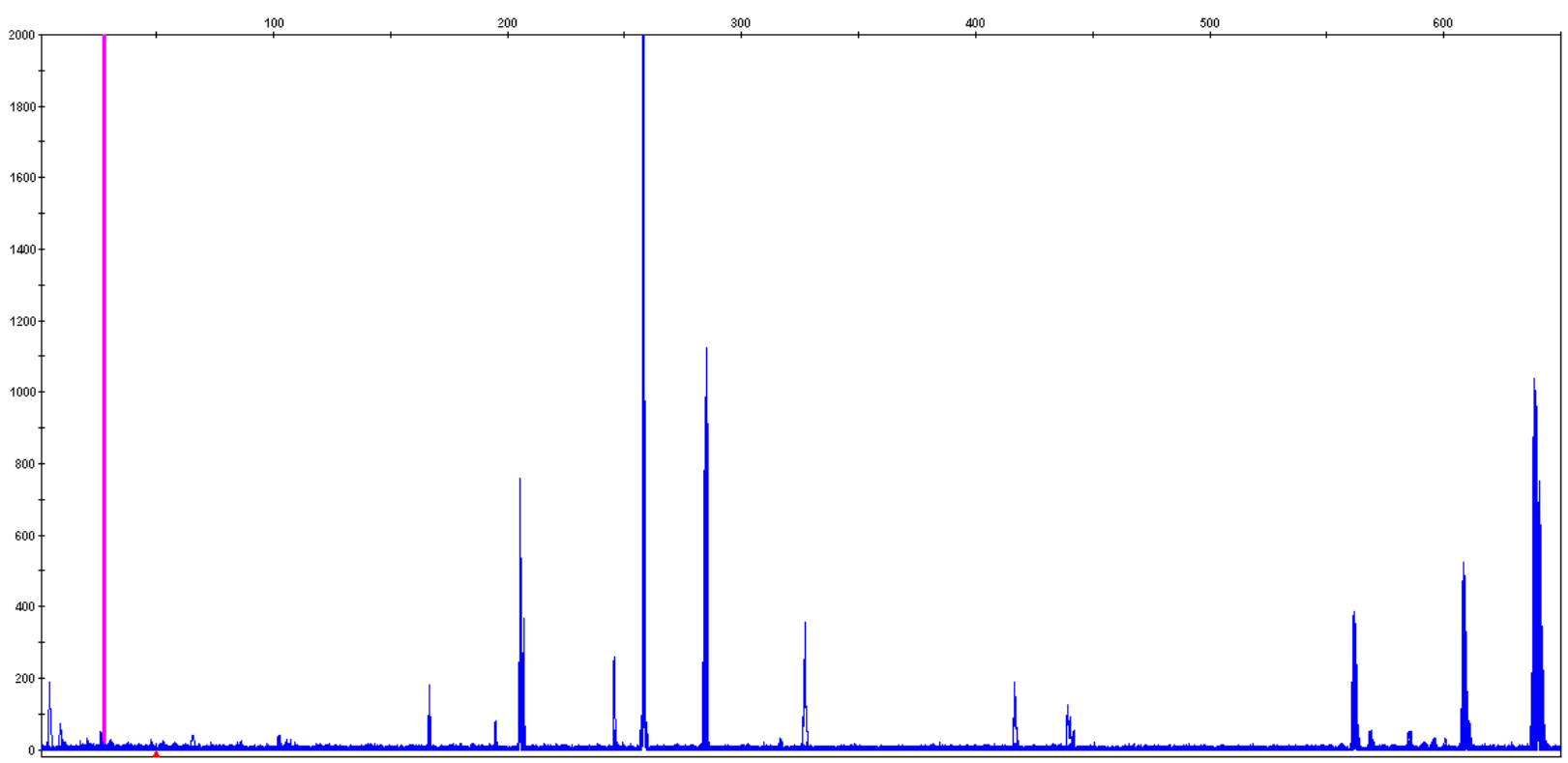

Figure 13. Sample AOA electropherograms. (A) is a representative electropherogram for one plot for the AOA using the AluI restriction enzyme in Plot 33. (B) is a composite electropherogram created in Genemapper that shows every peak obtained for the archaea in all plots using the AluI restriction enzyme. Values on the $\mathrm{X}$ axis are peak length in base pairs. Values on the $\mathrm{Y}$ axis are relative fluorescence of the peaks in relative fluorescence units. 


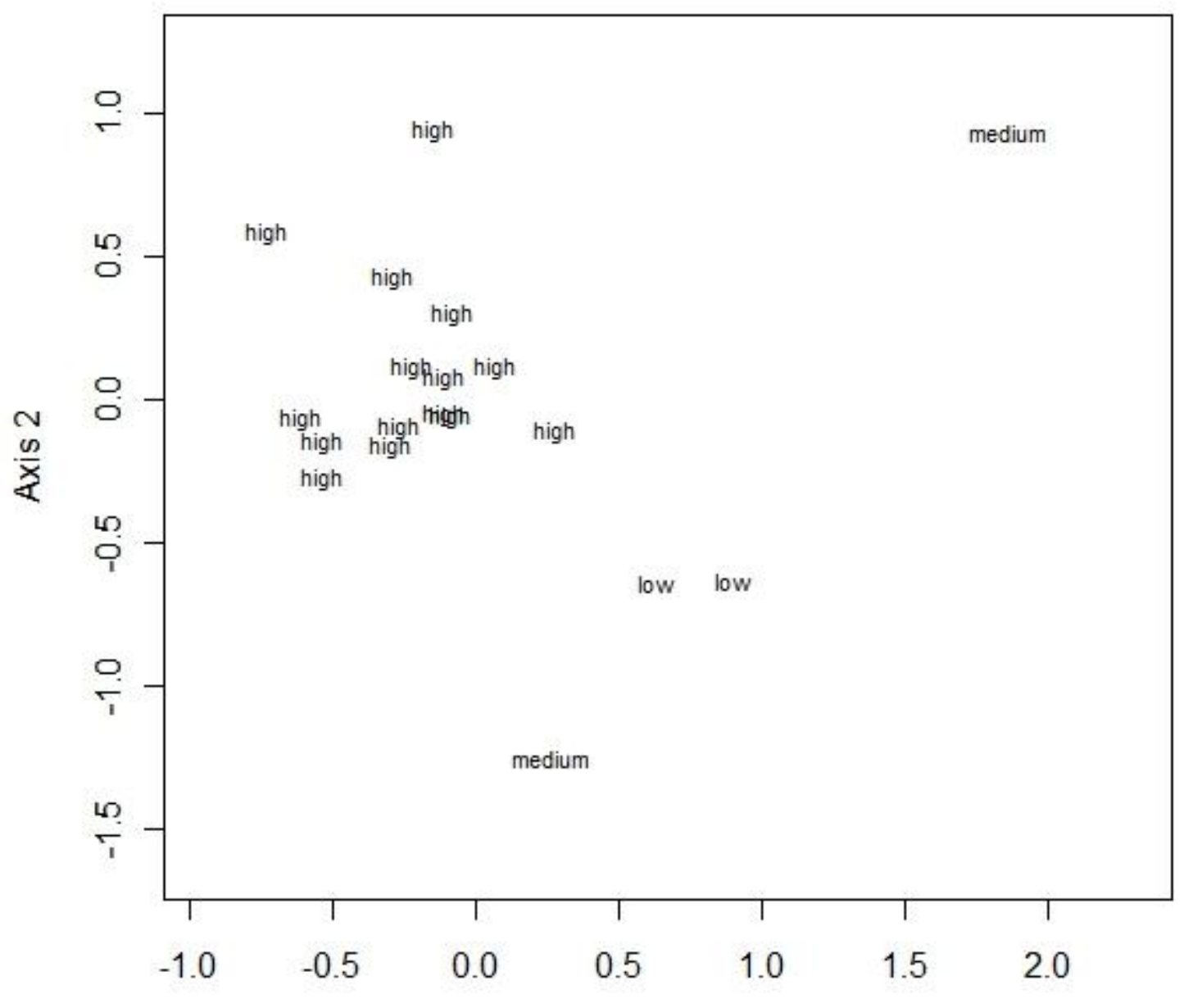

Axis 1

Figure 14. nMDS ordination of bacterial OTUs labeled by the reaction conditions necessary to amplify bacterial amoA genes. Plots 19 and 37 were labeled as "low", plots 3 and 5 were labeled as "medium", and all other plots were labeled as "high". See Figure 5 for details on the reasons for these labels. 
(A)

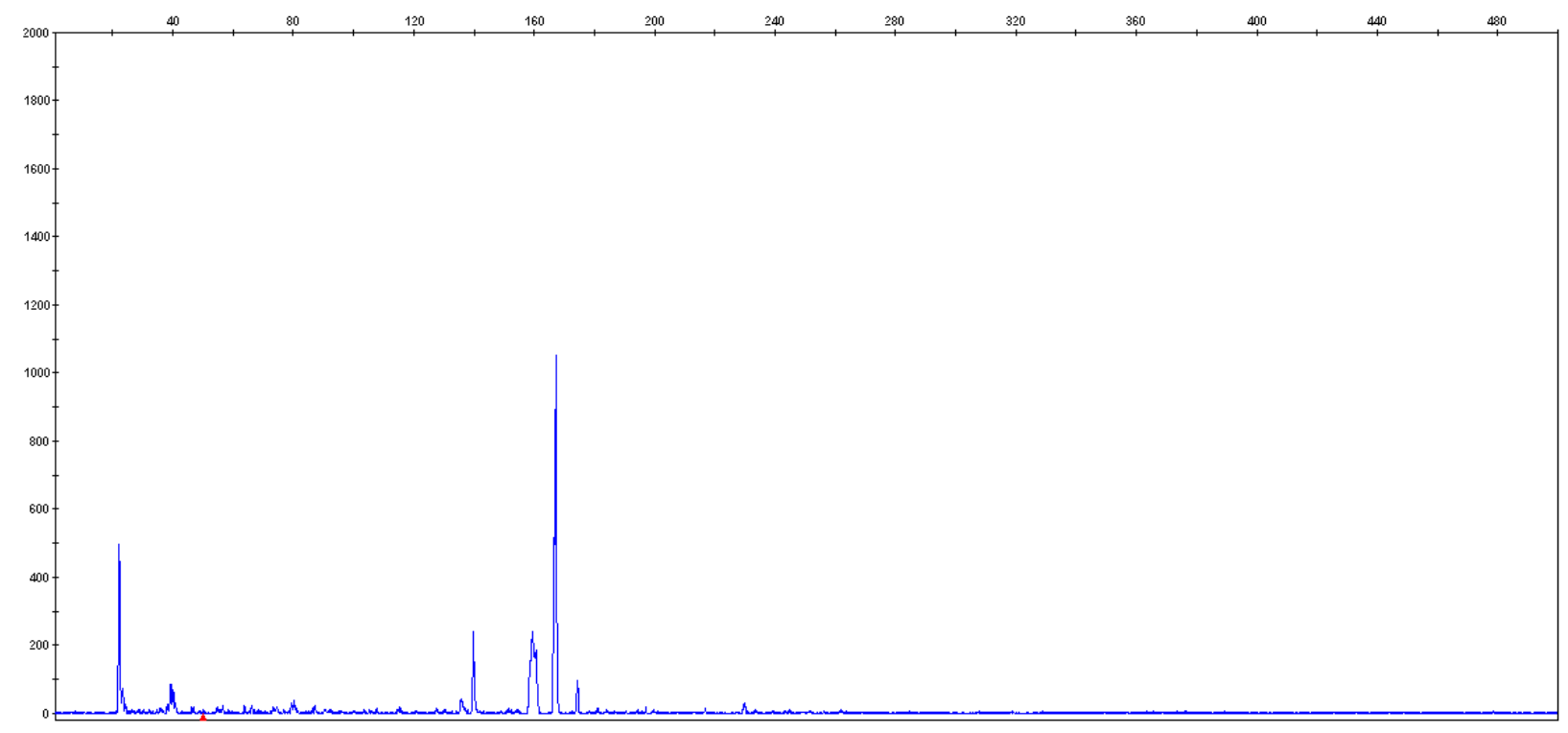

(B)

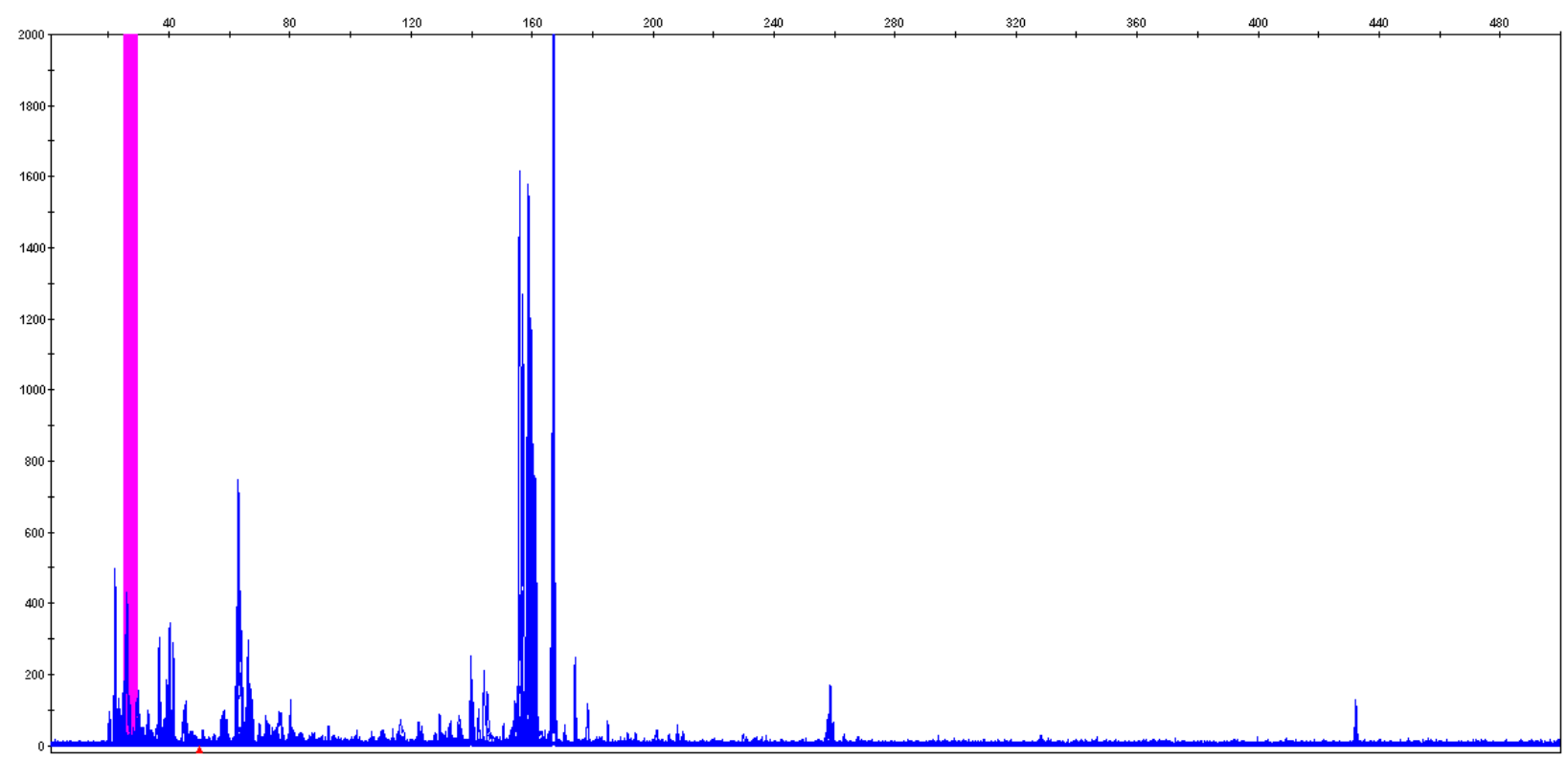

Figure 15. Sample AOB electropherograms. (A) is a representative electropherogram for one plot for the AOB using the HaeIII restriction enzyme in Plot 10. (B) is a composite electropherogram created in Genemapper that shows every peak obtained for the bacteria in all plots using the HaeIII restriction enzyme. Values on the $\mathrm{X}$ axis are peak length in base pairs. Values on the $\mathrm{Y}$ axis are relative fluorescence of the peaks in relative fluorescence units. When contrasted with Figure 13, the AOB appear to be a much more complex community than the AOA. 
(A)

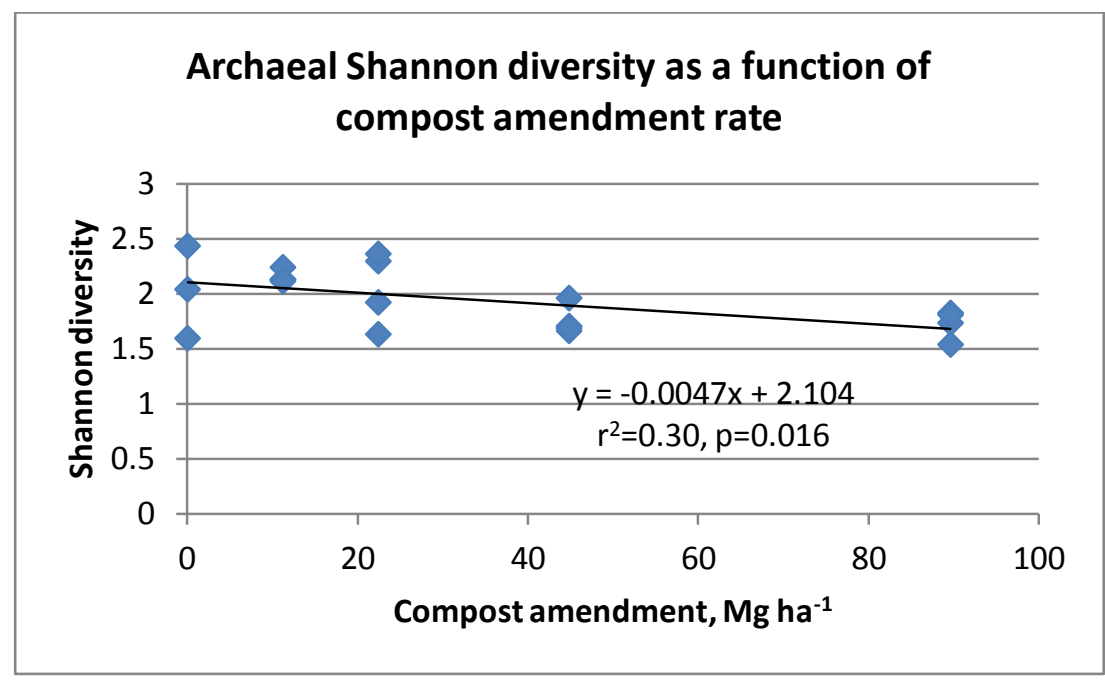

(C)

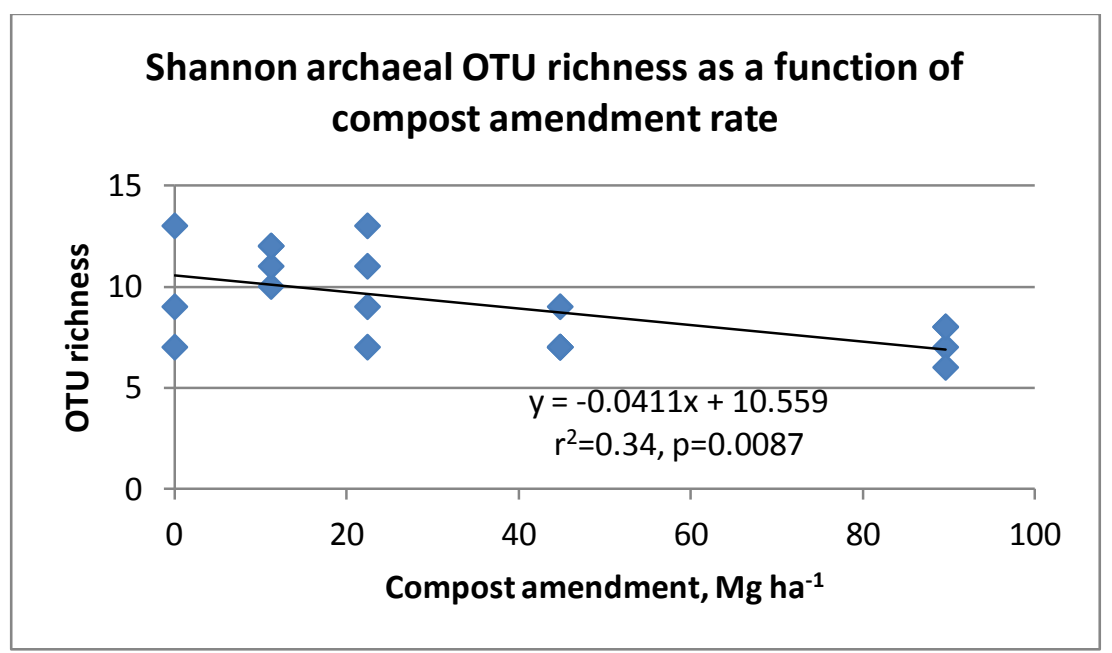

(B)

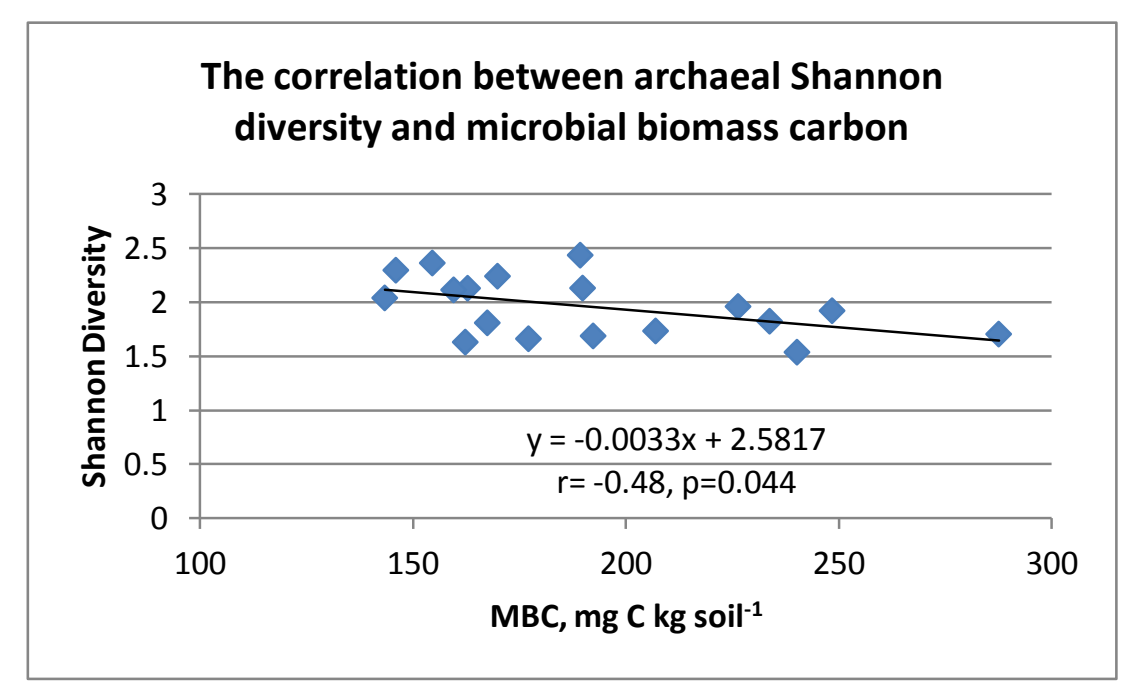

(D)

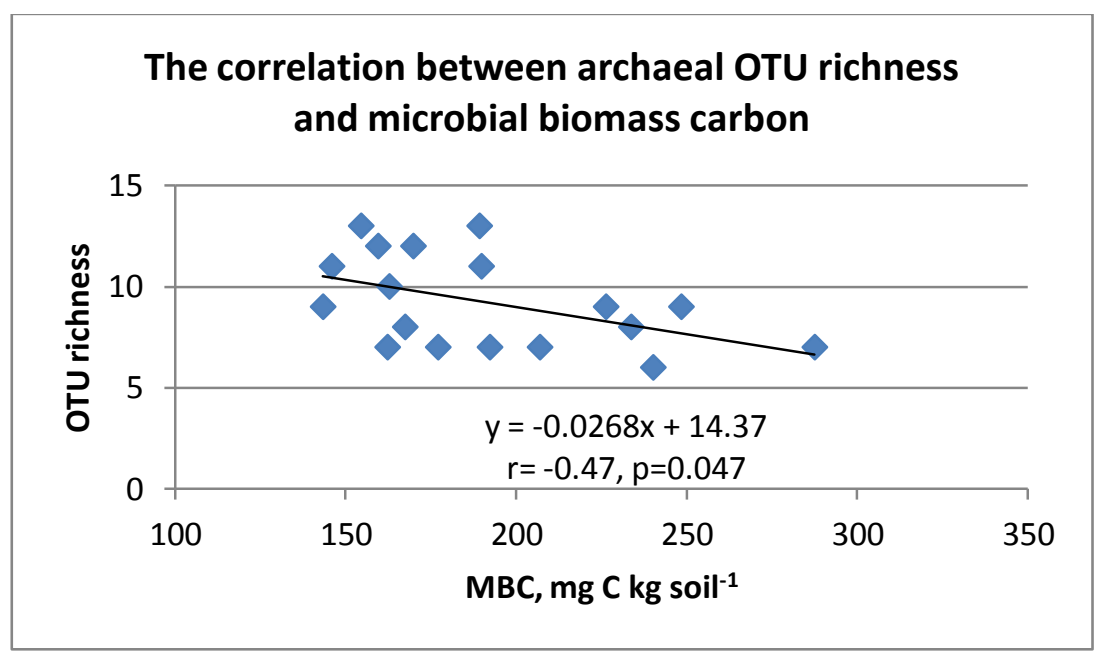

Figure 16. Significant relationships between archaeal Shannon diversity metrics, compost amendment, and biochemical variables. 
(A)

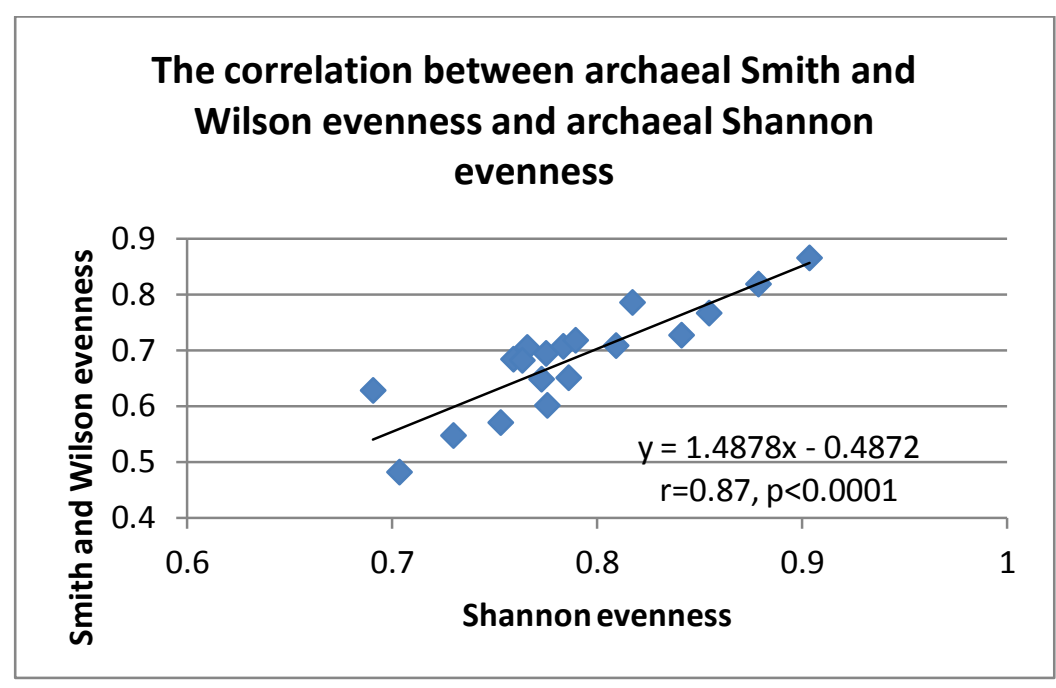

(B)

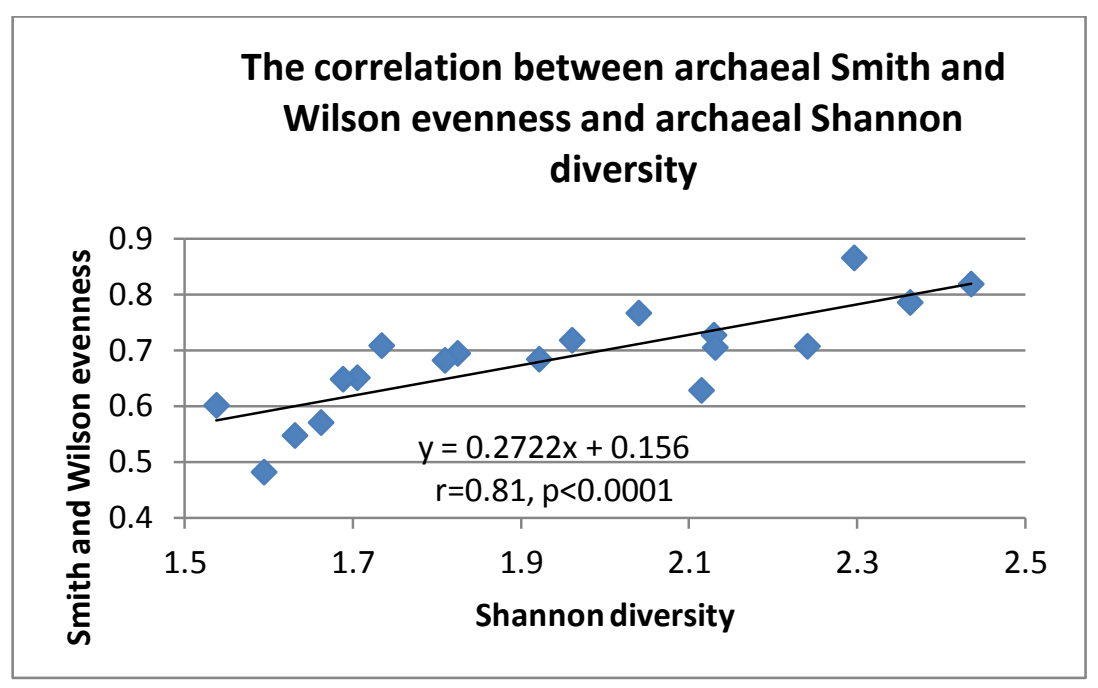

(C)

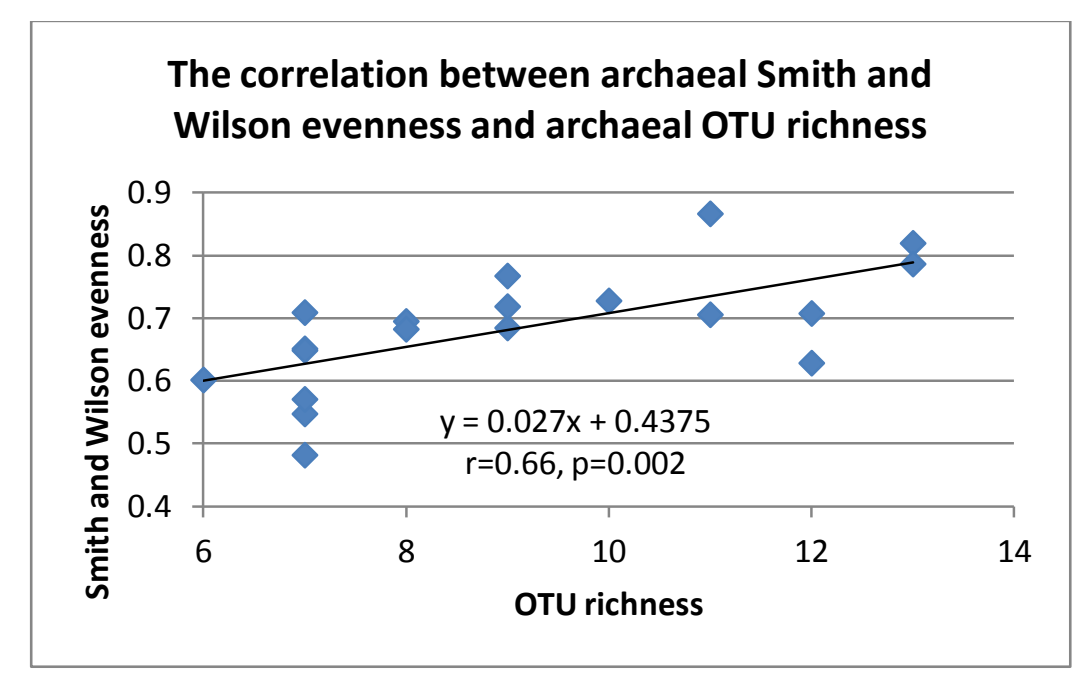

Figure 17. Correlations between archaeal Shannon and Smith and Wilson diversity values. 


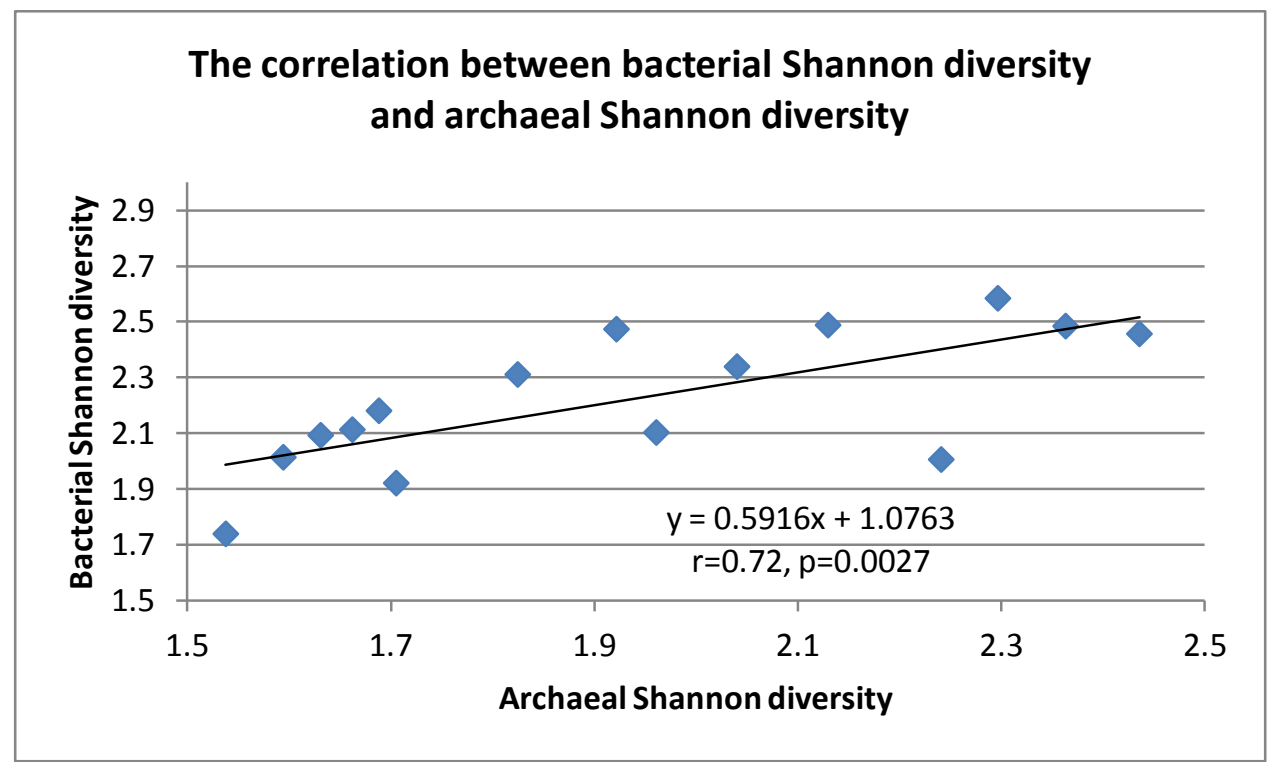

Figure 18. The relationship between archaeal and bacterial Shannon diversity values for the plots. 
(A)

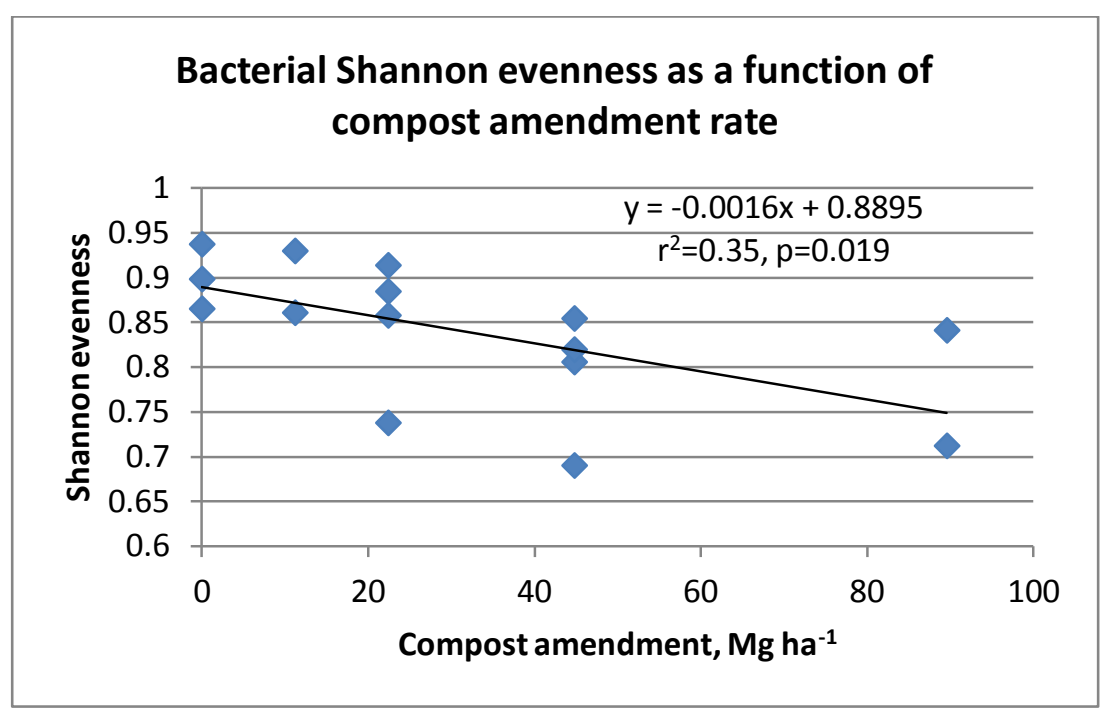

(B)

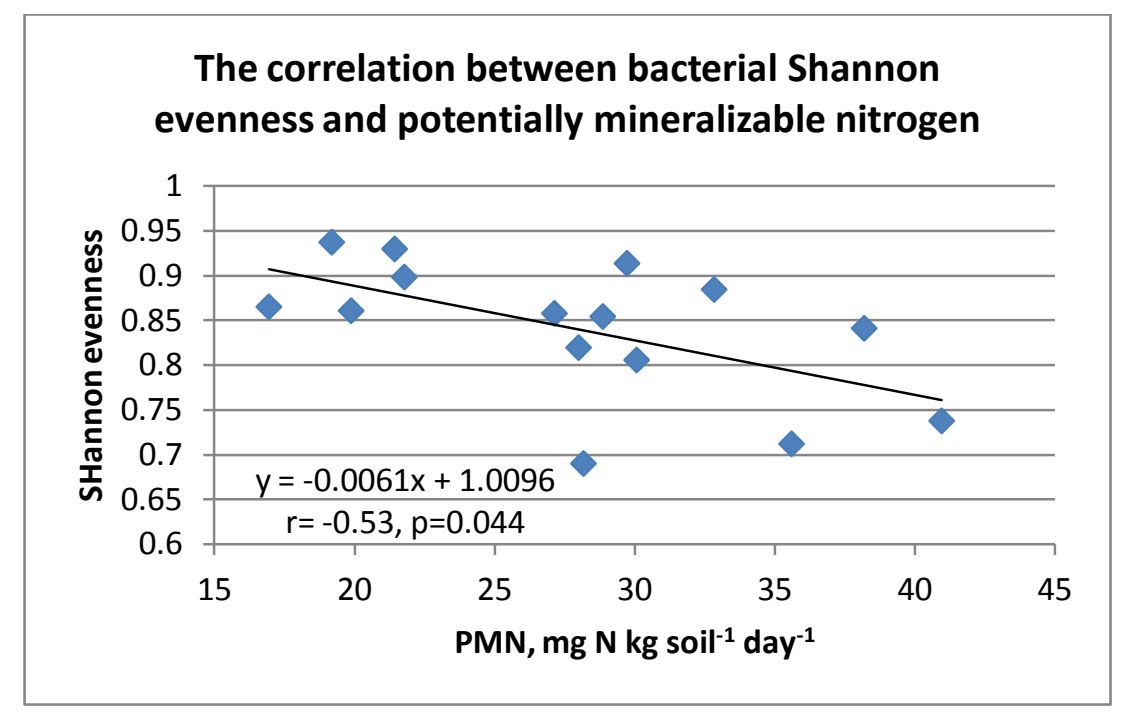

(C)

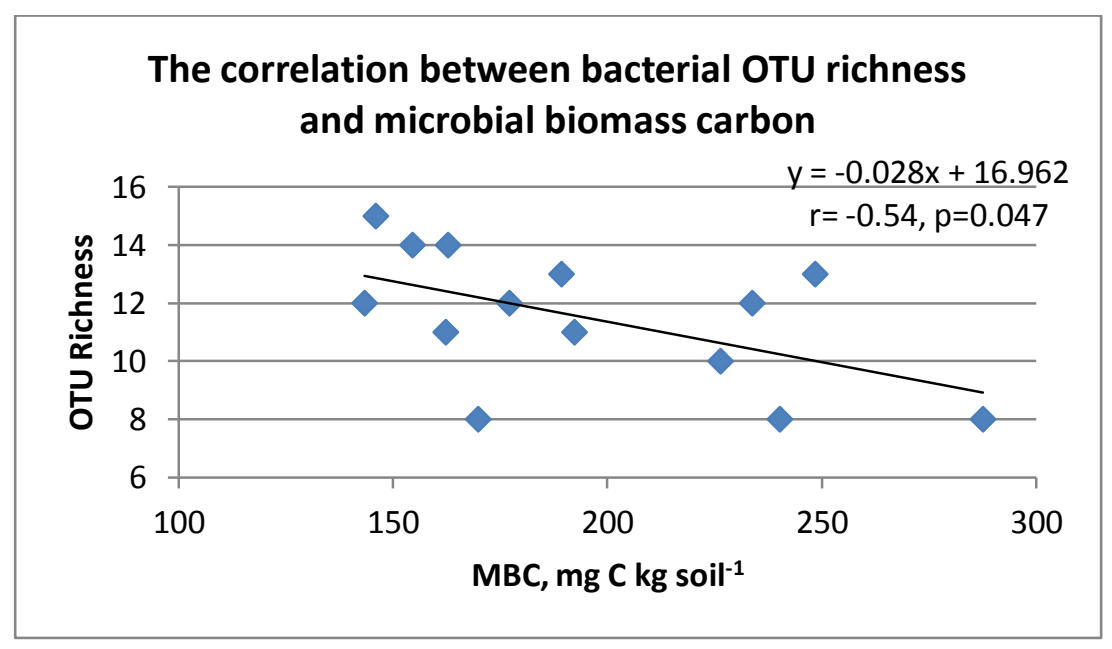

Figure 19. Significant relationships between bacterial Shannon diversity metrics and environmental variables. 


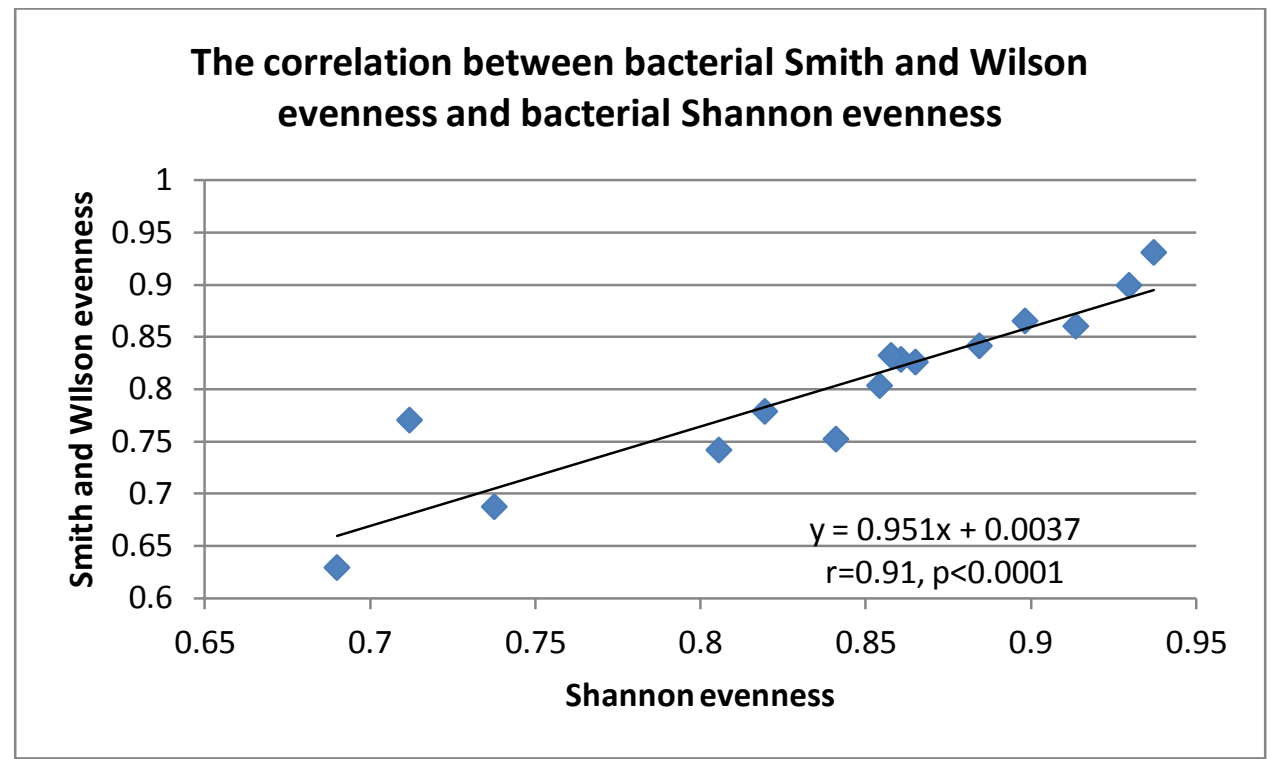

Figure 20. The relationship between bacterial Smith and Wilson evenness and bacterial Shannon evenness. 
(A)

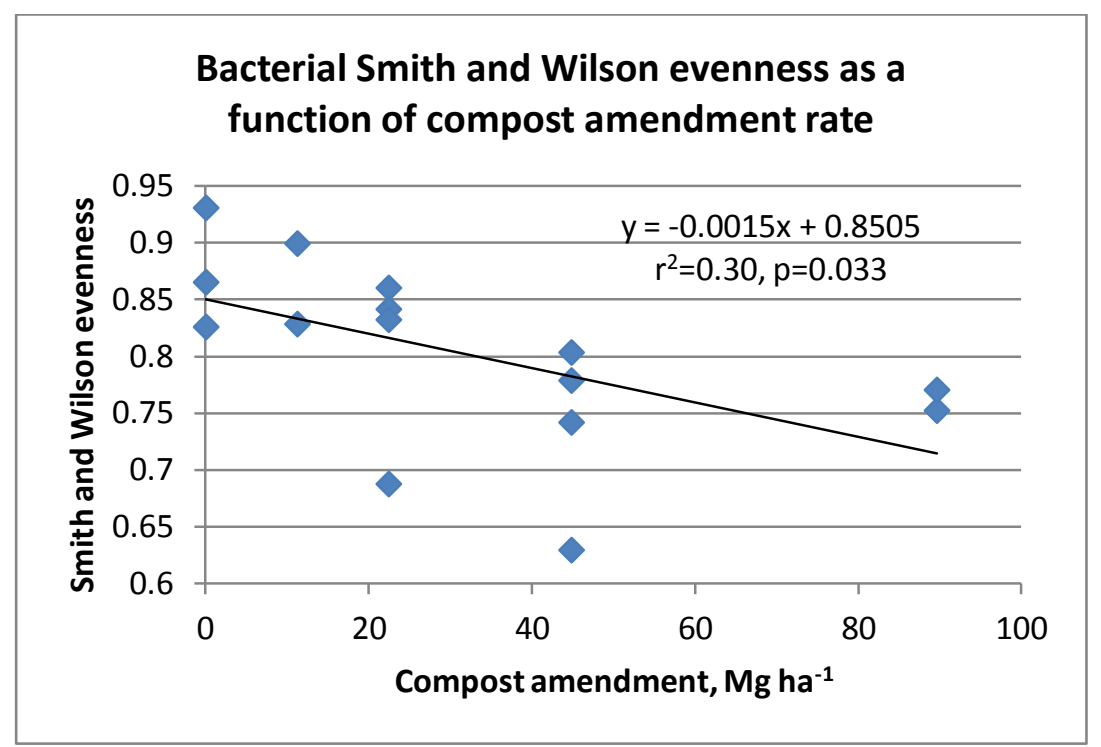

(B)

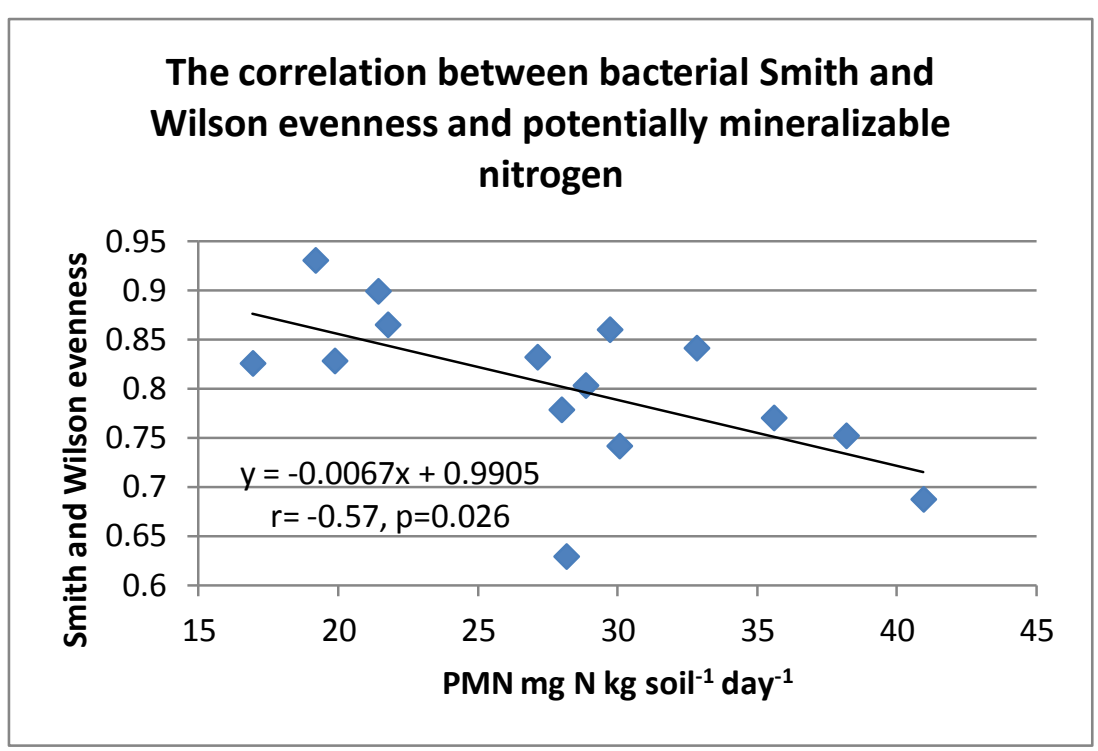

Figure 21. Significant relationships between bacterial Smith and Wilson evenness and environmental variables. 


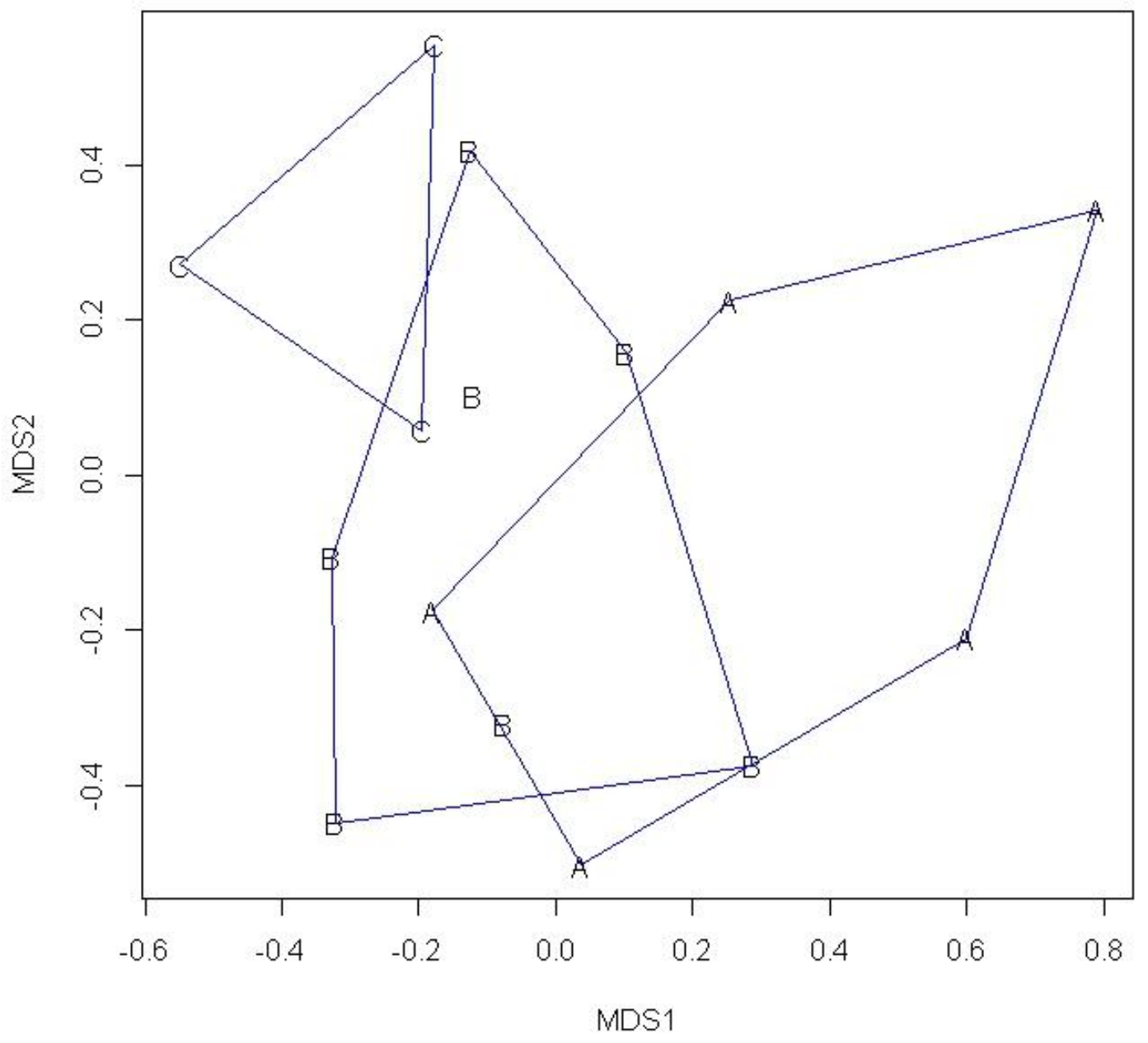

Figure 22. nMDS ordination of bacterial community similarity with plots labeled by a posteriori PMN categories. Points labeled by the letter A had low nitrogen mineralization rates, those labeled by $\mathrm{B}$ had medium nitrogen mineralization rates, and those labeled by $\mathrm{C}$ had high nitrogen mineralization rates. The shapes drawn around the points delineate the areas in which all low, medium, and high nitrogen mineralization plots were respectively found. 


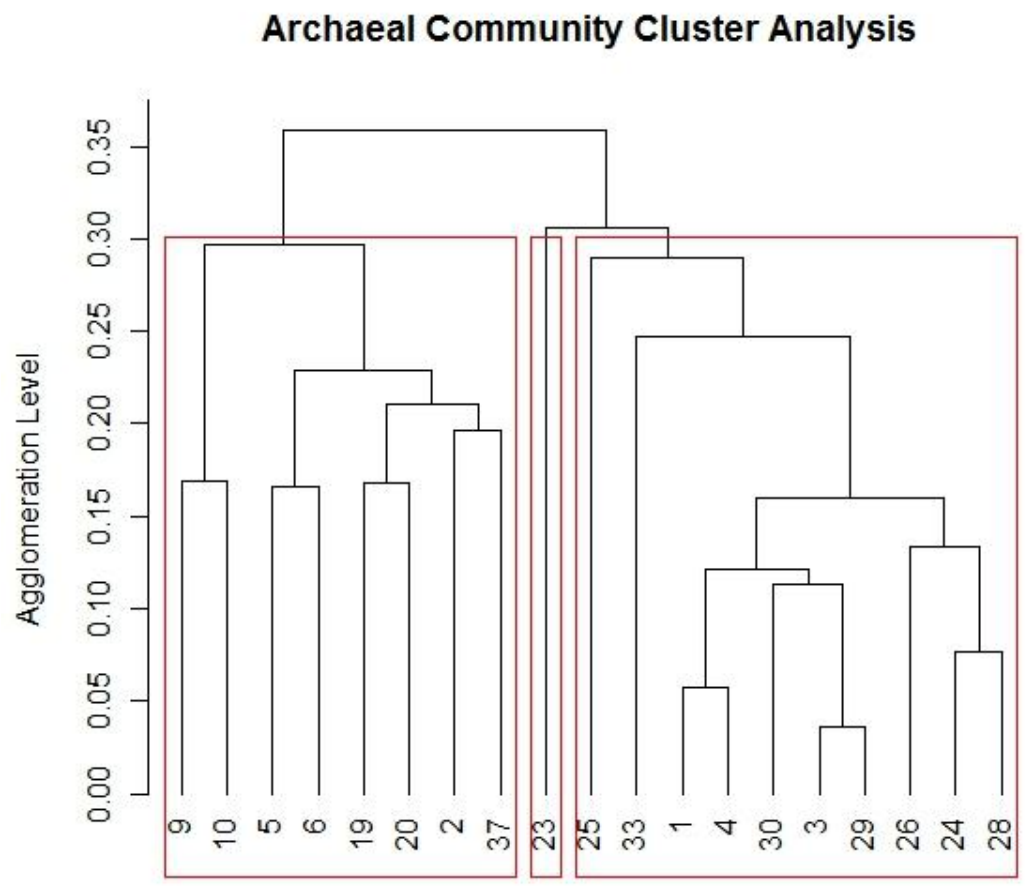

Plot Number

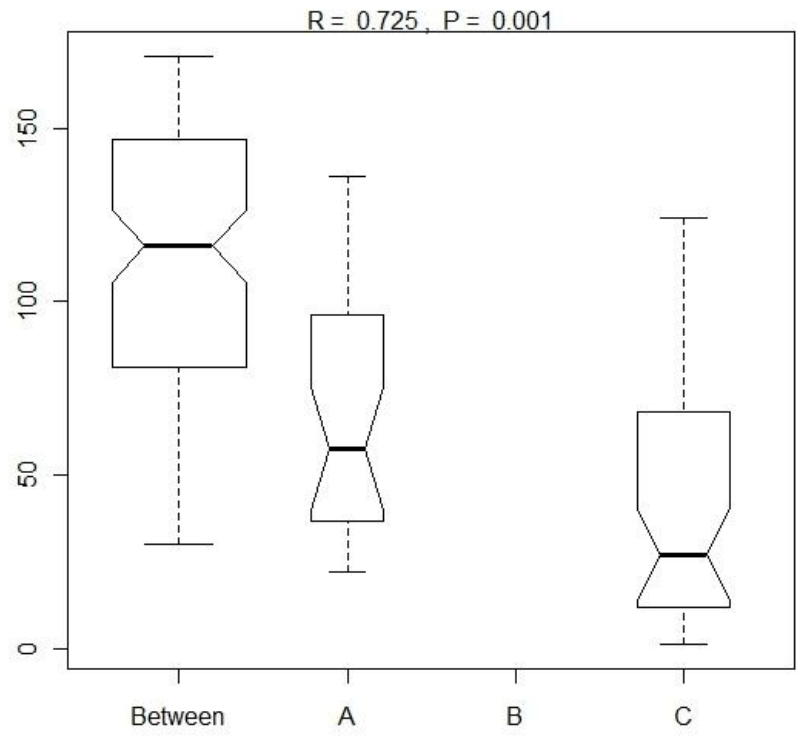

Figure 23. The process by which optimum ANOSIM values for the AOA were obtained. (A) shows a dendrogram of AOA community structure using Bray-Curtis dissimilarity and average linkage. Idealized groups comprised of the most similar communities were created by splitting groups at a Bray-Curtis dissimilarity value of 0.3 . This yielded three groups, one of which had only one member (plot 23). These groups were then added to the original dataset and labeled as either A, B, or C. (B) shows a boxplot of ANOSIM results based on the groups obtained from (A). Mean ranked

dissimilarity within Group A and within Group C are significantly lower than mean rank dissimilarity between all plots. Note that Group B had only one member and so could not be ranked. While an $\mathrm{R}$ value of 1 is hypothetically possible, this analysis shows that the highest $\mathrm{R}$ value realistically possible when three groups were created based on Bray-Curtis dissimilarity is 0.725 . 


\section{Bacterial Community Cluster Analysis}

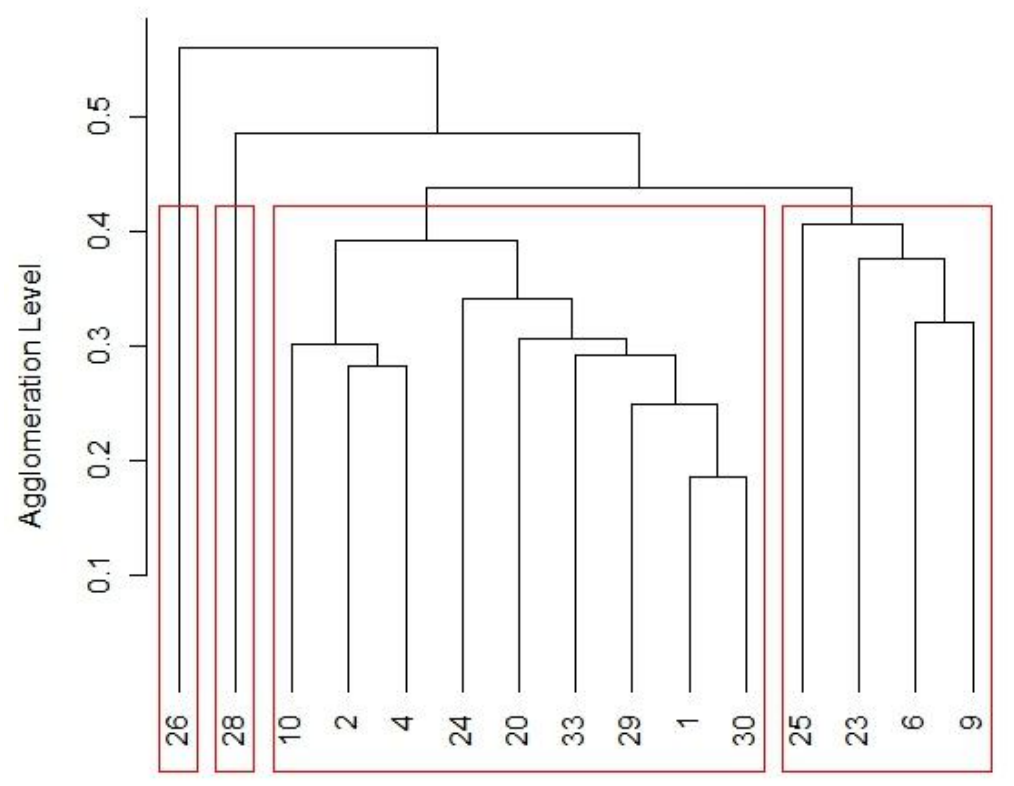

Plot Number

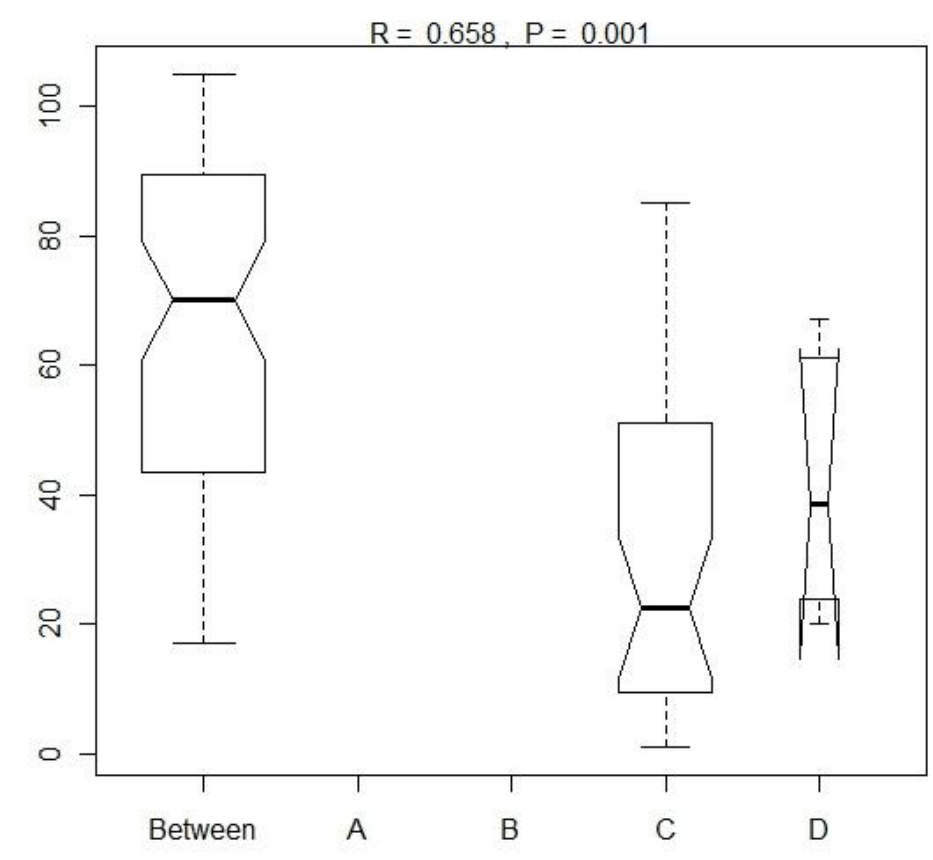

Figure 24. The process by which optimum ANOSIM values for the AOB were obtained. (A) shows a dendrogram of AOB community structure using Bray-Curtis dissimilarity and average linkage. Idealized groups comprised of the most similar communities were created by splitting groups at a Bray-Curtis dissimilarity value of approximately 0.43 . This yielded four groups, two of which had only one member (plot 26 and plot 28). These groups were then added to the original dataset and labeled as either A, B, C, or D. (B) shows a boxplot of ANOSIM results based on the groups obtained from (A). Mean ranked dissimilarity within Group C and within Group D are significantly lower than mean rank dissimilarity between all plots. Note that Group A and Group B each had only one member and so could not be ranked. While an $\mathrm{R}$ value of 1 is hypothetically possible, this analysis shows that the highest $\mathrm{R}$ value realistically possible when fourgroups were created based on Bray-Curtis dissimilarity is 0.658 . 


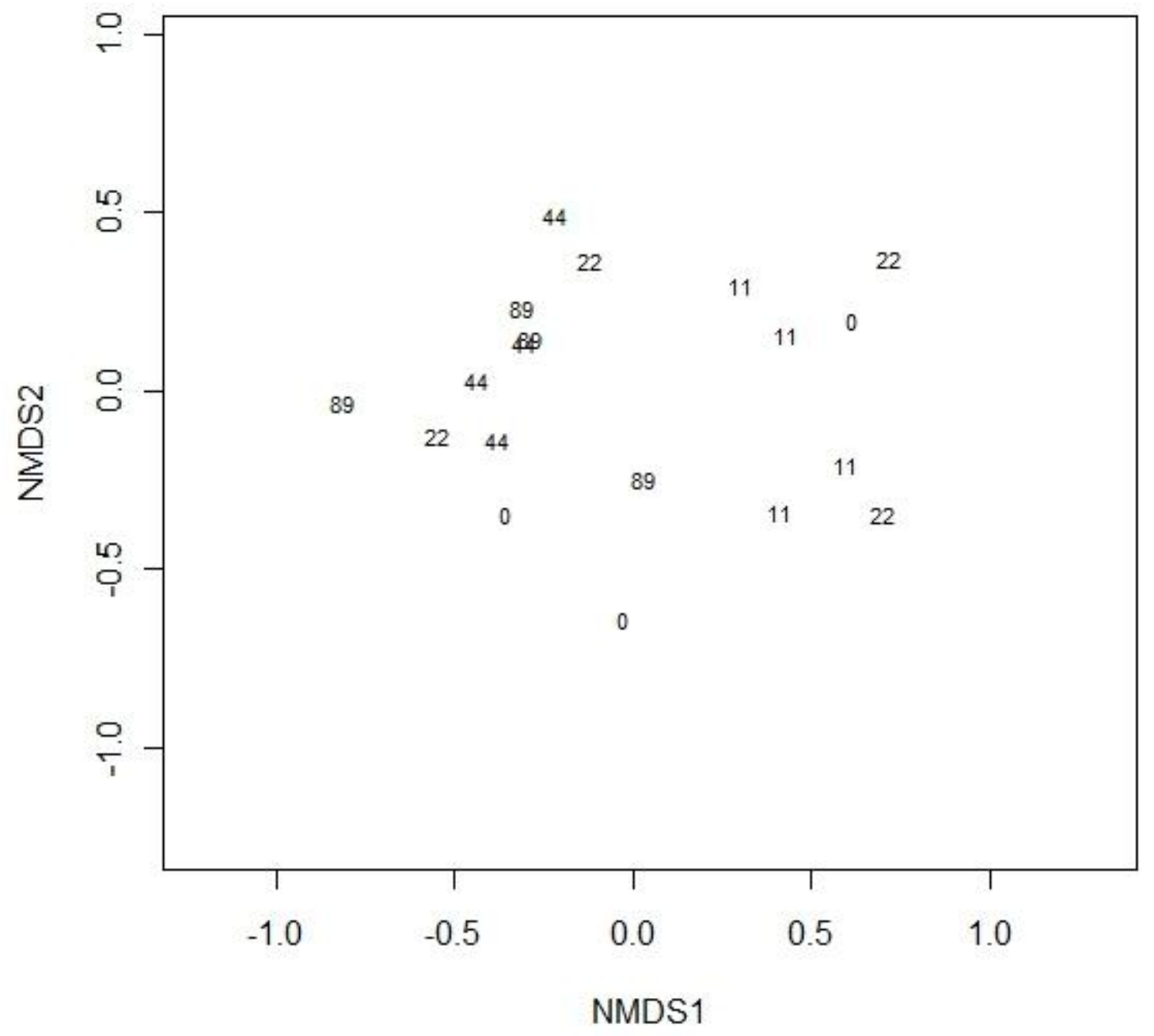

Figure 25. nMDS ordination of AOA community similarity with plots labeled by compost amendment rate, in $\mathrm{Mg} \mathrm{ha}^{-1}$. In this case, the amendment rates were rounded off to whole numbers for the sake of clarity. 


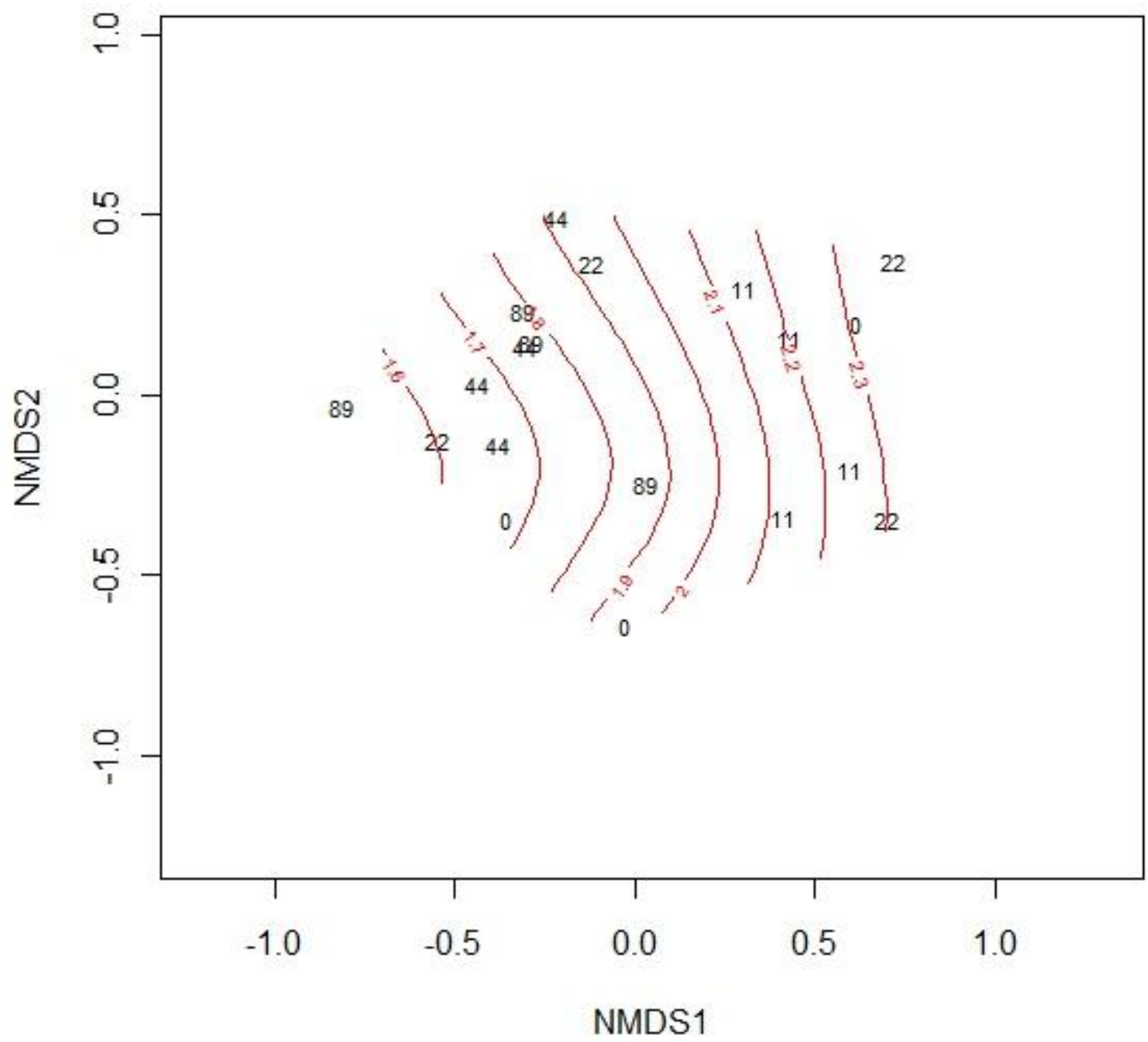

\begin{tabular}{cccc}
\hline Variable & $\mathbf{r}^{2}$ & p-value & $\begin{array}{c}\text { Deviance } \\
\text { explained }\end{array}$ \\
\hline MBC & 0.59 & 0.0045 & $67 \%$ \\
PMN & 0.52 & 0.03 & $64.7 \%$ \\
PAO & 0.30 & 0.25 & $46.50 \%$ \\
pH & 0.76 & 0.0027 & $86.8 \%$ \\
Extracted DNA & 0.68 & 0.0074 & $80 \%$ \\
Soluble carbon & 0.099 & 0.48 & $24.4 \%$ \\
Shannon Diversity & 0.93 & $<0.0001$ & $95.2 \%$ \\
\hline
\end{tabular}

Figure 26. Surface fitting of archaeal Shannon diversity on a nMDS ordination of community similarity. A table of relevant statistical values for this surface fit as well as for surface fitting of other variables is included for comparison. Plots are labeled by compost amendment rate in $\mathrm{Mg}$ $\mathrm{ha}^{-1}$, rounded down to whole numbers for the sake of visual clarity. Compare also to Figure 31. 


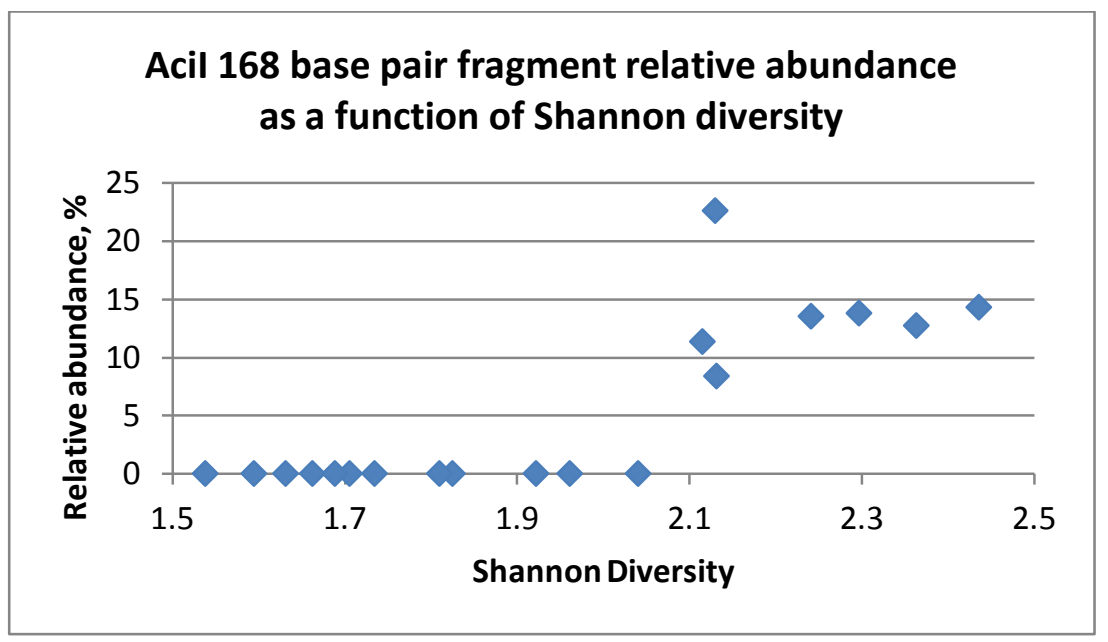

(B)

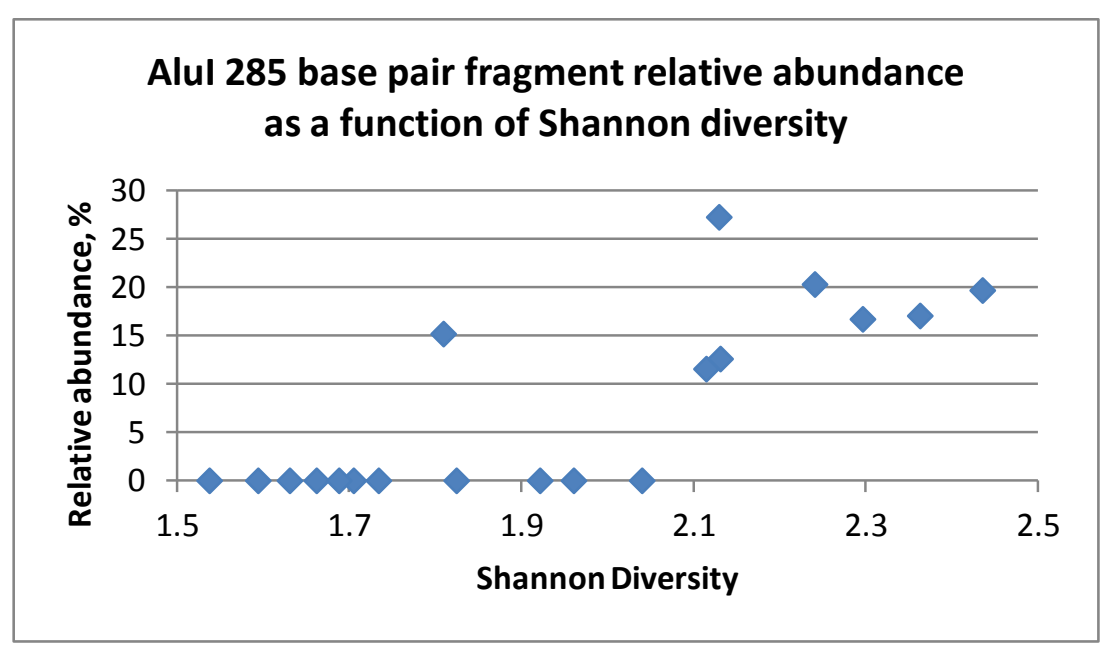

(C)

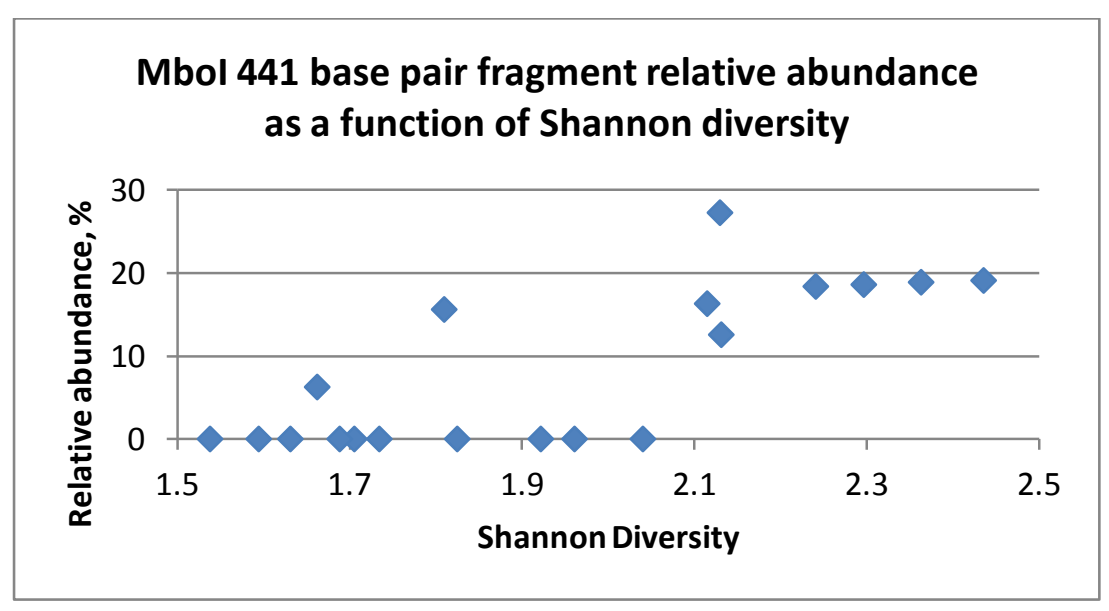

Figure 27. Relative abundance of select archaeal OTUs as a function of archaeal Shannon diversity. 


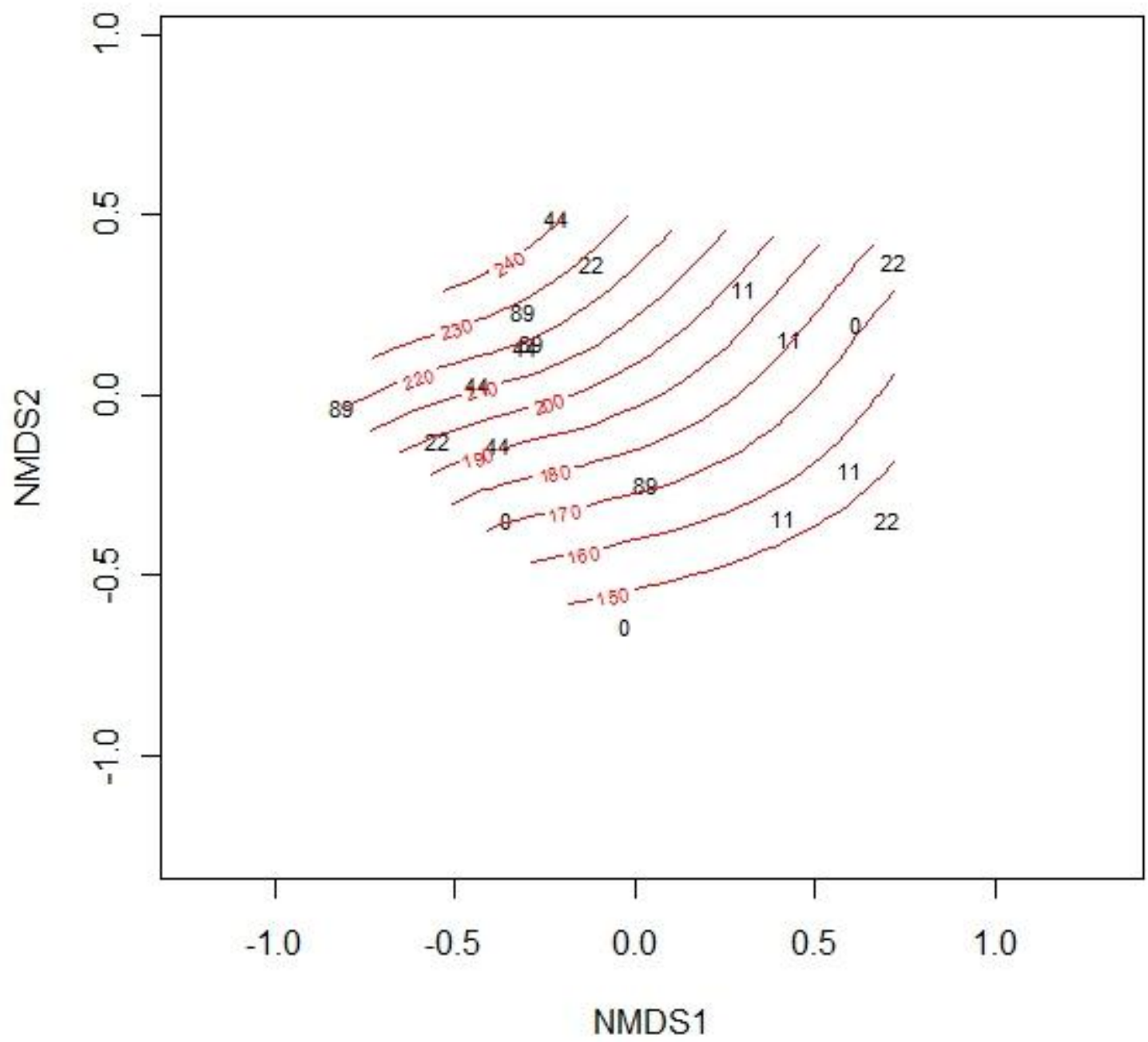

\begin{tabular}{cccc}
\hline Variable & $\mathbf{r}^{2}$ & p-value & $\begin{array}{c}\text { Deviance } \\
\text { explained }\end{array}$ \\
\hline MBC & 0.59 & 0.0045 & $67 \%$ \\
PMN & 0.52 & 0.03 & $64.7 \%$ \\
PAO & 0.30 & 0.25 & $46.50 \%$ \\
pH & 0.76 & 0.0027 & $86.8 \%$ \\
Extracted DNA & 0.68 & 0.0074 & $80 \%$ \\
Soluble carbon & 0.099 & 0.48 & $24.4 \%$ \\
Shannon Diversity & 0.93 & $<0.0001$ & $95.2 \%$ \\
\hline
\end{tabular}

Figure 28. Surface fitting of MBC values on a nMDS ordination of AOA community similarity. A table of relevant statistical values for this surface fit as well as for surface fitting of other variables is included for comparison. Plots are labeled by compost amendment rate in $\mathrm{Mg}$ ha, rounded down to whole numbers for the sake of visual clarity. Compare also to Figure 31. 


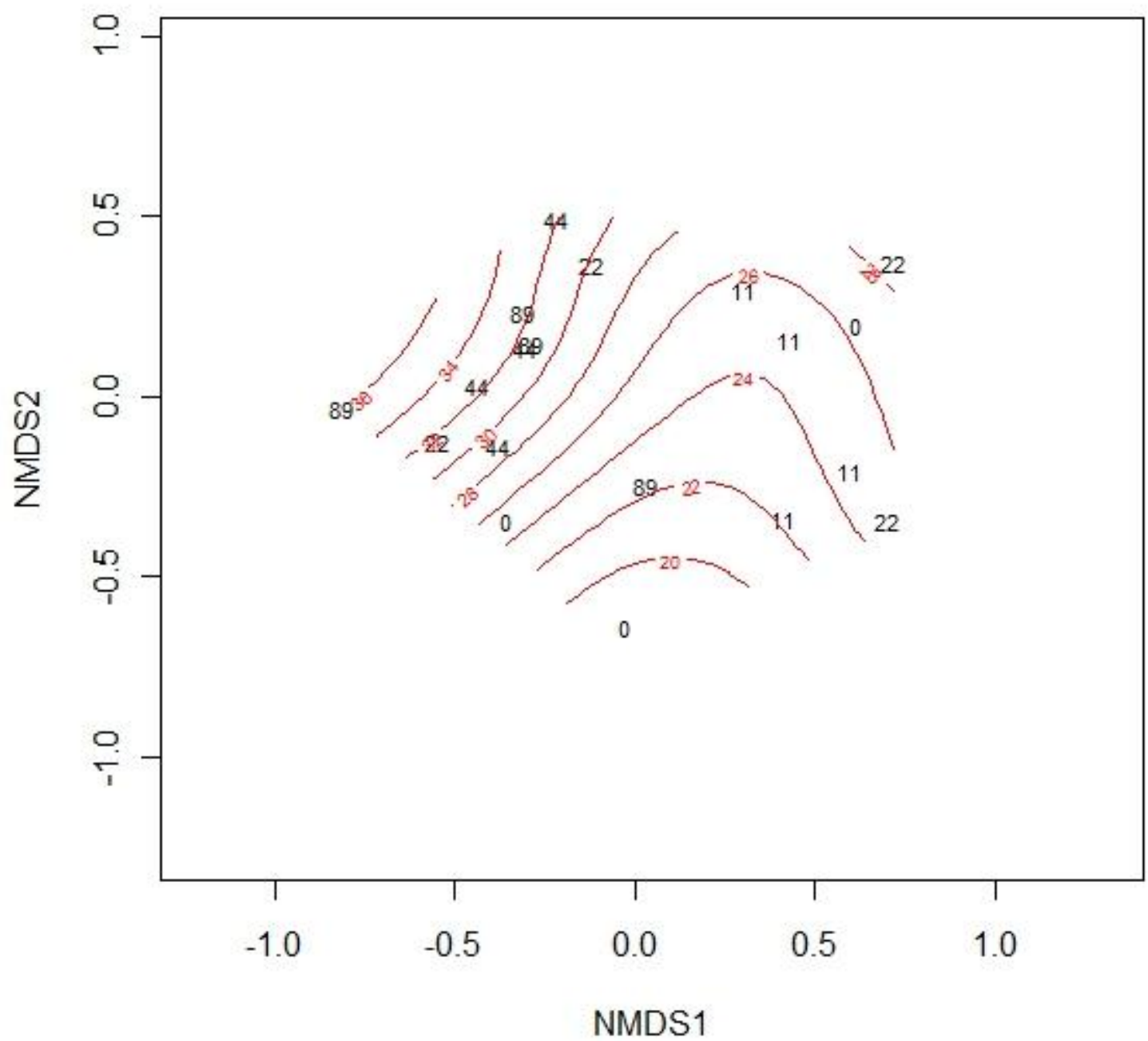

\begin{tabular}{cccc}
\hline Variable & $\mathbf{r}^{2}$ & p-value & $\begin{array}{c}\text { Deviance } \\
\text { explained }\end{array}$ \\
\hline MBC & 0.59 & 0.0045 & $67 \%$ \\
PMN & 0.52 & 0.03 & $64.7 \%$ \\
PAO & 0.30 & 0.25 & $46.50 \%$ \\
pH & 0.76 & 0.0027 & $86.8 \%$ \\
Extracted DNA & 0.68 & 0.0074 & $80 \%$ \\
Soluble carbon & 0.099 & 0.48 & $24.4 \%$ \\
Shannon Diversity & 0.93 & $<0.0001$ & $95.2 \%$ \\
\hline
\end{tabular}

Figure 29. Surface fitting of PMN values on a nMDS ordination of AOA community similarity. A table of relevant statistical values for this surface fit as well as for surface fitting of other variables is included for comparison. Plots are labeled by compost amendment rate in $\mathrm{Mg}$ $\mathrm{ha}^{-1}$, rounded down to whole numbers for the sake of visual clarity. Compare also to Figure 31. 


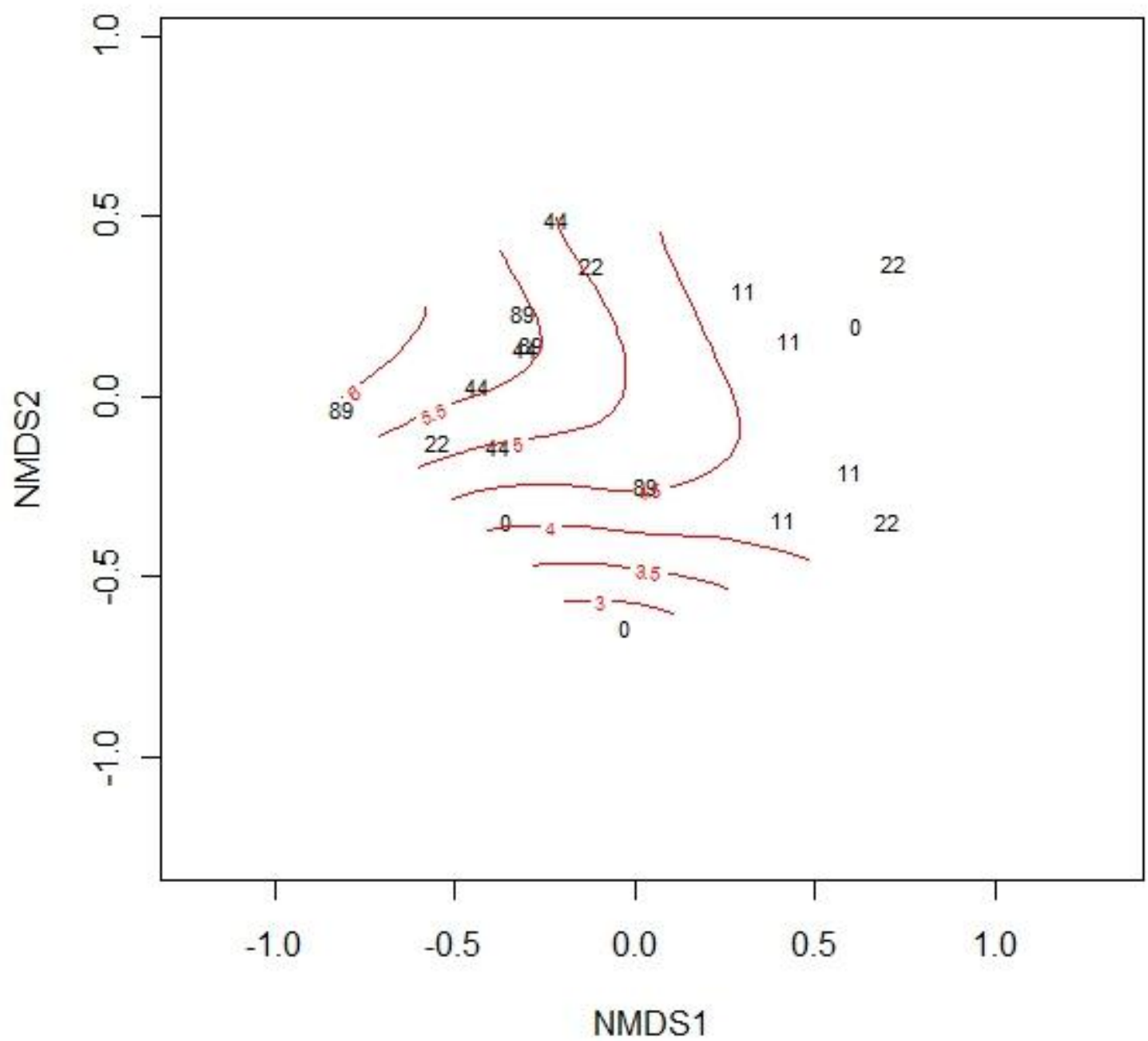

\begin{tabular}{cccc}
\hline Variable & $\mathbf{r}^{2}$ & p-value & $\begin{array}{c}\text { Deviance } \\
\text { explained }\end{array}$ \\
\hline MBC & 0.59 & 0.0045 & $67 \%$ \\
PMN & 0.52 & 0.03 & $64.7 \%$ \\
PAO & 0.30 & 0.25 & $46.50 \%$ \\
pH & 0.76 & 0.0027 & $86.8 \%$ \\
Extracted DNA & 0.68 & 0.0074 & $80 \%$ \\
Soluble carbon & 0.099 & 0.48 & $24.4 \%$ \\
Shannon Diversity & 0.93 & $<0.0001$ & $95.2 \%$ \\
\hline
\end{tabular}

Figure 30. Surface fitting of extracted DNA values on a nMDS ordination of AOA community similarity. A table of relevant statistical values for this surface fit as well as for surface fitting of other variables is included for comparison. Plots are labeled by compost amendment rate in $\mathrm{Mg}$ $\mathrm{ha}^{-1}$, rounded down to whole numbers for the sake of visual clarity. Compare also to Figure 31. 


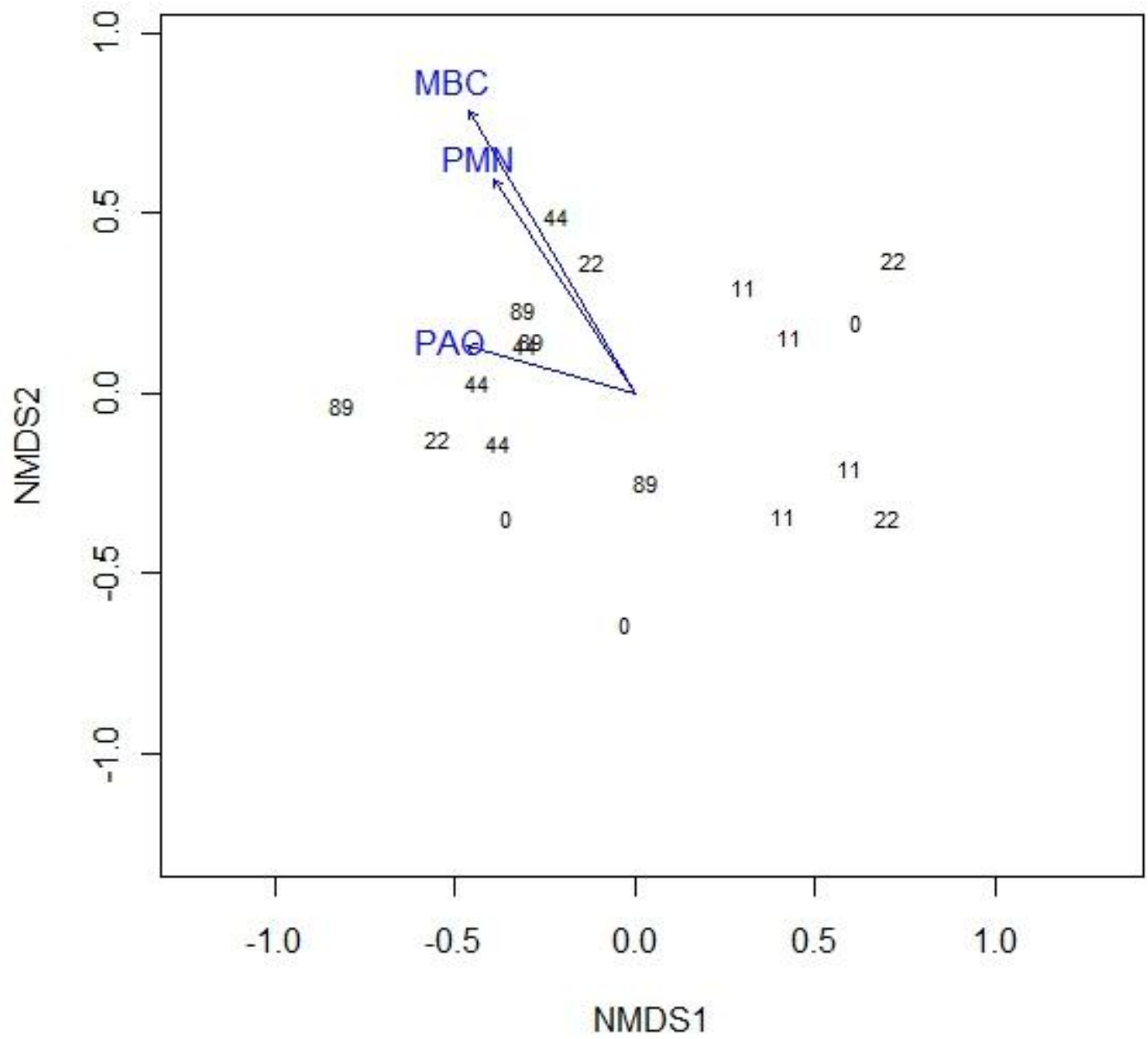

\begin{tabular}{ccccc}
\hline Variable & NMDS Axis 1 & NMDS Axis 2 & $\mathbf{r}^{2}$ & p-value \\
\hline MBC & -0.51 & 0.86 & 0.57 & 0.001 \\
PMN & -0.55 & 0.84 & 0.35 & 0.047 \\
PAO & -0.96 & 0.27 & 0.16 & 0.262 \\
pH & -0.82 & 0.58 & 0.52 & 0.004 \\
Extracted DNA & -0.68 & 0.73 & 0.37 & 0.029 \\
Soluble carbon & -0.54 & -0.84 & 0.14 & 0.302 \\
Shannon diversity & 0.98 & 0.18 & 0.90 & 0.001 \\
\hline
\end{tabular}

Figure 31. Environmental fitting of important variables over a nMDS ordination of archaeal community similarity. Compare to values seen with surface fitting (Figures 26 and 28- 30). Values under the headings "NMDS Axis 1" and "NMDS Axis 2" are the relative length and direction the vector extends along the given axis. Plots are labeled by compost amendment rate in $\mathrm{Mg} \mathrm{ha}^{-1}$, rounded down to whole numbers for the sake of visual clarity. 


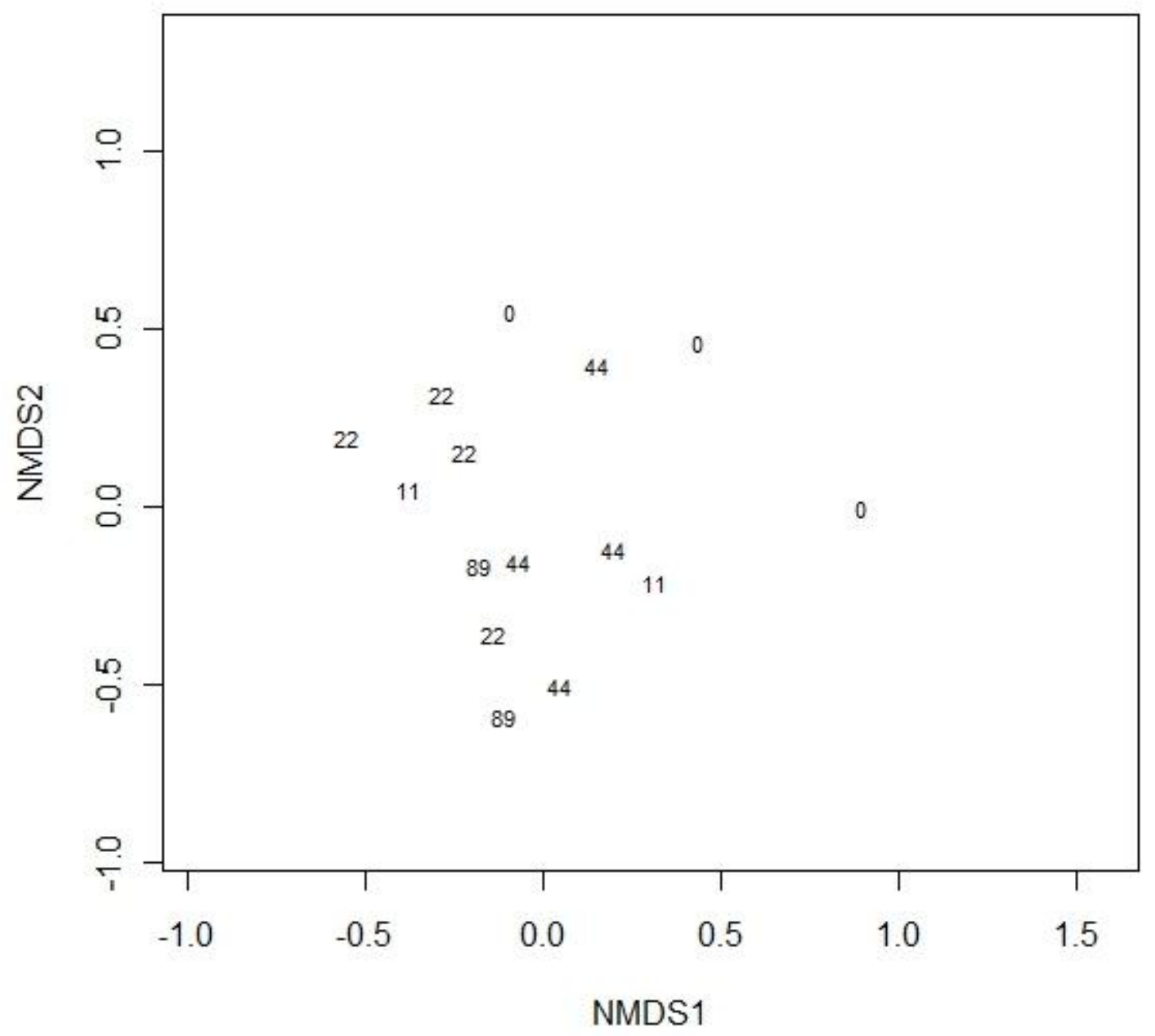

Figure 32. nMDS ordination of AOB community similarity. Plots are labeled by compost amendment rate in $\mathrm{Mg} \mathrm{a}^{-1}$, rounded down to whole numbers for the sake of visual clarity. 


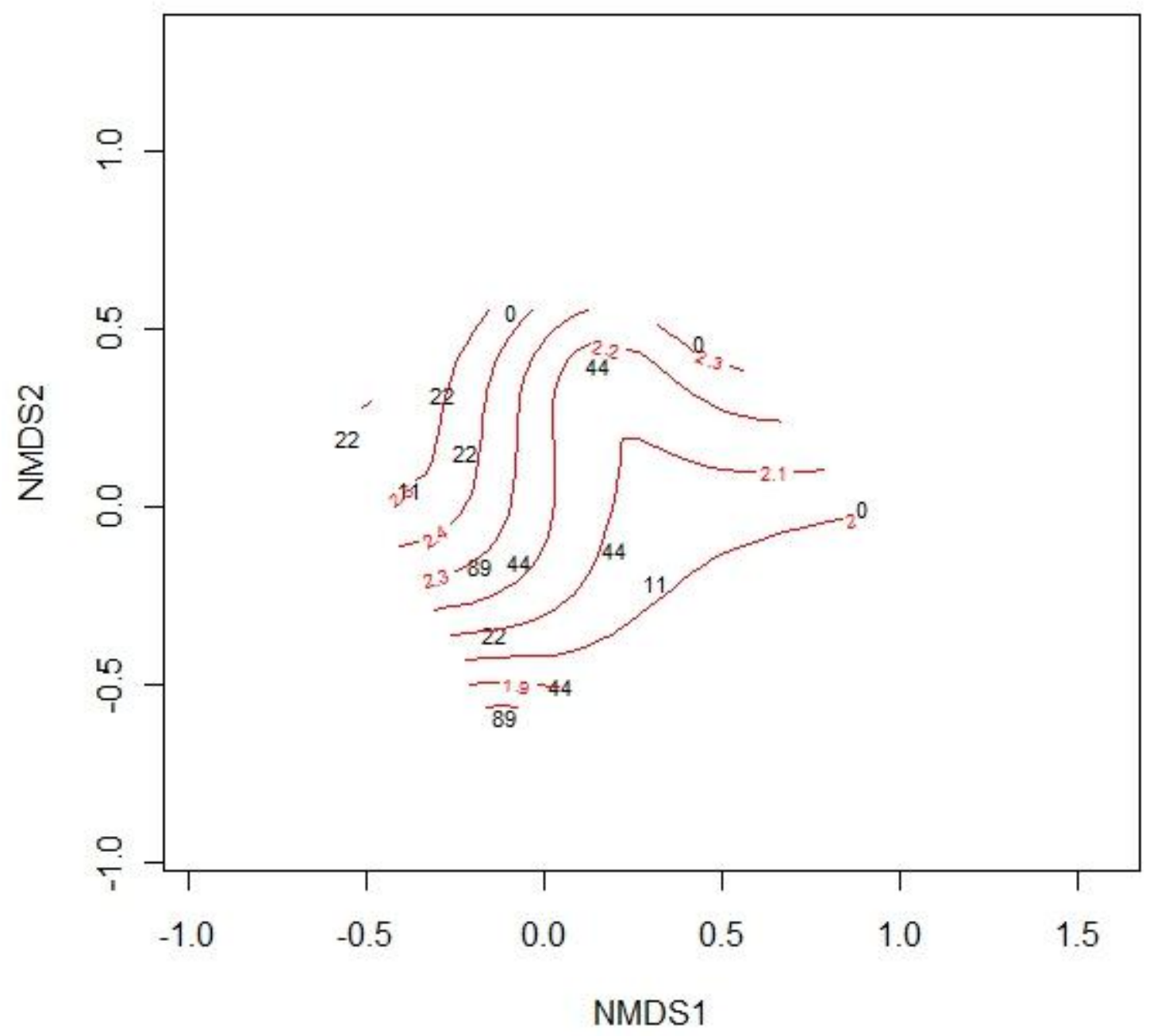

\begin{tabular}{cccc}
\hline Variable & $\mathbf{r}^{2}$ & p-value & $\begin{array}{c}\text { Deviance } \\
\text { explained }\end{array}$ \\
\hline MBC & 0.19 & 0.112 & $30.6 \%$ \\
PMN & 0.46 & 0.0093 & $54.1 \%$ \\
PAO & 0.42 & 0.026 & $51.7 \%$ \\
pH & 0.35 & 0.036 & $44.9 \%$ \\
Extracted DNA & 0.69 & 0.022 & $82.2 \%$ \\
Soluble carbon & 0.25 & 0.070 & $35.8 \%$ \\
Shannon Diversity & 0.98 & $<0.0001$ & $99.2 \%$ \\
\hline
\end{tabular}

Figure 33. Surface fitting of bacterial Shannon diversity on a nMDS ordination of community similarity. A table of relevant statistical values for this surface fit as well as for surface fitting of other variables is included for comparison. Plots are labeled by compost amendment rate in $\mathrm{Mg}$ $\mathrm{ha}^{-1}$, rounded down to whole numbers for the sake of visual clarity. Compare also to Figure 38. 


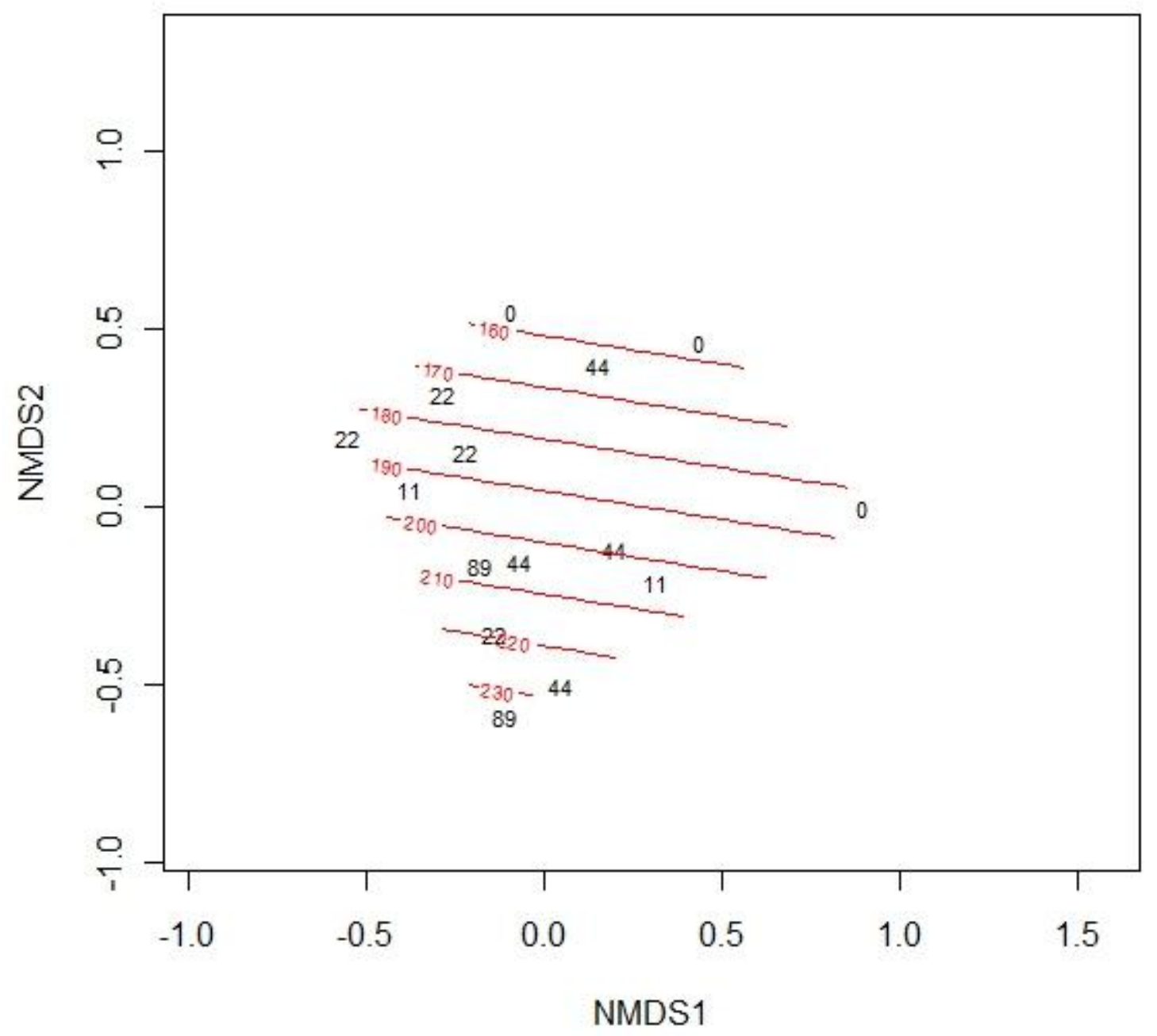

\begin{tabular}{cccc}
\hline Variable & $\mathbf{r}^{2}$ & p-value & $\begin{array}{c}\text { Deviance } \\
\text { explained }\end{array}$ \\
\hline MBC & 0.19 & 0.112 & $30.6 \%$ \\
PMN & 0.46 & 0.0093 & $54.1 \%$ \\
PAO & 0.42 & 0.026 & $51.7 \%$ \\
pH & 0.35 & 0.036 & $44.9 \%$ \\
Extracted DNA & 0.69 & 0.022 & $82.2 \%$ \\
Soluble carbon & 0.25 & 0.070 & $35.8 \%$ \\
Shannon Diversity & 0.98 & $<0.0001$ & $99.2 \%$ \\
\hline
\end{tabular}

Figure 34. Surface fitting of MBC on a nMDS ordination of AOB community similarity. A table of relevant statistical values for this surface fit as well as for surface fitting of other variables is included for comparison. Plots are labeled by compost amendment rate in $\mathrm{Mg} \mathrm{ha}^{-1}$, rounded down to whole numbers for the sake of visual clarity. Compare also to Figure 38. 


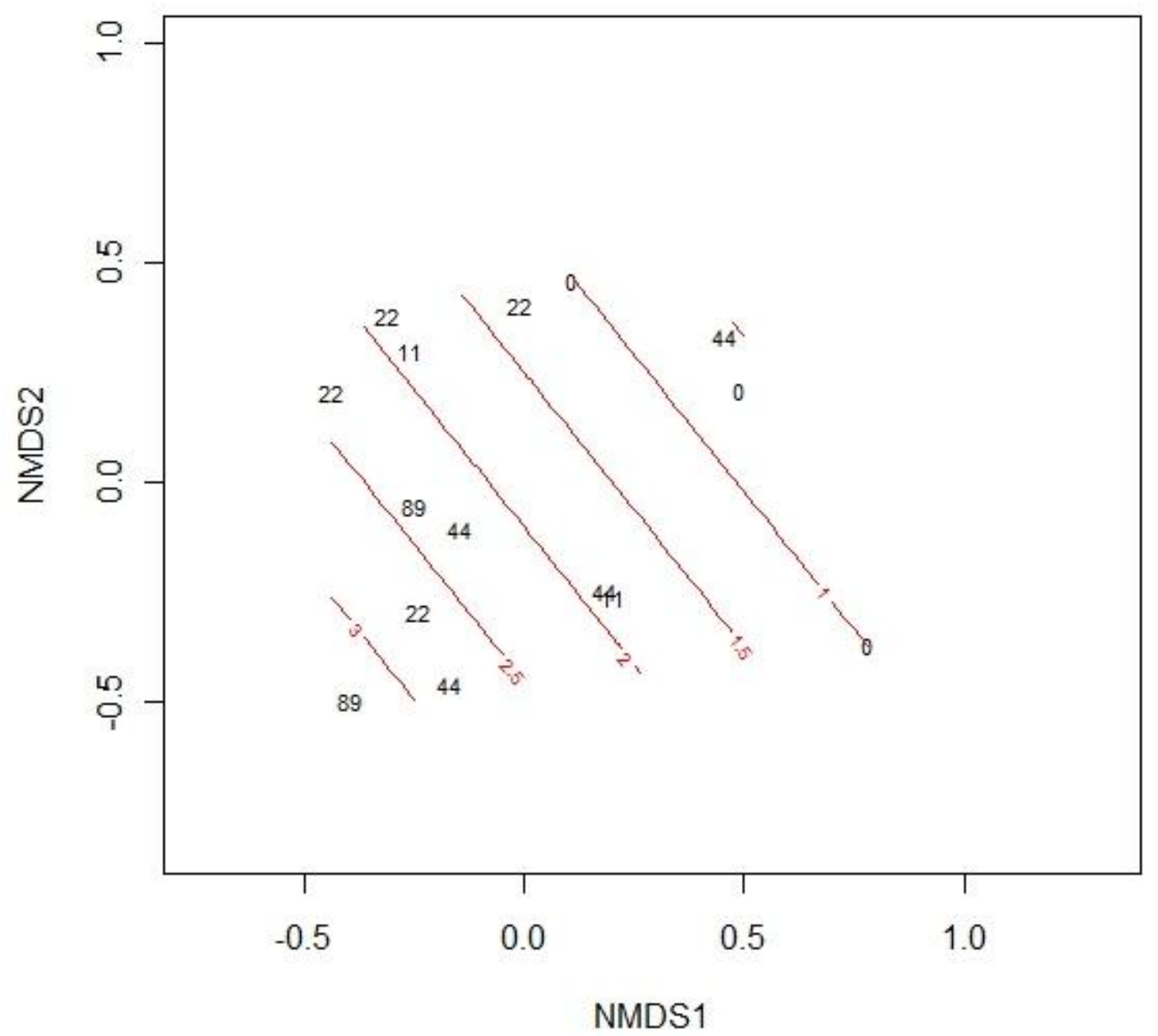

\begin{tabular}{cccc}
\hline Variable & $\mathbf{r}^{2}$ & p-value & $\begin{array}{c}\text { Deviance } \\
\text { explained }\end{array}$ \\
\hline MBC & 0.19 & 0.112 & $30.6 \%$ \\
PMN & 0.46 & 0.0093 & $54.1 \%$ \\
PAO & 0.42 & 0.026 & $51.7 \%$ \\
pH & 0.35 & 0.036 & $44.9 \%$ \\
Extracted DNA & 0.69 & 0.022 & $82.2 \%$ \\
Soluble carbon & 0.25 & 0.070 & $35.8 \%$ \\
Shannon Diversity & 0.98 & $<0.0001$ & $99.2 \%$ \\
\hline
\end{tabular}

Figure 35. Surface fitting of PAO on a nMDS ordination of AOB community similarity. A table of relevant statistical values for this surface fit as well as for surface fitting of other variables is included for comparison. Plots are labeled by compost amendment rate in $\mathrm{Mg} \mathrm{ha}^{-1}$, rounded down to whole numbers for the sake of visual clarity. Compare also to Figure 38. 


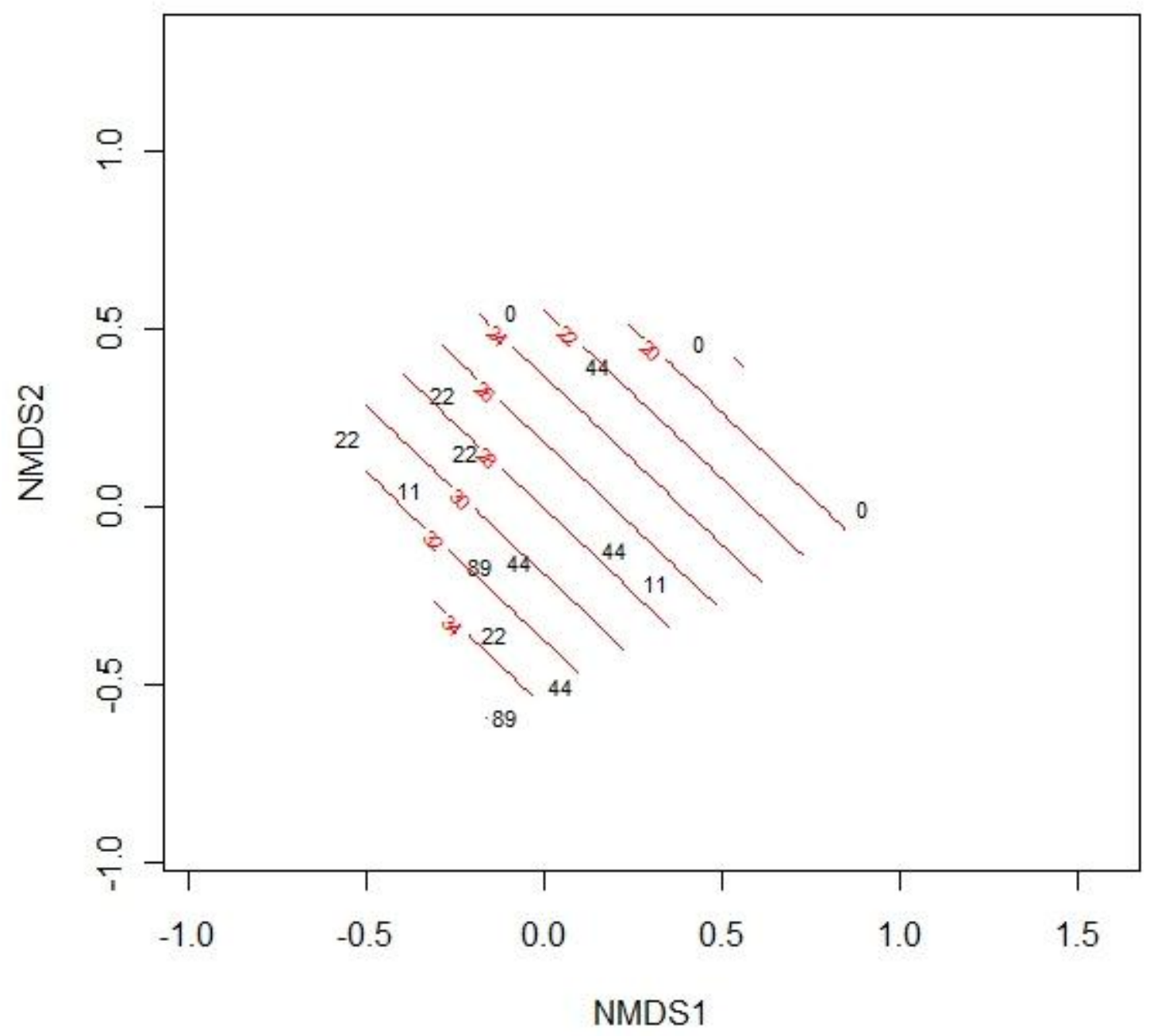

\begin{tabular}{cccc}
\hline Variable & $\mathbf{r}^{2}$ & p-value & $\begin{array}{c}\text { Deviance } \\
\text { explained }\end{array}$ \\
\hline MBC & 0.19 & 0.112 & $30.6 \%$ \\
PMN & 0.46 & 0.0093 & $54.1 \%$ \\
PAO & 0.42 & 0.026 & $51.7 \%$ \\
pH & 0.35 & 0.036 & $44.9 \%$ \\
Extracted DNA & 0.69 & 0.022 & $82.2 \%$ \\
Soluble carbon & 0.25 & 0.070 & $35.8 \%$ \\
Shannon Diversity & 0.98 & $<0.0001$ & $99.2 \%$ \\
\hline
\end{tabular}

Figure 36. Surface fitting of PMN on a nMDS ordination of AOB community similarity. A table of relevant statistical values for this surface fit as well as for surface fitting of other variables is included for comparison. Plots are labeled by compost amendment rate in $\mathrm{Mg} \mathrm{ha}^{-1}$, rounded down to whole numbers for the sake of visual clarity. Compare also to Figure 38. 


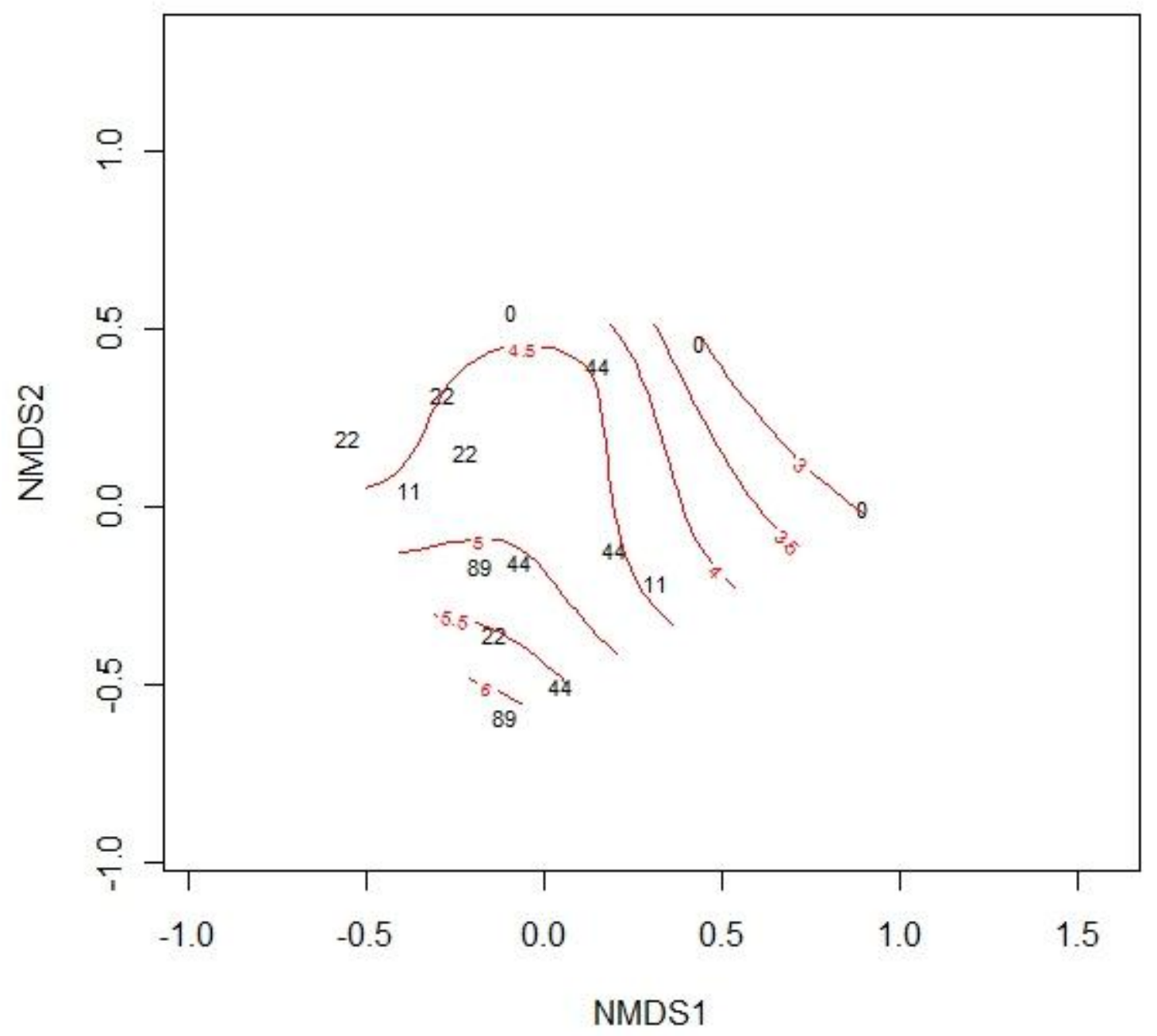

\begin{tabular}{cccc}
\hline Variable & $\mathbf{r}^{2}$ & p-value & $\begin{array}{c}\text { Deviance } \\
\text { explained }\end{array}$ \\
\hline MBC & 0.19 & 0.112 & $30.6 \%$ \\
PMN & 0.46 & 0.0093 & $54.1 \%$ \\
PAO & 0.42 & 0.026 & $51.7 \%$ \\
pH & 0.35 & 0.036 & $44.9 \%$ \\
Extracted DNA & 0.69 & 0.022 & $82.2 \%$ \\
Soluble carbon & 0.25 & 0.070 & $35.8 \%$ \\
Shannon Diversity & 0.98 & $<0.0001$ & $99.2 \%$ \\
\hline
\end{tabular}

Figure 37. Surface fitting of extracted DNA concentration on a nMDS ordination of AOB community similarity. A table of relevant statistical values for this surface fit as well as for surface fitting of other variables is included for comparison. Plots are labeled by compost amendment rate in $\mathrm{Mg} \mathrm{ha}^{-1}$, rounded down to whole numbers for the sake of visual clarity. Compare also to Figure 38. 


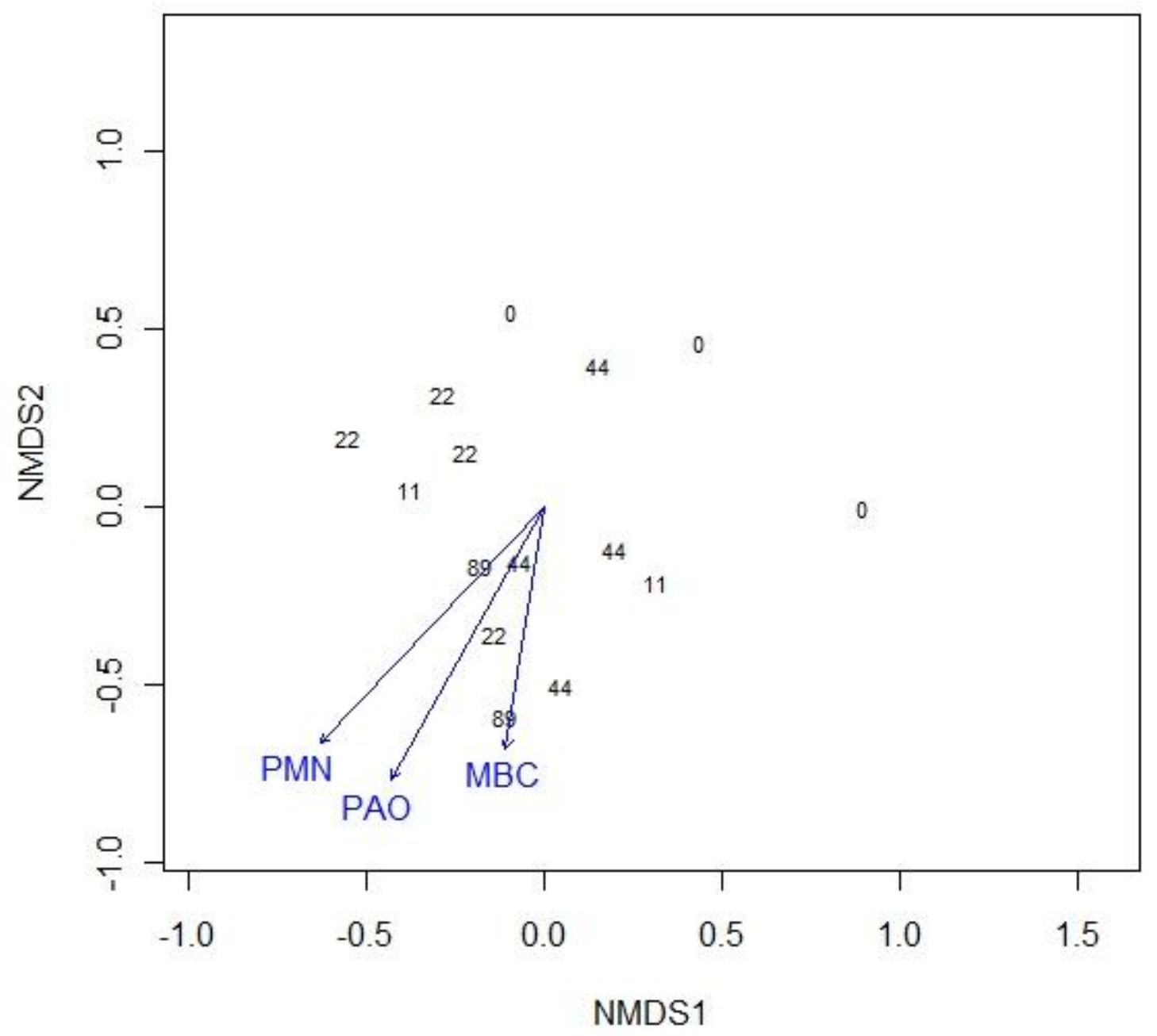

\begin{tabular}{ccccc}
\hline Variable & NMDS Axis 1 & NMDS Axis 2 & $\mathbf{r}^{2}$ & p-value \\
\hline MBC & -0.16 & -0.99 & 0.31 & 0.11 \\
PMN & -0.69 & -0.73 & 0.54 & 0.01 \\
PAO & -0.49 & -0.87 & 0.50 & 0.018 \\
pH & -0.72 & -0.69 & 0.43 & 0.04 \\
Extracted DNA & -0.61 & -0.80 & 0.55 & 0.01 \\
Soluble carbon & -0.59 & -0.81 & 0.36 & 0.068 \\
Shannon Diversity & -0.57 & 0.82 & 0.80 & 0.001 \\
\hline
\end{tabular}

Figure 38. Environmental fitting of important variables over a nMDS ordination of bacterial community similarity. Compare to values seen with surface fitting (Figures 33-37). Values under the headings "NMDS Axis 1" and "NMDS Axis 2" are the length and direction the vector extends along the given axis. Plots are labeled by compost amendment rate in $\mathrm{Mg} \mathrm{ha}^{-1}$, rounded down to whole numbers for the sake of visual clarity. 


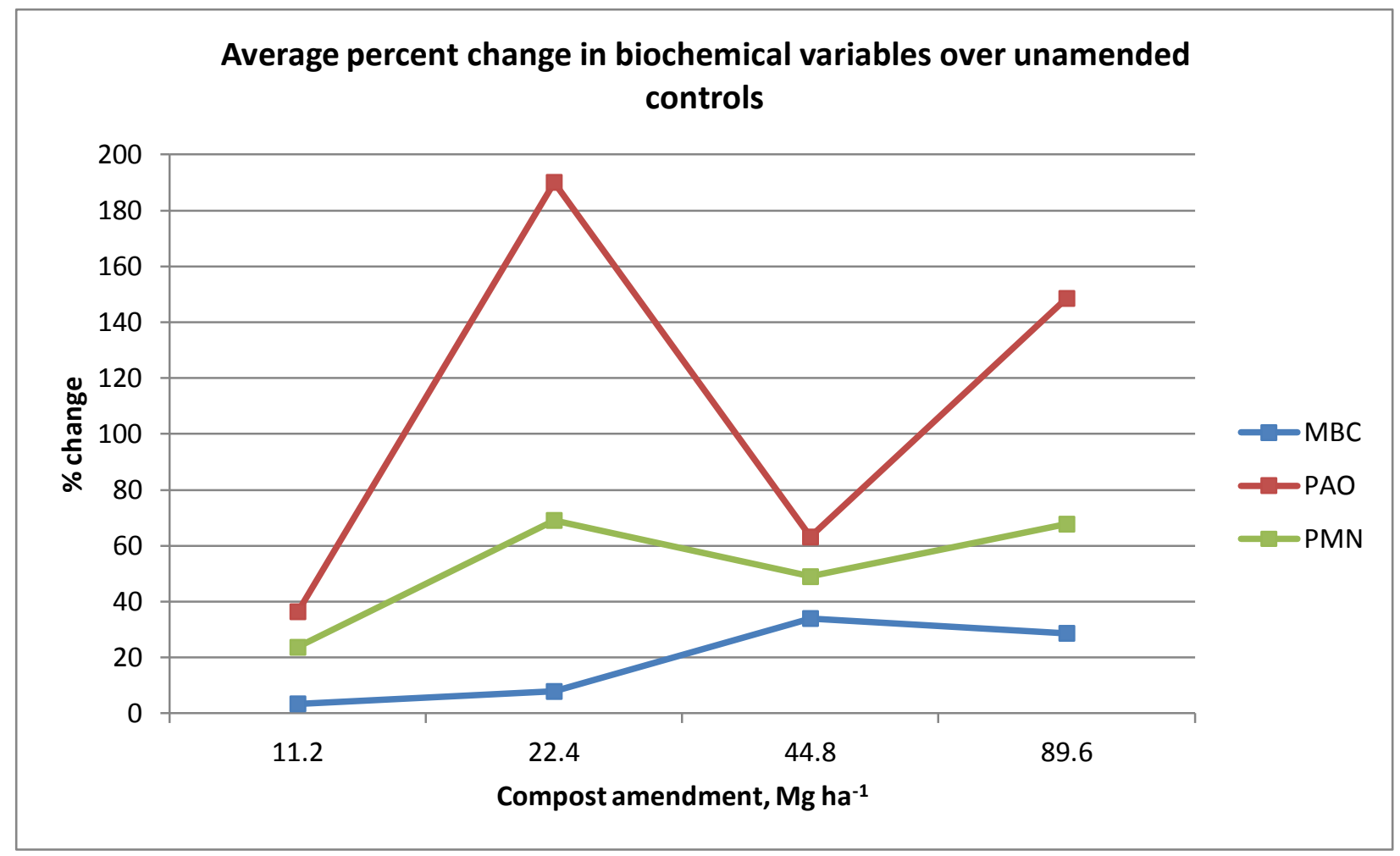

Figure 39. Average percent change in biochemical variables for compost-amended plots relative to unamended control plots. 
(A)

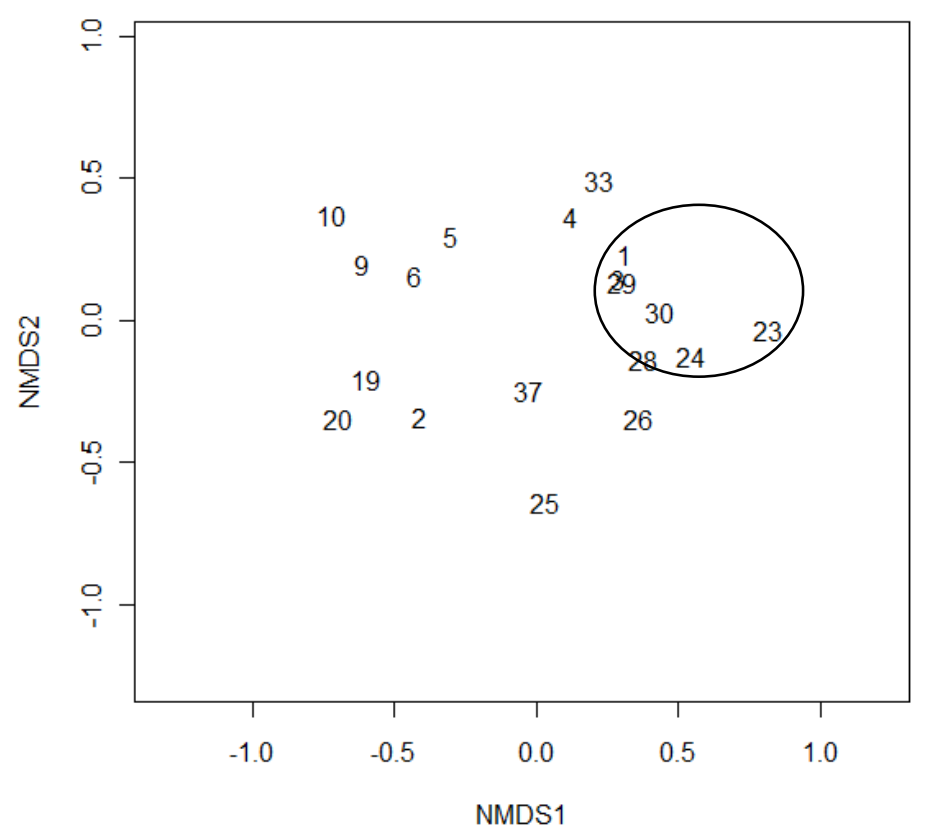

(B)

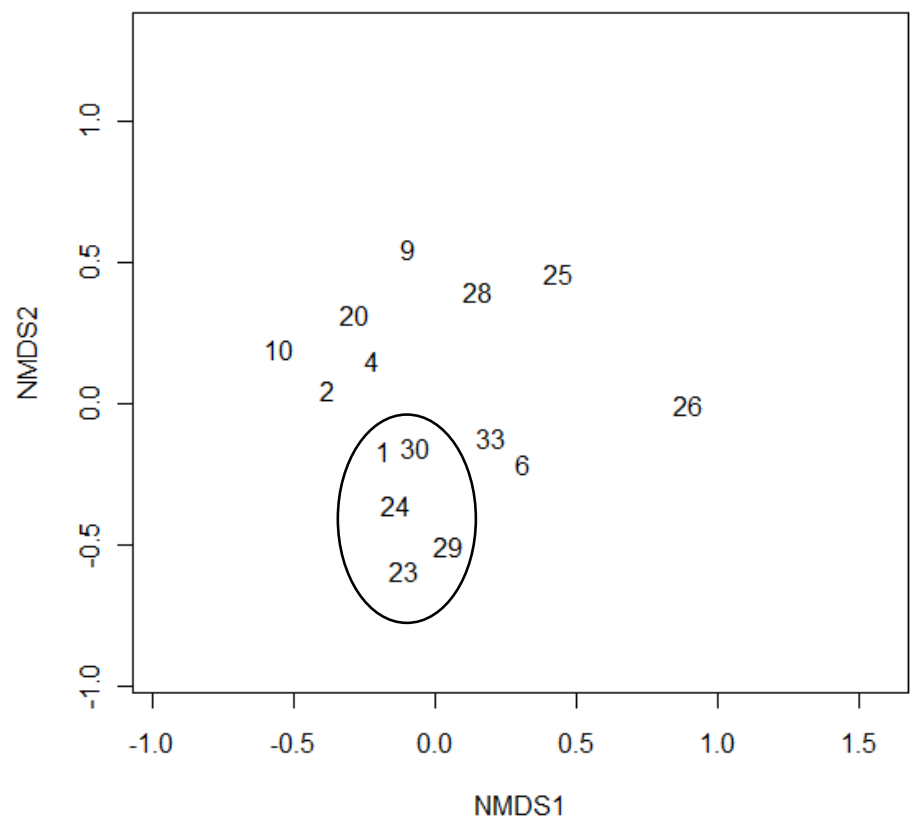

Figure 40. Comparison of nMDS ordinations for the AOA and AOB. (A) is an ordination of the AOA; (B) is an ordination of the AOB. Five plots were ordinated similarly for both bacteria and archaea: plots 1, 23, 24, 29, and 30. Otherwise, ordinations of community composition were distinctly different between AOA and AOB. 


\section{Appendix 1. R code and tutorial}

A file directory (where all files will be saved and retrieved from with this $\mathrm{R}$ session) was established by going to file $\rightarrow$ change dir and selecting the appropriate location.

Datasets were added into $\mathrm{R}$ using the table function:

master.r5= read.table("Master Spreadsheet 5\% relative abundance.csv", header=T,sep=",")

where master.r5 is the name the table is being saved under, header=T ensures $\mathrm{R}$ reads the first row of the Excel document as a heading, and sep="," specifies that the file is comma separated.

The vegan library (necessary for many of the statistical packages needed) was downloaded by going to Packages $\rightarrow$ install package(s) $\rightarrow$ USA (PA 1) $\rightarrow$ vegan. After the file was installed, it was loaded by going to Load package $\rightarrow$ vegan.

The vegan library was then added to the current session with the command:

library(vegan)

\section{ANOVA/Regression}

To do simple linear regressions and one-way ANOVAs, the column headings from master.r5 were saved as objects:

$\operatorname{attach}($ master.r5)

which could be undone as follows:

$\operatorname{detach}($ master.r5)

Then an object was saved from the linear model regressing one column from another:

$\mathrm{A}=\operatorname{lm}($ adjusted.PMN adjusted.MBC)

summary(A)

The summary provides regression equation (in this case, adjusted PMN= 0.9994 (adjusted.MBC) + 11.3979), $\mathrm{r}^{2}$ and $\mathrm{P}$ values:

Df Sum Sq Mean Sq F value $\operatorname{Pr}(>\mathrm{F})$

adjusted.PMN $136.53 \quad 36.53 \quad 3.1740 .0927$.

Residuals $17195.65 \quad 11.51$ 
Signif. codes: 0 '***' 0.001 '**' 0.01 '*' 0.05 '.' 0.1 ' ' 1

1 observation deleted due to missingness

$>$ summary $(\mathrm{CN})$

Call:

$\operatorname{lm}($ formula $=$ adjusted.MBC $\sim$ adjusted.PMN $)$

Residuals:

Min 1Q Median 3Q Max

$\begin{array}{lllll}-5.4799 & -1.4361 & -0.7237 & 1.2791 & 8.3634\end{array}$

Coefficients:

Estimate Std. Error t value $\operatorname{Pr}(>|t|)$

(Intercept) $11.3979 \quad 3.3163 \quad 3.437 \quad 0.00315 * *$

$\begin{array}{lllll}\text { adjusted.PMN } & 0.9994 & 0.5609 & 1.782 & 0.09269\end{array}$.

$--$

Signif. codes: 0 '***’ 0.001 '**’ 0.01 '*’ 0.05 '.' 0.1 ' ' 1

Residual standard error: 3.392 on 17 degrees of freedom

(1 observation deleted due to missingness)

Multiple R-squared: 0.1573, Adjusted R-squared: 0.1078

F-statistic: 3.174 on 1 and 17 DF, p-value: 0.09269.

If the variable is categorical, ANOVA can be performed using the following code:

$\mathrm{B}=$ factor(B)

$\mathrm{B}=\operatorname{aov}(\mathrm{A})$

summary(B)

Multiple comparisons were then performed using SAS.

\section{Dendrograms}

Dendrograms can be created based on community or chemical similarity as follows:

In addition to vegan, load cluster library:

library(cluster)

Create a distance matrix:

r5A.dist=vegdist(master.r5[,22:43],method="bray") 
Bray-Curtis method is used for the distance matrix because it can use relative abundance as well as presence-absence data, and it ignores shared absences. This makes it useful for molecular biology and TRFLP specifically.

Then a linkage method has to be chosen. There are four common possibilities for community datasets (single, complete, wards, and average). Average is most often used in molecular biology/genetics:

single=hclust(r5A.dist,method="single")

complete=hclust(r5A.dist,method="complete")

average=hclust(r5A.dist, method="average")

ward=hclust(r5A.dist,method="ward")

Thes can be visualized using the plot function:

plot(single)

Then you want to compare these dendrograms to what would be seen using Euclidean distance.

euclid=vegdist(master.r5[,22:43],method="euclid")

The following calculates the cophenetic distance using the different-linked dendrograms:

coph.single=cophenetic(single)

coph.complete $=$ cophenetic(complete)

coph.average $=$ cophenetic(average $)$

coph. ward=cophenetic(ward)

The cophenetic correlation (a measure of how accurately a dendrogram retains the pairwise distances of the original unmodeled points) can then be calculated:

cor(euclid,coph.single)^2

cor(euclid,coph.complete)^2

cor(euclid,coph.average) $)^{\wedge} 2$

cor(euclid,coph.ward)^2

Whichever of this gives the highest correlation value is probably the best linkage method to use. Many times, several methods are very similar; in these cases I will use the average linkage.

At this point you only use the dendrogram with the preferred linkage method.

The dendrogram can be viewed and edited using some combination of the following code: 
plclust(average, hang=-0.5, hmin=0,square=TRUE, labels=master.r 5 Treatment, axes=TRUE, frame.plot=TRUE, ann=TRUE, main="Cluster Analysis--Average Linkage and Bray-Curtis Distance Metric",sub="", xlab="Group Membership", ylab="Agglomeration Level")

hang $=-0.5$ puts branches so they all end at the same point, $h \min =0$ suppresses detail at the bottom of the tree, labels=master.r5\$Treatment labels the points by (in this case) the compost amendment level each plot received as seen in dataset master.r5,axes=TRUE draws axes on the plot, frame.plot=TRUE puts a square frame around the plot, ann=TRUE adds in the default annotation (title and $\mathrm{x}$ and $\mathrm{y}$ axis labels), main="Cluster..." adds the quoted titled, sub="" creates an empty subtitle, xlab="Group..." adds the quoted $\mathrm{x}$ axis label, and ylab="Agglom..." adds the quoted title as the $\mathrm{y}$ axis label.

The dendrogram can be cut into groups based on similarity as such:

rect.hclust(average, 5)

which visually splits the sites into 5 different groups.

rect.hclust(average,3)

would split the sites into 3 groups based on similarity.

\section{ANOSIM}

Using r1A.dist, the distance matrix generated using vegan:

r5A.anosim=anosim(r5A.dist, master.r5\$Treatment,perm=999)

This is running analysis of similarity, which is a useful measure of the differences between categorical variables in similarity matrices. master.r5 indicates the category being tested for significance is the Treatment category of dataset master.r5, while the distance matrix its being correlated with is r5A.dist. perm=999 indicates that it is being run with 999 permutations.

Every two sites in the dataset have a value from 0 to 1 indicating (using Bray-Curtis calculation in this case) how similar their communities are. What this procedure does is take all the pair-by-pair comparisons of similarity and ranks them from least dissimilar to most dissimilar. These rank dissimilarities are then sorted by whether they are comparisons within a level of a given treatment, or between levels of a different treatment. The technique is trying to see whether rank dissimilarity is significantly lower within a level than between levels. Then it is randomly permuted- all the rank dissimilarities are randomly placed into either between levels, or within a given level.

summary(r5A.anosim)

gives information such as the $\mathrm{R}$ value ( a high $\mathrm{R}$ value indicating that community similarity within a level is much greater than between levels) and $\mathrm{P}$ value.

r5A.anosim \$dis.rank shows the rank dissimilarity for each comparison. 


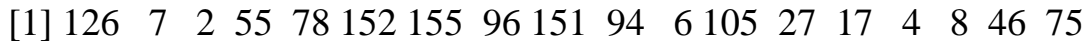

[19] 107137792910111645411621221151231031111081253516

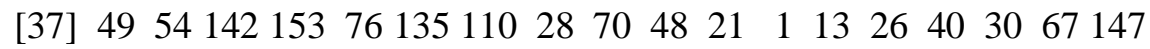

[55] $1449915410919124 \quad 47 \quad 33 \quad 14 \quad 18 \quad 53 \quad 90 \quad 22 \quad 91 \quad 61 \quad 50121161$

[73] $10414811210257100 \quad 64594451385615611811712797 \quad 60$

[91] $72 \quad 6223251196617016714016616014915913413011382171$

[109] $169158168165157163132136241508688 \quad 847471 \quad 87128 \quad 34$

[127] $164146 \quad 8014113113813314365 \quad 5813993 \quad 42 \quad 92 \quad 7314512995$

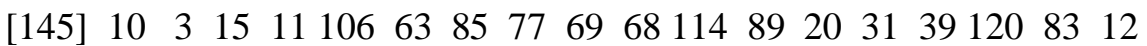

[163] $9 \begin{array}{lllllllll}98 & 37 & 5 & 36 & 43 & 52 & 32 & 81\end{array}$

r5A.anosim\$class.vec shows what type of comparison was being made for the rank dissimilarities above. In this example, there are 3 "within level" type comparisons: A, B, and C.

[1] Between Between Between Between Between Between Between Between Between

[10] C C Between Between Between Between Between Between Between

[19] Between Between Between A A Between Between Between Between

[28] Between A A Between Between Between Between A B

[37] B Between Between B B B Between Between Between

[46] Between B B B B Between B Between Between

[55] B B B Between Between Between Between B B

[64] B B Between Between Between B B B Between

[73] Between Between Between B B $B \quad$ B Between A

[82] Between Between Between Between Between A A Between Between

[91] Between Between A Between Between Between Between Between A

[100] A Between Between Between Between A B B Between

[109] Between Between Between B B B $B \quad$ Between B

[118] Between Between Between Between B $\quad$ B $\quad$ B $\quad$ B $\quad$ Between

[127] Between Between Between Between B B $\quad$ B $B$ Between

[136] C Between Between Between Between Between Between Between Between

[145] Between Between Between Between Between Between A Between Between

[154] Between Between A Between Between Between Between A B

[163] B B Between B B Between B Between Between

Levels: Between A B C

Finally, the information can be visualized as a boxplot:

plot(r5A.anosim) 


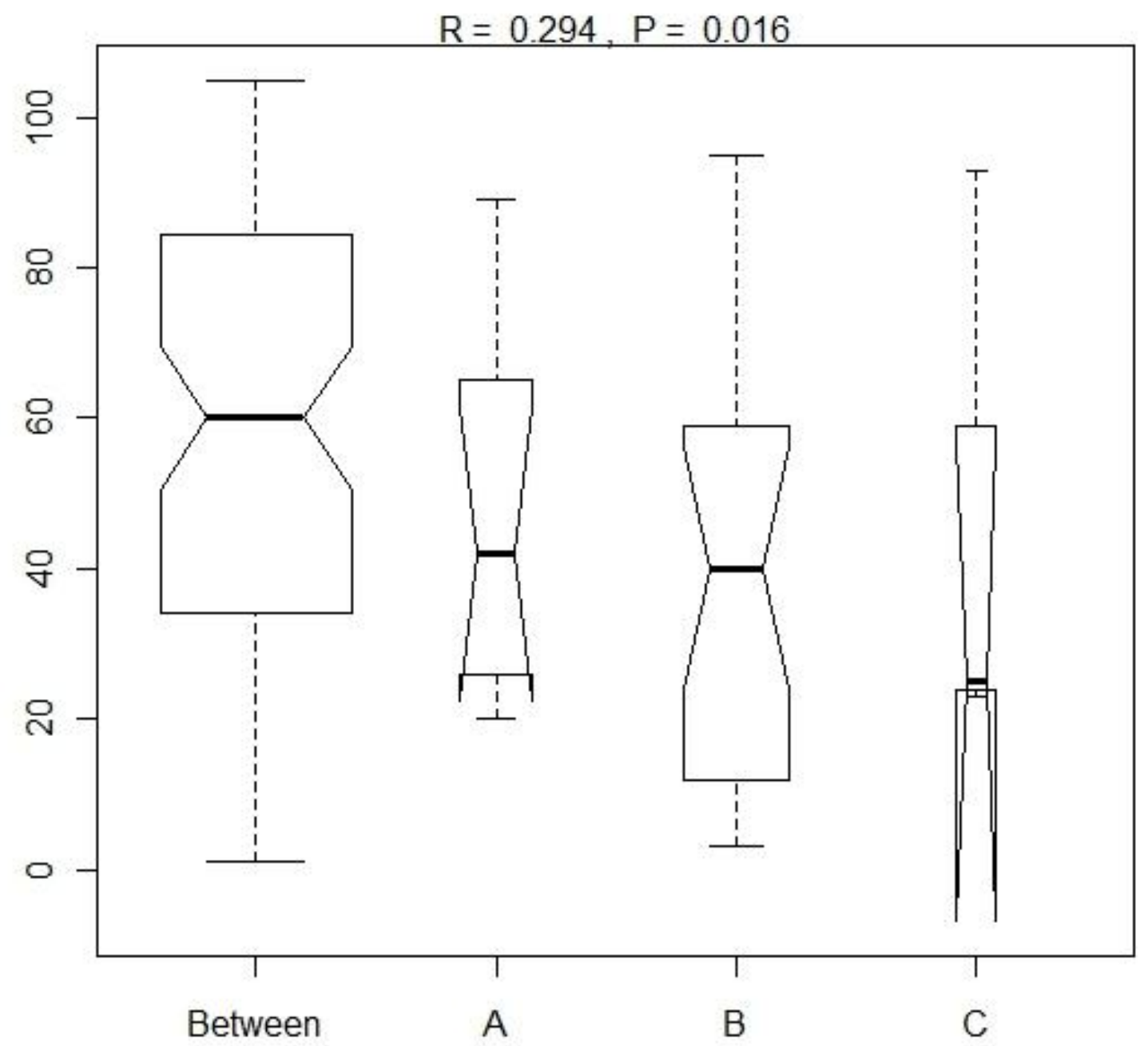

In this instance, you can see wide spreads in dissimilarity within levels as well as between. Average dissimilarity (as indicated by the dark band) are lower within all levels than between them. This is indicated by $\mathrm{R}$ and $\mathrm{P}$ values shown.

\section{nMDS}

nMDS ordinations were performed as follows:

Column numbers for each heading in dataset master.r5 were viewed by using the code:

colnames(master.r5) 
nMDS was run using the following command:

master.r5A.MDS=metaMDS(master.r5[,22:43])

where master.r5A.MDS is the nMDS of the AOA community similarity, and the information in brackets are columns 22 to 43 in dataset master.r5, which correspond to the AOA OTUs.

If the resulting stress value is $>10$ after nMDS, rerun the code as follows:

master.r5A.MDS=metaMDS(master.r5[,22:43],k=3)

where $\mathrm{k}=3$ is adding a third dimension to the ordination. This should reduce the stress- keep adding dimensions until stress is below 10, if possible.

Occasionally, nMDS will not work and instead put out an error message. This is almost always because two of the sites have the exact same community information. In this case, use the following code:

master.r5A.MDS=metaMDS(master.r5[,22:43],zerodist="add")

where zerodist="add" introduces some slight variation between the two identical sites.

The ordination can be visualized in many different ways:

plot(master.r5A.MDS,type="n")

creates a blank plot.

text(master.r5A.MDS,label=master.r5\$Treatment,cex=0.7)

adds in the data points, and labels them by their treatment level. cex $=0.7$ controls the size of the labels on the ordination, higher is larger and lower is smaller.

text(master.r5A.MDS, display="species",cex=0.5,col="blue")

adds in where the specific species would ordinate using display="species". col="blue" makes the color of the OTUs labels blue on the ordination.

plot(master.r5A.MDS,type="t")

plots the ordination by site number, and also plots the individual species.

plot(master.r5A.MDS\$points,type="n")

text(master.r5A.MDS\$points, labels=master.r5\$Plots)

These lines of code readjust the ordination so that it is centered around where the points are located.

fit=goodness (master.r5A.MDS)

plot(master.r5A.MDS\$points,type="n") 
text(master.r5A.MDS\$points,labels=master.r5\$Plots)

points(master.r5A.MDS,cex=fit)

plots the stress of each point on the ordination. A larger circle indicates that that individual point was more stressed (i.e. could not be represented in the ordination space particularly well). This information is not particularly necessary since you already have an overall stress value, but it is sometimes useful to have a visual representation.

Visually, this produces:

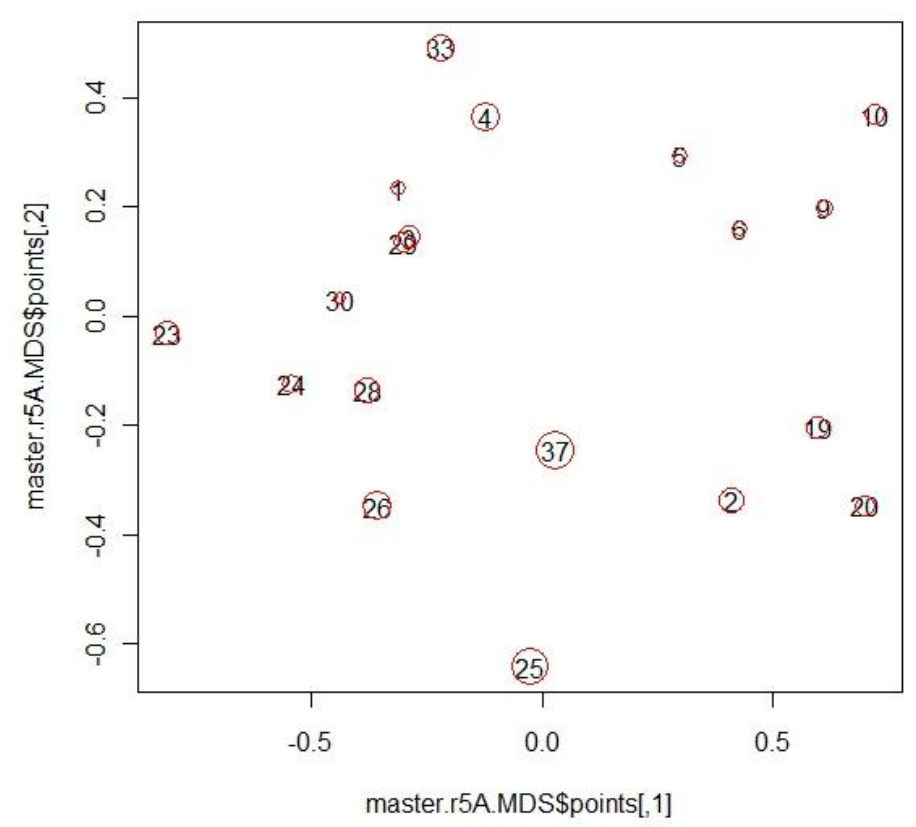

Environmental fitting, which indicates the spatial direction on the ordination where a given continuous variable is most strongly associated, can be done as follows:

envfit=envfit(master.r5A.MDS,master.r5\$adjusted.PMN,permu=999) plot(envfit,col="blue")

This will create an environmental fit on the ordination of the variable adjusted.PMN from the dataset master.r5. The environmental fit arrow is blue in this case when plotted.

To determine how well this environmental fit is working, and the coordinates where it is located, the name of the object can be entered.

envfit

***VECTORS

NMDS1 NMDS2 r2 $\operatorname{Pr}(>\mathrm{r})$ 
Ordisurf overlays of continuous variables on the ordination can also be performed. This involves the computer building a model that shows (like elevation on a topographic map) the gradient of that continuous variable over the spatial ordination. A linear gradient will indicate a very strong relationship between community similarity and that continuous variable.

The following code is used:

div.overlay=with(master.r5, ordisurf(master.r5A.MDS, master.r5\$Archaea.Shannon.Diversity,add=T))

using the nMDS ordination master.r5A.MDS, dataset master.r5, and variable Archaea.Shannon.Diversity.

summary(div.overlay) provides the following information:

summary(div.overlay)

Family: gaussian

Link function: identity

Formula:

$\mathrm{y} \sim \mathrm{s}(\mathrm{x} 1, \mathrm{x} 2, \mathrm{k}=$ knots $)$

<environment: 0x026dca00>

Parametric coefficients:

Estimate Std. Error t value $\operatorname{Pr}(>|t|)$

(Intercept) $1.93784 \quad 0.01706 \quad 113.6<2 \mathrm{e}-16 * * *$

$---$

Signif. codes: 0 '***’ 0.001 '**' 0.01 '*’ 0.05 '? 0.1 ' ’ 1

Approximate significance of smooth terms:

edf Ref.df $\mathrm{F}$ p-value

$\mathrm{s}(\mathrm{x} 1, \mathrm{x} 2) 5.751 \quad 7.23732 .795 .08 \mathrm{e}-07 * * *$

$--$

Signif. codes: 0 ‘*** 0.001 '**' 0.01 '*' 0.05 '? 0.1 ' ’ 1

R-sq. $($ adj $)=0.929$ Deviance explained $=95.2 \%$

GCV score $=0.008582$ Scale est. $=0.0055325 n=19$

The important things to see here are the p-value, R-sq.(adj), and Deviance explained. These are giving an indication of how well the information is being modeled. 
The visual of this is as follows:

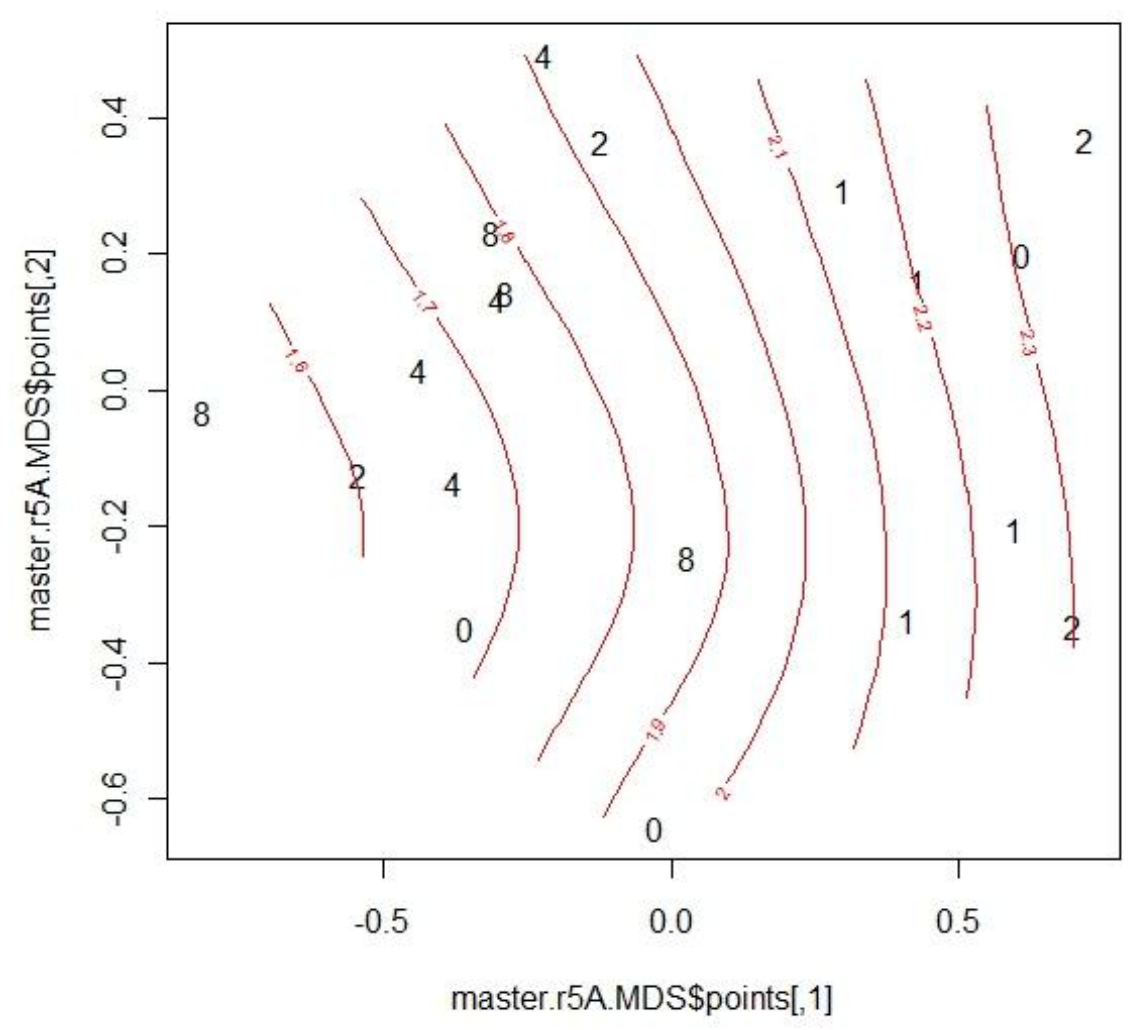

The red lines and values show the gradient and gradient values of the continuous variable over the community similarity information. In this case, the gradient is almost linear, which indicates that the primary differences in community similarity seen here are due to differences in calculated diversity (as you would expect). However, if the values from the summary (p-value, R-sq (adj), and Deviance explained) were low, even if the visual looked like this the model would not be very valuable. This would be because the diversity values of the individual points would not actually fit the gradient overlain on the ordination well.

There are a number of other things that can be adjusted to make nMDS graphs more informative or look more professional.

cor(master.r5A.MDS\$points[,1],master.r5\$pH)

cor(master.r5A.MDS\$points[,2],master.r5\$pH)

will spit out where the given continuous variable (in this case, $\mathrm{pH}$ ) will load on the ordination on either the $\mathrm{X}$ axis [,1] or the $\mathrm{Y}$ axis [,2]. This information can be useful to put into a table for large numbers of continuous variables.

indx=as.numeric( master.r5\$Treatment $)$ 
points(master.r5A.MDS,display="sites",pch=c(2,16)[indx],cex=0.8)

legend("topright",levels(master.r5\$Treatment),pch=c(2,16))

These lines replace the numbers or letters from a categorical variable on the ordination with symbols. $\mathrm{pch}=\mathrm{c}()$ is what creates the symbols- you need one for each treatment type and the numbers in parentheses are what determines what symbols are used (you can use from 1 to about 25- looking up "pch in R" online will show you what symbol each number corresponds to). The last line of code puts a legend in the upper right corner of the ordination- the legend will be labeled by whatever the levels of the categorical variable are.

ordiellipse(master.r5A.MDS, master.r5\$Treatment,col="blue")

This function creates an ellipse around one standard deviation from the central point a given level of a categorical variable (in this case, treatment) would be located on the ordination. Visually it looks like this:

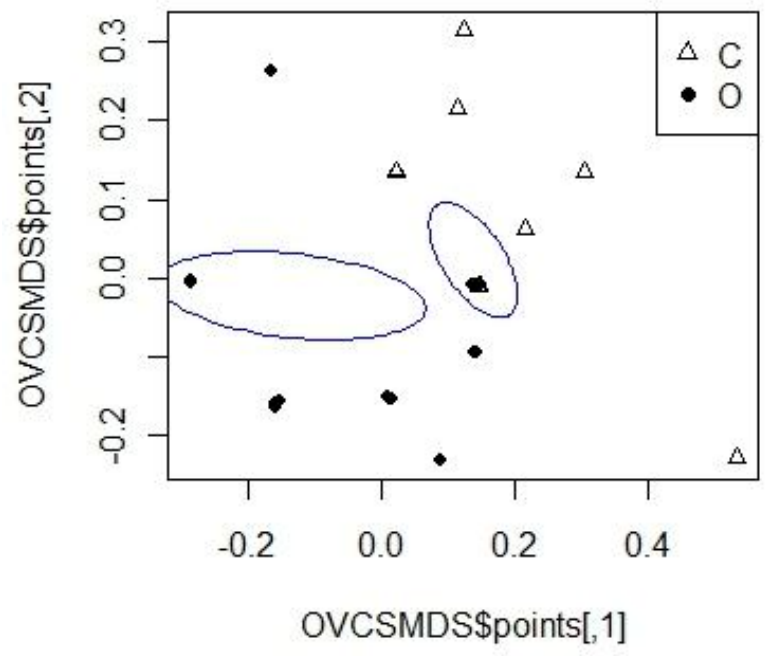

ordihull(master.r5A.MDS, master.r5\$Treatment,col="blue")

This code puts polygons around all the members of a given level of treatment, as seen here: 


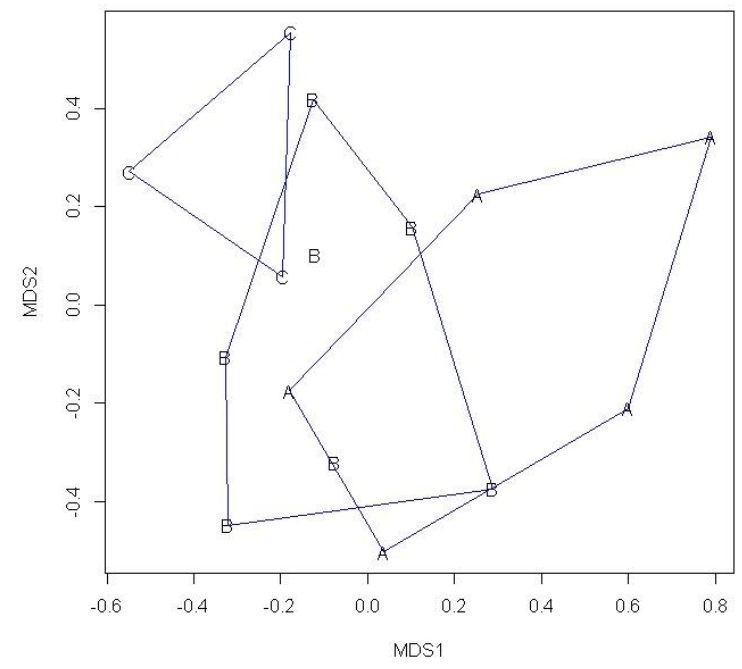

ordispider(master.r5A.MDS, master.r5\$Treatment)

This code draws a line from the center of where a given level of treatment would be located to each data point in that level. 